\title{
One for all, all for the Customer : studies on self- managing teams in services
}

Citation for published version (APA):

de Jong, A. (2003). One for all, all for the Customer : studies on self-managing teams in services.

[Doctoral Thesis, Maastricht University]. Universiteit Maastricht. https://doi.org/10.26481/dis.20030327aj

Document status and date:

Published: 01/01/2003

DOI:

10.26481/dis.20030327aj

Document Version:

Publisher's PDF, also known as Version of record

\section{Please check the document version of this publication:}

- A submitted manuscript is the version of the article upon submission and before peer-review. There can be important differences between the submitted version and the official published version of record.

People interested in the research are advised to contact the author for the final version of the publication, or visit the DOI to the publisher's website.

- The final author version and the galley proof are versions of the publication after peer review.

- The final published version features the final layout of the paper including the volume, issue and page numbers.

Link to publication

\footnotetext{
General rights rights.

- You may freely distribute the URL identifying the publication in the public portal. please follow below link for the End User Agreement:

www.umlib.nl/taverne-license

Take down policy

If you believe that this document breaches copyright please contact us at:

repository@maastrichtuniversity.nl

providing details and we will investigate your claim.
}

Copyright and moral rights for the publications made accessible in the public portal are retained by the authors and/or other copyright owners and it is a condition of accessing publications that users recognise and abide by the legal requirements associated with these

- Users may download and print one copy of any publication from the public portal for the purpose of private study or research.

- You may not further distribute the material or use it for any profit-making activity or commercial gain

If the publication is distributed under the terms of Article $25 \mathrm{fa}$ of the Dutch Copyright Act, indicated by the "Taverne" license above, 


\section{One for All, All for the Customer}

Studies on Self-Managing Teams in Services 
(C) 2003, Ad de Jong, Maastricht.

All rights reserved. No part of this publication may be reprinted or utilized in any form or by any electronic, mechanical or other means, now known, or hereafter invented, including photocopying and recording, or in any information storage or retrieval system, without written permission from the copyright owner.

ISBN: $90-9016630-0$

Printed by: DATAWYSE, Maastricht 


\section{One for All, All for the Customer}

\section{Studies on Self-Managing Teams in Services}

\section{PROEFSCHRIFT}

ter verkrijging van de graad van doctor aan de Universiteit Maastricht,

op gezag van de Rector Magnificus, Prof. Dr. A.C. Nieuwenhuijzen Kruseman, volgens het besluit van het College van Decanen, in het openbaar te verdedigen

op donderdag 27 maart 2003 om 16:00 uur

door

Adam de Jong 


\section{Promotores:}

Prof. Dr. J.C. de Ruyter

Prof. Dr. J.G.A.M. Lemmink

Beoordelingscommissie:

Prof. Dr. Ir. B.G.C. Dellaert

Prof. Dr. G.M. Duijsters (Technische Universiteit Eindhoven)

Prof. Dr. R.H.G. Meuwissen RA 


\section{Acknowledgements}

During my PhD period I became aware that writing a dissertation is quite a lonely job in which you often have to struggle on your own. The days that a PhD candidate independently works on his specific project are many ... Nevertheless, I would only tell half the truth if I do not emphasize the importance of teamwork as well. The cooperation with my competent and committed colleagues has been indispensable to accomplish this dissertation.

Many persons have contributed in many ways to make my PhD a success. I would like to take the opportunity to sincerely thank them. To begin with, I would like to thank my promoters Ko de Ruyter and Jos Lemmink for their dedicated and inspiring support. More than four years ago, we had our first meeting together. One of the things I still remember from that moment was their enthusiasm each time the word "multi-level" came up. In that period they took me to a lovely terrace at the "Onze Lieve Vrouwen" plein for a special beer in order to show me that Maastricht was "the" place to be. Their sight-seeing strategy worked out well. I was impressed.

Specifically, I owe grateful words to Ko de Ruyter. Our innumerable discussions were sometimes exhausting but always meaningful and have contributed to the dissertation in its current mode. Yet, I'm still impressed with his "helicopter-view" when setting out the conceptual pathways of this dissertation. His energetic style of working and inspiring enthusiasm motivated me to develop my skills and have lifted me up to a higher academic level. He demonstrated a great willingness and assiduity to consciously consider the drafts I handed in each time. The many corrections that were made are proof of his great commitment. His inexhaustible support remained not restricted to the core $\mathrm{PhD}$ work. As a real mental coach he also knew when and how to speak out inspiring words to trigger my attention and to enhance my self-esteem. Finally, I need to mention his amazing creativity to make things more appealing. Ask Ko, for example, to come up with an attractive title for a paper or a flashing picture for a presentation. He knows!

Also, I sincerely like to acknowledge the contribution of Jos Lemmink. From the start of this PhD project, we have had memorable discussions about which strategy would be the best to follow. His differentiated opinion and valuable suggestions made me aware of the importance of carefully considering the available alternatives when making conceptual or methodological choices. His critical attitude urged me to motivate each strategic decision that was taken. Furthermore, I am especially thankful for his compliance to offer me valuable data sources to do research on. Last but not least, I remember his fatherly and patient advice about how to write procedural letters in an appropriate way.

All in all, the intimate teamwork with $\mathrm{Ko}$ and Jos, and other colleagues has already resulted in several academic publications and I sincerely wish to continue this cooperation in my future academic career. The whole is really more than the sum of the parts alone... 
I would like to express my gratitude towards the members of my graduation committee, Prof. Dr. Ir. B. G. C. Dellaert, Prof. Dr. G. M. Duijsters, and Prof. Dr. R. H. G. Meuwissen RA for reading the manuscript. Their valuable comments and suggestions inspired me to put the finishing touches to this dissertation.

Moreover, I gratefully wish to thank my (former) roommates: Sandra Streukens, Claudia van Oppen, Jill Lei, and Allard Van Riel for their agreeable presence. I really can say that I have had an enjoyable time with all of them. They managed to enlighten the occasional monotony of daily PhD life. Furthermore, I sincerely acknowledge their constructive critics and valuable comments with respect to my dissertation.

I would also like to thank some other colleagues for checking the language of this dissertation and for their useful remarks: Charles Pahud de Mortanges, Lisa Deutskens, Mirella Kleijnen, Toñita Perea y Monsuwé, Sonja Wendel, and Caroline Wiertz. Furthermore, I gratefully acknowledge the members of the secretariat for their support, especially Babette Moelee.

I would also like to speak out my thanks to one organization, which decided not to be called by narme, for the resources it offered me do research on. I particularly wish to thank Ton Baggerman. His ongoing support and valuable comments enabled me to collect the data for on important part of my study. Also thanks for the nice discussions we have had about child psychiatry and about how to deal with young children in daily life. His altruistic point-of-view made me aware of the fact that there is more in life than just business or money.

I would like to thank my family and friends. Particularly I wish to thank my parents for their care and support. They have always respected my decision not to become a farmer but to follow an academic career. Especially in the first years of my $\mathrm{PhD}$ period they provide me with sleeping facilities and food to fulfill my primary necessities of life. Despite their busy life, they always kept a listening ear to my study experiences. Also, I would like to thank my brothers and sisters for their warm attention during my study. Their presence makes me still aware of the blessings of a rich family life. Furthermore, I would like to thank all other persons that showed interest during my dissertation period and took the effort to visit me in Maastricht.

Finally, I would like to sincerely thank Heleen, my wife. Her moral support inspired me to go on and to complete this study. Her love and care, and particularly her "no-nonsense" mentality proved to be vital motivational ingredients for a guy like me. Heleen, thank you so much for your understanding and support in this sometimes difficult period. Thank you! 


\section{Table of Contents}

\section{Acknowledgements}

1 Introduction

1.1 Self-Managing Teams: A New Management Phenomenon ……….....................2

1.2 Self-Managing Teams: An Interdisciplinary Approach .....................................

1.3 The Impact of Self-Managing Teams on Marketing Effectiveness ..................... 8

1.4 Self-Managing Team Service Performance: A Critical Linkage ....................... 9

1.5 Service Context: A Contingency Factor ...................................................... 11

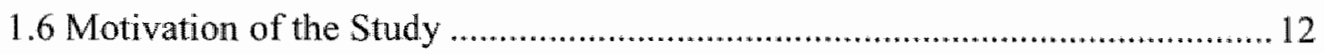

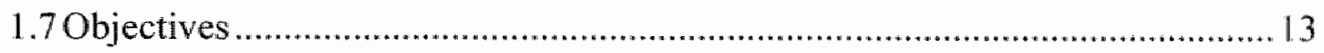

1.7.1 Objectives Chapter 2 .................................................................. 14

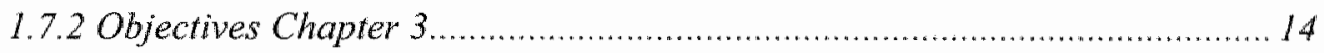

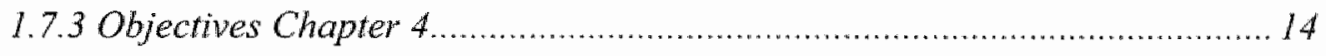

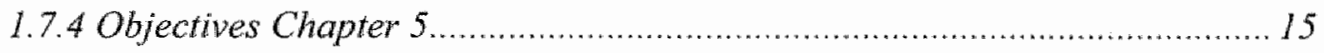

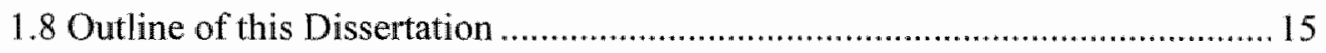

\section{Service Climate in Self-Managing Teams:}

A Business-to-Business Study .............................................................19

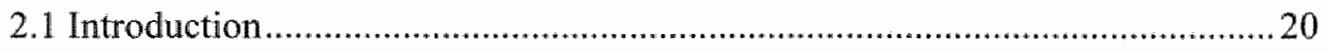

2.2 Self-Managing Team Service Climate ..........................................................21

2.3 The Impact of Self-Managing Team Service Climate on Service

Performance ......................................................................................... 2

2.4 Antecedents of Self-Managing Team Service Climate ............................... 22

2.4.1 Context-Team Interface …................................................................ 22

2.4.2 Team-Employee Interface ............................................................... 24

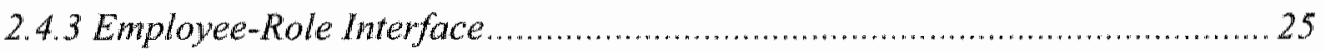

2.4.4 Refinement of the Conceptual Framework............................................. 26

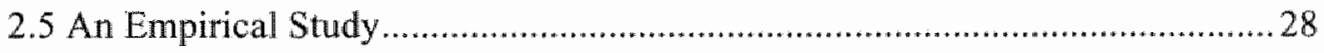

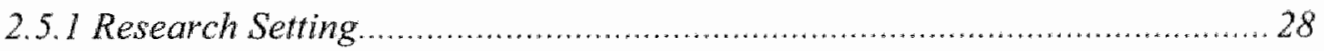

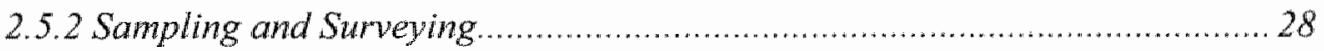

2.5.3 Questionnaire Development ……..................................................... 29

2.5.4 Data Analysis ............................................................................. 34

2.6 Discussion ................................................................................................

2.7 Theoretical Implications ........................................................................... 39

2.8 Managerial Implications ........................................................................ 
I would like to express my gratitude towards the members of my graduation committee, Prof. Dr. Ir. B. G. C. Dellaert, Prof. Dr. G. M. Duijsters, and Prof. Dr. R. H. G. Meuwissen RA for reading the manuscript. Their valuable comments and suggestions inspired me to put the finishing touches to this dissertation.

Moreover, I gratefully wish to thank my (former) roommates: Sandra Streukens, Claudia van Oppen, Jill Lei, and Allard Van Riel for their agreeable presence. I really can say that I have had an enjoyable time with all of them. They managed to enlighten the occasional monotony of daily $\mathrm{PhD}$ life. Furthermore, I sincerely acknowledge their constructive critics and valuable comments with respect to my dissertation.

I would also like to thank some other colleagues for checking the language of this dissertation and for their useful remarks: Charles Pahud de Mortanges, Lisa Deutskens, Mirella Kleijnen, Toñita Perea y Monsuwé, Sonja Wendel, and Caroline Wiertz. Furthermore, I gratefully acknowledge the members of the secretariat for their support, especially Babette Moelee.

1 would also like to speak out my thanks to one organization, which decided not to be called by name, for the resources it offered me do research on. I particularly wish to thank. Ton Baggerman. His ongoing support and valuable comments enabled me to collect the data for on important part of my study. Also thanks for the nice discussions we have had about child psychiatry and about how to deal with young children in daily life. His altruistic point-of-view made me aware of the fact that there is more in life than just business or money.

I would like to thank my family and friends. Particularly I wish to thank my parents for their care and support. They have always respected my decision not to become a farmer but to follow an academic career. Especially in the first years of my $\mathrm{PhD}$ period they provide me with sleeping facilities and food to fulfill my primary necessities of life. Despite their busy life, they always kept a listening ear to my study experiences. Also, I would like to thank my brothers and sisters for their warm attention during my study. Their presence makes me still aware of the blessings of a rich family life. Furthermore, I would like to thank all other persons that showed interest during my dissertation period and took the effort to visit me in Maastricht.

Finally, I would like to sincerely thank Heleen, my wife. Her moral support inspired me to go on and to complete this study. Her love and care, and particularly her "no-nonsense" mentality proved to be vital motivational ingredients for a guy like me. Heleen, thank you so much for your understanding and support in this sometimes difficult period. Thank you!

Ad de Jong. Werkendam, December 15, 2002 


\section{Table of Contents}

\section{Acknowledgements}

\section{Introduction}

1.I Self-Managing Teams: A New Management Phenomenon ................................ 2

1.2 Self-Managing Teams: An Interdisciplinary Approach ....................................... 5

1.3 The Impact of Self-Managing Teams on Marketing Effectiveness .....................8

1.4 Self-Managing Team Service Performance: A Critical Linkage ......................... 9

1.5 Service Context: A Contingency Factor .......................................................... 11

1.6 Motivation of the Study .......................................................................... 12

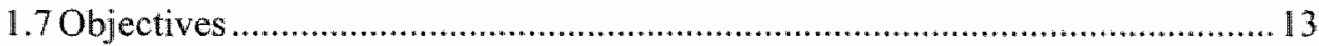

1.7.1 Objectives Chapter 2....................................................................... 14

1.7.2 Objectives Chapter 3..................................................................... 14

1.7.3 Objectives Chapter 4......................................................................... 14

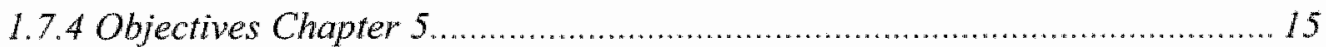

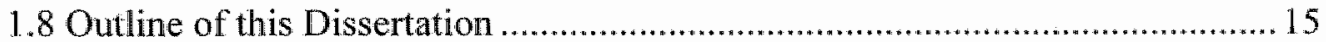

\section{Service Climate in Self-Managing Teams:}

A Business-to-Business Study .......................................................... 19

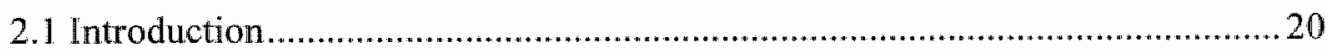

2.2 Self-Managing Team Service Climate ........................................................... 21

2.3 The Impact of Self-Managing Team Service Climate on Service

Performance .............................................................................................. 21

2.4 Antecedents of Self-Managing Team Service Climate .....................................22

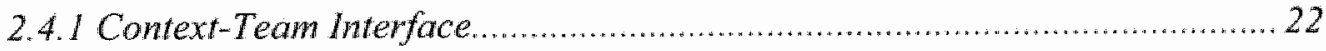

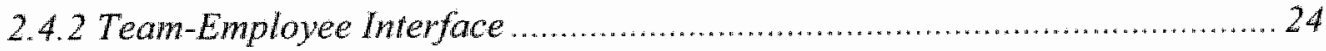

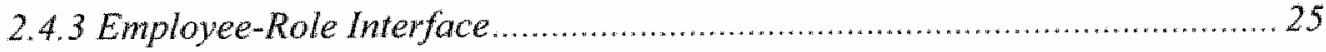

2.4.4 Refinement of the Conceptual Framework ...........................................226

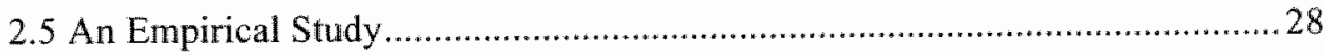

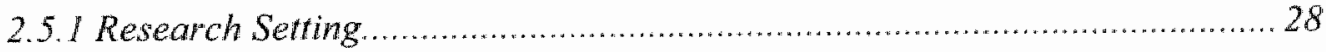

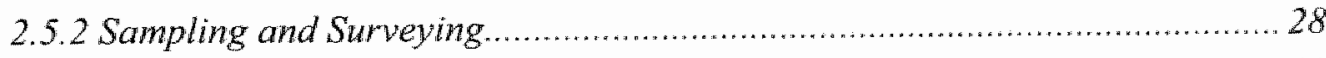

2.5.3 Questionnaire Development........................................................... 29

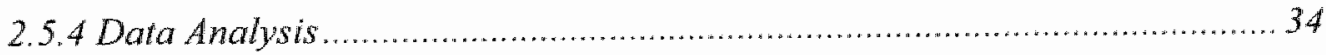

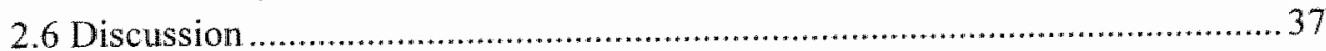

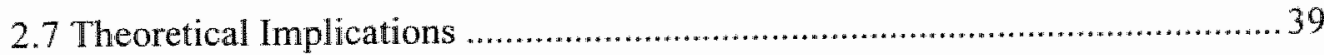

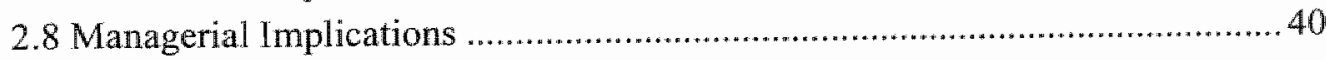




\section{Antecedents and Consequences of Service Climate in Boundary-Spanning Self-Managing Service Teams:}

A Contingency Approach. 43

3.1 Introduction. 44

3.2 Development of a Conceptual Framework 45

3.2.1 Self-Managing Team Service Climate. 45

3.2.2 Antecedents of Self-Managing Team Service Climate . 46

3.2.3 Contingency One: Assessment of Predictor-Criterion Relationships Across Levels.

3.2.4 Contingency Two: Assessment of Predictor-Criterion Relationships Across Service Types

3.2.5 Consequences of Self-Managing Team Service Climate..... 50

3.2.6 Contingency Three: Assessment of Consequences Across Service Types ..... 53

3.3 An Empirical Study. 53

3.3.1 Research Setting. 53

3.3.2 Sampling and Surweying. 53

3.3.3 Measurement Issues. 54

3.3.4 Analysis 60

3.4 Discussion 66

3.5 Limitations and Theoretical Implications 68

3.6 Managerial Implications

3.7 Appendix: Model Specification

\section{Adaptive versus Proactive Behavior in Service Recovery:} The Role of Self-Managing Teams

4.1 Introduction.

4.2 Development of a Conceptual Framework

4.2.1 Adaptive and Proactive Recovery Behavior

4.2.2 Antecedents of Adaptive and Proactive Recovery Behavior

4.2.3 Assessment of Predictor-Criterion Relationships Across Levels of Analysis. 79

4.2.4 Consequences of Adaptive and Proactive Recovery Behavior.

4.3 Empirical Study

4.3.1 Research Setting.

4.3.2 Sampling and Surveying.

4.3.3 Measurement lssues.

4.3.4 Data Analysis

4.4 Discussion.

4.5 Limitations and Theoretical Implications 


\section{Antecedents and Consequences of the Adoption-Level of Information Technology in Self-Managing Service Teams}

5.1 Introduction 100

5.2 Adoption-Level of IT in Services 101

5.3 Adoption-Level of IT and Service Performance. 102

5.4 Antecedents of the Adoption-Level of IT in Self-Managing Service Teams.. 103

5.4.1 Organizational Characteristics. 104

5.4.2 Technology Characteristics. 105

5.4.3 User Characteristics. 105

5.5 Refinement of the Conceptual Framework 107

5.6 An Empirical Study 108

5.6.1 Research Setting.. 108

5.6.2 Sampling and Surveying. 109

5.6.3 Measurement Issues. 109

5.6.4 Data Analysis 114

5.7 Discussion 120

5.8 Theoretical Implications 122

5.9 Managerial Implications 123

6 Conclusion 125

6.1 Synopsis 126

6.2 Main Conclusion of the Chapters 127

6.2.1 Chapter 2 127

6.2.2 Chapter 3 127

6.2.3 Chapter 4

6.2.4 Chapter 5

6.3 An Integrated Perspective 128

6.3.1 Social and Technical Task Determinants of Self-Managing Team Service

Performance.

6.3.2 Individual versus Shared Perceptions.

6.3.3 The Influence of Self-Managing Team Service Performance on External

Marketing Outcomes.....

6.3.4 Virtual Self-Managing Teams: A Future Challenge 


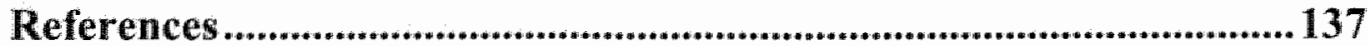

Nederlandse Samenvatting …........................................................................153

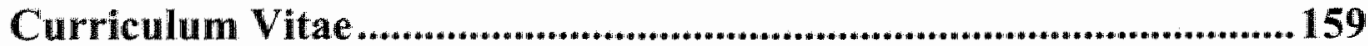


Chapter 1

Introduction 
"Two are better than one, because they have a good return for their work: If one falls down, his friend can help him up... Though one may be overpowered, two can defend themselves. A cord of three strands is not easily broken"

(Salomon, Ecclesiastes 4)

This introduction offers a description of the topic of this dissertation and the goals it sets out to achieve. In addition, we discuss the motivation underlying our study and the specific objectives formulated in the separate chapters. Finally, this chapter concludes with an outline of the remainder of this thesis.

\subsection{Self-Managing Teams: A New Management Phenomenon}

Since biblical times people have realized the power of cooperative teamwork. Although the terms 'team' and 'synergy' were unknown, king Salomon has already argued the advantages of people working together. The wise words of king Salomon can be very wel $\rfloor$ applied to the battlefield of today's service-oriented economy. Current companies frequently operate in increasingly competitive markets that are characterized by new technological developments, and more demanding customers. For many companies the implementation of self-managing teams seems an appropriate management strategy to effectively respond to the competitive challenges in the current business environment.

The title of this dissertation "One for All, All for the Customer" refers to teamwork in relation to customer service. "The "One for Alll" principle indicates the importance to individual employees to exert cooperative effort to the benefit of the team, being separate vital parts that form one body. The implication is that when employees are given the autonomy to practice integrative teamwork and they operate as a unity in delivering service towards external customers, this "All for the Customer" approach will lead to improved performance including higher customer satisfaction scores and increased productivity rates.

In current academic literature a large amount of books and articles have been devoted to work teams of employees that self-manage their daily job activities (e.g., Cohen 1994; Cohen and Ledford 1994; Cordery et al. 1991; Emery and Fredenhall 2002; Gladstein 1984; Goodman et al. 1988; Hackman 1987, 1990; Kirkman and Rosen 1999; Manz and Sims 1995; Pearce and Ravlin 1987; Spreitzer et al. 1999; Trist et al. 1977; Wall et al 1986; Wellins et al 1991; Yeatts and Hyten 1998). Selfmanaging teams (SMTs) have been related to increased productivity (Cohen and Ledford 1994; Emery and Fredenhall 2002; Goodman et al. 1988; Kirkman and Rosen 1999; Spreitzer et al. 1999; Trist et al. 1977; Wellins et al. 1991), improved customer service (Emery and Fredenhall 2002; Kirkman and Rosen 1999; Spreitzer et al. 1999; Wellins et al. 1991), safety (Cohen and Ledford 1994; Goodman et al. 1988; Trist et al. 1977), higher levels of job satisfaction (Cordery et al. 1991; Wall et al. 1986), and organizational commitment (Cordery et al. 1991). Although our knowledge on SMTs is accumulating, the overwhelming majority of studies have been conducted on the 
effective implementation of SMTs in manufacturing settings, while research on boundary-spanning SMTs in service organizations has remained scarce (Spreitzer et al. 1999; Emery and Fredenhall 2002).

Manufacturing companies can be typically qualified as 'closed' organizations, since the production process is not visible for the customers. Conversely, service companies are relatively 'open' organizations in which customers have a prominent role, as they are able to observe or even to participate into the service delivery process. In the service marketing literature it has been widely acknowledged that the personal interactions between front-line employees and customers concern a fundamental aspect of service operations (Bitner et al. 1994). This implies that well-founded service management research should take an interdisciplinary approach, which involves a combination of human resource management and service marketing perspectives. To appropriately evaluate the management of service operations, the use of internal performance quality standards (e.g., job satisfaction and organizational commitment) and traditional productivity criteria needs to be complemented. with customer quality evaluations about services delivery processes and measures of customer behavior. Therefore, in-depth investigations on SMTs as an innovative service management approach require an interdisciplinary perspective.

Yet, an increasing number of service companies has allocated greater collective authority for customer service delivery to SMTs to facilitate an efficient and effective integration of a wide range of knowledge, skills and abilities required to perform the increasingly complex bundle of customer service activities (e.g., Griffin et al. 1994; Helfert and Vith 1999, Spreitzer et al. 1999). Surveys of the Fortune 1000 companies conducted in 1987 and 1993, for instance, reveal that front-office SMT implementation by service firms has increased from $22 \%$ to $52 \%$ (Spreitzer et all. 1999).

The majority of service companies operate in increasingly competitive markets, which are characterized by new technological developments and more demanding customers having diversified requests. For many of these companies the implementation of SMTs seems an appropriate management strategy to effectively respond to the competitive challenges in the current business environment. Therefore, a growing number has introduced SMTs as a substitute for traditional hierarchical management structures and as a tool to enhance service quality and productivity (e.g., Emery and Fredenhall 2002; Spreitzer et al. 1999).

A number of recent academic studies demonstrate that work teams, which selfdirected their daily service activities, performed significantly better on customer parameters (e.g., service quality, customer satisfaction) and on productivity parameters (e.g., sales volume, profit) than traditional work groups (Batt 1999; Emery and Fredenhall 2002). Contrary to these findings, other studies have found that the implementation of teams did not increase profitability (e.g., Bursic 1992, Goodman 1979; Wall et al. 1986) or have warned to be cautious about the benefits of SMTs in services (e.g., Spreitzer et al. 1999). For example Chaston (1998) demonstrates that the implementation of SMTs in services has led to decreases in customer quality expectations and employee productivity. Again, other researchers have argued that the absence of positive results of implementing self-managing teams might be due to flawed research designs (e.g., Cohen and Ledford 1994; Goodman et al. 1988; Hackman 1990) or process losses such as social loafing, free-riding, and groupthink 
(e.g., Albanese and Van Fleet 1985; Harkins 1987; Polley and Van Dyne 1994). In sum, the scarce and inconclusive research findings on self-managing teams in services are indicative of the necessity for a broader investigation of the marketing effectiveness of SMT's in service companies.

In organizational literature groups of employees that are self-managing are indicated as teams rather than groups (Yeatts and Hyten 1998). Although the terms group and team have been used to reflect different entities, the conceptual distinction between groups and teams is frequently diffuse . Generally, the concept of group is perceived as a more generic term and has been used to indicate a larger numbers of social and organizational structures (Hackman 1990) than the concept of teams. Teams can be characterized as intact and clearly identifiable groups of employees operating within an organization that have to accomplish some tasks that result in a product or service (Hackman 1990; Hackman and Oldham 1980; Yeatts and Hyten 1998). Brannick and Prince (1997, p. 4) defined teams as: "two or more people with different tasks who work adaptively to achieve specified and shared goals". They argue that teams distinguish themselves from groups, since team members share some explicit common goals. Katzenbach and Smith (1993) denoted that individuals" shared commitment to some specified common goals concerns an essential characteristic of teams. This common commitment motivates individual employees to hold each other responsible for their team"s performance. To achieve these goals, team members need to cooperate. It has been stated that interpersonal processes, as are coordination, communication and cooperation among team members form another essential aspect of the teams (e.g., Brannick and Prince 1997; Campion et al. 1993, 1996; Yeatts and Hyten 1997). When no collaboration among team members is required to carry out task activities and/or to achieve team goals, the team is merely a collection of individual employees (Shonk 1992).

The essential hallmark of SMTs concerns the delegation of managerial responsibilities toward team members, which distinguishes them from work teams in general. A SMT consists of employees who are jointly responsible for managing and performing complete tasks that result in a product or service being delivered (Hackman 1990; Hack and Oldham 1980; Yeatts and Hyten 1998). As a result of the increased authority, SMTs possess considerable control over group norms, individual team member's behavior and team performance (Hackman 1976; Polley and Van Dyne 1994). Typical responsibilities that are delegated to team members are the management of daily activities, monitoring the team's productivity, and regulating the quality of team performance (Yeatts and Hyten 1998). SMTs commonly have distinctive roles or tasks to be completed. These tasks are generally rotated among team members to make employees multi-skilled leading to role-flexibility and job enrichment (Klein 1994; Polley and Van Dyne 1994). SMTs can therefore be defined as: "groups of interdependent employees who have complementary skills and possess the collective authority and responsibility of managing and performing relatively whole tasks in order to achieve specified shared goals".

The unique feature of self-managing teams concerns the application of the selfmanagement principle. Self-management can be applied both at individual and at

\footnotetext{
'This is the main reason why we use the terms "team', "group", and "work group' interchangeably in the remainder of thiss dissertation.
} 
group level. Individual-level self-management is characterized by the provision of autonomy to individual employees who work independently and make job-related decisions on their own without help from others (Manz and Sims 1989). Selfmanagement applied at group level differs from individual-level self-management, since the different members of the team have to collaborate to determine work procedures or problem solving approaches to achieve the formulated objectives (Kirkman and Rosen 1999; Uhl-Bien and Graen 1998).

\subsection{Self-Managing Teams: An Interdisciplinary Approach}

The SMT approach is an interdisciplinary phenomenon, which is grounded in different research streams, such as management and organizational theories, system theories, team literature, communication literature, and social psychology (Tubbs 1994; Yeatts and Hyten 1998). With the start of the industrial revolution at the turn of the $20^{\text {th }}$ century classical organizational theories emerge on how to best manage companies to achieve a rationally and efficiently working organization (Gerth and Mills 1958; Fayol 1949; Taylor 1911). It has been argued that optimal organizational efficiency could be established by implementing rational administrative procedures (Davis 1971; Hackman and Oldham 1980). One leading rationale behind this perspective was the division of labor. It has been stated that the simplification and the specialization of jobs would lead to a maximization of work efficiency. Workers would become easier experts of their specialized job without the requirement of overall organizational knowledge. The principles of the classical theories are still reflected in SMTs. SMTs are designed in such a way that the most adequate and rational work procedures are followed. Since empowered team members have intimate knowledge of their own work, they are better able to make appropriate decisions on task-related issues.

In classical theories the employee perspective on work environment has been disregarded. In response to this lack of attention the human relations movement approach emerges that emphasized employee's well-being and the occurrence of positive human relations as relevant determinants of organizational performance (Argyris, 1957, 1964; Barnard 1938; McGregor 1960; Parker 1984). Various theoretical approaches have originated from this movement such as the human resource perceptive and the participative management perspective. One basic principle underlying the human resource approach is that employees should be considered as valuable resources that need to be developed by the organization (Miles 1965). Advocates of this perspective emphasized the importance of a reasonable and a polite respectful treatment of employees by managers. Furthermore, they have argued that allowing employees to participate in decision-making would result in better problem solving and stated that management of organizations should be involved with the development of employees' knowledge, skills, and abilities to enhance their value to the organization. Subsequently, it was assumed that employee's motivation to participate in decision-making may resolve their higher-order needs, like the need for self-actualization and autonomy (Maslow 1970). Another, more recent, perspective within the human relation movement concerns the participative management approach. This perspective distinguishes itself from the human resource approach by paying 
more attention to the relevance of employee participation in task-related decision making (Anthony 1978; Blauner 1964; Hackman and Oldham 1976; Lawler 1986; Susman 1979). It has been argued that a high degree of employee participation in jobrelated decision-making has positive effects on employees' social and psychological health and forms in this way a strategy to improve job performance (Davis 1977). Furthermore, it has been contended that employees are better able to make task-related decisions on themselves, since they possess more knowledge and experience of their own job activities compared to their supervisors. The participative management approach or the so-called involvement approach has been widely introduced in organizations (e.g., Bowen and Lawler 1995a,b). Organizational structures that are associated with limited employee participation are quality circles, committees, and task forces. Committees and task forces are commonly associated with temporary shortterm activities. Quality circles commonly focus on general goals, like to enhance the efficiency of working procedures or to reduce production costs. In contrast to these organizational structures, SMTs form a clear illustration of advanced participative decision-making practice because employees are allowed to make virtually all decisions related to day-to-day task activities (Magjuka 1991/1992; Pearce and Ravlin 1987; Polley and Van Dyne 1994).

During the second part of the $20^{\text {th }}$ century many theories have emerged that conceptualized the organization as "a system with many interdependent parts that are linked by the social dynamics of human beings working together" (Holt 1990, p.50). Earlier organizational theories and research have mainly focused on individual jobs, while comparatively little attention has been paid to the organization and the external environment as whole systems in relation to workplace practice. However, proponents of systems theories have argued that managers should pay more attention to the organization as a whole entity and the larger external environment surrounding the organization (Silverman 1970). It has been contended that economic, political, cultural, and sociological conditions in the external environment may have an effect on the organization as a whole, rather than on some specific parts of the organization. Instead of investigating individual employee behavior in organizations, systems theories explicitly focus on the different aspects of the organizational system and examine the relationships among organizational units, as are work teams, departments, offices, and branches within the organization and relationships between these organizational units with other organizations or with external environmental conditions outside the organization.

Many systems theories mainly focus on systems within the organization and are referred to as closed systems theories. Initially most systems theorists investigated systems within organization, while not explicitly considering the linkage between aspects of the external environment and the organization. In response to this lack of attention, various researchers started to take an open systems perspective. This approach contains a broader view because it focuses both on systems within organizations and on the exchange process between the focal organization as an entity and its environment (Berrien 1968; Katz and Kahn 1978; Miller 1978). Several researchers are aware of the relevance of the surrounding organizational context when investigating organizations, but take a closed systems perspective. They argued that many intra-organizational variables, as are organizational commitment, quality of 
work life, and job satisfaction could be assessed without severe methodological problems, whereas environmental variables, like political climate, cultural changes, and economic developments usually are variables that are not easy to operationalize or to assess (Zey-Ferrell 1979). Despite the methodological difficulties related to research of the environmental conditions, several researchers emphasize the importance to consider the organizational environment by taking a more pronounced environmental perspective (e.g., Perrow 1986).

One of the most important foundations bearing relevance to the phenomenon of SMTs involves the social technical systems theory, which is principally a closed systems approach. A key assumption of the social technical systems theory is that a joint optimization and a balanced trade-off between social systems and task systems of the organization forms a crucial condition to an effective integration of these highly interrelated systems and will improve work team effectiveness (Mathieu and Day 1997; Pasmore 1988; Pasmore et al. 1982; Tesluk et al. 1997). Task issues involve the actual work that team members need to accomplish, while relationship or social issues concern how well employees are able to cooperate with their colleagues within the work team and with employees from other entities within the organization. In addition to social and technical systems, it as been argued to consider the external political, sociological, economic, and cultural context in which SMTs occur (Mowday and Sutton 1993). SMTs are formed in organizations that commonly operate in a complex and rapidly changing environment and have to deal with demanding customers, suppliers, new legislation, ecological systems, and rapid technological developments. Therefore, top-managers require an in-depth understanding of this rapidly changing environment to improve the SMT performance.

Crucial elements of the social system are group processes and group composition. In the team literature, communication literature, and social psychology literature the social dynamics of groups in relation to team performance have been extensively investigated (e.g., Campion et al. 1993; Campion et al. 1996; Festinger 1954; Hyatt and Ruddy 1997; Katz and Kahn 1978; Mathieu and Day 1997; Tubbs 1994). Group processes refer to social phenomena that are the result of interactions among team members (Helfert and Vith 1999). It has been demonstrated that interpersonal processes, such as the establishment of supportive group norms, the level of group cohesiveness, and the quality of communication among team members are important determinants of team performance (e.g., Helfert and Vith 1999; Morrison and Phelps 1999; Tubbs 1994; Yeatts and Hyten 1998). Another prevalent theme in the team literature is group composition. It has been emphasized that managers should carefully select team members to compose balanced teams of adequate sizes, which include a mix of multi-skilled members that have complementary knowledge and abilities. Well-composed teams possess higher levels of collective knowledge, which result in increased performance (Cohen 1994; Campion et al. 1993; Klein 1994).

Many studies on organizational effectiveness have focused on changes in the social system, while technical aspects of teamwork, as are workflow procedures, individual versus integrated task activities, and technology commonly have got fewer research attention (Goodman et al. 1988; Kelly 1978; Polley and Van Dyne 1994). Yet, instrumental work behaviors are critical variables that connect team member knowledge, skills, abilities and efforts to relevant team performance criteria (Tesluk et 
al. 1997). Several studies have paid attention to technical issues, as are task interdependence and workflow patterns (e.g., Campion et al. 1993, 1996; Larsson and Bowen 1989; Polley and Van Dyne 1994; Tesluk et al 1997; Van der Vegt et al. 2001). In some work environments certain task characteristics are more relevant than in others. Team task activities in operating rooms and psychotherapy for example, are highly integrated and characterized by high levels of interdependence. Conversely, pharmacy, housekeeping services, and data processing are typical examples of work situations in which each individual team member primarily performs his/her task activities separately and there exists no workflow among the different members of the team. Due to the recent technological developments, IT systems have become another prevalent technical task element of today's workplace. It has been argued that the use of information technology facilitates the coordination among employees within the SMTs and between SMTs within the organization and with their customers (Rathnam et al. 1995; Yeatts and Hyten 1998). The use of shared customer database systems for example, improves employee access to relevant customer information and facilitates coordination among employees within SMTs leading to more accurate and timely customer service (Bitner et al. 2000; Rathnam et al. 1995). Notwithstanding the increasing dominance of IT practice in current organizational workplace, adoption of IT in relation to SMTS has rarely been investigated (Janz 1999; Janz et al. 1997). This lack of focused research provides motivation for future investigations to allow for a better understanding of the nature of IT adoption practice in team-based service delivery.

\subsection{The Impact of Self-Managing Teams on Marketing Effectiveness}

The central theme in this dissertation is the marketing effectiveness of SMTs operating in a service environment. Marketing effectiveness concerns a differentiated phenomenon having three major dimensions (Cameron 1986; Heskett et al. 1997; Spreitzer et al. 1999), which is commonly indicated by: (1) internal quality of work measures, which is usually indicated by employee perceptions of their work environment, (2) customer measures, as are customer perceptions of service quality, customer satisfaction, and customer loyalty, and (3) various kinds of productivity measures, like service revenues, sales volume, and response time. However, frequently no significant relationships have been found among the measures of these different performance dimensions (e.g., Meyer and Gupta 1995; Spreitzer et al. 1999). This socalled performance paradox involves another need for investigating the marketing effectiveness of SMTs.

The multidimensional nature of marketing effectiveness is reflected by the different reasons why service organizations adopt SMTs. To begin with, it has been argued that self-management is particularly suited for complex services delivery processes, which are subject to relatively high levels of variability and behavioral uncertainty due to diversity of customer demand, customer participation (Batt 1999; lacobucci 1998; Larsson and Bowen 1989; Van Looy et al. 1998), and the adoption of innovative boundary-spanning technologies (Bitner et al. 2000). Devolving authority to employees allows for greater flexibility and adaptability in performing service 
activities through a more timely problem anticipation and resolution, better integrated employee collaboration, and more efficient and accurate knowledge exchange (Berry et al. 1990 lacobucci 1998). For example, records of Virginia Blood Services, a notfor-profit service company that provides blood and blood components to patients, show that the implementation of SMTs has led to a better quality of communication, improved morale, and increased productivity (Bak et al. 1995). SMTs practice leads through a higher quality of service to increased levels of customer satisfaction and customer loyalty. In other words, the collective responsibility, the interpersonal processes, like task-related communication, collaboration and coordination, as well as a rationalized group design make SMTs crucial drivers of customer service quality (e.g., Helfert and Vith 1999).

Secondly, allowing employees a greater degree of autonony can also be viewed as excellent strategy to improve quality of work life, which is a crucial precondition to deliver outstanding customer service. SMTs may enrich the work environment by providing team members with the opportunity to employ different skills, to fulfill multiple roles within the team, to complete meaningful pieces of work, and to perform tasks that affect other team members (Klein 1994). As such, SMTs can enhance employee quality of work life in terms of job satisfaction, commitment, and turn over. It also has been argued that the adoption of team-based structures leads to a more cooperative and socially interdependent work environment, which will motivate employees to collectively deal with the newly acquired responsibilities (Scott and Tiessen 1999). Furthermore, teams are an integrative social structure in which team members better know and understand each other, which lead to a better fulfillment of their social needs (Larson and LaFasto 1989; Plunkett and Fournier 1991). Team members who experience pro-social attitudes from team colleagues will be stimulated to use this supportive attitude when providing service to external customers.

Finally, from a financial point of view, managers introduce empowered teams to increase their profits. SMTs are being viewed as a substitute of organizational hierarchy and might replace entire management levels, which is likely to cut labor costs (Spreitzer et al. 1999). Furthermore, relinquishing daily managerial responsibilities to teams of employees will increases flexibility and adaptability leading to better and quicker problem solving, closer employee cooperation and more efficient and accurate information exchange. As a result of these highly integrated working relationships, company productivity rates are likely to increase profits (Emary and Fredenhall 2002).

\subsection{Self-Managing Team Service Performance: A Critical Linkage}

Service companies typically have more transparent boundaries in comparison with their manufacturing counterparts, as the interpersonal encounter between front-line employees and customers involves a central feature of the service delivery process (Bitner et al. 1994). This implies that customer perceptions of the quality of service delivered by the customer-contact employees concern a fundamental parameter of service firm effectiveness. Through perceived service quality, other parameters such as 
customer satisfaction, customer loyalty and, eventually profitability are largely determined.

The central role of front-line employee performance illustrates the inherent interdisciplinary nature of the topic, which involves a synthesis of human resource management and service marketing (Bowen 1990; Grönroos 1990; lacobucci 1998). An increasing amount of studies have empirically investigated linkages between employee experiences and customer experiences to explain service firm performance. In the service marketing literature several measures of employee-related performance in service organizations have been proclaimed as adequate predictors of external performance measures, namely service value (Heskett et al. 1997), employee selfefficacy (Hartline and Ferrell 1996), employee job satisfaction (Hartline and Ferrell 1996; Sergeant and Frenkel 2000), employee loyalty (Loveman 1998), organizational commitment (Allen and Grisaffe 2001; Sergeant and Frenkel 2000), quality of work life (Spreitzer et al. 1999), commitment to customer service (Peccei and Rosenthal 1997), employee perceived product/service quality (Schmitt and Allscheid 1995), extra-role behaviors at external customers (Bansal et al. 2001), and capacity to satisfy customers (Sergeant and Frenkel 2000).

In many other studies the concept of service climate has been proposed as a crucial mediator of internal operational performance and external marketing effectiveness parameters (Andrews and Rogelberg 2001; Johnson 1996; Schneider 1990; Schneider et al. 1992, 1993, 1998, 2002; Schneider and Bowen 1985, 1995; Yagil and Gal 2002). It has been argued that the concept of service climate is a better predictor of external marketing effectiveness measures, like customer parameters and financial criteria (e.g., Schneider et al. 1992), than are measures of general workplace practices. In an empirical study Schneider and Bowen (1985) have found that employees' evaluations of the company's provided service quality have stronger linkages with customers' evaluations of customer service than have employee evaluations of general organizational human resource issues. The concept of service climate has been commonly defined as "shared employee perceptions of company procedures and policies with regard to customer service". So far, service climate has been usually conceptualized as a global construct reflecting the general company policies and procedures intended to improve service quality (Schneider et al. 1996, 1998). Since many service companies realize the relevance of SMTs as a means to improve their marketing effectiveness, there is an urgent need to investigate concrete service practices in work groups rather than global company strategies with regard to service quality policies and procedures. As a result, we focused on service operations in a specific work group context and developed the concept of SMT service climate defined as "perceptions of the manifestation of SMT attitudes and practices aimed at effective performance in service delivery to customers" (cf. Schneider and Bowen 1993). The concept of SMT service climate comprises a wide range of behaviors that are collectively undertaken by the team members, as are proactive corrective actions, service improvement initiatives, and being flexible and open-minded toward customers (e.g., Iacobucci 1998; Pulakos et al. 2000). In other words, SMT service climate refers to employees' opinions about the quality of service practice they perceive and experience within their work group. It has been argued that a climate defined at work group level includes a considerable behavioral component (Zohar 2000). Similarly, 
SMT service climate includes various behavioral and attitudinal performance aspects that are related, but may be distinct in some way. On the one hand, employees require listening skills to accurately consider customers' viewpoints and opinions in order to appropriately adjust their service approach, while, on the other hand, taking initiative to change existing service problems is another crucial component of service performance. To get a thorough insight into the distinctive aspects that make up SMT service performance we compare adaptive and proactive performance behavior as two typical representatives of SMT service performance (e.g., Hartline and Ferrell 1996; Morrison and Phelps 1999) and examine to what extent they are distinct components that are complementary to the establishment of SMT service performance.

While SMT service climate and its components typically reflect social practice, the socio-technical systems theory also focuses on technical work aspects as another key element of SMT performance. In this époque of technological advancements, the adoption of IT typically represents technical task aspects, which complements the aforementioned SMT service performance instruments of nowadays" service companies. Many organizations are characterized by a diffuse IT adoption practice. Therefore, we distinguish between adoption-rates of standardized and customized IT types in order to acquire a comprehensive understanding of the impact of service supporting IT on SMT service performance.

\subsection{Service Context: A Contingency Factor}

There is wide consensus on the contention that the nature of employee-customer encounters may substantially vary across service settings. The nature of service performance depends on the market context (i.e., business-to-business versus businessto-consumer) and the type of service provided (i.e., routine versus non-routine services). Employee-customer interactions vary on a continuum from short, standard, and low-contact modes to extended, highly intensive encounters between service providers and employees (Anderson et al. 1997).

Services in business-to-business marketing settings are predominantly complex and extended in nature and are commonly characterized by intensive encounters between service providers and their business customers (Wetzels et al. 1998). In contrast, the nature of employee-customer interactions in business-to-consumer service situations widely varies across types of services and ranges from rather complex services that require comprehensive knowledge and skills, and high levels of customization such as financial consults (e,g., providing a mortgage) to routine-based standardized activities in low customer-contact service modes (e.g., offering a burger menu in a fast food restaurant) (e.g., Kellog and Chase 1995; Larsson and Bowen 1989; Verma 2000). Bowen and Lawler (1992) have argued that different types of services require different levels of empowerment to deliver excellent customer service. High levels of autonomy may be particularly relevant in highly differentiated, personalized customer services, while the procedural ly-driven product-line approach as proposed by Levitt (1972) can be best applied to service situations in which employees have to carry out specific activities according to prescribed rules. For example, in industrial cleaning companies employees are usually tied to rigid scripts, 
which leave them little room for discretion when cleaning the floor carpet or washing a wall. Although several taxonomies have been developed to map the different types of service (e.g., Kellogg and Nie 1995), the moderating influence of typical contextual features such as type of service or service department size have been rarely incorporated or even considered as moderators when investigating empirical linkages between internal and external organizational performance parameters (Johnson 1996; Schneider et al. 2002). To get an in-depth understanding of the moderating role of these contextual features it is relevant to compare internal-external performance linkages across different types of service settings.

\subsection{Motivation of the Study}

The overall motivation of this thesis is based on the importance of appropriate service operations management as a driver of the service company's marketing performance. In service marketing literature there is growing evidence of the positive impact of innovative service management approaches, like empowering front-line employees and the use of teamwork on marketing parameters, as are quality of employee work life, customer satisfaction with the provided service quality, and company profitability (e.g., Berry et al. 1994; Emery and Fredenhall 2002; Hartline and Ferrell 1996; Helfert and Vith 1999; Spreitzer et al. 1999; Teare et al. 1999; Van Looy et al. 1998). In managerial practice many companies have reported considerable increases in service productivity due to the implementation of empowered customer teams. Savoy Group of hotels and restaurants reported that cross-functional teamwork has led to improved customer service. Kennametal Hertel Limited, a division of Kennametal Inc. (USA) indicated that the formation of a value added team has led to considerable efficiency improvements in customer service procedures and a considerable increase in the company's world sales. Despite the growing number of academic studies on teamwork and empowerment in services, little is known about of the nature of service practice within SMTs. Since implementation of SMTs in service companies has become commonplace, it is imperative to investigate what social dynamics and technical task aspects drive service quality practice in service teams that self-manage their daily task activities.

Based on an extensive literature review we distinguish the following three major aspects of SMT service performance: (1) service climate, (2) service recovery performance, and (3) IT adoption. First, in the service marketing literature it has been widely recognized that the presence of an organizational climate for service is a crucial determinant of external marketing outcomes in service companies (e.g., Johnson 1996; Schneider 1990; Schneider et al. 1992, 1996, 1998; Schneider and Bowen 1985, 1995). The continuing emphasis in academic studies on the concept of service climate affirms its importance in service marketing practice (Andrews and Rogelberg 2001; Schneider et al. 2002; Yagil and Gal 2002). Many studies have investigated the antecedents of service climate and in turn have demonstrated empirical linkages between organizational service climate and external customer-based parameters and 
productivity (e.g., Schneider and Bowen 1985; Schneider et al. 1998). Despite the relevance of a climate of service in organizations, little is known about group processes and organizational conditions that determine service climate at work group level in business-to-business and business-to-consumer service settings.

Secondly, another major issue in the services marketing literature concerns the effective recovery of customer service problems. Problems in service delivery usually concern complex and idiosyncratic problems that cannot be solved by the standard service delivery procedures (Hart et al. 1990). The delegation of decision-making authority to work groups allows employees the freedom and flexibility to collectively use extra-role behaviors in order to effectively deal with these differentiated service problems (Hartline and Ferrell 1996; Morrison and Phelps 1999). Although it has been acknowledged that improvisation skills and behavioral initiative are relevant to effectively manage and prevent customer problems (e.g., Iacobucci 1998), research on the role of distinctive recovery behaviors in self-managing service teams has remained scarce.

Thirdly, while service climate and extra-role recovery behavior typically reflect the social dynamics associated with SMT service performance, following the social technical systems theory, it has been emphasized that technical task issues, as are workflow patterns and IT systems form another driver of SMT performance (e.g., Pasmore et al. 1982; Rathnam et al. 1995; Tesluk et al. 1997). In response to the recent proliferation of IT service-supporting systems in many service organizations, several recent studies have recognized and emphasized the significance to investigate the adoption of IT systems in services (Bitner et al. 2000; Parasuraman and Grewal 2000; Quinn 1996). So far, however, few studies have investigated the use of IT by front-line empowered employees (e.g., Griffin et al. 1994), while research on the adoption of IT by customer service teams is even scarcer (Rathnam et al. 1995).

Another issue pertains to the external marketing consequences of service performance in SMTs. So far, several studies have investigated internal performanceexternal performance linkages primarily at organizational level and have demonstrated the relevance of organizational service practice to customer-based parameters and company profitability (e.g., Heskett et al. 1997; Schmitt and Allscheid 1995; Schneider et al. 1998). In contrast, research on linkages at the group level has remained scarce (e.g., Kirkman and Rosen 1999; Spreitzer et al. 1999) indicating the relevance to pay broader research attention to these internal-external linkages from a group-level point of view.

\subsection{Objectives}

In this dissertation, we focus on the effectiveness of self-managing teams as a strategic management tool to improve the firm's service operations. A central feature of the activities of the self-managing teams under study involves the interpersonal employeecustomer encounters. The separate chapters clearly discuss the relevant literature, their objectives and their theoretical as well as their managerial implications in relation to different relevant service performance parameters in different types of service settings. 
Nevertheless, it is of fundamental importance to explicate the outline of the overall objective of this dissertation and how the aims of the different chapters are related to the key objective

The overall aim of the dissertation is to determine the impact of SMTs on marketing effectiveness in service companies. To gain better insight into self-managing team performance we identify the relevant antecedents of different aspects of selfmanaging team performance across service industries and establish linkages between those SMT performance aspects and external marketing outcomes. To address this overall objective effectively, we formulate specific purposes for the different chapters in which we address our general objective from different perspectives.

\subsubsection{Objectives Chapter 2}

In Chapter 2, we focus on SMT service climate in teams that operate in a business-tobusiness service context and provide after-sales services. In this chapter we build a comprehensive model of antecedents and consequences of SMT service climate. We take a broad research perspective on SMT service climate considering various antecedents from multiple interfaces. The objectives of this chapter are to: 1) develop a comprehensive conceptual framework grounded in several research fields that identifies antecedents and consequences of SMT service climate, and 2) to empirically determine the antecedents and consequences of SMT service climate.

\subsubsection{Objectives Chapter 3}

In Chapter 3, we further examine the role of SMT service climate in SMTs that operate in a business-to-consumer environment providing core services. In contrast to chapter 2 , we take a more focused, social systems perspective and elaborate on the various supportive interpersonal processes within and between teams throughout the organization to emphasize the relevance of interpersonal processes to SMT performance (Yeatts and Hyten 1998). Furthermore, we take some contingencies into account and: (1) compare SMT service climate in routines services to SMT service climate in non-routine services, and (2) make a distinction between group-level and individual-level manifestations of the antecedent variables. The objectives of chapter 3 are to: 1) develop a conceptual framework of antecedents and consequences of SMT service climate taking a social systems perspective, 2) to determine whether the antecedents and consequences of SMT service climate are contingent on the type of service offered, 3) to explore the effects of group-level and individual-level antecedents on SMT service climate perceptions.

\subsubsection{Objectives Chapter 4}

In Chapter 4 we investigate the role of adaptive and proactive recovery behavior in SMT's that are operational in a business-to-consumer context and deal with service recovery. Again, we take a social systems perspective and develop a framework of antecedents and consequences of adaptive and proactive recovery behavior. Furthermore, we take a contingency perspective, as we: (1) compare adaptive behavior 
to proactive behavior, and (2) make a distinction between group-level and individuallevel effects of the antecedents. The objectives of chapter 4 are to: 1) develop $a$ conceptual framework of antecedents and consequences of adaptive and proactive recovery behawior, 2) to determine the differences in antecedents and consequences between adaptive and proactive recovery behavior, and 3) to explore the antecedent effects on adaptive and proactive recovery behavior at the group level and the individual level of analysis.

\subsubsection{Objectives Chapter 5}

In chapter 5, we study the adoption-level of standardized and customized types of IT by SMTs operating in a business-to-consumer environment providing core service. We developed conceptual framework of antecedents and consequences of the adoption rates of IT. Based on a literature review, we discern three types of antecedents of IT adoption: organizational characteristics, technology characteristics, and user characteristics. Within this examination, we distinguish between adoption-levels of standardized IT and customized IT. The objectives of this chapter are: 1) to develop a theoretical framework, based on several literature streams, that identifies antecedents and consequences of the adoption-level of standardized and customized IT by SMTs, 2) to empirically examine whether the level of IT adoption is a critically differentiating factor of SMT service performance, and 3) to determine the differences between the adoption of standardized IT and customized IT types.

\subsection{Outline of this Dissertation}

This dissertation discusses service performance from a SMT perspective. It contributes to different literature streams, integrates different theoretical perspectives, employs multiple data sources and applies advanced statistical data analysis techniques. Each chapter focuses on SMT service performance in one or more different service marketing settings. We investigate distinctive aspects of SMT service performance in differentiated service contexts to allow for generalizations as well as to identify relevant contingencies of SMT service performance.

In Chapter 2 and 3, we develop and discuss the concept of SMT service climate. We expand previous academic literature that discusses service climate at the organizational level (e.g., Schneider et al. 1996, 1998) by shifting our focus to service practice at the work group level. In Chapter 2, we discuss the role of SMT service climate in SMTs operating in a business services setting, offering after-sales services. We take a comprehensive perspective on SMT service climate and build an extensive model considering antecedents from various interfaces. Social technical systems theory and contemporary SMT theorists (Cohen 1994; Gladstein 1984; Goodman et al. 1988; Hackman 1987, 1990; Pearce and Ravlin 1987; Yeatts and Hyten 1998) have indicated that a sound functioning social system is relevant to SMT performance. Following this rationale, in Chapter 3 we take a more pronounced, social systems perspective and consider the role of supportive social processes within and between teams associated with SMT service climate. How do people within teams and across teams get along 
with each other? Next, previous research has demonstrated that supportive group norms are crucial in encouraging employees to carry out appropriate performance behaviors (Morrison and Phelps 1999; Helfert and Vith 1999). Subsequently, the operational nature of work group climate reflects a considerable behavioral component (Zohar 2000), which is indicative of the importance to consider supportive social processes when investigating SMT performance. Moreover, the findings from Chapter 2 reported a positive influence of group norms on SMT service climate confirming the importance to take supportive social processes within teams and between teams throughout the organization into account when investigating service climate in SMTs.

Furthermore, while business-to-business services are commonly characterized by high-contact encounters between suppliers and their business customer, the nature of employee-customer interactions in consumer service markets may widely range from highly intensive to short low-contact encounters. This motivates us to take a contingency approach by comparing routine services to non-routine settings. Another elaboration involves the distinction between group-level and individual-level manifestations of antecedent variables. In order to determine to what extent employee's perceptions of SMT service climate are based on idiosyncratic cognitive schemas or on inter-subjective team member perceptions.

In Chapter 4 we continue to take a social systems perspective and examine the impact of adlaptive and proactive behavior on service recovery in SMTs that operate in a consumer services context. While Chapter 2 and 3 discuss SMT service climate as an integral construct of work group service practice encompassing differential performance behaviors and attitudes, in Chapter 4 we distinguish between adaptive and proactive behavior as distinctive components that make up such a work group climate for service. Given the operational nature of work climate in SMTs, it is significant to consider distinctive servicing behaviors to get a more thorough insight into the separate aspects that constitute SMT service performance (Zohar 2000). Especially in an after-sales service context explicit servicing behaviors are required to achieve excellent service recovery practice (Iacobucci 1998).

In Chapter 2, 3, and 4 we primarily focus on the impact of social dynamics on SMT performance. In contrast, in Chapter 5 we take a technical task systems perspective and focus on instrumental performance behavior another crucial aspect of social technical systems theory. Specifically, we focus on the antecedents and consequences of SMT's adoption of distinctive IT types.

In addition to differences with regard to focal SMT performance constructs and service settings, all chapters share a number of common features. Since the selfmanagement principle involves the basic feature of SMTs, tolerance-of-selfmanagement is included as a determinant in all developed conceptual frameworks of SMT performance. In all empirical studies, mediator models are developed and tested, in which the different focal SMT performance constructs (i.e., SMT service climate, adaptive and proactive recovery behavior, adoption-level of standardized and customized IT) are specified as mediators of internal operations and external marketing effectiveness criteria. In these models antecedents were investigated of these SMT performance constructs and in turn linkages were established between these constructs and external marketing outcomes including customer-based parameters and productivity measures. 
With respect to the statistical analyses techniques employed, in all chapters we are dealing with hierarchical data structures; employees are 'nested' within SMTs. This implies two different levels of analysis: the employee level and the group level. To effectively analyze the hierarchical data that were collected we employed hierarchical linear models.

Furthermore, in this dissertation we are examining the relationships between internal performance and external performance variables at the aggregated level of analysis. It has been argued that it is conceptually more appropriate to analyze employee-customer relationships at aggregated level, as individual customers typically observe the output of interpersonal work processes of service team members (Allen and Grisaffe 2001). Moreover, the data of individual employees were collected without identifying information that allows them to be linked with the appropriate customer. As such, it was not practically possible to match employee-customer data at individual level. Similarly, the employee-productivity relationships are analyzed at aggregate level, since the productivity criteria commonly involve measures defined at the group level. Finally, Chapter 6 provides a summary of the main conclusions and offers suggestions for additional theory and research. Figure 1-1 and Table 1-1 summarize the outline of this dissertation.

\section{Figure 1-1: Visual Representation of the Topics Discussed in this Dissertation}

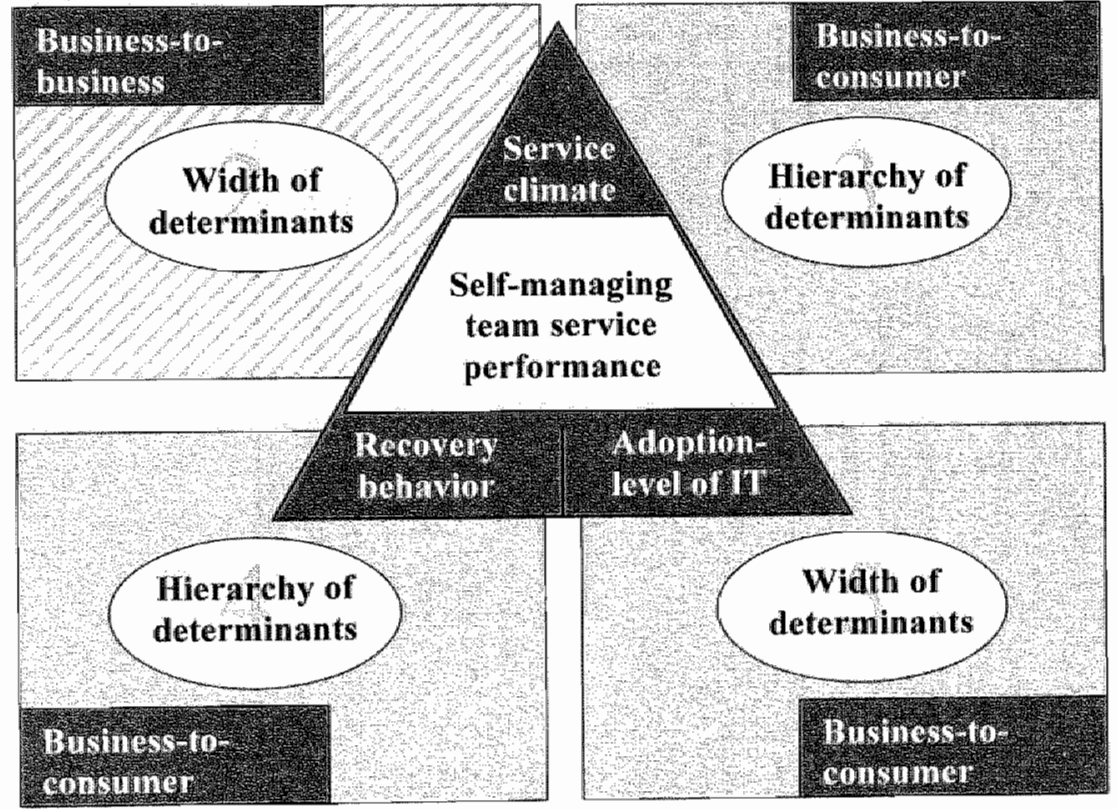




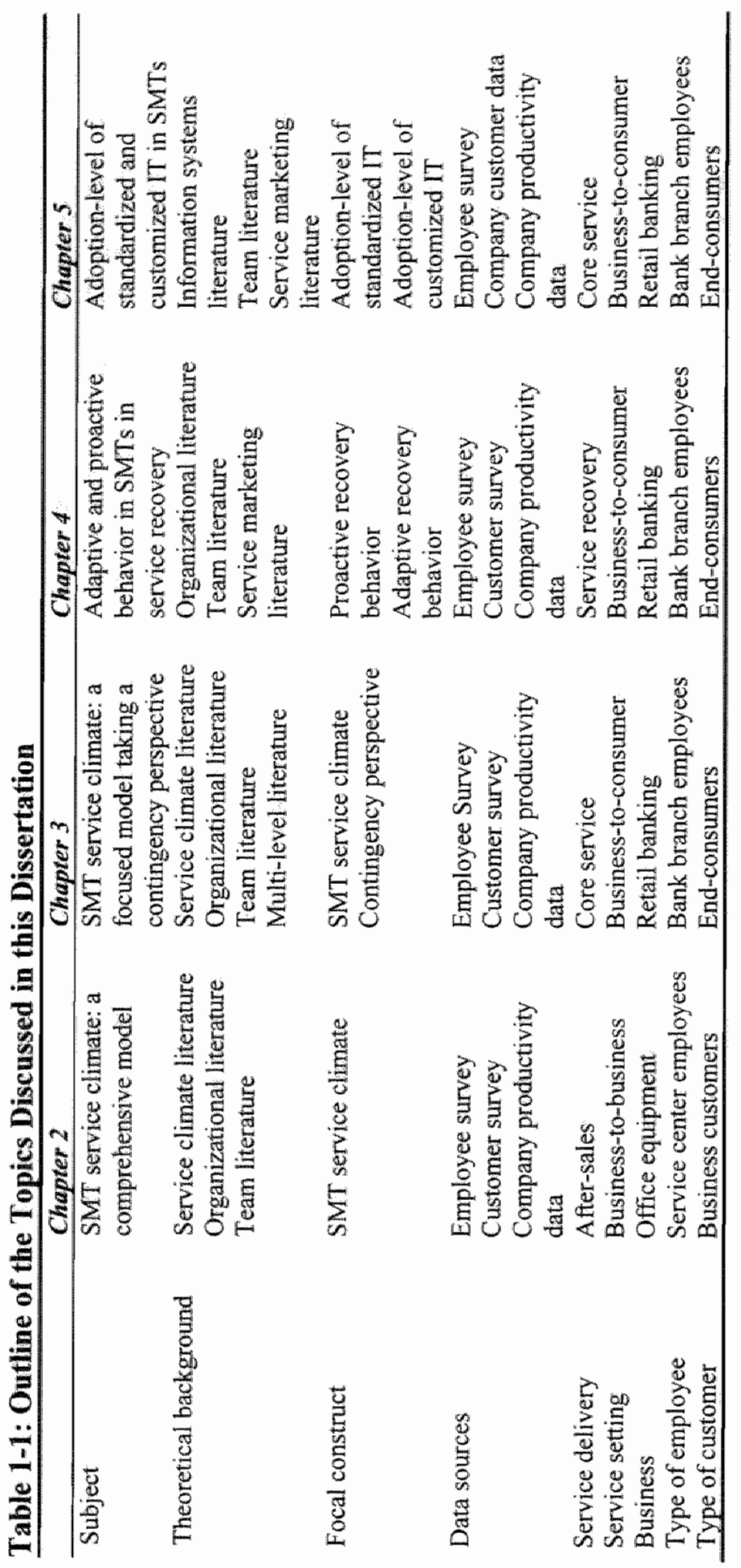




\section{Chapter 2}

\section{Service Climate in Self-Managing Teams:}

\section{A Business-to-Business Study}

Drawing from the organizational behavior and services marketing literature, we develop a conceptual model of self-managing team (SMT) service climate, taking into account characteristics of the organizational context, the SMT and the individual employee. In order to assess the impact of SMT service climate, we include a number of internal consequences (i.e., in-company performance data) and external service performance outcomes (i.e, customer perceived service quality). As a result of the hierarchically nested data-structure (i.e, groups and individuals), we investigate the antecedents of SMT service climate in service groups using a multi-level approach. By making a distinction between group-factors and within-group deviation scores, we are able to assess whether the exact nature of the predictor criterion relationships differs. We demonstrate that higher levels of employee perceived SMT service climate positively affect customer perceived service quality and first-time-fixed rates. Furthermore, our results reveal that particularly group-level factors have a significant impact on SMT service climate, indicating the efficacy of multi-level lechniques in modeling team-employee relationships. 


\subsection{Introduction}

Service excellence has become a key competitive advantage in virtually all industries (Albrecht and Zemke 2001). In providing the flexibility and individualized care entailed in the service proposition, companies must rely to a large extent on their customer contact employees" attitude and behavior towards providing quality service. Indeed, from recent research it has become clear that a climate for customer service among these employees is of paramount importance to service performance outcomes, varying from internal operational metrics to customer evaluations (Andrews and Rogelberg 2001; Schneider et al. 1992, 1996; Schneider and Bowen 1985). It is widely recognized that such a service orientation requires the delegation of authority to the organizational front-line in order to deal with the relatively high levels of variability and behavioral uncertainty commonly associated with the delivery of services (Batt 1999; Larsson and Bowen 1989). It has also been argued that teamwork is crucial for the delivery of service quality (Berry et al. 1994). Therefore, an increasing number of companies (e.g., Lockheed Martin Government Electronic Systems, Prudential Life and Pensions, and Twentieth Century Insurance) have delegated the collective responsibility for customer service quality to self-managing teams (SMTs) to allow for the efficient and effective orchestration of the broad range of knowledge, skills and abilities needed in performing service activities (Griffin et al. 1994; Helfert and Vith 1999; Spreitzer et al.1999). There is some empirical evidence that SMTs perform significantly better in terms of service quality and sales volume than teams that were under management control (Dumaine 1994; Batt 1999). However, an in-depth insight into the key factors that drive SMT service performance in boundary-spanning environments is largely lacking. Furthermore, it is not clear whether these factors operate at the individual level or at the group level. With the advent of multi-level modeling, it has now become possible to differentiate between individual and teamrelated factors. This provides a more comprehensive perspective on SMT-related issues and the linkage between internal and external effectiveness measures (Kidwell and Mossholder 1997). Such a perspective is taken in this chapter.

The chapter is structured as follows. First, we introduce the concept of SMT service climate as a critical variable in relation to boundary-spanning work groups and develop a conceptual model of its employee-level and aggregate-level antecedents. Moreover, we review a number of key performance parameters of a climate for service in SMTs. Subsequently, we empirically test whether SMT service climate is a critically differentiating factor between teams with respect to both customer-based and company-based verifiable performance measures in an after-sales business services setting. In our empirical study, we also assess a two-level model to determine which antecedents affect SMT service climate perceptions of individual group members. We conclude the chapter by discussing our findings as well as their theoretical and managerial implications. 


\subsection{Self-Managing Team Service Climate}

The concept of service climate has emerged as the 'missing link' between internal and external service performance parameters (Andrews and Rogelberg 2001). It has been argued that as a linkage construct service climate has superior predictive power in relation to organizational effectiveness over other constructs that have been advanced in the organizational behavior and marketing literature, such as job satisfaction, organizational commitment and quality of work life (e.g., Schneider et al 1992). So far, service climate has predominantly been operationalized as the shared employee perceptions of company procedures and policies on the quality of customer service. With the recent implementation of SMTs in many service organizations, however, it seems of fundamental interest to broaden the research scope and investigate the concept at the work group level (Helfert and Vith 1999; Zohar 2000). Following previous research, we conceptualize SMT service climate as a work group property that reflects the manifestation of SMT practices aimed at effective performance in service delivery to customers (cf. Schneider and Bowen 1993). Operationally, it concerns initiatives and deliberate actions to improve the service delivery process and promote customer service quality standards that are collectively undertaken by the SMT. At the organizational level, service climate is a broad, strategically focused construct (Schneider et al. 1996). At the SMT level we propose that it concerns the implementation of organizational policies and procedures as an integral part of work group efforts. Hence, it reflects SMT employees' attitudes towards practices they perceive and experience in their team concerning the firms' strategic service goals. Conceptually, our decision to develop a context-specific construct builds on recent studies that suggest that such measures are stronger related with organizational antecedents and outcomes than more general measures (Ellemers et al. 1998; Zohar 2000). In the next sections we focus on these antecedents and outcomes.

\subsection{The Impact of Self-Managing Team Service Climate on Service Performance}

Recent studies have emphasized the importance of service climate to customer evaluations (e.g., Peccei and Rosenthal 1997; Schneider et al. 1998) and productivity criteria (Singh 2000). Loveman (1998) argues that capable employees who are enthusiastic about delivering great service enhance customer satisfaction. Furthermore, it has been empirically demonstrated that the extent to which employees are involved in seeking information from colleagues and customers in order to improve service quality is positively related to customer perceived service quality (Johnson 1996). In addition, Schneider et al. (1998) have found that an organizational climate that encourages service employees to exert effort and to use their competencies on delivering high service quality, in turn, yield positive customer evaluative judgments with respect to the service delivery. Therefore, we propose that SMT service climate is a differentiating factor with respect to service quality, as perceived by customers: 
$H_{j}: S M T s$ with a higher level of service climate receive higher customer perceived service quality evaluations than lower-level SMTs.

In the services marketing literature service quality and productivity are posited as two related but distinct aspects of service performance (Singh 2000). Service quality is primarily concerned with how the service is delivered and often concerns processoriented, subjective measures based on customer ratings. In contrast, service productivity is frequently assessed by objectively verifiable and quantifiable service outcomes. Typical examples of service productivity measures are: "response time' and 'percentage of technical problems solved in one call' (Hyatt and Ruddy 1997). Ideally, service productivity and quality should be positively related. In practice, however, discrepancies between productivity and quality result from the underlying tension between efficiency and effectiveness in services (Singh 2000). Nevertheless, it has been argued that employees who are committed to deliver service quality will be able to handle these conflicting interests, as the rationale for many productivity standards is ultimately to improve service quality (Heskett et al. 1997). In line with this reasoning, we posit that the level of SMT service climate makes a difference in terms of productivity metrics:

$H_{2}:$ SMTs with a higher level of service climate deliver higher levels of service productivity than lower-level SMTs.

\subsection{Antecedents of Self-Managing Team Service Climate}

As SMT service climate is expected to be a key driver of team performance, it is relevant to investigate its determinants. In line with previous work on teams (e.g., Campion et al.1996), three categories of antecedents are discerned. First of all, metaanalytic studies of team effectiveness identified characteristics of the organizational context as a major driver of work group attitudes and behavior (Campion et al. 1993, 1996). Hyatt and Ruddy (1997, p. 577), for instance, note that: "too often researches of group effectiveness focus on the group itself and neglect the environment in which the group operates". A second group of antecedents pertains to processes that take place within the team (Campion et al. 1996). This second group of antecedents reflects the interface between team and employee. Finally, previous research has identified individual service employee role characteristics as a third category of determinants (Hartline and Ferrell 1996).

\subsubsection{Context-Team Interface}

Several characteristics of the organizational context in which service groups operate are likely to influence team members' capacity and/or willingness to engage in continuous improvement of the service performance of their team. We discern three context-team antecedents: tolerance-of-self-management, formalization and inter-team communication. Our choice of antecedents variables was governed by the three main 
inherent features that differentiate SMTs from other traditional work groups; higher levels of autonomy, functional flexibility and coordination between teams (Barker 1993, Klein 1994).

Tolerance-of-self-monagement. Tolerance-of-self-management refers to the freedom given to work teams to practice the principles of self-management ( $\mathrm{c}$.f., tolerance-offreedom, Hartline and Ferrell 1996). Several studies have emphasized the importance of a general organizational orientation in which employees have the discretion to make day-to-day decisions about job-related activities (Bowen and Lawler 1992, Hartline and Ferrell 1996). In a work group context, tolerance-of-self-management concerns the ability of the group members to make task-related decisions and the acceptance of the responsibility for the outcomes of these decisions (Campion et al. 1993). By allowing customer-contact employees to make these decisions, management relinquishes control over many aspects of the service delivery process. As a result, team members are stimulated to take initiative and use their judgment when dealing with customers (Hill 1991). It has been argued that authority and initiative enhance SMT members' sense of responsibility, promotes a vision that is compatible with an organization's strategic objectives, increases organizational service learning (Hays and Hill 2001) and allows for a more proficient processing of information (Griffin et al. 1994). "Therefore, we hypothesize that:

$\mathrm{H}_{3}$ : There will be a positive effect of tolerance-of-self-management on SMT service climate.

Formalization. Formalization is the extent to which work activities imposed by upper management on the team are defined formally by administrative rules, policies and procedures (Ford and Slocum 1977). Especially under conditions of boundaryspanning self-management, clarity in terms of rules, administrative procedures and organizational policies is of crucial interest (Rathnam et al. 1995). Although it has been argued that formalized rules and regulations may constrain employees" ability to respond effectively to customer requirements (Hartline and Ferrell 1996), a number of studies have conceptually supported and empirically demonstrated the positive impact of formalization on service-oriented employee variables (Michaels et al. 1988, 1996). The rationale being that by making the content of service quality goals and objectives more explicit, formalization enables team members to make more objective decisions about whether to "internalize" the service quality goals of the organization as their own (of., Morris and Steers 1980). Furthermore, service processes that are driven by operationally useful rules and procedures may enhance team members' perceptions of the service quality in the organization. Therefore, we hypothesize that:

\section{$H_{4}:$ There will be a positive impact of formalization on SMT service climate.}

Inter-team communication. It has been argued that the implementation of SMTs leads to an expansion of horizontal communication, employees rely less on formal hierarchical channels (Bartol and Hagmann 1992). Furthermore, Sundstrom et al. (1990) demonstrate that the exchange of information between teams is key factor in 
determining team effectiveness. The coordination of service-oriented activities and information exchange, therefore, either enhances or constrains team members' ability to respond effectively to customer requirements (Peccei and Rosenthal 1997). Bansal et al. (2001, p. 69) state that "transparent communication in organizations improves frontline employees ability to provide other organizational members and customers with useful information and better service'. Finally, Schneider et al. (1994) report that communication across functional boundaries is significantly associated with a serviceoriented climate. Similarly, Sergeant and Frenkel (2000) empirically demonstrate that the support from other departments in the organization exerts a direct positive effect on employees" perceptions of their capacity to satisfy customers. Therefore, we hypothesize:

$H_{5}$ : There will be a positive impact of inter-team communication on SMT service climate.

\subsubsection{Team-Employee Interface}

Team Norms. It has been reported that team norms have a considerable impact on team performance (Feldman 1984; Yeatts and Hyten 1998). Norms are defined as: "standards that are shared by group members which regulate group behavior" (Cohen 1994 , p. 85). Barker (1993) notes that the emergence of normative rules is one of the building blocks of SMTs. The central issue here is the role of consensus-building in establishing team norms on service-related issues. When there is agreement about norms, the dominant responses of individual team members are compatible with one another. Argote (1989, p.138), for instance, notes: "that agreeing about how to solve work problems may be more important than the particular problem-solving method selected". Shared visions and values bind employees together in the collaborative pursuit of customer service goals. As individuals jointly work together by sharing information, they become convinced that everyone should contribute and that by cooperating they can all accomplish the task successfully (Kouzes and Posner 1987). Hence, we hypothesize, therefore, that team norms will have a positive impact on SMT service climate:

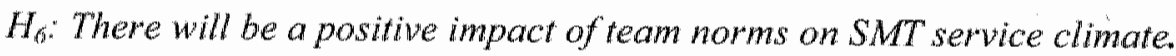

Team Goal Setting. Self-management entails the process that groups develop their own goals. In contrast with team norms, goals are specific, measurable levels of performance (Yeatts and Hyten 1998). Most previous goal-setting research has focused on the specific nature and content of assigned goals (Locke et al. 1981). However, with the introduction of SMTs, rather than investigating the specific content or structure of goals, more emphasis has been put on the process of participation of individual team members in the establishment of their own group goals recently (Barker 1993; Manz and Sims 1987; Uhl-bien and Graen 1998). Several researchers have concluded that the motivation to achieve team goals is highest when the team is allowed to establish its own goals based on management's mission for the team (Hackman and Walton 1986; Neck et al. 1996). Kalbaugh (1998) convincingly argues that when team 
members participate in determining their own goals, they are more likely to be committed to them. As such, group service goals will have a strong impact on the team"s service effectiveness (Yeatts and Hyten 1998). Therefore, in order to emphasize the importance of the process of developing performance parameters, it is hypothesized that:

$H_{7:}$ There will be a positive impact of team goal setting on SMT service climate.

\subsubsection{Employee-Role Interface}

Role Stress. Service teams are boundary-spanning units. As such, they have to balance the interests of the organization and the customer, a task that may be stressful (Rathnam et al. 1995). Two dimensions of role stress have been discerned in the literature; role ambiguity and role conflict (Boles and Babin 1996). Role ambiguity occurs when team members lack the information necessary for performing their role and role conflict is the result of the incompatibility between the firm's and the customer's interest (Hartline and Ferrell 1996; Singh 1993). Role stress may increase team members" uncertainty about the best way to perform their jobs and induces team members to think that the SMT service climate of their team is lower than members that do not experience role stress. Hence, we propose that:

$H_{8}$ : There will be a negative impact of role ambiguity of individual employees on SMT service climate.

$H_{9}$ : There will be a negative impact of role conflict of individual employees on SMT service climate.

Figure 2-1: Relationships in the Conceptual Framework

\section{Antecedents}

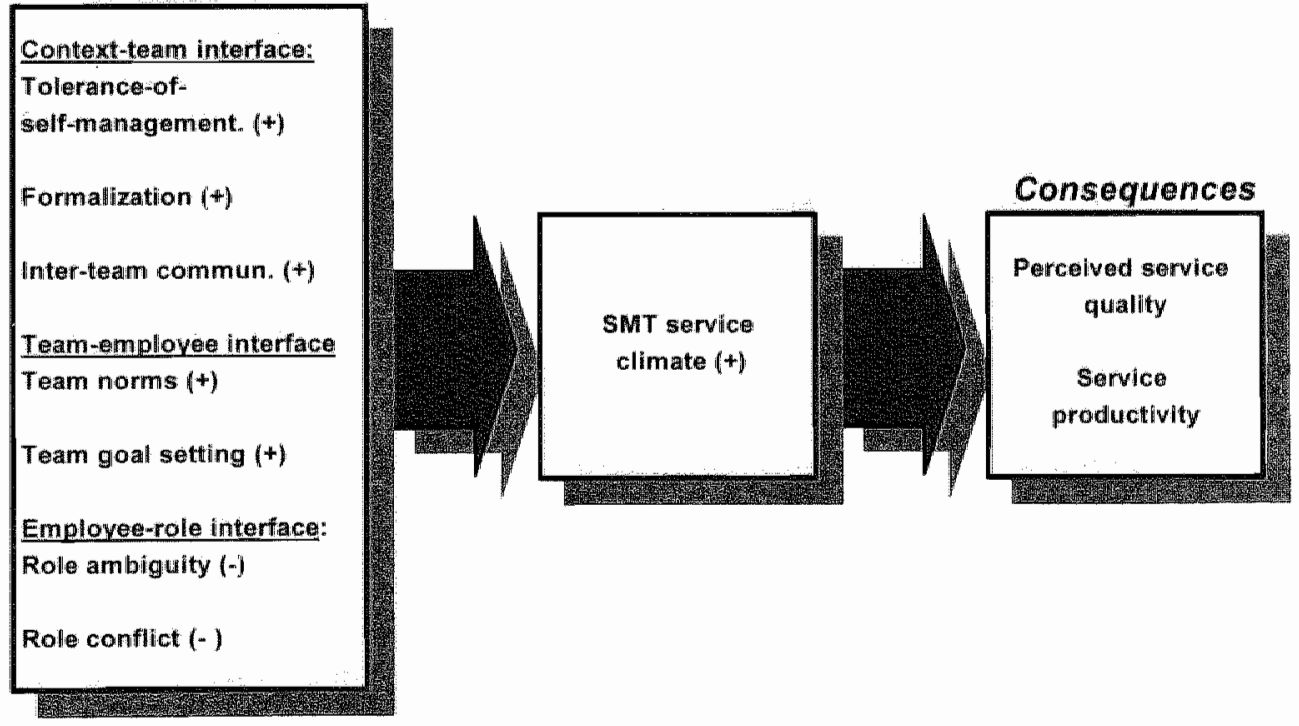


Figure 2 - represents the following conceptual model in which the aforementioned hypotheses are summarized.

\subsubsection{Refinement of the Conceptual Framework}

An important feature of our study concerns the hierarchical structure of the employee data, I.e., employees are nested within SMTs. Therefore, we propose to nuance aforementioned conceptual framework by taking different levels of analysis into account. Several arguments may be advanced in support of such a refinement. To begin with, the different levels of analysis reflect qualitatively different perspectives. More specifically, the individual data corresponds to subjective appraisals, while the aggregated data corresponds to the inter-subjective perceptions of team members (De Jonge et al. 1999). Furthermore, a comparison of relationships between variables across levels of analysis is of fundamental interest to determine whether predictoreriterion relationships occur at the individual and/or at the group level (Bolon 1999; Ostroff 1993a).

Previous multi-level research has primarily investigated individual outcome variables (e.g., Steenkamp et al. 1999). However, it also makes both conceptual as well as empirical sense to consider multiple levels of analysis in predicting group outcomes, such as SMT service climate. Several authors have argued that group outcomes are composite functions of individual and collective contributions of employees (e.g., Kozlowski and Klein 2000). Therefore, when individual employee ratings are used to measure group outcome variables, it adds incremental value to simultaneously consider the individual level and the group level of analysis and to distinguish between differences in shared perceptions of SMT service climate across teams (i.e., betweengroups differences) and between differences in how SMT service climate is perceived (i.e., within-group differences) by employees within a team. Furthermore, recent empirical studies have demonstrated that within-group deviation of contextual variables is not only the result of random error (as opposed to systematic variance), but also may reflect perceptual differences of the work environment (Ostroff 1993a; Van Yperen and Snijders 2000). Within-group variation of SMT service climate assessments may, for instance, result from individual differences among employees caused by diversity in demographic background, diversity in management-team member relationships or diversity in role positions within the team (Klein et al. 2001; Ostroff 1993a; Van Yperen and Snijders 2000). Another source of individual differences pertains to the idiosyncratic way in which perceptions of employees of the organizational environment are formed (Brown and Leigh 1996). Accordingly, the outcome variable SMT service climate is modeled to have both an individual-level and a group-level variance component (Snijders and Bosker 1999) in investigating how it depends on the different antecedents that are specified at the different levels.

Context-team antecedents (i.e, tolerance-of-self-management, formalization, inter-team communication) and team-employee antecedents (i.e., team norms, and team goal setting) explicitly refer to group features. The focus of this chapter is to investigate how these group features (indicated by shared perceptions) rather than perceptual differences of these group features (indicated by within-group deviations) are related to SMT service climate assessments. Therefore, we propose to examine these variables at the group level exclusively. Group averages are suggested to be more 
reliable and better indicators of the actual group characteristics than any single individual's score (e.g., Campion et al. 1993). Aggregation is justified when people within the team respond in a consistent way (e.g., James 1982). Hence, team constructs were aggregated at group level. With respect to the employee-role variables (i.e., role ambiguity and role conflict), however, it is unclear to what degree differences in these role stressors occur between SMTs or within SMTs. Contrary to explicit group features, within-group deviations of role stressor variables do not simply indicate perceptual differences among team members within the SMT, but may also reflect unique team members experiences due to their specific position within the SMT (e.g., back-office vs. front-office workers). These differences emerge even in situations where employees are highly interdependent, share the same jobs, role demands, and responsibilities (e.g., Van Yperen and Snijders 2000). On the other hand, SMTs are characterized by integrated working relationships among team members that include interpersonal processes, as are coordination, collaboration and communication. As such, individual team members' role stress experiences within a given team are likely to show some interdependence, suggesting the relevance to consider multiple levels of analysis and to distinguish between unique experiences of the role stressors (indicated by individual score minus the group mean) ${ }^{\prime}$ on the one hand, and the group-level factors of these variables (indicated by group means) on the other hand. Since grouplevel specifications of role stressors contain these contextual influences that are not captured by individual-level specifications, we state that:

\section{$H_{10}:$ At the group-level of analysis there will be negative effects of $\left(H_{10 a}\right)$ role ambiguity and $\left(H_{l 0 \mathrm{~b}}\right)$ role conflict that account for a significant amount of additional variance in individual employee perceptions of SMT service climate.}

Before we discuss an empirical test of our conceptual framework, we need to make a final methodological refinement pertaining to the linkage of our focal construct to its consequences. Conceptually, aggregate-level performance evaluations may be rooted in the fact that employees who work together closely in a work group context will adjust their discretionary behaviors in reference to the skills, preferences, and behaviors of co-workers, as suggested by Meyer and Allen (1997). Accordingly, Allen and Grisaffe (2001) argue that aggregate-assessments of customer evaluations are needed when "the overall picture presented to customers is the result of multiple efforts of employees who must interact with each other to get the work done" (p. 223). In addition, it has been contended by the outgroup-homogeneity theory that raters tend to perceive other groups as more homogeneous than their own group (Quattrone and Jones 1980). With respect to the linkage between employee and customer perceptions of team performance, this implies that individual team members may have relatively nuanced opinions regarding their own team's performance, because they are very knowledgeable about the work practice within their team, while external customers

\footnotetext{
'Within-group deviation is similar to group-mean centering. In all analyses level I ( were group-mean centered and level 2 (=-group-fevell) variables were grand-mean centered to (1) distinguish between within-group and between-groups variance, (2) to reduce multicollinearity and (3) to facilitate model estimation (cf. Bryk and Raudenbush 1992).
} 
tend to observe the quality of service provided by one or more team members as a general characteristic of a uniform 'out-group'. Furthermore, due to privacy restrictions policies of the company, it was not possible to measure the paired individual perceptions of employees and customers. Therefore, individual employee scores as well as individual customer scores were aggregated to the group level of analysis and the linkage between our focal construct and its consequences was tested using the team as unit of analysis. Having introduced and refined our conceptual framework, we discuss an empirical test of the model in the next section.

\subsection{An Empirical Study}

\subsubsection{Research Setting}

Members of self-managing after-sales service groups of a major manufacturer of office equipment (e.g., printers, copiers, etc) in the Netherlands and their customers were surveyed. The firm employs approximately 17,500 people worldwide and has offices in 30 countries. It has a dominant presence in medium and high volume industrial printing and copying segments and strives to maintain long-standing relationships with its customers on the basis of service excellence. Most of the firm revenues result from service, rather than selling equipment. The service business unit in the Netherlands employs approximately 250 employees, the majority of which are divided in 26 SMTs with an average size of 8.7 service engineers. Self-management was introduced to provide higher after-sales service quality. More specifically, the key responsibilities of the groups include (1) corrective maintenance and (2) call screening (i.e., solving technical problems that cannot be solved by a simple phone call). As most customers are large firms with an extensive product range, team activities involve operational planning, developing objectives and monitoring performance. The implementation of self-management is considered to be an important organizational change process. Therefore, the practical rationale for conducting our study was to examine its impact on service performance and to evaluate the central role of SMT service climate.

\subsubsection{Sampling and Surveying}

Due to the limited number of employees (and teams) we conducted a census, i.e. all employees were approached to participate in our study. A mail questionnaire was designed containing closed and open-ended questions. The questionnaires were returned to the researcher by mail. The population included 226 service engineers organized in 26 teams. An effective response rate of $69.5 \%$ ( $=157$ respondents) was achieved. For the customer survey a random sample was drawn, with a minimum of 75 customers per SMT. Mail questionnaires containing closed and open-ended questions were sent to the selected customers. The questionnaires were returned to the researcher by mail. The total sample included 2250 customers. In total, 672 questionnaires (response rate $29.9 \%$ ) were used for the analysis. At a minimum, 3 employees and 15 customers were effectively surveyed per team. The following sample profile emerges on the basis of the demographics variables. In our sample $56.2 \%$ of the employees was 
younger than 40 years old. With respect to education, the large majority of employees has a technical background $(89.2 \%)$ and more than half of the service engineers have extensive company experience $(58.6 \%>9$ years), whereas most people onlly have few team experience $(64.2 \%<3$ years $)$.

\subsubsection{Questionnaire Development}

All scale items of the employee survey were measured with a 7-point scale, ranging from 'strongly disagree' (1) to 'strongly agree' (7). The assessment of SMT service climate ( 7 items) was based on items specifically developed for this study on the basis of interviews with service engineers and scales developed by Sclaneider et al. (1992) and Peceei and Rosenthal $(1997)^{2}$. The operationalization of tolerance-of-selfmanagement ( 7 items) was largely based upon the tolerance-of-freedom instrument of the LBDQ XII, which assesses the degree of autonomy given to employees to manage their task responsibilities themselves (Cook et al. 1981). Formalization (2 items) was measured using items adapted from a scale developed by Ferrell and Skinner (1988). The inter-team communication-scale ( 3 items) was based on items adapted from a scale developed by Campion et al. (1993). The instrument for team norms ( 4 items) was based on the work of Hackman (1987). The assessment of team goal setting (4 items) was based on a scale developed by Locke and Latham (1984) and the self-goal setting instrument of Manz and Sims (1987). Role ambiguity (6 items) and role conflict ( 7 items) were measured using the instrument developed by Rizzo et al. (1970).

We used two techniques to investigate the factor structure and item loadings. First, we examined coefficient alphas, and the factor structure (through a principal component analysis) for all the scale items simultaneously. An eight-factor structure was achieved with items loading on the a priori dimensions. Next, we applied confirmatory factor analysis (CFA) using LISREL (Jöreskog and Sörbom 1993) to assess the critical measurement properties of the scalles. For each interface in the conceptual framework a separate factor model was proposed including the items of the antecedents of that specific interface and the items of our focal construct SMT service climate. First, a four-factor model was tested including the items of tolerance-of-selfmanagement, formalization, inter-team communication and SMT service climate $\left(\chi^{2}(\mathrm{~d})=171.01(146) ; \mathrm{GFI}=0.91 ; \mathrm{AGFI}=0.88 ; \mathrm{RMSEA}=0.097 ; \mathrm{NFI}=0.91 ; \mathrm{CFI}=\right.$ 0.98 ). Secondly, a three-factor model was tested including the items of team norms, team goal setting, and SMT service climate $\left(\chi^{2}(\mathrm{df})=96.26(87) ; \mathrm{GFI}=0.93\right.$; $\mathrm{AGFI}=$ $0.90 ; \mathrm{RMSEA}=0.036 ; \mathrm{NFI}=0.92 ; \mathrm{CFI}=0.98$ ). Finally, a three-factor model concerning the items of the employee-role antecedents role ambiguity and role conflicts as well as the items of SMT service climate was tested $\left(\chi^{2}(\mathrm{df})=184.40(167)\right.$; $\mathrm{GFI}=0.90 ; \mathrm{AGFI}=0.87 ; \mathrm{RMSEA}=0.031 ; \mathrm{NFI}=0.90 ; \mathrm{CFI}=0.98)$. The indices of all three tested factor models provided a good fit indicating that each of these scale constructs is unidimensional (Steenkamp and Van Trijp 1991). Additionally, construct

\footnotetext{
${ }^{2}$ An additional confirmatory factor analysis was conducted to validate our key construct SMT service climate. The results showed clear unidimensionality $\left(\chi^{2}(\mathrm{df})=1.79 .63(132) ; \mathrm{GFI}=0.90 ; \mathrm{AGFI}=0.86\right.$; $\mathrm{RMSEA}=0.052$; $\mathrm{NFI}=0.89 ; \mathrm{CFI}=0.96$ ) and discriminant walidity in relation to its rival linkage constructs: "team commitment" (Van den Heuvel et al. 1995), and 'job satisfaction" (Churchill et ail. 1974).
} 
reliability was tested. All constructs used in this study showed coefficient $\alpha$ 's higher than .70 (except for formalization, $a=.66$ ), which indicates that the constructs report rather reliable scales (Nunnally and Bernstein 1994). In Table 2-1 the items and ocoefficients of the scales used in this study are represented. The fit indices of the factor models, construct reliabilities and items of the scales are represented in Table 2-1.

Next, for each factor-model within-method convergent validity was examined by investigating the significance and magnitude of the item loadings. For all three independently conducted CFAs the included items loaded significantly on their respective construct (all t-values were significant at .05 significance level) where all iterns had a standardized loading of at least 0.50 (except one item loading, which was between .40 and, 50$)$. In addition, discriminant validity was evaluated by testing whether pairs of constructs were correlated less than unity (c.f., Anderson and Gerbing 1988). Chi-square difference tests with 1 d.f. were used to test for unity between pairs of constructs. All tests were significant at $p<.05$.

Furthermore, the demographic variables age and organizational tenure were selected and included as control variables when analyzing the hypothesized relationships.

\section{Table 2-1: Results of Confirmatory Factor Analyses}

\section{Measures Employee Data}

Fit indices (CFA with SMT service climate and context-team antecedents): $\chi^{2}(\mathrm{df})=171.01(146)$; $\mathrm{GFI}=0.91 ; \mathrm{AGFI}=0.88 ; \mathrm{RMSEA}=0.097 ; \mathrm{NFI}=0.91 ; \mathrm{CFI}=0.98$

Fit indices (CFA with SMT service climate and team-employee antecedents): $\chi^{2}(\mathrm{~d} f)=96.26(87)$; $\mathrm{GFI}=0.93 ; \mathrm{AGFI}=0.90 ; \mathrm{RMSEA}=0.036 ; \mathrm{NFI}=0.92 ; \mathrm{CFI}=0.98$

Fit indices (CFA with SMT service climate and employee-role antecedents): $\chi^{2}(\mathrm{df})=184.40$ (167); $\mathrm{GFI}=0.90 ; \mathrm{AGFI}=0.87 ; \mathrm{RMSEA}=0.031 ; \mathrm{NFI}=0.90 ; \mathrm{CFI}=0.98$

SMT service climate $(n=7 ; \alpha=.90)$

1. Our team is always working to improve the quality of service prowided to customers.

2. Our team has specific ideas about how to improve the quality of service provided to customers.

3. Our team often makes suggestions about how to improve the service quality in our service organization.

4. In our team we put a lot of efforts into our jobs to try to satisfy customer expectations.

5. No matter how we feel, in our team we al ways put ourselves out for every customer we serve.

6. Within our teann, employees often go out of their way to help customers.

7. In our team we often discuss how to improve service quality.

Tolerance-of-self-management $(\mathrm{n}=7 ; a=.90)$

1. In our team we are permitted to use our own judgment in solving problems.

2. In our team we are encouraged to take initiative.

3. Our team is allowed a high degree of initiative.

4. In our team we are allowed complete freedom in our work.

5. In our team we are allowed to do our work the way we think best.

6. As a team we are able to handle all tasks assigned to us ourselves.

7. In our team we are trusted to exercise good judgement.

Formalization $(\mathrm{n}=2 ; \alpha=.66)$

1. Clear and planned goals and objectives are set for service team performance by upper management.

2. Service performance rules and procedures are laid down in clear and understandable written agreements. 


\section{Table 2-1: Results of Confirmatory Factor Analyses (Continued)}

\section{Measures Employee Dara (Continued)}

Inter-team communication $(n=3 ; \alpha=.89)$

1. The information exchange with other teams about customers is good.

2. Our team is willing to share information with other teams.

3. The information exchange with other teams helps us in serving our customers.

Team norms $(n=4 ; \alpha=.79)$

1. Within our team, standards are developed to judge our performance by.

2. Our team members share common expectations about the behavior of all work group members.

3. Our team members have identified the strengths and weaknesses of the individual work group members.

4. Our team members share common expectations about the behavior of particular work group members with specific responsibilities.

Team goal setting $(n=4 ; \alpha=.83)$

1. In general, we define the goals for our own team.

2. We are allowed to define performance goals for our team.

3. We establish our own task goals.

4. We set our own goals for group performance.

Role ambiguity $\left(\mathrm{n}=6 ; \alpha={ }_{\text {. }} 84\right.$ )

1. I know exactly what is expected of me. (reversed)

2. I feel enough time to complete my work. (reversed)

3. Clear, planned goals and objectives for my job. (reversed)

4. I know that I have divided my time properly. (reversed)

5. I know what my responsibilities are. (reversed)

6. Explanation is clear of what has to be done (reversed)

Role conflict $(n=7 ; a=.87)$

1. I have to do things that should be done differently.

2. I receive an assignment without the manpower to complete it.

3. I have to buck a rule or policy in order to carry out an assignment.

4. I receive incompatible requests from two or more people.

5. I do things that are apt to be accepted by one person and not accepted by other

6. I receive an assignment without adequate resources and materials to execute it.

7. I work on unnecessary things.

\section{Measures Customer Data}

Fit indices: $\chi^{2}(\mathrm{df})=39.52(20) ; \mathrm{GFI}=0.98 ; \mathrm{AGFI}=0.95 ; \mathrm{RMSEA}=0.062 ; \mathrm{NFI}=0.99 ; \mathrm{CFI}=0.99$

Customer Perceived Service Quality $(n=8 ; a=.93)$

1. Time needed for the service engineers to arrive.

2. Time taken by the service engineers for the repair works.

3. The ability of the service engineers to solve your problem in one visit.

4. The availlability of spare parts during the service visit.

5. The competence of the service engineers.

6. Understanding for the problem by the service engineers.

7. Readiness of the service engineers to take your wishes into account when planning the service visit,

8. The manner in which the serwice engineers present themselves.

With regard to the customer survey, all scale items were measured with 9-point scales ranging from 'very dissatisfied' to "very satisfied'. The scalle for customer perceived service quality ( 8 items) was based on the SERVQUAL-instrument developed by Parasuraman et al. (1988). Confirmatory factor analysis indicated unidimensionality of the construct $\left(\chi^{2}(\mathrm{df})=39.52(20) ; \mathrm{GFI}=0.98 ; \mathrm{AGFI}=0.95 ; \mathrm{RMSEA}=0.062 ; \mathrm{NFI}=\right.$ 0.99 ; $\mathrm{CFI}=0.99$ ). Furthermore, service productivity was assessed using two criterion measures calculated on the basis of information from the company's internal service 
management database. The first criterion was 'response time failure', or the percentage of service visits that service technicians fail to arrive at customer's site within the agreed response time target. As a second criterion was used 'first-time-fixed rate', or the percentage of first time service visits that the service technicians managed to fix the service problem.

Table 2-2 indicates the means, standard deviations and correlations between SMT service climate and the outcome variables, while in Table 2-3 the means, standard deviations and correlations of the employee variables at individual level and group level are represented.

\section{Table 2-2: Means, Standard Deviations, and Correlations at the Group Level}

\begin{tabular}{|c|c|c|c|c|c|}
\hline Variables & Mean (s.d.) & $\overline{1}$ & 2 & $\overline{3}$ & $\overline{4}$ \\
\hline 1. SMT service elimate & $5.19(.45)$ & - & & & \\
\hline 2. Perceived service quality & $6.14(.29)$ & $.54^{* *}$ & - & & \\
\hline 3. Response time failure $(\%)$ & $81.13(10.77)$ & -.08 & -.18 & - & \\
\hline 4. First-time-fixed rate $(\%)$ & $97.42(1.08)$ & .29 & $.54^{* 4}$ & $-.40^{* 00}$ & - \\
\hline
\end{tabular}

It has been argued that corrections for individual-level measurement error should be made first, before comparing individual and aggregate-level correlations (Ostroff 1993a). Therefore, we calculated individual-level correlations between the antecedents and SMT service climate after increasing the reliability (= Cronbach's $\alpha$ ) to .85 for constructs that had lower reliabilities, using the following equation:

$$
r_{x y}^{\prime}=r_{x y} \frac{\sqrt{r_{x x}^{\prime \prime} r_{y y}^{\prime}}}{\sqrt{r_{x x} r_{y y}}},
$$

where $r_{x y}^{\prime}=$ estimated correllation between variables $x$ and $y$ if their reliabilities are changed,

$r_{x x}^{\prime}=$ changed reliability for $x$,

$r_{y y}^{\prime}=$ changed reliability for $y$,

$r_{x x}=$ obtained reliability for $x$,

$r_{y y}=$ obtained reliability for $x$.

Overall, the results indicate some increase of the individual-level correlations, but do not imply dramatic changes in the magnitude differences between individual-level and group-level correlations (Nunnally and Bernstein 1994). 


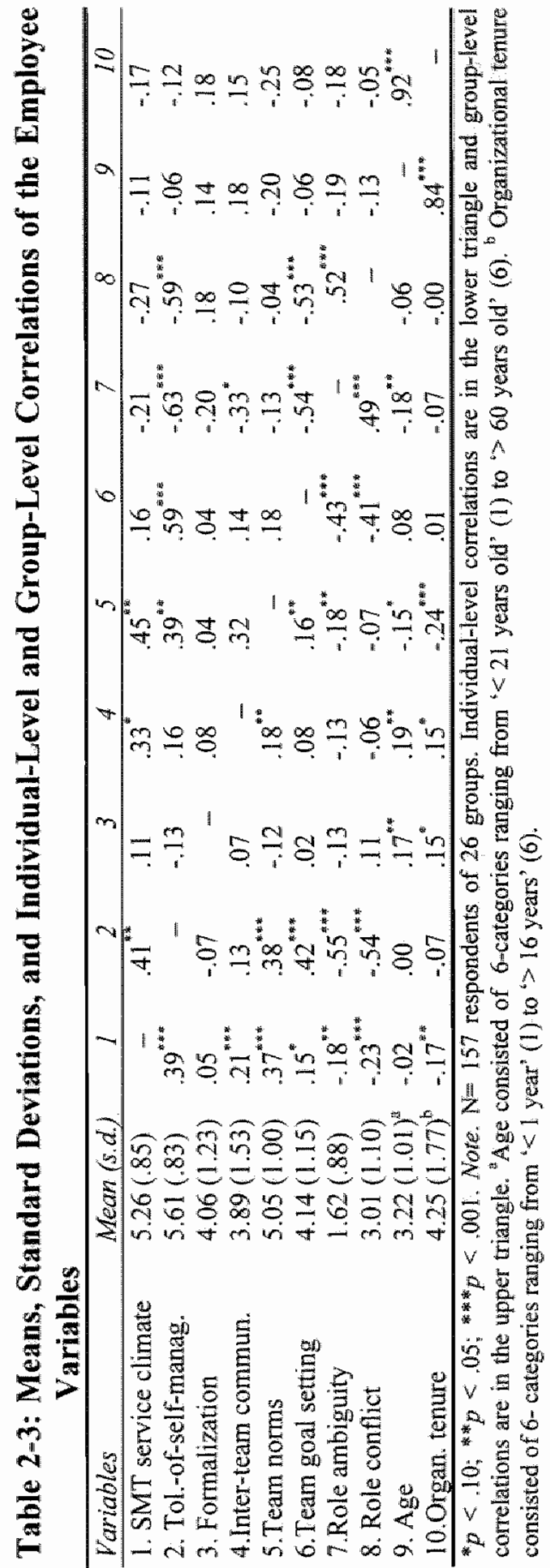




\subsubsection{Data Analysis}

First, empirical justification for aggregation of the employee variables and perceived service quality was tested by means of the $r_{W G(j)}$ coefficient, which is an indicator of within-group agreement (James et al. 1993) and the ICC (1) coefficient, which refers to the ratio of within-group and between-groups variance. For all variables the median values of the $r_{W G(j)}$-coefficients (ranging from .75 to .95 ) are above .70 indicating consistency in ratings among employees within groups (James 1982). Furthermore, the ICC (1) coefficients of SMT service climate, the context- team antecedents, and teamemployee antecedents (ICCs range .07 from to .30) indicate that for these variables a substantial part concerns between-groups variance (c.f., Van Yperen and Snijders 2000 ). The obtained ICC correlations for perceived service quality $(\mathrm{ICC}=.03)$, role ambiguity $(\mathrm{ICC}=.03)$, and role conflict $(\mathrm{ICC}=.05)$ are lower and imply that these variables are relatively more based on individual differences.

$\mathrm{Next}$, in order to test the propositions stated in $\mathrm{H}_{1}$ and $\mathrm{H}_{2}$ we performed a Wilcoxon-Mann-Whitney test. The choice for a non-parametric method was made because of the relatively small sample size (c.f., Siegel and Castellan 1988). By means of a median split the 26 service teams were divided into a higher-level and a lowerlevel climate category.

Our findings are reflected in Table 2-4 and indicate that higher-level service climate teams have significantly higher scores on perceived service quality than lowerlevel teams $(Z=-3.103[p=.002])$. Hence, we fail to reject $H_{1}$. In addition, we also tested whether higher-level climate teams are more productive. No significant differences between higher-level and lower-level climate teams exist with regard to response time $(Z=-1.386[p=.166])$, whereas significant differences occur with respect to first-time-fixed rate $(\mathrm{Z}=-3.256[p=.001])$. Therefore, $\mathrm{H}_{2}$ is supported for first-time-fixed rate, while it is rejected for response time.

\section{Table 2-4: Results of the Wilcoxon-Mann-Whitney test}

\begin{tabular}{l|ccccc}
\hline Variable & Median values of climate categories & $\begin{array}{c}\text { Wilcoxon } \\
\text { W-value }\end{array}$ & $\begin{array}{c}\mathrm{Z}- \\
\text { value }\end{array}$ & $\begin{array}{c}p- \\
\text { value }\end{array}$ \\
\hline & $\begin{array}{c}\text { Lower-level } \\
\text { climate categovy }\end{array}$ & $\begin{array}{c}\text { Higher-level } \\
\text { climate category }\end{array}$ & & & \\
Perceived service quality & 5.98 & 6.27 & 115.00 & -3.100 & .002 \\
Response time failure $(\%)$ & 82.61 & 80.00 & 112.00 & -1.386 & .166 \\
First-time-fixed rate $(\%)$ & 96.79 & 98.17 & 148.50 & -3.256 & .001 \\
\hline
\end{tabular}

In addition, we tested the antecedent-SMT service climate relationships $\mathrm{H}_{3}-\mathrm{H}_{10}$. Our conceptual framework of the antecedents of SMT service climate includes variables at two levels of aggregation: the individual and the team level. Such data are designated as multi-level data (Bryk and Raudenbush 1992). The levels are hierarchical, as employees are nested within groups. The question how to investigate hierarchically ordered systems, such as service teams, has been a concern for quite some time. Conventional statistical techniques (e.g., ordinary regression analysis) ignore this hierarchy and may, therefore, lead to incorrect results (Bryk and Raudenbush 1992). Hierarchical linear models, also called multi-level models, on the contrary, are an effective approach to deal with hierarchically nested data structures. (Hofmann 1997; 
Raudenbush 1993). For the conduction of the multi-level analyses the computer program MLwiN (Goldstein et al. 1998) was employed which calculates regression estimates by means of an iterative approach known as the EM algorithm (Bryk and Raudenbush 1992; Dempster et al. 1977; Groldstein 1995).

Two-level models were specified to test the hypotheses $\mathrm{H}_{3}-\mathrm{H}_{10}$, where level 1 reflects 157 employees and level 2 contains 26 service teams. These two-models include a level 1 submodel specifying the effects of the within-group deviation variables and a level 2 submodel specifying the effects of group-level variables:

Level 1:

(2) $\mathrm{SERVCLIM}_{i j}=\beta_{0 j}+\beta_{1 j} \mathrm{AGE}_{i j}+\beta_{2 j} \mathrm{TEN}_{i j}+\beta_{3 j} \mathrm{AMB}_{i j}+\beta_{4 j} \mathrm{CONF}_{i j}+e_{i j}$

Level 2:

$$
\begin{aligned}
& \beta_{0 j}=\gamma_{00}+\gamma_{01} \mathrm{TOL}_{j}+\gamma_{02} \mathrm{FORM}_{j}+\gamma_{03} \mathrm{INTER}_{j}+\gamma_{04} \mathrm{NORM}_{j}+\gamma_{05} \mathrm{GOAL}_{j}+ \\
& \gamma_{06} \mathrm{AGE}_{j}+\gamma_{07} \mathrm{TEN}+\gamma_{08} \mathrm{AMB}_{j}+\gamma_{09} \mathrm{CONF}_{j}+u_{0 j}
\end{aligned}
$$

$$
\beta_{q j}=\gamma_{q 0}+u_{q j} \text { for } q(=1, \ldots, 4)
$$

where $i$ stands for individuals; $j$ indicates groups; SERVCLIM involves employee's SMT service climate appraisal; $A G E$ and TEN, refer to employee's age and tenure, respectively; $A M B$ and CONF, indicate employee's degree of role ambiguity and role conflict; TOL, FORM, INTER, NORM, and GOAL are tolerance-of-self-management; formalization, inter-team communication, team norms, and team goal setting, respectively. Substituting Equations $3 \mathrm{a}-3 \mathrm{~b}$ into Equation 2 yields the following multilevel model:

$$
\begin{aligned}
& \text { SERVCLIM }_{i j}=\gamma_{00}+\gamma_{10} \mathrm{AGE}_{i j}+\gamma_{20} \mathrm{TEN}_{i j}+\gamma_{30} \mathrm{AMB}_{i j}+\gamma_{40} \mathrm{CONF}_{i j}+\gamma_{01} \mathrm{TOL}_{j} \\
& +\gamma_{02} \mathrm{FORM}_{j}+\gamma_{03} \mathrm{INTER}_{j}+\gamma_{04} \mathrm{NORM}_{j}+\gamma_{05} \mathrm{GOAL}_{j}+\gamma_{06} \mathrm{AGE}_{j}+\gamma_{07} \mathrm{TEN}_{j}+ \\
& \gamma_{08} \mathrm{AMB}_{j}+\gamma_{09} \mathrm{CONF}_{j}+u_{0 j}+u_{i j}+u_{2 j}+u_{3 j}+u_{4 j}+e_{i j} .
\end{aligned}
$$

The individual-level error term $e_{i j}$ is normally distributed with a mean of 0 and variance $\sigma^{2}$. The random effects $u_{q(}(q=0,1,2,3,4)$ are multivariate normal distributed over teams with an expected value of 0 , var $\left(u_{q j}\right)=\tau_{q q q}$, where, $u_{q j}$ is the unique deviation of group $j$ from the overall effect on the intercept $\left(\beta_{0 j}\right)$, while controlling for the group-level predictor variables. The coefficients $\beta_{0 j,}, \beta_{1 j}, \ldots, \beta_{4 j}$ were specified as random coefficients; i.e., the coefficients were allowed to vary across groups.

Table 2-5 presents the results of our multi-level analyses. The following analysis strategy was used. To begin with, we estimated a model (Model A) by specifying the demographic variables (i.e., age, organizational tenure) and the employee-rolle antecedents at the individual level, as well as the context-team and the team-employee antecedents at the team level in order to investigate how much of the total variance in the outcome variable can be explained by these specified variables. Secondly, Model B was estimated. In this model all variables specified at individual 
level in the previous model (Model A) are group mean centered (i.e., the raw (Eoriginal) scores of the individual-level role stress variables $x_{i j}$ are replaced by the within-group deviation scores, where the group means of these variables are introduced as level 2 variables). This distinction was made to determine whether the group-level specifications of the role stress variables explain additional variance in team member's SMT service climate assessments.

Multi-level models are considered as contextual models that may be subject to multi-collinearity. Therefore, ordinary regression analyses were conducted to investigate multi-collinearity of Model A and Model B by means of the Variance Inflation Factor (VIF). The VIF's of all variables of Model A and B are lower than respectively 3.7 and 2.6 . Thus, no severe multi-collinearity problems were to be expected (Kleinbaum et all 1988).

To test $\mathrm{H}_{3}$ to $\mathrm{H}_{10}$ the significance of the regression coefficients in Model B was inspected. The results of Model B show a significant positive effect of the following antecedents: tolerance-of-self-management, formalization, inter-team communication, and team norms, on SMT service climate. Hence, we fail to reject $\mathrm{H}_{3}, \mathrm{H}_{4}, \mathrm{H}_{5}$, and $\mathrm{H}_{6}$, respectively. Additionally, it turns out that team goal setting has no significant impact on SMT service climate, which implies that we have to reject $\mathrm{H}_{7}$. Furthermore, there exist no significant individual-level effects of role ambiguity and role conflict on SMT service climate, indicating that $\mathrm{H}_{8}$ and $\mathrm{H}_{9}$ are rejected. Furthermore, our results report a significant negative group-level effect of role conflict on SMT service climate, while no group-level effect of role ambiguity appears. An additional raw score analysis was conducted tot test whether the magnitudes of within-group deviation coefficients and between-groups coefficients significantly differ. We found no significant magnitude difference in individual-level and group-level effects with respect to role ambiguity $\left(\% / \sigma_{8}(\mathrm{~s} . \mathrm{e})=.-.176(.201),[p=.189]\right)$, whereas the between-groups effect of role conflict was significantly greater in magnitude when compared to its individual-level counterpart $\left(\gamma_{09}\right.$ (s.e. $\left.)=-.239(.127),[p=.030]\right)$. These findings indicate that $\mathrm{H}_{10 \mathrm{a}}$ is rejected, while $\mathrm{H}_{00}$ is supported. This implies that shared role conflict experiences rather than unique team member experiences of role conflict negatively influence team members' SMT service climate assessments.

With regard to the demographic predictors age and organizational tenure, it appears that the group- mean centered variables are significantly related to SMT service climate, while the group-level variables show no significant effects. Differences in age and organizational tenure among employees of the same team are significantly related to their different perceptions on the SMT team service climate of their group. Put differently, organizational tenure of an employee of a given team affects primarily his subjective assessment of SMT service climate of the team. Finally, it can be observed that the percentage of explained group-level variance is higher compared to the individual-level variance, which signifies that between-groups differences of SMT service climate are more effectively explained relative to withingroup deviations. 
Table 2-5: Results of the Multi-level Analyses

\begin{tabular}{|c|c|c|}
\hline & Modell A & Model B \\
\hline & & \\
\hline \multirow{2}{*}{\multicolumn{3}{|c|}{ Individual-lewel coefficients }} \\
\hline & & \\
\hline Age & $.323(.110)^{* * *}$ & $.387(.132)^{* *}$ \\
\hline Organizational tenure & $-.231(.062)^{* * *}$ & $-.236(.072)^{* *}$ \\
\hline Role ambiguity & $-.058(.086)$ & $-.013(.099)$ \\
\hline Role conflict & $-.183(.072)^{* * *}$ & $-.106(.082)$ \\
\hline \multicolumn{3}{|l|}{ Group-level coefficients". } \\
\hline Tolerance-of-self-manag. & $.333(.149)^{*}$ & $.356(.179)^{*}$ \\
\hline Formalization & $.168(.080)^{*}$ & $.228(.087) *$ \\
\hline Inter-team communication & $.158(.071)^{*}$ & $.176(.075)^{* * *}$ \\
\hline Team norms & $.205(.110)^{* *}$ & $.205(.116)^{*}$ \\
\hline Team goal setting. & $.156(.105)$ & $.165(1.15)$ \\
\hline Age & & $.056(.245)$ \\
\hline Organizational tenure & & $-.116(1.40)$ \\
\hline Rolle ambiguity & & $-.285(.216)$ \\
\hline Role conflict & & $-.281(117)^{* * *}$ \\
\hline \multicolumn{3}{|l|}{ Explained wariance $(\%)$} \\
\hline Individual-level & $25.9 \%$ & $25.3 \%$ \\
\hline Group-level & $51.6 \%$ & $46.7 \%$ \\
\hline
\end{tabular}

\subsection{Discussion}

The objective of this chapter was to investigate antecedents and consequences of SMT service climate in self-managing service groups, taking into account individual-level and group-level relationships. One important consequence of this type of climate is that customers evaluate service units that are dedicated to provilding quality services more favorably. In other words, a collectively active involvement with service quality results in higher customer ratings. This is in line with earlier studies that have focused on the linkage between service climate and customer perceptions and affirms the importance of service climate as a linkage variable (Schneider and Bowen 1985). In addition, SMT service climate positively affects the service productivity measured as first-time-fixed rate. Apparently, SMT service climate leads to more effectively processing the service problems, which in turn results into better problem solving of customer requests. In contrast, SMT service climate has no impact on the other service productivity measure response time. It may very well be that the relationship between quality-oriented climate and the service productivity may be influenced by conflicting demands for quality (by customers) and productivity (by management) as suggested by Singh (2000). Moreover, this relationship may also be mediated by the idiosyncratic product history and/or product range that each team has to service. 
In addition, we find a positive relationship between tolerance-of-selfmanagement and SMT service climate. It appears that an organizational setting that is conducive to autonomy and initiative creates a level of involvement with the impact of service provision on the customer (Nygren and Levine 1996). This is in line with the extant view in organizational theory that service employees need a less mechanistic control system than manufacturing employees (Bowen and Lawler 1992). At the same time, however, we find that formalization also has a positive impact on SMT service climate. This is illustrative of the fact that in combination with a certain degree of autonomy teams also have a need for clear rules and regulations established by the organization in performing service tasks. This is also reflected by the positive effect of team norms on our key variable. Consensus among team members on how to work together and how to solve work problems promotes a mutual involvement with regard to offering service excellence and enhances performance, as suggested by Ephross and Vassil (1988) and Argote (1989). In order to both enjoy the freedom of tolerance-ofself-management and the frame of reference consisting of organizational rules and regulations as well as team-based norms, it seems important that there is adequate inter-team communication, since self-managing work groups are actively responsible for obtaining and sharing information with other departments in the organization in order to establish a SMT climate to providing service quality. Remarkably, our findings revealed no significant impact of team goall setting on SMT service climate. Apparently, SMT service climate is dependent on the emergence of team norms on services-related issues rather than on the process how to develop realistic service quality goals.

Next, the results suggest that shared role conflict experiences rather than unique team member experiences of role conflict negatively influence individual member's SMT service climate assessments. As SMT service climate may be potentially at odds with organizational efficiency, shared role conflict experiences of team members form barrier to a focused involvement with providing service quality to the customer. Surprisingly, no evidence was found for relationships between role stressor variables and the key construct at individual level of analysis. Apparently, SMT service climate is more related to aggregate factors than to the difficulties involving the customercontact position of individual employees. Furthermore, the absence of any relationship between role ambiguity and SMT service climate may be attributed to the fact that the self-management approach enables employees to acquire the information needed to fulfill their roles. As a result, the impact of role ambiguity may be less than in more traditional service positions.

Finally, at the individual level of analysis our empirical findings show that the age and the organizational tenure of employees have a strong significant impact on their subjective assessment of SMT service climate. Team members that have a longer length of tenure relative to their colleagues within the team report lower assessments of SMT service climate. This may result from the fact that organizational veterans in the team may be more resistant to the adoption of self-management as yet another process of organizational change and innovation than their younger team colleagues. On the other hand, however, when accounting for the effect of organizational tenure, age has a positive influence on team members' subjective perception of the service climate of their SMT. Feedback from the SMTs that participated in our study with 
respect to this seemingly contradictory finding attributed this to the fact that the older team members (in a team) frequently paint a more positive picture of SMT service climate of their team than the younger ones. As the elder ones frequently feel more responsible for the SMT service climate process, they tend to have more positive perceptions. In sum, we conclude that our findings underscore the incremental value of a cross-level approach to SMT service climate. The results of this cross-level analysis indicate that both individual-level and team-level variables are crucial in explaining variance in SMT service climate.

\subsection{Theoretical Implications}

Part of the strength of a research project lies in the recognition of its limitations. These limitations may serve as points for a future research agenda. To begin with, our results are based on the results of a sample of customer-contact service employees of one after-sales service business unit and their customers. This approach is quite likely to have contributed to the internal validity of our study, however it questions the external validity of our findings. As a result, this study needs to be replicated in other aftersales service settings in order to generalize our findings. Another shortcoming concerns common method variance, which may have inflated the relationships estimated between the constructs that were used as antecedents to SMT service climate. For future research we recommend using several independent data sources. Furthermore, the cross-sectional nature of our study is certainly a limitation. The functioning of teams in organizations involves a dynamic process that changes over time. Future research should elaborate on this group dynamies by conducting longitudinal designs.

Secondly, with regards to our conceptual framework, we focused exclusively on the SMT service climate. It may very well be that another type of climate, SMT productivity climate, may also play an important role and that service quality and productivity are distinct aspects of service team performance. The diverging demands from customers and management underscore the importance to focus not only on quality, but also on productivity goals to create an optimal balance (Alper and Tjosvold 1998; Helfert and Vith 1999). Therefore, in further research the impact of SMT service climate to productivity and its relationship to SMT service climate is required. The use of additional productivity indicators is recommended.

Thirdly, in our study we applied one-dimensional constructs only. Especially with regards to tolerance-of-self-management, recent studies suggest the application of a similar, but more sophisticated multi-dimensional construct of empowerment. Kirkman and Rosen (1999), for example, decompose empowerment into (1) potency, (2) meaningfulness, (3) autonomy, and (4) impact. Future research should, therefore, address the different aspects of the antecedent constructs.

A final limitation that warrants attention is the fact that we estimated a model in which antecedents included at individual level were different from the antecedents at aggregate level. Based on conceptual and methodological arguments, context-team and team-employee antecedents were aggregated. However, a large amount of individual variance in our model remains unexplained, which raises the important, but still 
unanswered empirical question whether antecedents should be aggregated or not to explain maximal variance in team performance. De Jonge et al. (1999) have investigated whether aggregated antecedents of employee performance data significantly add explained variance beyond the individual antecedents. They suggested that the added value of aggregated antecedents depends on whether the outcome variable is a typical individual perception or a more situation-based construct. Therefore, more research is needed to examine models that specify antecedents of service team outcomes at the individual and the team level simultaneously (cf. Kirkman and Rosen 1999; Tesluk et al. 1996).

\subsection{Managerial Implications}

Our findings also suggest a number of managerial implications. First and foremost, it has been demonstrated that SMT service climate has an impact on customer evaluations of service quality. From a managerial standpoint it seems worthwhile to promote this type of climate in SMTs. Our study suggests a number of points to focus on.

In the first place, the strong negative effect of role conflict indicates that those teams, which members are collectively embarrassed by the conflicting demands from the organization and the team and customer are characterized by a lower SMT service climate. To enhance SMT service climate, management should rank the objectives of the organization, the team or the customer. In addition, it seems important to pay attention to employee tolerance-of-self-management. The body of literature on this topic suggests that employees who experience their tasks as more meaningful, who believe that they have the competency to participate effectively, or have the impression that suggestions are taken seriously by management will be more committed to providing the customer with excellent service (Thomas and Velthouse 1990). Also, the positive effect of formalization is illustrative of the fact that clear rules and regulations are needed to stimulate SMT service climate. Particularly, the implementation of the self-management principle needs a frame of reference that may reduce uncertainty. Therefore, it seems important to review policies and guidelines regarding selfmanagement of the service organization. Additionally, we found that inter-team communication is critical. The willingness of team workers to improve service aspects depends largely on effective informational exchanges with upper management and other work units (Peccei and Rosenthal 1997). Therefore, attention needs to be paid to providing a communication infrastructure that is conducive to the seamless sharing of information, using mediated (e.g., e-mail and intranet) as well as face-to-face communication opportunities. Another critical point concerns the occurrence of team norms. Norms are the informal rules that guide team members' behavior. The existence of service quality-oriented norms implies high agreement among team members and enhances the involvement with the team working procedures. To strengthen team norms periodical meetings could be organized during which team employees can discuss for example, the effectiveness of working procedures 
(Wageman 1997). Finally, the strong impact of demographic factors on how employees perceive SMT service climate suggests that careful attention should be paid to the composition of self-managing service teams. In conclusion, both individual and aggregate factors should be taken into account in promoting the important construct of SMT service climate. 


\title{
Chapter 3
}

\section{Antecedents and Consequences of Service}

\author{
Climate in Boundary-Spanning
}

\section{Self-Managing Service Teams:}

\section{A Contingency Approach}

This chapter examines antecedents and consequences of service climate in boundaryspanning self-managing service teans (SMTs) that deliver routinized and knowledgeintensive financial services. The link between antecedents, or employee-perceived team characteristics, and SMT service climate is investigated using data collected at two points in time. The hierarchically nested data-structure (i.e, employees nested within groups) faeilitates a multi-level analysis of individual-and group-level effects of team environment perceptions on SMT service climate. Results support positive individual-level effects of tolerance of self-management, flexibility and inter-team and intra-team support. Additionally, group-level intra-team support accounts for a significant amount of incremental variance in SMT service climate perceptions and a significantly incremental group-level effect of flexibility was found in relation to the delivery of non-routine or knowledge-intensive services. Finally, it was found that variability in climate between self-managed service teams is significantly related to various service performance parameters such as customer perceived service quality. share of customer and productivity. Moreover, the positive relationship between SMT service climate and customer quality evaluations is contingent on the type of service. 


\subsection{Introduction}

Research on the boundary-spanning service employees has shown that delegating authority to employees allows for greater flexibility and adaptability in performing service activities through better problem solving, closer employee cooperation and more efficient knowledge transference (Hartline and Ferrell 1996; Peccei and Rosenthal 1997; Sergeant and Frenkel 2000). In line with this, a growing number of service organizations has introduced boundary-spanning self-managing teams (SMTs) as a substitute for hierarchic layers of management (Gilson et al. 2001; Spreitzer et al. 1999). Due to diversity of customer demand and customer participation, it has been argued that self-management is particularly suited for boundary-spanning services delivery processes (Donellon 1996).

Service firms, such as Federal Express and American Express, have proclaimed substantial increases in marketing productivity and revenue due to implementation of SMTs (Dumaine 1994). However, this anecdotal evidence of SMT effectiveness is not anchored in substantive research (Stewart and Barrick 2000). Earlier studies have generally supported the efficacy of SMT implementation for improving employee satisfaction, but findings have been inconclusive concerning their effect on service performance measures, such as productivity and customer perceived quality (Cohen and Bailey 1997). While Emery and Fredenhall (2002) and Batt (1999) report that SMTs perform significantly better in terms of service quality and sales volume than teams that were under management control, Chaston (1998) shows that the implementation of SMTs by service firms has resulted in an adverse impact on service quality and productivity. The apparent inconsistencies in the literature suggest a need to develop a more in-depth understanding of SMTs for service delivery and address this need by focusing on a number of theoretical and methodological issues that, to our knowledge, have been left unresolved so far. As Banker et al. (1997) suggest, "there is a need for developing a contingency theory for work teams relating their performance trajectories with their antecedents, structure and environment." (p. 27).

In addition, it has been convincingly demonstrated that a climate fostering service excellence is a key factor in predicting marketing performance at the firm level (Schneider et al. 1998). Accordingly, we propose to develop a climate construct that is proximal to perceptions of work group practices, as such a construct allows a more accurate account for intra-firm variability in team performance across different types of services (Shalley et al. 2000). Furthermore, as team climate is largely shaped by task design characteristics and group processes (Cohen and Bailey 1997), we explore how these foundation issues of self-management influence team service climate. We propose that individual employee perceptions of team service climate are dependent on contextual characteristics, such as autonomy, functional flexibility and interdependency (Barker 1993; Klein 1994). Third, team service climate represents the perceptions of team members whereby each team member may possess a unique perception of self-management characteristics. Therefore, the effect of these contextual predictors may vary at the group level, as well as at level of the individual team member (Ostroff 1993a; Neuman and Wright 1999). This raises the issue of conceptualizing and operationalizing variables at two distinct levels, an approach that 
has been left relatively uncharted in the marketing field and that has yiellded contradictory findings, particularly in relation to variability between inter-firm units in the organizational behavior literature (Van Yperen and Snijders 2000).

The purpose of this chapter is to extend our understanding of SMTs in service firms by making four contributions to the extant literature, based on a number of contingencies. First, we develop and empirically test a framework that identifies relevant antecedents of SMT service climate. Second; we investigate whether contextual predictors offer incremental explanation of SMT service climate at the group level in addition to individual-level effects. Third, since it has been argued that service task variability affects teamwork effectiveness (Davis 1999), we examine whether this framework is contingent on the type of services offered. Finally, by employing data collected from bank employees (at ${ }_{\mathrm{T}}$ and, 7 months later, at $\mathrm{T}_{2}$ ) and of their customers (at $\mathrm{r}_{2}$ ), we examine the lagged effects of SMT service climate on customer perceived quality, share of customer and service productivity.

\subsection{Development of a Conceptual Framework}

\subsubsection{Self-Managing Team Service Climate}

Conceptually, service climate refers to employee perceptions of company procedures and policies with regard to customer service. Over the years, considerable attention has been devoted to this concept (Andrews and Rogelberg 2001; Schneider, et al. 1992, 1996; Schneider and Bowen 1985). While various employee-based measures (e.g., employee satisfaction) have been advanced as drivers of organizationally relevant outcome measures, it has been argued that service climate has superior predictive power (e.g., Schneider et al. 1992). One important reason may be that unlike individual, attitudinal outcomes such as employee satisfaction, the climate construct can be extended to theoretically valid measures of organizational properties (Lincoln and Zeitz 1980). With the rapid proliferation of SMTs in service organizations, it seems relevant to broaden the research scope and investigate the climate concept at the work group level (Gilson et al. 2001; Zohar 2000). At the organizational level, service climate has been treated as a broad, strategically focused construct (Schneider et al. 1996), while SMT service climate concerns the application of organizational policies and procedures as an integral part of work group practices. In line with earlier studies, we define SMT service climate as team member perceptions of the manifestation of SMT attitudes and practices aimed at effective performance in service delivery to customers (cf., Schneider and Bowen 1993). SMT service climate involves purposive actions like service improvement initiatives and promoting service quality standards, which are undertaken by SMT members. As such, it can be regarded as an internal measure of SMT performance. Methodologically, it has been shown that variance in more proximal or context-specific measures can be more accurately related to contextual predictor variables (Ellemers et al. 1998; Zohar 2000). In the next section, we focus on these antecedents of SMT service climate. 


\subsubsection{Antecedents of Self-Managing Team Service Climate}

Numerous attempts have been made to identify a comprehensive set of predictor variables for explaining measures of SMT team effectiveness from the perspective of the individual team member (e.g., Helfert and Vith 1999; Spreitzer et al. 1999). Our choice of predictor variables was governed by three main characteristics that differentiate service SMTs from other traditional work groups: higher levels of autonomy, functional flexibility, and interdependency within and between teams (Campion et al. 1993). As an organizational and marketing control model, selfmanagement has its roots in the so-called involvement approach (Bowen and Lawler 1992; Lusch and Jaworski 1991) according to which employees are capable of coordination, planning and controlling services. A central concept to the involvement approach is empowerment, which refers to the fact that employees must both be given a certain degree of autonomy in the initiation and continuation of work behavior and processes and have the competence to perform job-related activities with skill (Chiles and Zorn 1995; Hartline and Ferrell 1996). Self-efficacy theory (Bandura 1986) proposes that tolerating self-management increases employees" motivation to contribute to quality service delivery. Therefore, a major issue in the context of service SMTs concerns tolerance-of-self-management (Spreitzer et al. 1999), which is the delegation of managerial skills to SMTs by allowing them to take decisions when handling operational problems during the service delivery process instead of scripted rules and management control. Tolerance-of-self-management (tolerance) by organizations is a necessary condition for applying the principles of self-management and as such this contextual variable has been shown to be critical to the attitude and behavior of service employees (Batt 1999; Bell and Menguc 2002). Having to struggle against organizational policies or behavior of management that is not conducive to the practice of self-management is likely to decrease the ability of team members to deliver service quality to customers and makes it unlikely that a service climate will be established (Schneider et al. 1998). Hence, we state that:

\section{$H_{1}$ : There will be a positive effect of tolerance on SMT service climate.}

In addition, members of SMTs need to possess the ability to utilize the delegated authority optimally and this ability has been associated with a number of synergistic processes within and between teams. First, SMT members ought to be capable of performing a variety of team tasks, whether these are operational, managerial or administrative in nature (Spreitzer et al. 1999). Flexibility in job design, or the capacity to adapt, has been advanced as a hallmark feature of SMTs (Barry and Stewart 1997). As the spectrum of tasks to be undertaken by SMTs is considerably larger, job assignments are rapidly evolving and SMTs are highly interdependent, members need to be flexible and multi-skilled (Batt 1999; Sundstrom et al. 1990). Recent research (Marks et al. 2001; Mathieu et al. 2000), has demonstrated that the capacity to perform inter-role behaviors facilitates team goal attainment. By fulfilling an increasing number of roles and developing a breadth of experience in issues across the whole 
spectrum of service quality, the functional flexibility of team menbers contributes to desirable service performance outcomes (Lawler et al. 1995; Lowry 2000). Therefore, we hypothesize that perceptions of team member flexibility is a second relevant foundation for the establishment of service climate:

\section{$\mathrm{H}_{2}$ : There will be a positive effect of flexibility on SMT service climate.}

The internal marketing literature suggests that an orientation towards serving customers is strongly dependent on a service culture within the firm, i.e., employees supporting each other (George 1990; Grönroos 1990). Morover, recent research on organizational citizenship behavior of individual (retail) service employees has demonstrated that co-worker involvement reduces boundary-spanner role stress perceptions and increases service performance (Babin and Boles 1996; Bell and Menguc 2002; Bettencourt and Brown 1997). The implication is that when service employees experience peer-based learning and a service-driven attitude from coworkers, they will be motivated to carry over this attitude in their encounters with customers. Frequently, cooperative (inter)action within and between SMTs is required to successfully address customer service requests and create a service-oriented work environment (Horwitz and Neville 1996). The services marketing literature argues that supportive teamwork is essential for implementing service quality improvements (Berry et al. 1994). Previous research on work teams has shown that both the presence of an encouraging team-context and a supportive attitude within the team itself are crucial determinants of team effectiveness (Campion et al. 1996). Schneider et al. (1998) have demonstrate empirically that an interdepartmental service orientation is a strong foundation of an organizational climate for service. Similarly, Sergeant and Frenkel (2000) show that support from other departments has a positive impact on the capacity of employees to satisfy customers. Polley and Van Dyne (1994) argue that self-management is particularly dependent on a focus on collaborative endeavors and Batt (1999) has shown that such an orientation is a key success factor of SMT effectiveness. Conceptually, we distinguish between inter-team support and intra-team support as determinants of SMT service climate. Inter-team support refers to team member perceptions of the internal service and communication between teams and other units within the organization, whereas intra-team support concerns the willingness of the members of a team to offer help and to deliver service to the other members of the group to attain work group goals (Campion et al. 1993). Therefore, we hypothesize:

$H_{3:}$ There will be a positive effect of inter-team support on SMT service climate. $H_{4}$ : There will be a positive effect of intra-team support on SMT service climate. 
Our identification of antecedents is primarily based on conceptual and empirical support for predicting SMT service climate on the basis of individual-level measures. While some researchers claim that the individual perspective constitutes the only proper unit of analysis, others argue that the study of group phenomena can only be analyzed in a meaningful way at the group level (e.g., Lincoln and Zeitz 1980). In the next section we discuss the unit of analysis controversy in relation to the aforementioned antecedents of SMT service climate. The purpose is to examine whether predictor-criterion relations offer incremental explanation at the group level.

\subsubsection{Contingency One: Assessment of Predictor-Criterion Relationships Across Levels}

Individual (or within-group) variation with respect to contextual predictors of SMT service climate may stem from actual differences among employees. Self-management teams are frequently designed with deliberate diversity, which may be dependent on demographics such as age, tenure and expertise (e.g., back-office vs. front-office specialization) as well as psychological characteristics (including values, personality factors and cognitive models) (Campion et al. 1996). Social cognitive theory postulates that individuals develop cognitive schemes in their perception of the social environment and that these cognitive representations are interpreted in terms of past experiences and values (Brown and Leigh 1996; Burke et al. 1992). As a result of cognitive processing, similar or joint experiences may lead to different perceptions, depending on individual interpretations (Bandura 1997). Empirical research on work groups has demonstrated that within-group perceptual deviation reflects systematic (as opposed to random) variance that may be representative of differential cognitive appraisals of the team environment (Ostroff 1993a; Van Yperen and Snijders 2000). Hence, there seems to be conceptual and empirical justification for the use of individual-level measures in explaining SMT service climate.

However, group process theorists have shown that interpersonal processes work to influence group outcomes and that the effects of group membership should be taken into account (Shaw 1981). It has been advanced that by evoking the notion of climate, attention is drawn to the fact that each team may develop a unique set of norms and mental models regarding desirable behavior (e.g., the level of support to other team members), reflecting between-groups differences (Mathieu and Kohler 1990). Such shared beliefs or compositional group-level effects stem from explicit and implicit processes with the team. Motivated by the need for social presentation and cognitive consistency (Festinger 1954), individual employees may deliberately use sociallyinduced cognitive and affective strategies to change or to converge with the perceptions of other team members (e.g., by showing enthusiasm when supporting other team members) in order to reach socially desirable outcomes. On the other hand, group processes also operate in an implicit manner. For instance, it has been demonstrated that individuals in groups automatically imitate the cognitions and affect of team members through vicarious learning, emotional contagion, groupthink, and interaction synchrony (e.g., Bandura 1986; Bartel and Saavedra 2000). Based on these group processes, theorists have argued that an assessment of group-level phenomena necessarily involves aggregating individual-level perceptual measures to examine 
additional cross-level relationships between group-level predictors and individual-level outcome variables. Although there has been comparatively empirical neglect of crosslevel effects, research on withdrawal behavior (absenteeism and lateness) in teams of service employees lends support to the influence of group-level predictors on individual employee behavior beyond individual-level antecedents. Mathieu and Kohler (1990) and Blau (1995) have reported significant effects of aggregrated, grouplevel variables on individual employee behavior in auto-repair, hospital and banking service teams. These results seem to support Bryk and Raudenbush's (1992) contention that group-level aggregations of contextual properties represent a distinctively different perspective that may not be captured by the individual-level measures (Bliese 2000; Ostroff 1993a). Therefore, we hypothesize that:

\section{$H_{5}:$ At the group-level of analysis there will be positive effects of $\left(H_{5 a}\right)$ tolerance, $\left(H_{5 b}\right)$ flexibility, $\left(H_{5 c}\right)$ inter-team support, and $\left(H_{5,}\right)$ intra-team support that account for a significant amount of additional variance in individual employee perceptions of SMT service climate.}

\subsubsection{Contingency Two: Assessment of Predictor-Criterion Relationships Across Service Types}

Positive linear relationships between synergistic team processes and team-member related outcomes (e.g., worker satisfaction, commitment to the team) are supported empirically across various contexts, ranging from administrative or production routines to complex new service development projects (Campion et al. 1996). However, it has been argued that the variability in the magnitude of reported predictor-criterion relationships may be indicative of moderator variables (Stewart and Barrick 2000). Indeed, information processing theory (Nadler and Tushman 1988) suggests that the association between team process and outcome variables may be contingent on task characteristics, such as complexity, uncertainty and low predictability, that demand frequent information exchange and close cooperation between and within SMTs. Task types have often been classified in terms of a routine-non-routine continuum (David et al. 1989) whereby the performance of SMTs that are primarily responsible for routine tasks are less likely to be affected by flexibility and interdependency (Stewart and Barrick 2000).

Davis (1999) proposes that the aforementioned continuum would also be the most appropriate classification criterion for services. For instance, the work of SMTs primarily engaged in the provision of routine financial services (e.g., managing checking or savings accounts) involves repetitive and standardized transactions during relatively short encounters with customers, while the performance of SMTs that render non-routine services (e.g., investment counseling or personal estate planning) relies on more specialized skills and expertise, exchange of information and level of customization. Hence, the effectiveness of SMTs delivering non-routine services is likely to be relatively strongly dependent on integrative mechanisms that enable members of the team to work on the basis of common assumptions and have compatible expectations about responsibilities and mutual behavior (Weick and Roberts 1993). Recent research by Marks et al. (2000) demonstrates that the 
development of shared beliefs regarding processes in work teams fosters coordinated task behavior and the ability to adapt dynamically in uncertain environments. Particularly in the case of non-routine services, norm congruence and shared understanding on how to function as an SMT will impact service climate perceptions. Therefore, we expect that moderation by service type will occur primarily with regard to the compositional group-level (as opposed to the individual-level) effects of tolerance, flexibility and inter- and intra-team support on SMT service climate. Since the moderator effect of service type is contingent on the relatively higher levels of coordination and interdependency associated with non-routine services, we expect that moderation of group-level predictors differs significantly from moderation at the individual level. The empirical justification for this expectation is based on recent research by Stewart and Barrick (2000) who failed to find significant moderation effects of task type on the individual-level relationships between synergistic team processes (i.e., information exchange and flexibility) and performance in manufacturing teams. Thus, we posit:

\section{$H_{6}:$ The positive effects of $\left(H_{60}\right)$ tolerance, $\left(H_{6 b}\right)$ flexibility, $\left(H_{60}\right)$ inter- team support $\left(H_{6 d}\right)$ and intra-team support on SMT service climate will be moderated by service type, such that effects will be significantly stronger at the group level for non-routine services than for routine services.}

\subsubsection{Consequences of Self-Managing Team Service Climate}

Research on boundary-spanning service functions has shown that measures of effectiveness generally fall into three categories: (1) employee attitudes, (2) customerbased parameters, such as perceptions of quality and (3) productivity criteria reflected in idiographic objective metrics (Emery and Fredenhall 2002; Singh 2000). Evidence from the team as well as the services marketing literature clearly shows that employee perceptions mediate the relationship between organizational properties and external performance (Cohen and Bailey 1997; Loveman 1999). Therefore, we examine the impact of SMT service climate on customer and productivity parameters.

The assessment of the linkage between team service climate and its consequences involves aggregating team member perceptions as well as customer perceptions to the group level. Our choice for the group as unit of analysis is based on previous studies (Allen and Grisaffe 2001; Meyer and Allen 1997). It has been argued that aggregate-level assessments of customer evaluations are required, since customers observe the outcome of integrative working relationships among multiple employees (Allen and Grisaffe 2001). Furthermore, it has been posited by outgroup-homogeneity theory that people tend to perceive other groups as more uniform than their own group (Quattrone and Jones 1980). Regarding the linkage between employee and customer perceptions of team performance, this implicates that individual team members may have relatively nuanced opinions regarding their own team's performance, because they are well-known with the daily practice within their team, while external customers are likely to generalize the quality of service offered by one or multiple team members as a common characteristic of a homogeneous 'out-group'. Moreover, it 
is not possible to empirically match employee and customer evaluations and productivity criteria at the individual level of analysis. Therefore, individual employee scores as well as individual customer scores were aggregated to the group level of analysis and the linkage between our focal construct and its consequences was tested using the team as unit of analysis.

There is ample evidence that employee perceptions of service climate at the firm level have a positive influence on customer perceptions of service quality (Schneider et al. 1996, 1998; Schneider and Bowen 1985). In addition to psychological outcome parameters, it has been argued recently that the behavioral outcome 'share of customer", or the number of services purchased from a specific service provider, is a key marketing performance indicator (Babin and Attaway 2000). The overall premise is that the impact of policies and practices aimed at serving the customer should also be observable in customer behavior, as both perceived service quality and purchase behavior are closelly related and should be evaluated simultaneously in pursuing profitability (Soteriou and Zenios 1999). Service firms may also focus on productivity as a performance parameter, focusing on quantifiable behavioral standards of employee behavior, such as volume of services sold (Singh 2000). However, recent evidence suggests that especially in the area of services trade-offs should be made between establishing a focus on delivering quality services and sales ratios per employee (Anderson et al. 1997; Singh 2000). Hence, we expect that a strong orientation of the SMT on providing high-standard services will result in decreased productivity.

It has been suggested in both the service marketing and team literature that inconsistencies in performance assessment may be contingent on the time frame taken in the analysis. It has been demonstrated that there is a delay between the implementation of self-management and the realization of performance improvements (Banker et al. 1997). As a result of, for instance, problems in the initial phase of implementation, the impact of team service climate on outcome variables may be more appropriately assessed over a period of time (Cohen and Bailey 1997). Empirical evidence from the services marketing literature also shows that customers' assessments of service quality are relatively constant and subject to slow change (Bolton and Drew 1991). Schneider et al. (1998) provide evidence for the long-run impact of service climate at the firm level. They report a delayed effect of employee perceptions of (global) service climate experiences on customer perceived service quality three years later. Moreover, Bernhardt et al. (2000) argue that the true impact of service changes in terms of observable customer behavior (e.g., actual services purchased) can only be assessed longitudinally. Therefore, based on parallel findings from the team and services marketing literatures, we propose that:

$H_{7}$ : At the group level of analysis, there will be a positive effect of SMT service climate at ${ }_{11}$ on customer perceived service quality at $T_{2}$. $H_{\delta}$ : At the group level of analysis, there will be a positive effect of SMT service climate at $r$ on share of customer at $r_{2}$.

$H_{9}$ : At the group level of analysis there will be a negative effect of SMT service climate at $T_{1}$ on service productivity at $T_{2}$. 


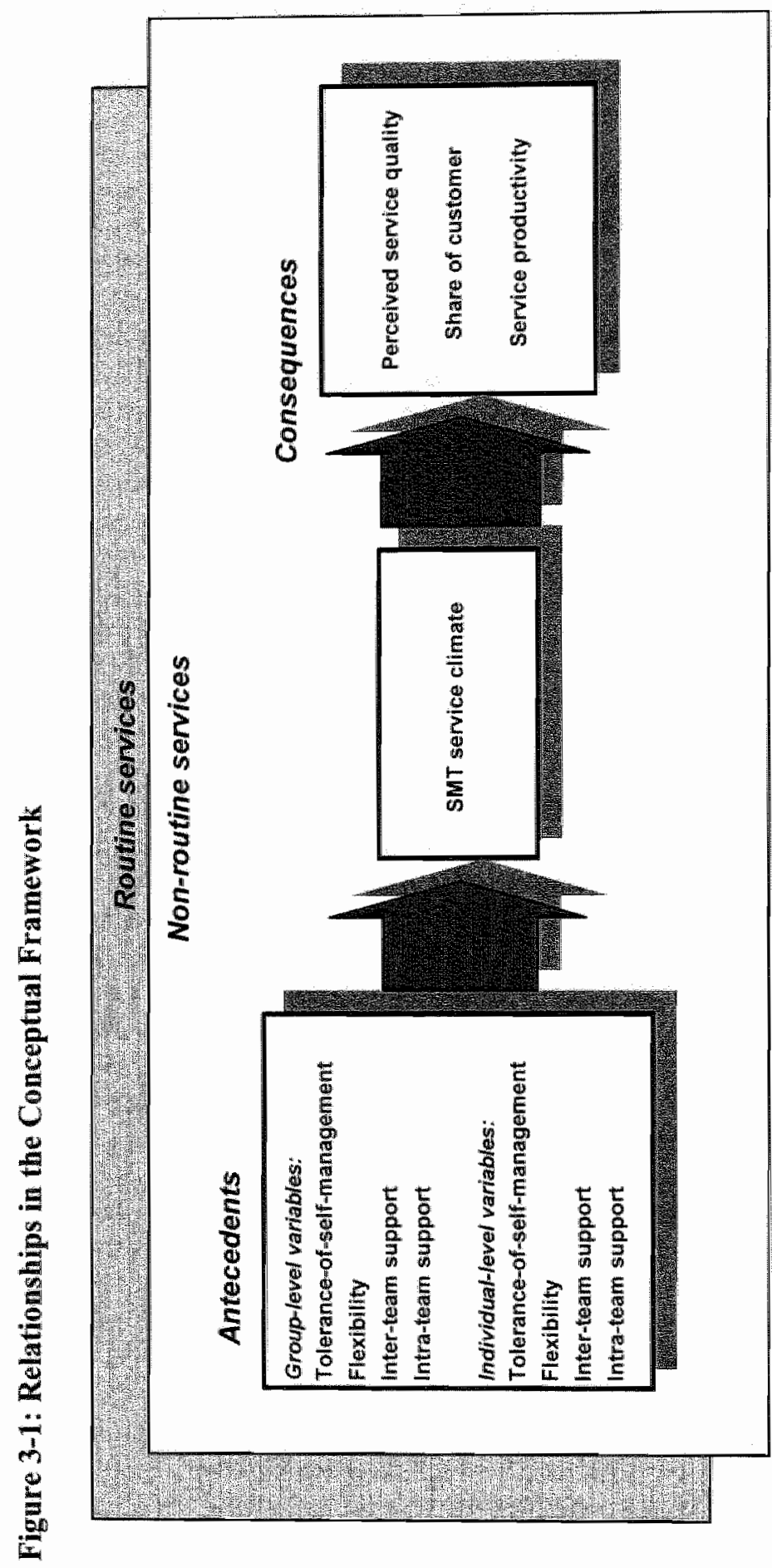




\subsubsection{Contingency Three: Assessment of Consequences Across Service Types}

Finally, we pose that the impact of SMT service climate on the aforementioned parameters may also be contingent on the type of service. Non-routine service delivery frequently involves dealing with complex problems and equivocal situations that may benefit from an extended dialog within the team and between team members and their customers. Furthermore, research on organizational learning shows that knowledgeintensive operations frequently display considerably steeper learning curves than more routine processes (Banker et al. 1997). Therefore, we hypothesize that:

$H_{10}$ : At the group level of analysis, the positive effects of SMT service climate at $T_{1}$ on ( $H_{\text {hou }}$ ) customer perceived service quality at $\mathrm{T}_{2}$ and on $\left(H_{10 b}\right)$ share of customer at $r_{2}$ and the negative effect on $\left(H_{10}\right)$ service productivity at $r_{2}$ will be moderated by service type, such that effects will be significantly stronger at the group level for non-routine services than for routine services.

Figure 3-1 reflects our conceptual framework, which provides a summary of the issues discussed so far. Now that we have outlined our contingency approach, we report on an empirical assessment of our conceptual framework in the next section.

\subsection{An Empirical Study}

\subsubsection{Research Setting}

Members of SMTs of a large Dutch bank and their customers were surveyed. The bank employs approximately 48,000 people and has 424 branch offices in order to maintain a high local presence. It operates both in business and in consumer markets and promotes service excellence as a key to marketing success. Within each branch a wide range of services are offered; non-routine, knowledge-intensive services, such as investment counseling, trust services, business consulting and estate planning and routine or transaction-intensive services, such as checking and savings accounts, currency exchange and credit application accounts. Within each branch separate SMTs are responsible for the different service types (i.e., 'financial' vs. 'client' advisory teams). The implementation of SMTs was considered to be an important organizational change process by the bank. Therefore, the practical rationale for conducting our study at the initiation phase and seven months later was to evaluate the central role of SMT service climate and examine its impact on service performance.

\subsubsection{Sampling and Surveying}

Data was collected by means of self-report questionnaires from individual employees organized in SMTs (at $r_{1}$ and, 7 months later, at $r_{2}$ ) and of their customers (at $r_{2}$ ). Mail questionnaires. were sent to employees as well as customers of 61 SMTs. For the employee survey, all members of the SMT were invited to participate. In total 939 
questionnaires were returned at $\mathrm{r}_{1}(76.4 \%)$ and 730 questionnaires at $\mathrm{T}_{2}(62.1 \%)$. For the customer survey, a random sample of 150 customers per SMT was drawn at $\mathrm{T}_{2}$. In total 1884 questionnaires were returned to the researchers by mail $(20.8 \%)$. For the employee survey, 568 questionnaires from 36 non-routine service teams ( 316 questionnaires from 36 teams at $\mathrm{r}$ and 252 questionnaires from 33 teams at $\mathrm{r}_{2}$ ) and 917 questionnaires from 25 routine service teams ( 509 questionnaires from 25 teams at $\mathrm{n}$ and 408 questionnaires from 23 teams at $1_{2}$ ) were used for further analysis. For the customer survey, 957 questionnaires of the customers form 36 non-routine service teams and 577 questionnaires of 25 routine service teams were employed for the analysis.

Regarding the employee survey, the following sample profiles for $n$ and $n$ emerge. In the non-routine service teams, the majority of the employees are older than 40 years $(52.9 \%$ at $\mathrm{Tl}$ and $55.6 \%$ at $\mathrm{T} 2$ ), whereas in the routine services setting most members are younger than 40 years old $\left(59.5 \%\right.$ at $\mathrm{r}_{1}$ and $57.9 \%$ at $\left.\mathrm{T}_{2}\right)$. With respect to education and organizational tenure, the majority of respondents of non-routine service teams has completed tertiary education $\left(53.5 \%\right.$ at $\mathrm{T}$ and $58.3 \%$ at $\mathrm{T}_{2}$ ) and has extensive company experience $\left(61.1 \%>5\right.$ years at $\mathrm{n}_{1}$ and $59.1 \%>5$ years at $\left.\mathrm{T}_{2}\right)$. Conversely, for teams delivering routine services most respondents are high school graduates $(53.8 \%$ at $\mathrm{TI}$ and $55.9 \%$ at $\left.\mathrm{r}_{2}\right)$ and many of them have been with the bank for a relatively short time $\left(47.5 \%<4\right.$ years at $T_{1}$ and $50.0 \%<4$ years at $\left.T_{2}\right)$. With respect to the customer survey, the following sample profile was acquired. The majority of the respondents were male $(63.8 \%)$ and older than 44 years $(58.5 \%)$. Virtually all respondents have a long-lasting relationship with the bank $(93.1 \%>5$ years) and half of them visits the bank at least once a month $(49.8 \%)$.

\subsubsection{Measuremem Issues}

The assessment of SMT service climate was based on items specifically developed for this study on the basis of in-depth interviews with front-line employees and scales developed by Schneider et al. (1992) and Peccei and Rosenthal (1997). Whereas service climate concerns a global concept that involves organizational policies and procedures in relation to the firms' strategic service goals, the concept SMT service climate is primarily behavioral in nature and involves service-oriented work group practices. The operationalization of tolerance was largely based upon an instrument developed by Cook et al. (1981). Flexibility, inter-team and intra-team support were measured using items adapted from scales developed by Campion et al. (1993). All scale items of the employee survey were measured with a 7-point scale, ranging from 'strongly disagree' (1) to 'strongly agree' (7).

We employed two techniques to test the factor structure and item loadings of the data collected at $\mathrm{Tl}$. We initially examined coefficient alphas and the factor structure (through principal component analysis) for all the scale items simultaneously. A fivefactor structure was achieved with items loading on the a priori dimensions. In addition, the items were subjected to confirmatory factor analysis (CFA) using LISREL (Jöreskog and Sörbom 1993) to assess the critical measurement characteristics. The fit indices of the proposed factor model, construct reliabilities of the scales and confirmatory factor loadings with t-values for each item are represented in Table 3-1. 
Table 3-1: Measures and Validation

\begin{tabular}{lc}
\hline Measures & item- lond- \\
mean ings value
\end{tabular}

Employee data

Fit indices: $\chi^{2}(\mathrm{df})=925.40(314) ;$ GFI $=0.92 ;$ A GFI $=0.91$; RMSEA $=0.049 ;$ NFI $=0.90 ;$

CFI $=0.93$

SMT service climate $(n=6 ; \alpha=.86$ at $\mathrm{ri} ; \alpha=.88$ at $\mathrm{r})$

1. Our team is always working to improve the quality of service provided to customers.

$5.81 \quad .78 \quad 25.54$

2.Our team has specific ideas about how to improve the quality of service Provided to customers.

3.Our team often makes suggestions about how to improve the service Quality in our service organization.

4. In our team we put a lot of efforts into our jobs to try to satisfy customer expectations.

5.No matter how we feel, in our team we always put ourselves out for every customer we serve.

6. Within our team, employees often go out of their way to help customers.

Tolerance-of-self-management $(n=6 ; \alpha=.89$ at $\mathrm{n} ; \alpha=.90 \mathrm{at} \mathrm{r})$

1. In our tean we are permitted to use our own judgment in solving. problems.

2.In our team we are encouraged to take initiative.

3.Our team is allowed a high degree of initiative.

4. In our team we are allowed complete freedom in our work.

5 In our team we are allowed to do our work the way we think best.

6 As a team we are able to handle all tasks assigned to us ourselves.

Flexibility $(n=4 ; a=.68$ at $n ; a=.74$ at $n)$

1.In our team it is easy to fill in for each other.

2.Most team members know each other's tasks.

3.I have much confidence that my team colleagues would be able to take over my activities.

4. Exchanges in team roles and responsibilities cause few problems.

Inter-team support $\left(n=7 ; \alpha=.83\right.$ at $\mathrm{n} ; \alpha=.83$ at ${ }_{\mathrm{T2}}$ )

(one-reversed item)

1.Other teams act in a responsive manner when we forward customer complaints.

2.The knowledge of the other teams assists us in serving customers.

3.The quality of service delivered by other teams to our team is good.

4. Because of insufficient feedback from other teams our service to customers is substandard. (reversed item)

$\begin{array}{lll}5.47 \quad .66 & 18.03\end{array}$

$\begin{array}{lll}5.97 & .58 & 15.49\end{array}$

$5.69 \quad .66 \quad 17.94$

$4.68 \quad .48 \quad 12.50$

5. Other teams provide good feedback on how to serve customers.

6. The cooperation between teams is good.

7.The employees of the other teams are helpful in solving problems of customers.

Intra-team support $(\mathrm{n}=4 ; \alpha=.66$ at $\mathrm{T} 1 ; \alpha=.68$ at $\mathrm{m} 2)$

1.In our team we help each other in serving the customer.

2. The mutual support of team members is highly valued.

3. Each team member is personally responsible for the assistance of other members in serving the customer.

\begin{tabular}{lll}
4.44 & .55 & 16.03 \\
4.93 & .56 & 16.56 \\
4.64 & .75 & 23.75 \\
& & \\
3.46 & .53 & 15.28 \\
4.66 & .54 & 15.80 \\
4.32 & .85 & 28.56 \\
4.71 & .75 & 24.09 \\
5.06 & .68 & 19.88 \\
5.18 & .79 & 23.57 \\
& & \\
4.98 & .51 & 15.03 \\
5.04 & .52 & 14.67 \\
\hline
\end{tabular}

4. In our team members need not formally be monitored with regard to the assistance of colleagues. 
Table 3-1: Measures and Validation (Continued)

Measures

$\begin{array}{ccc}\text { item- load- } & \text { t- } \\ \text { wean } & \text { ings } & \text { value }\end{array}$

Customer data

Fit indices: $\chi^{2}(\mathrm{~d})=44.64(20) ; \mathrm{GFI}=0.99 ; \mathrm{AGFI}=0.98 ; \mathrm{RMSEA}=0.036 ; \mathrm{FI}=0.99 ; \mathrm{CFI}=1.00$

Customer Perceived service Quality $(n=8 ; a=.92)$

1.The extent to which the employees make clear appointments.

$4.10 \quad .62$

26.17

$2.5 p e e d$ at which the promised information is provided.

$4.04 \quad .65$

27.46

3. The friendliness and politeness of the employees.

$4.38 \quad .72$

31.71

4. The competence of the service employees.

$4.07 \quad .82$

37.20

5. The time taken by the employees to serve you.

$4.34 \quad .75$

33.12

6. The attention the service employees pay to you.

$4.25 \quad .82$

37.79

7.The extent to which the service employees show empathy.

$4.03 \quad .81$

37.83

8. The readiness of the employees to help you.

$4.25 \quad .86$

40.41

\section{Share of Customer}

Averaged customer usage rates $(\%)$ of the different services offered:

\begin{tabular}{l|l}
\multicolumn{1}{c|}{ Non-rowtine services } & \multicolumn{1}{c}{ Routine services } \\
\hline Mortgages, Loans $(53.6 \%)$ & Checking account $(95.2 \%)$ \\
Investuitent funds $(52.7 \%)$ & Savings account $(79.1 \%)$ \\
Stocks $(43.9 \%)$ & Electronic banking/Telebanking $(30.3 \%)$ \\
lnsurances $(46.5 \%)$ & Currency exchange $(20.1 \%)$ \\
& Credit application accounts $(44.9 \%)$ \\
& Travel services $(18.7 \%)$ \\
\hline
\end{tabular}

Note: all t-values are significant at $p<.05$.

The indices of the proposed factor model demonstrate a good fit $\left(\chi^{2}(\mathrm{df})=938.88(314)\right.$; GFI $=0.92 ;$ AGFI $=0.91 ;$ RMSEA $=0.049 ; \mathrm{NFI}=0.90 ;$ CFI $=0.93$ ), showing unidimensionality of the scales (Steenkamp and Van Trijp 1991)'. Construct reliabilities of the scales were tested by means of Cronbach's alpha. Coefficients of all measures were higher than .65 , which implies that reliability is deemed acceptable (Nunnally and Bernstein 1994).

Next, within-method convergent validity was examined by investigating the significance and magnitude of the item loadings. All items loaded significantly on their respective construct (minimum t-value $=12.50$ ), where 95 percent of all items had a standardized loading of at least 0.50 . In addition, discriminant validity was evaluated. All Chi-square difference tests $(1 \mathrm{df})$ were significant $(p<.05)$ indicating that all pairs of constructs were correlated less than I (c.f., Anderson and Gerbing 1988).

In addition, the demographic variables education, organizational tenure and age, as well as the workgroup design variables 'team size' and 'percentage of front-office workers' (i.e., those employees with direct customer-contact responsibilities) and "nonroutine services' (i.e., a dummy variable reflecting the service type, where 'non-routine services' were coded as 1 and 'routine services' were coded as 0 ) served as control variables when estimating the hypothesized relationships.

\footnotetext{
'In order to assess the construct validity of our focal variable, we conducted an additional CFA in which we included both SMT service climate and its conceptual counterpart 'overall service climate' (Schneider et al. 1998). The results $\left(\chi^{2}(\mathrm{df})=236.74(43) ; \mathrm{GFI}=0.97 ; \mathrm{AGFI}=0.95 ; \mathrm{RMSEA}=0.057 ; \mathrm{NFI}=0.98 ; \mathrm{CFI}=0.98\right)$ are indicative of the unidimensionality of both constructs. To determine discriminant walidity a Chi-square difference test ( 1 d.f.) was performed to test for unity between both constructs. The test showed significance at $p<.05$.
} 
Two performance measures "customer perceived service quality" and "share of customer' were measured via the customer survey. The scale for the service quality was based on the SERVQUAL-instrument developed by Parasuraman et al. (1988). Our goal was to measure the quality of the services delivered by the service employees. Therefore, we restricted our measure to eight items that specifically assess employeerelated aspects of quality (e.g., Hartline and Ferrel.] 1996). Items were measured on a 5 point scale ranging from "very" dissatisfied" (1) to "very satisfied" (5). Principal component analysis showed construct validity (a single factor was extracted with factor loadings for all items $>0.70$ ). In addition, a CFA was conducted to assess measurement properties. The fit indices in Table $3-1$ provide evidence of unidimensionality $\left(\chi^{2}(\mathrm{df})=\right.$ 44.64(20); $\mathrm{GFI}=0.99 ; \mathrm{AGFI}=0.98 ; \mathrm{RMSEA}=0.036 ; \mathrm{NFI}=0.99 ; \mathrm{CFI}=1.00)$, construct reliability and convergent validity (all loadings $>.70$ and significant). Secondly, customers were asked to indicate which types of services they used in order to obtain the measure "share of customer" (parameter indicates average number of different services purchased per customer). Table 3-1 also provides an overview of the different non-routine and routine services.

Finally, we used data from the bank's internal database on the two service types, i.e., life insurance policies and investment portfolios for non-routine services and number of checking and savings accounts for routine serwice. The aforementioned parameters reflect the average amount of services sold per team member per year and are used as a measure of "service productivity".

Means, standard deviations, individual-level and group-level correlations between the employee variables are presented in Table 3-2, revealing that non-routine service delivery is associated with higher-educated employees, smaller team sizes, higher percentages of front office workers, and higher levels of tolerance as opposed to routine service delivery. It has been argued that corrections for individual-level measurement error should be made first, before comparing individual and aggregatelevel correlations (Ostroff 1993a). Therefore, we calculated individual-level correlations between the antecedents and SMT service climate after increasing the reliability (= Cronbach"s alpha) to .85 for constructs that had lower reliabilities. In general, the results show some increase of the individual-level correlations, implying small changes in the magnitude differences between individual-level and group-level correlations (Nunnally and Bernstein 1994). In Table 3-3 group-level means, standard deviations and (partial) correlations of employee variables and external outcomes are represented. SMT service climate appears to have the highest bivariate correlations with customer perceived service quality. Furthermore, it appears that the antecedent-perceived service quality correlations are noticeably weaker when the effect of SMT service climate is accounted for, implying that SMT climate mediates the antecedent-perceived service quality relationships (c.f., Baron and Kenny 1986). In relation to share of customer and service productivity, the mediating role of SMT service climate is less obvious. 


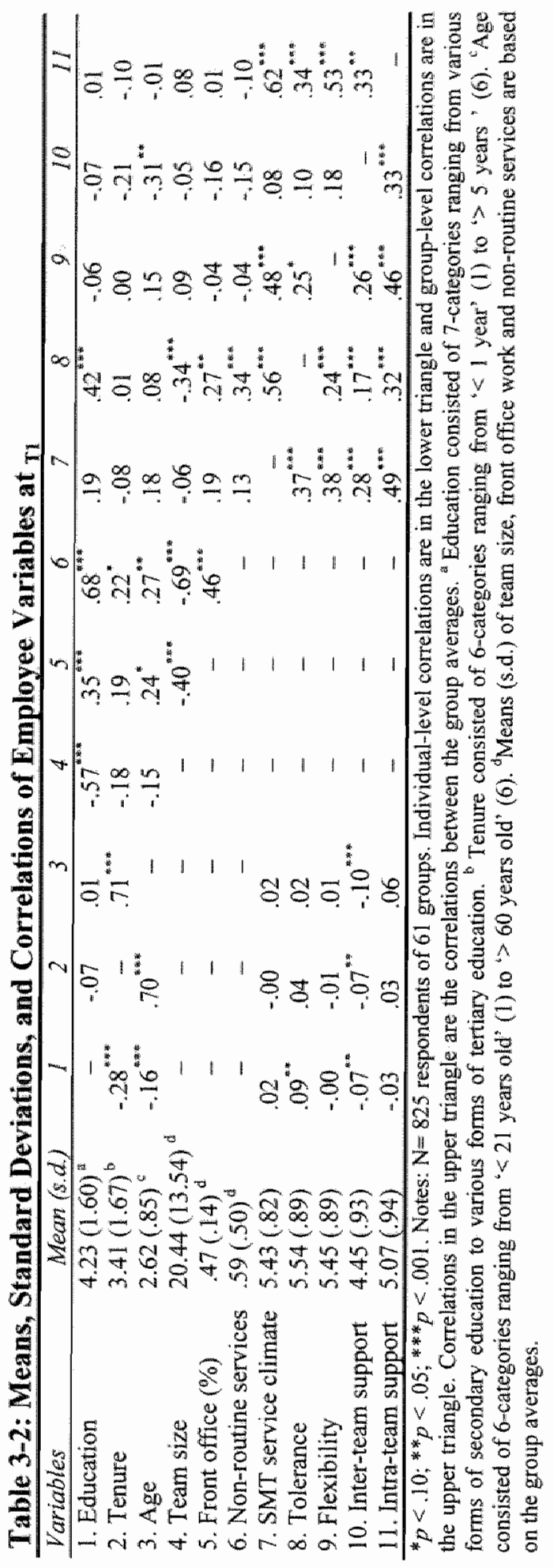




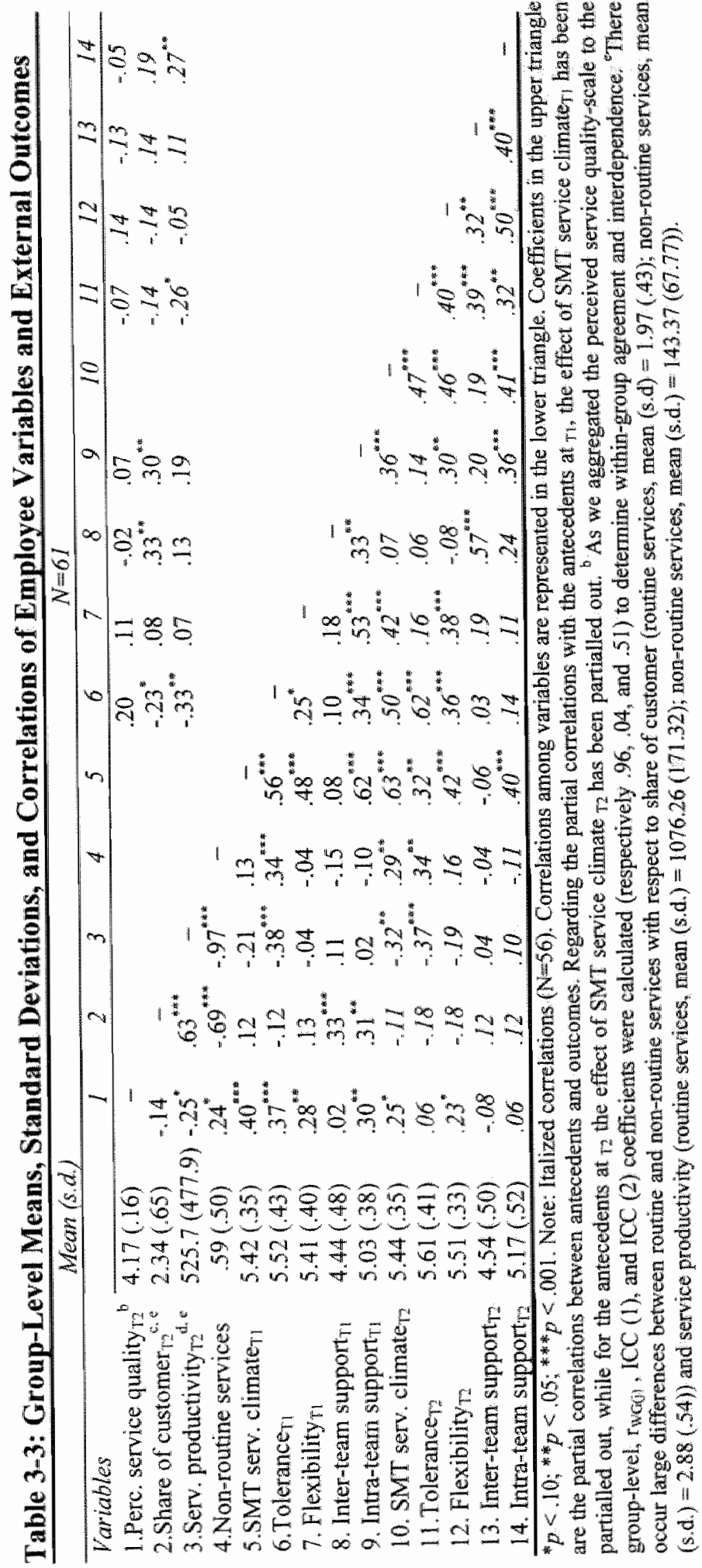




\subsubsection{Analysis}

A crucial aspect of data on group phenomena concerns the hierarchical structure of, for instance, employees who are nested within SMTs. Conventional statistical techniques (e.g., ordinary regression analysis) ignore this hierarchy and may, therefore, lead to biased results (Bryk and Raudenbush 1992). Multi-level techniques are effective means to deal with hierarchical data structures (Raudenbush 1993) and can help to disentangle the effects of subjective assessments (leading to within-group differences) from those of group factors (leading to between-groups differences). In order to test the relationships between SMT service climate and its antecedents empirically, twolevel models were specified. Level 1 contains the individual score, while level 2 reflects the group mean, which was based on the averaged employee scores within a group. In order to compare between-groups and within-group coefficients, the four antecedent variables were split into the group mean and the within-group deviation score (individual score minus the group mean) ${ }^{2}$. The coefficient of the group means concerns the between-groups coefficient, whereas the coefficient of the within-group deviation scores stands for the within-group coefficient (Bryk and Raudenbush 1992; Snijders and Bosker 1999). With regard to the interpretation of both coefficients, it is of interest to evaluate whether the within-group deviation coefficient and the betweengroups coefficient are equal. First, when these two coefficients are significant and equal, the variable functions principally at the individual level, with no separate main effect at the group level. Secondly, when the coefficient is significant for the group mean, but not significant for the within-group deviation, the effect is present only at the group level. Thirdly, however, when the coefficient is significant for the deviation variable and not significant for the group mean, the effect is solely based on social comparison within the group. Finally, when both the group mean and the within-group coefficient are significant, but different from each other, there is both an individual effect and an independent group-level effect (Van Yperen and Snijders 2000).

Table 3-4: Indices of Within-Group Agreement and Between-Groups Differences

\begin{tabular}{|c|c|c|c|c|c|c|}
\hline \multirow{3}{*}{ Variablle } & \multicolumn{6}{|c|}{ Reliability-coefficients } \\
\hline & \multicolumn{2}{|c|}{ rwG(s)-coefficient } & \multicolumn{2}{|c|}{$\begin{array}{c}\text { ICC (1) } \\
\text { coefficient }\end{array}$} & \multicolumn{2}{|c|}{$\begin{array}{c}\text { ICC (2) } \\
\text { coefficient }^{\text {"t }}\end{array}$} \\
\hline & $\pi$ & $\mathrm{n}_{2}$ & $\mathrm{TH}$ & $r$ & & $T^{2}$ \\
\hline SMT set"vice climate & .94 & .94 & .06 & .08 & .46 & .51 \\
\hline Tolerance & .95 & .95 & .16 & .14 & .72 & .66 \\
\hline Flexibility & .88 & .88 & .11 & .05 & .63 & .38 \\
\hline Inter-team suppont & .92 & .92 & .18 & .13 & .75 & .67 \\
\hline Intra-team suppont & .84 & .84 & .09 & .10 & .57 & .57 \\
\hline
\end{tabular}

"ICC (1) and ICC (2) coefficients are corrected fior measurement error, which is defined as [1 - $\alpha$ ] (cf., Van Yperen and Snüders 2000).

\footnotetext{
${ }^{2}$ Within-group deviation is similar to group-mean centering. In all analyses, level 1 variables were group-mean centered and level 2 variables were grand-mean centered to (1) distinguish between within-group and betweengroups variance, (2) to reduce multicollinearity and (3) to facilitate nodel estimation (cf. Bryk and Raudenbush 1992).
} 
In Table 3-4 the average $r_{W G(j)}$-coefficients and ICC (intra-class correlation) coefficients are presented that were calculated to examine tolerance, flexibility, interteam support, intra-team support and SMT service climate on within-group agreement

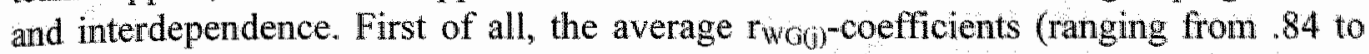
.95 at $\mathrm{T}_{1}$, as well as at $\mathrm{T}_{2}$ ) are high for all variables and show high consistency in ratings among employees within groups. Next, the average ICC (1) coefficients (ranging from .06 to .18 at $\mathrm{T}$ and from .05 to .14 at $\mathrm{T}_{2}$ ) indicate that for all variables a small to moderate part concerns between-groups variance. Furthermore, recent studies have emphasized the relevance to consider the size of the group when determining interdependence. Therefore, we calculated ICC (2) coefficients, as this measure of interdependence also accounts for group size. $90 \%$ of the ICC (2) values are above .50 providing evidence for reliable group means, which permits the detection of aggregatelevel relationships even in the case of relatively small ICC (1) values (Bliese 2000). In sum, these findings indicate that the assessments of the antecedents and SMT service climate are based on shared and unique employee perceptions.

We tested $\mathrm{H}_{1}-\mathrm{H}_{6}$ with employee data at $\mathrm{Tl}$ and estimated multi-level models by means of MLwiN software (Rasbash et al. 2000). The analysis strategy involves a stepwise approach. First, the control variables and both individual-level and grouplevel specifications of the four SMT antecedents were included (Model A1). Next, interactions were specified between the dummy variable non-routine services and the SMT antecedents (Model A2). Specification of the models is rendered in the appendix.

Multi-level models are considered as contextual models that may be subject to multi-collinearity. Therefore, ordinary regression analyses were conducted to investigate multi-collinearity by means of the Variance Inflation Factor (VIF). The VIFs of the control variables and the predictor variables are lower than 3.9 and 2.0 respectively. Hence, no severe multi-collinearity problems were encountered (Kleinbaum et al. 1988).

In Table 3-5 the results of the multi-level analyses are represented. We tested the hypotheses by determining the significance of the unstandardized regression coefficients for Model A2. To begin with, a significant positive within-group deviation effect of tolerance appears on SMT service climate, which means that $\mathrm{H}_{1}$ is supported. In addition, a positive within-group deviation effect of flexibility on SMT service climate is found, indicating support for $\mathrm{H}_{2}$. Next, the positive relationship between the within-group deviation coefficient of inter-team support and SMT service climate indicates support for $\mathrm{H}_{3}$. Furthermore, there exists a significant positive within-group deviation effect of intra-team support on SMT service climate, implying that $\mathrm{H}_{4}$ is supported.

To test the cross-level hypothesis we also investigated the group-level effects of the antecedents on SMT service climate. There exist significant positive effects of tolerance, flexibility, and intra-team support, while the effect of inter-team support is not significant. When comparing the between-groups coefficients to the with-group ones, the results indicate that these coefficients do not significantlly differ for tolerance and flexibility, while for inter-team support the between-groups coefficient appears to be significant smaller in magnitude than the within-group coefficient. Only for intra- 
team support the magnitude of the between-groups coefficient is significant greater compared to within-group coefficient. This means that $\mathrm{H}_{5 \mathrm{a}}, \mathrm{H}_{5 \mathrm{~b}}$, and $\mathrm{H}_{5 \mathrm{c}}$ are rejected and that $\mathrm{H}_{s d}$ is supported.

Table 3-5: Results of the Multi-Level Analyses

\section{Model A1}

\section{Model A2}

\begin{tabular}{|c|c|c|c|c|}
\hline & $\begin{array}{l}\text { Coefficient } \\
(\mathrm{SE})^{b}\end{array}$ & $\begin{array}{l}\triangle \text { Magnitude } \\
\text { coefficient }\end{array}$ & $\begin{array}{l}\text { Coefficient } \\
(\mathrm{SE})^{\mathrm{b}}\end{array}$ & $\begin{array}{l}\Delta \text { Magnitude } \\
\text { coefficient }\end{array}$ \\
\hline Dependent variable: & \multicolumn{2}{|c|}{ SMT Service climate $\mathrm{TI}$} & \multicolumn{2}{|c|}{ SMT Service climate n } \\
\hline Intercept: & $.573(.713)$ & & $.827(.766)$ & \\
\hline \multicolumn{5}{|l|}{ Contral vartables level ${ }^{a}$ : } \\
\hline Education & $-.017(.017)$ & & $-.018(.017)$ & \\
\hline Tenure & $-.027(.021)$ & & $-.021(.021)$ & \\
\hline Age & $.040(.039)$ & & $.036(.040)$ & \\
\hline \multicolumn{5}{|l|}{ Control variables level $2^{a}$} \\
\hline Education & $-.015(.063)$ & $.003(.065)$ & $.011(.067)$ & $.006(.070)$ \\
\hline Tenure & $-225(.082)^{* *}$ & $-.198(.085)^{* *}$ & $-.219(.084)^{* *}$ & $-.198(.087)^{*}$ \\
\hline Age & $.361(.153)^{* * *}$ & $.322(.1 .59)^{*}$ & $.317(.160)^{*}$ & $277(.167)^{34}$ \\
\hline Team size & $.004(.003)$ & & $.004(.003)$ & \\
\hline Front office $(\%)$ & $-.082(.199)$ & & $-.085(.208)$ & \\
\hline Non-routine services & $.179(.101)^{*}$ & & $.182(.106)^{*}$ & \\
\hline \multicolumn{5}{|l|}{ Predictors level I": } \\
\hline Tolerance & $.220(.032)^{*}$ & & $.224(.031)^{* * * *}$ & \\
\hline Fiexibility & $.163(.033)^{* * 4}$ & & $.170(.033)^{* * 4}$ & \\
\hline Inter-team suppoit & $.133(.034)^{* *}$ & & $.134(.034)^{* * *}$ & \\
\hline Intra-team support & $.238(.031)^{\text {水水 }}$ & & $.23 \mathrm{~J}(.032)^{* *}$ & \\
\hline \multicolumn{5}{|l|}{ Predictors level I": } \\
\hline Tolerance & $.219(.080)^{*}$ & $.000(.086)$ & $.193(.082)^{* *}$ & $-.021(.088)$ \\
\hline Flexibility & $.160(.094)^{*}$ & $-.008(.099)$ & $.217(.099)^{* 2}$ & $.055(.105)$ \\
\hline Inter-team Support & $-.006(.071)$ & $-.141(.077)^{*}$ & $-.039(.074)$ & $-.172(.080)^{*}$ \\
\hline Intra-team Support & 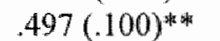 & $.262(.105)^{* * *}$ & $.460(.102)^{* *}$ & $.224(.107)^{*}$ \\
\hline \multicolumn{5}{|l|}{ Cross-level interactions } \\
\hline Tolerance L $1 \times$ Non-routine & & & $-.035(.025)$ & \\
\hline Flexilbility LI $\times$ Non-routine & & & $-.042(.028)$ & \\
\hline Inter-team $L 1 \times$ Non-poutine & & & $-.021(.027)$ & \\
\hline Intra-team $L I \times$ Non-routine & & & $.034(.027)$ & \\
\hline \multicolumn{5}{|l|}{ Level 2 interactions ": } \\
\hline Tolerance L2 $\times$ Non-routine & & & $-.007(.031)$ & $-.003(.03 \|)$ \\
\hline Plexibility L2 $\times$ Non-routine & & & $.074(.033)^{*}$ & $.086(.034)^{* *}$ \\
\hline Inter-team L.2 $\times$ Non-routine & & & $-.002(.031)$ & $.002(.031)$ \\
\hline \multirow{2}{*}{$\begin{array}{l}\text { Intra-team L2 } \times \text { Non-routine } \\
\text { Increase in model fit: }\end{array}$} & & & $-.047(.036)$ & $-.054(.037)$ \\
\hline & \multicolumn{2}{|c|}{$x^{2}(21)=362.7^{* *}$} & $x^{2}(8)=11.4$ & \\
\hline \multicolumn{5}{|l|}{ Explained variance $(\%)$} \\
\hline Individual-level & $37.9 \%$ & & $38.2 \%$ & \\
\hline Group-level & $58.9 \%$ & & $60.0 \%$ & \\
\hline
\end{tabular}

$\overline{p<.05 ;} p<.01$. Note: significance is based on one-tailed tests. "2unstandardized regression coefficients.

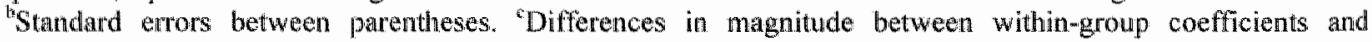
between-groups coefficients were tested by means of raw-score analyses and reflected by the presented level 2 coefficients. 
In relation to the control variables, our findings show a significant negative group-level effect of tenure on SMT service climate, where this negative group-level effect of tenure appears to be significantly stronger compared to its individual-level coefficient. Next, there is a significant positive group-level effect of age on the outcome variable, which is significantly greater in magnitude than its individual-level counterpart. Furthermore, there exists a significant positive effect of the non-routine services dummy on SMT service climate.

In addition, we tested whether the antecedent-SMT service climate relationships differ across serwice settings by specifying interactions between the dummy "nonroutine services" and the antecedents at individual level and group level. The inclusion of these interaction terms does not significantly improve the fit of Model A2 relative to Model A1. There occurs one significant positive interaction of non-routine services $x$ flexibility at the group level. Adding this interaction term to the model leads to a significant increase in model fit $\left(\chi^{2}(1)=5.922,[p<.05]\right)$ indicating support for $\mathrm{H}_{6 \mathrm{~b}}$. Specifically, the magnitude of this group-level interaction effect is significantly greater relative to its individual-level counterpart. This finding shows that shared perceptions of flexibility are significantly stronger related to SMT service climate in non-routine services. The specified group-level interactions of non-routine services with respect to tolerance, inter-team and intra-team support appear to be non-significant, which implies that there are no differences in group-level effects of these antecedents across service types. Hence, $H_{6 a}, H_{6 c}$, and $H_{6 b}$ are rejected. Finally, the analysis reports a higher percentage of explained individual-level variance compared to group-level variance indicating that between-groups differences of SMT service climate are more effectively explained than within-group differences.

In order to substantiate our results and to acquire further insight into our data, several additional analyses have been performed. The results of these additional analyses are presented in Table 3-6. First, we investigated the delayed effects of the predictor variables at $\mathrm{T}_{1}$ on SMT service climate at $\mathrm{T}_{2}$ (Model $\mathrm{B} 1$ ). The results of this lagged analysis show a pattern, which is largely consistent with the cross-sectional analysis (Model A2). Specifically, the antecedent effects appear to be persistent over time demonstrating the robustness of the antecedent-SMT service climate relationships across varying time frames. In contrast to the results of Model A2, a positive grouplevel interaction of non-routine services $x$ inter-team support occurs, indicating the importance of inter-team support in non-routine services in the longer term. Secondly, we conducted the simulation procedure Gibbs sampling (Gilks et al. 1996) to test the accuracy and stability of parameter estimates (Model B2). The parameter values obtained through this simulation were fairly similar to the Model A2 estimates. Thirdly, the Chow $F_{c}$ was performed test to determine whether there has been a structural change in the antecedent-SMT service climate relationships between $r$ and 12. The Chow $F_{6}$ test reports no significant $F$-value $\left(F_{25,1435}=1.00\right)$, which indicates that there are no structural alterations over time. Overall, this model validation indicates insensitivity of the results to varying time frames and different estimation methods, which confirms consistency in findings and provides additional support for their managerial relevance. 
Table 3-6: Results of Additional Multi-Level Analyses Model B1 (Lagged analysis) Model B2 (Gibbs sampling)

\begin{tabular}{|c|c|c|c|c|}
\hline & $\begin{array}{l}\text { Coefficient } \\
\left(\mathrm{SE}^{\mathrm{b}}\right.\end{array}$ & $\begin{array}{l}\text { A Magnitude } \\
\text { coef. }\end{array}$ & $\begin{array}{l}\text { Coefficient } \\
(\mathrm{SE})^{b}\end{array}$ & $\begin{array}{l}\Delta \text { Magnitude } \\
\text { coef. }\end{array}$ \\
\hline Dependent wariable & \multicolumn{2}{|c|}{ SMT service climate $r z$} & \multicolumn{2}{|c|}{ SMT service climate $\mathrm{TI}$} \\
\hline Intercept & $.477(1.020)$ & & $.842(.773)$ & \\
\hline \multicolumn{5}{|l|}{ Control variables level I } \\
\hline Education & $-.010(.026)$ & & $-.018(.017)$ & \\
\hline Tenure & $.009(.032)$ & & $-021(.021)$ & \\
\hline Age & $.130(.063)^{*}$ & & $.035(.040)$ & \\
\hline \multicolumn{5}{|l|}{ Conmol variables level $2^{a}$. } \\
\hline Education & $-.051(.092)$ & $-.028(.102)$ & $-.012(.069)$ & $.006(.071)$ \\
\hline Tenure & $-.164(.095)^{*}$ & $-.166(.107)$ & $-.219(.085)^{* *}$ & $-.96(.088)^{*}$ \\
\hline Age & $.488(.190)^{* *}$ & $.355(.215)^{*}$ & $.316(.163)^{*}$ & $.278(.169) *$ \\
\hline Team size & $.005(.004)$ & & $.004(.003)$ & \\
\hline Front office $(\%)$ & $-.350(.288)$ & & $-.088(.214)$ & \\
\hline Non-routine services & $.313(.150)^{*}$ & & $.182(.1 .07)^{*}$ & \\
\hline \multicolumn{5}{|l|}{ Predictors level I $\mathrm{n}$} \\
\hline Tolerance & $.114(.060)^{*}$ & & $.223(.032)^{* *}$ & \\
\hline Flexibility & $.238(.076)^{* *}$ & & $.169(.034)^{* *}$ & \\
\hline Inter-team support & $.100(.056)^{*}$ & & $.132(.031)^{* *}$ & \\
\hline Intra-team support & $140(.057)^{*}$ & & $.232(.031)^{* *}$ & \\
\hline \multicolumn{5}{|l|}{ Predictors level $2^{\mathrm{A}}$ : } \\
\hline Tolerance & $.212(.100)^{*}$ & $.096(.124)$ & $.194(.084)^{*}$ & $-.021(.090)$ \\
\hline Flexibility & $.205(.120)^{*}$ & $.010(.140)$ & $.214(.101)^{*}$ & $.064(.106)$ \\
\hline Inter-team Support & $.010(.089)$ & $-.092(.112)$ & $-.039(.075)$ & $-.168(.083)^{*}$ \\
\hline Intra-team Support & $.400(.121)^{* * *}$ & $.236(.142)^{*}$ & $.459(.105)^{* *}$ & $.214(.1109)^{* *}$ \\
\hline \multicolumn{5}{|l|}{ Cross-level interactions ad: } \\
\hline Tollerance-LI $\times$ Non-routine & $.006(.040)$ & & $-.035(.025)$ & \\
\hline Flexibility-L1 $\times$ Non-routine & $.025(.055)$ & & $-.041(.027)$ & \\
\hline Inter-tean-L1 $\times$ Non-routine & $.003(.043)$ & & $-.023(.025)$ & \\
\hline Intra-team-LI $\times$ Non-routine & $-.023(.046)$ & & $.035(.027)$ & \\
\hline \multicolumn{5}{|l|}{ Level 2 interactions } \\
\hline Tolerance L2 $\times$ Non-routine & $\therefore .008(.048)$ & $.002(.053)$ & $-.007(.031)$ & $-.002(.032)$ \\
\hline Flexibility-L2 $2 \times$ Non-routine & $.076(.045)^{*}$ & $.074(.050)$ & $.074(.033)^{*}$ & $.082(.034)^{* * *}$ \\
\hline Inter-team-L2 $\times$ Non-routine & $.089(.038)^{* *}$ & $.080(.043)^{*}$ & $-.002(.032)$ & $.002(.032)$ \\
\hline Intra-team-L2 $\times$ Non-routine & $-.087(.054)$ & $-.090(.061)$ & $-.046(.037)$ & $-.054(.038)$ \\
\hline \multicolumn{5}{|l|}{ Explained variance $(\%)$} \\
\hline Individual-level & $31.2 \%$ & & $37.7 \%$ & \\
\hline Group-level & $50.4 \%$ & & $57.9 \%$ & \\
\hline
\end{tabular}

$p<.05 ; p<01$. Note: significance is based on one-tailled tests. "Unstandardized regression coefficients. "Standard errors between parentheses. ${ }^{\circ}$ Differences in magnitude between within-group coefficients and betweengroups coefficients were tested by means of raw-score analyses and reflected by the presented level 2 coefficients. "Model B2: Gibbs-sampling (10000 iterations). Gibbs sampling (a Markov chain Monte Carlo (MCMC) works by simulating a new value for each parameter in turn from its conditional distribution assuming that the current values for the other parameters are the true values. The parameter estimates obtained by Gibbs sampling are fairly similar to the Model A2 estimates. 
In addition, the effect of SMT service climate at $n_{1}$ on several team outcomes at $r_{2}$ has been investigated. The hypotheses $\mathrm{H}_{7-9}$ were tested through a multivariate regression model formulated as a two-level hierarchical linear model. Level 1 refers to the dependent variables indexed by $h=1, \ldots, m$ and level 2 refers to the teams $j=1, \ldots, N$. Hence, each measurement of a dependent variable on some group is represented by a separate line in the data matrix, containing the values $j, h, Y_{h j}, x_{i j}$, and those of other explanatory variables. To represent the multivariate regression model as a hierarchical linear model, dummy variables $d_{1}$ to $d_{m}$ are used to indicate the dependent variables (i.e., perceived service quality ${ }_{\mathrm{T} 2}$, share of customer $\mathrm{T}_{2}$, and service productivity ${ }_{12}$ ). Dummy variable $d_{h}$ is 1 or 0 , depending on whether the data line refers to the dependent variable $Y_{h}$ or to one of the other dependent variables. With these dummies, the regression models for the $m$ dependent variables can be integrated into one twolevel hierarchical model by the following equation:

$$
Y_{h j}=\sum_{s=1}^{m i} \gamma_{0 s} d_{s h j}+\sum_{k=1}^{k} \sum_{s=1}^{n z} \gamma_{k s} d_{s h j} x_{k j}+\sum_{s=1}^{m n} e_{s j} d_{s h j}
$$

All variables (including the constant) are multiplied by the dummy variables. It should be noticed that in the sums over $s=1, \ldots, m$, only the term for $s=h$ renders a contribution, while all other terms disappear. The following regression equation, involves a simplified representation of equation 2 :

$$
\begin{aligned}
& Y_{h i}=\gamma_{0 h}+\gamma_{1 h} \text { SERVCLIM }_{\mathrm{T}, j}+\gamma_{2 h} \text { NROUT }_{j} \\
& +\gamma_{3 h}\left(\text { SERVCLIM }_{\mathrm{T} 1 j} \times \text { NROUT }_{j}+e_{h j},\right.
\end{aligned}
$$

where $Y_{h j}$ is the measurement on the $h^{\prime}$ th variable for group $j$, SERVCLIM $_{\mathrm{T} l}$ is the team's average SMT service climate score at $T$, and NROUT reflects the type of service.

Our results are presented in Table 3-7 and reveal significant positive effects of $\mathrm{SMT}_{\text {service climate }} \mathrm{T}_{1}$ on perceived service quality $\mathrm{r}_{2}$, and share of customer $\mathrm{r}_{2}$, and a significant negative effect on service productivity ${ }_{\mathrm{T} 2}$. These findings imply support for $\mathrm{H}_{7}, \mathrm{H}_{8}$, and $\mathrm{H}_{9}$. Furthermore, the service type dummy "non-routine services" is positively related to customer perceived service quality, while it is negatively related to share of customer and service productivity. In addition, interactions between service type and SMT service climate were tested. There exists a positive interaction effect of non-routine services $\times$ SMT service climate on perceived service quality, while no significant interactions appear in relation to share of customer and service productivity. Hence, $\mathrm{H}_{10 \mathrm{a}}$ is supported, while $\mathrm{H}_{10 \mathrm{~b}}$ and $\mathrm{H}_{10 c}$ are rejected. 
Table 3-7: The Results of the SMT Service Climate-Outcome Relationships

\begin{tabular}{|c|c|c|}
\hline & Model C1 & Model C2 \\
\hline & Coeffucient $(\mathrm{SE})^{b}$ & Coefficient $(\mathrm{SE})^{b}$ \\
\hline SER VCLIM $\rightarrow$ QUAL & $.941(.308)^{3}$ & $.969(.295)^{*}$ \\
\hline NROUT $\rightarrow$ QUALL & $.501(.313)$ & $.510(.299)^{*}$ \\
\hline SERVCLIM $_{\mathrm{TI}}$ NROUT $\rightarrow$ QUALR & & $.336(.134)^{* *}$ \\
\hline SERVCLIM ${ }_{\mathrm{TH}} \rightarrow \mathrm{SHARE}_{\mathrm{T} 2}$ & $.275(.119)^{* *}$ & $.268(.11 .8)^{* * *}$ \\
\hline NROUT $\rightarrow$ SHARETE & $-.953(.121)^{* *}$ & $-.955(.119)^{* *}$ \\
\hline SERVCLIM ${ }_{1} \times \mathrm{NROUT} \rightarrow \mathrm{SHARE}_{\mathrm{T} 2}$ & & $-.082(.053)$ \\
\hline $\mathrm{SERVCLIM}_{\mathrm{T} 1} \rightarrow \mathrm{SPROD}_{2}$ & $-73.862(30.076)^{* *}$ & $-72.430(29.961)^{* *}$ \\
\hline $\mathrm{NROUT} \rightarrow \mathrm{SPROD}_{\mathrm{I}}$ & $-922.734(30.539) *$ & $-922.305(30.403)^{* * *}$ \\
\hline 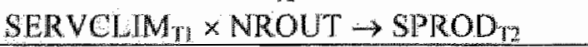 & & $16.811(13,570)$ \\
\hline Residual between-groups covariance terms & & \\
\hline$\sigma_{h}^{2}=\operatorname{var}\left(e_{h j}\right),(h=1)$ & $1.417(.256)$ & $1.298(.235)$ \\
\hline$\sigma_{t i}^{2}=\operatorname{var}\left(e_{h i}\right),(h=2)$ & $.211(.039)$ & $.206(.037)$ \\
\hline$\sigma_{i}^{2}=\operatorname{var}\left(e_{k j}\right),(h=3)$ & $13507.870(2440.253)$ & $13385.760(2423.142)$ \\
\hline$\sigma_{12}=\operatorname{cov}\left(e_{1, j}, e_{2, j}\right)$ & $-.041(.070)$ & $-.006(.066)$ \\
\hline$\sigma_{1,3}=\operatorname{cov}\left(e_{1,}, e_{3 j}\right)$ & $6.225(17.704)$ & $-.871(16.872)$ \\
\hline$\sigma_{23}=\operatorname{cov}\left(e_{2 j}, e_{3 j}\right)$ & $-7.755(6.927)$ & $-6.144(6.773)$ \\
\hline Increase in model fit ${ }^{\circ}$ : & $x^{2}(6)=232.45 *$ & $\chi^{2}(3)=10.32 *$ \\
\hline Increase in model fit & $x^{2}(3)=1.712$ & $\chi^{2}(3)=.854$ \\
\hline
\end{tabular}

\subsection{Discussion}

The key objective of our study was to empirically nuance the chain of events between perceptions of boundary-spanning service employees organized in SMTs and critical performance criteria, taking into account a number of relevant contingencies. Regarding the factors that shape employee perceptions of SMT service climate, we find that tolerance of self-management is an important antecedent. The aggregate measure of tolerance exhibits a significant positive effect on team service climate, but it does not account for additional variance in the team climate construct. Employees feel that the delegation of autonomy is conducive to developing a service orientation within SMTs, and this point of view does not differ across SMTs. This supports Spreitzer's (1995) conceptualization of empowerment as a gestalt that depends on employees' cognitions and individual interpretation of the organizational context (Spreitzer 1995).

Similarly, the positive effect of flexibility on SMT service climate operates predominantly at the individual level. However, in the case of non-routine service delivery there is a differential sensitivity to flexibility between SMTs. In this setting, service climate appraisal is primarily dependent on the social norm that has been developed within each SMT. In non-routine services, which are relatively more complex and delivered in extended encounters, members contribute unique experience 
and this requires integrating mechanisms and more coordination of effort (Davis 1999). A collective understanding of each other's roles and a shared conception of how the team should work together in providing sound financial advice to the customer enhances the team effectiveness. While in routine service delivery the development of interchangeable expertise contributes to team service climate perceptions at the individual level, this does not hold for a shared conception of the team's flexibility. This suggests that, for instance, cross training effort would be more beneficial at the individual employee level, focusing on individual skill requirements (e.g., Uhl-Bien and Graen 1998).

The positive effect of inter-team support on SMT service climate operates exclusively at the individual level. Employees who, in comparison to their colleagues within the SMT, show a more enthusiastic view on the intemal services from other teams have more positive perceptions of $\mathrm{SMT}$ service climate. This effect provides support for the contention that perceptions of a supporting organizational context strengthens teams' service climate (Spreitzer et al. 1999; Sundstrom et al. 1990). However, the shared perceptions of the team members are not congruent with this contention. In fact, the group-level effect is significantly weaker than its individuallevel counterpart. One explanation may lie in the occurrence of what has been termed the outgroup-homogeneity effect. Essentially, this refers to the fact that in ratings of characteristics of other groups, team members may exhibit higher levels of consensus (Quattrone and Jones 1980). Based on the relatively high ICCs and low group means of inter-team support, we conclude that collectively, team members are more critical of the support that they receive from other teams. The compositional effect of outgroup homogeneity apparently suppresses a (positive) group-level effect of inter-team support (or, 'we against them'), while individual deviations from the group mean remain consequential for SMT service climate. Interestingly, the results of the lagged analysis reveal a significantly positive group-level (interaction) effect for non-routine service delivery. It appears that the impact of the collective view on the support from other teams on a climate for the delivery of more complex services becomes apparent only after the cognitive barrier of outgroup-homogeneity has been overcome. As Nicholson and Johns (1985) suggest, the social dynamics of interdepartmental interactions in work settings develop on the basis of the attitude and behavior of external reference groups. The team perceptions of assistance from other teams depend on the extent to which actions from the outgroup are in or out of line with (pre)existing views. Members of SMTs that deliver non-routine services are more dependent on other teams and interact more frequently with employees from other SMTs. As a consequence, other groups within the organization are better able to "prove" their contribution to the objective of a service climate. A shared understanding of inter-team support is likely to enable teams to coordinate better, to identify where problems might occur and provide assistance in the delivery of non-routine financial services.

We find that the shared conceptions of how team members assist each other within the team account for variance in employees' perceptions of the service climate within their team. This effect is also consistent across time. In accordance with previous research, the willingness of group members to support each other proves to be the major driver of developing an atmosphere in which service performance is emphasized. (Hyatt and Ruddy 1997). Additionally, our results reveal that the group- 
level effects of age and tenure significantly strengthen the individual-level impact of these demographics on employee perceptions of the service climate within their team. Members of SMTs with a relatively high average age have significantly higher positive team service climate perceptions, whereas members of SMTs with a relatively high tenure exhibit a significantly less favorable view of team service climate. These results (as well as a unique group-level lagged effect for age) are in line with previous research (Martocchio 1989), which suggests that a better group-task fit may primarily emerge over time. At the same time, however, our results should be nuanced by the fact that having too many organizational veterans in an SMT may not be conducive to the development of a service-oriented atmosphere. Overall, we conclude that there is a differential sensitivity to the factors that shape employee perceptions of service climate across SMTs, despite the fact that the research was conducted among SMTs that were relatively homogenous, operating under the same branch management. As a result, each SMT has a unique shared conception of attitudes and practices aimed at effective performance in service delivery to customers and our analysis shows that work group properties make a difference.

Our findings demonstrate that service climate at $\pi_{1}$ is positively related to customer perceived quality $\mathrm{T}_{2}$, while this positive effect is significantly stronger for non-routine services. Thus, the direct relationship between organizational service climate and perceived service quality in financial services reported by Schneider et al. (1998) allso holds at the team level but seems to be contingent on the service type. Particularly in the delivery of non-routine services, which are often aimed at fulfilling specific needs, a climate focusing on service excellence provides added value for customers. A shared understanding of the way in which these relatively complex services can best be delivered leads to better coordination and mutual support which in turn assists in improving the team's ability to accomplish its objectives. In contrast, the relatively high within-group variability of SMT service climate for the routine service setting may have weakened the relationship between SMT service climate and perceived service quality (e.g., Schneider et al. 2002).

SMT service climate also contributes to a higher share of customer. At the same time, we find that SMT service climate is associated with lower service productivity levels. These results as well as the low correlations between these effectiveness measures may be indicative of what has been labeled the performance paradox, a phenomenon that has been encountered in many studies on organizational effectiveness (Meyer and Gupta 1995; Singh 2000). Anderson et al. (1997) contend that trade-offs between different performance parameters are probable in services and emphasize the necessity to set off customer parameters against productivity parameters in order to create an optimal balance.

\subsection{Limitations and Theoretical Implications}

Part of the strength of a research project lies in the recognition of its limitations. This may suggest potential issues that merit future research. In the first place, our findings suggest that the nature and consequences of SMT service climate depend on a number of contingencies. Therefore, this research should be replicated in other services 
settings (e.g., hospitals, after-sales services) to obtain an insight into whether our contingencies hold and/or whether other constructs are more appropriate in explaining SMT performance. For instance, while a recent study by Schneider et al. (2002) has identified service climate strength as a relevant contingency in this area of research, other researchers have advanced group potency and group efficacy as related constructs that may impact group performance (Cohen and Bailey 1997). Further research on contingencies and alternative constructs in the context of team-based service delivery is warranted.

Next, the significant differences in the magnitude of group-level and individuallevel effects for the inter-team support and intra-team support antecedents motivate future in-depth investigations to address the underlying theoretical mechanisms that cause these magnitude differences. Our findings in relation to inter-team support suggest the relevance to take distortions in employee perceptions into account when comparing relationships across levels. Ratings of situational elements may be affected by 'purpose of ratings', 'performance norms' and 'social dynamics' (e.g., Ostroff 1993b). For example, it makes a difference whether respondents evaluate their own team or other (rival) teams within the organization. In other words, the team members" varying motives and interests influence their workplace evaluation. Although recent multi-level research increasingly recognizes the importance to compare relationships across levels (De Jonge et al. 1999; Ostroff et al. 2002; Ostroff and Harrison 1999; Van Yperen and Snijders 2000), most articles primarily restrict their focus to methodological issues. Particularly, a conceptual perspective on within-group variations of aggregate-level issues has been largely ignored. Therefore, additional theoretical work is required on implicit and explicit processes between the individual service employees, their colleagues, and the broader service context.

In testing the link between SMT service climate and its antecedents, different levels of analysis were considered. Employee scores were repeatedly collected at two different time points to generalize over time and aggregated at the group-level to compare the consistency of the relationships across levels. An important drawback, however, remains common method variance, which may have inflated the relationships estimated between SMT service climate and its antecedents. For future research, we recommend the use of multiple independent data sources.

Finally, our study convincingly demonstrates that SMT service climate acts as a mediator of internal organizational performance and customer perceived service quality, while its mediating function in relation to share of customer and, particularly, service productivity appears more questionable. The diverging effects of SMT service climate on customer perceived service quality and share of customer, as opposed to service productivity, may motivate future research to investigate complementary mediator variables that explain this performance paradox between customer-based measures and productivity-based measures. To obtain a more balanced perspective future conceptual models need to include a more productivity-oriented service performance mediator that complements the mediating role of SMT service climate in relation to more productivity-oriented marketing outcomes (e.g., Singh 2000). 


\subsection{Managerial Implications}

Our findings also suggest a number of managerial implications. First, at the individual employee level, management should convey an ongoing commitment to selfmanagement by clearly articulating the boundaries of autonomy, providing sufficient access to resources and information, coaching and providing feedback, as well as offering individial team members the possibility of improving participative problemsolving and decision-making skills in training programs. Specifically, individual member skills that are conducive to efficient autonomous service delivery functioning include identifying and analyzing customer expectations, work process planning, goal setting and evaluating performance. Furthermore, (cross-)training is important for developing the interchangeable expertise and skills that are necessary for functional flexibility, inter-role awareness and knowledge acquisition within the team. In addition to class-room setting instructions and formal task- and job-rotation programs, on-thejob explanations and shadowing fellow team members for a day may enhance perceptions of flexibility and an understanding of how each team member contributes to serving the customer. While training and socialization also have an impact on the level of inter-team and intra-team collaboration and assistance, the importance of a supportive attitude could also be emphasized in selection procedures, for instance, by employing tests for applicants' pro-social value orientation and interpersonal skills.

At the group level, our results reveal that a shared understanding between team members of intra-team support in service delivery is an important service climateshaping factor. Therefore, management should seek ways to stimulate team members" mutual support. Team-level interventions that may be effective in creating a collective sense of support within the team include group exercises aimed at enabling team members to coordinate better, increase problem identification and provide assistance to colleagues, as well as the implementation of shared databases with the purpose to facilitate information exchange. In addition, offering group-level incentives or recognition for pro-social behavior could be useful. Furthermore, a shared conception of flexibility within the team seems particularly important in case of the delivery of non-routine or complex services. Therefore, training programs should be developed that focus on interchangeable expertise within the SMT. Also, group meetings could be devoted to increase team members' understanding of each other's tasks and roles and to discuss various strategies and behavioral criteria in team-process evaluations. As the impact of the assistance of other teams within the organization displays a delayed effect on service climate perceptions of SMT members involved in the delivery of complex services, group-level interventions may also be directed at inter-team support. In multi-team training programs, an internal service orientation should be developed by perspective taking and adaptive performance through role playing exercises and continuous improvement of communication and knowledge exchange between teams (Polley and Van Dyne 1994). In addition, our results with respect to team demographics could guide managers in the formation of SMTs in service organizations. Managers need to be sensitive to striking a balance in the SMT composition between age and tenure. 
Finally, managers should exercise patience in evaluating the impact of SMT implementation in service delivery. More importantly, they should be aware of the differential impact of SMT service climate on performance parameters. A trade-off should be made between customer- and company-based performance parameters (Anderson et al. 1997). Too much emphasis on perceived customer satisfaction or maximization of customer relationships might result in sub-goal optimization and decrease employee productivity to objectionable levels. Management must achieve an appropriate balance in relation to customer- and productivity issues by taking a dualgoal approach, setting explicit productivity-oriented performance goals as well as customer-oriented goals. Especially in the more quality-oriented customized services it remains a challenge to keep quality goals in line with productivity rates and managers need to realize that they practice priority setting. Overall, managers should recognize that a single optimal configuration of self-management in service firms does not exist and that it is important to take into account the impact of contingency factors.

\subsection{Appendix: Model Specification}

The basic multi-level model (Model A2) consists of a level-1 submodel specifying the effects of the within-group deviation variables and a level-2 submodel specifying the effects of group-level variables:

Level 1:

(A1) SERVCLIM $_{i j}=\beta_{0 j}+\beta_{1 j} \mathrm{EDUC}_{i j}+\beta_{2 j} \mathrm{TEN}_{i j}+\beta_{3 j} \mathrm{AGE}_{i j}+\beta_{4 j} \mathrm{TOL}_{i j}$

$+\beta_{5 j} \operatorname{FLEX}_{i j}+\beta_{6 j} \operatorname{INTER}_{i j}+\beta_{7 j} \operatorname{INTRA}_{i j}+e_{i j}$

Level 2:

(A2a) $\beta_{0 j}=y_{00}+\gamma_{01} \mathrm{EDUC}_{j}+y_{02} \mathrm{TEN}_{j}+y_{03} \mathrm{AGE}_{j}+y_{04} \mathrm{SIZE}_{j}+y_{05} \mathrm{FRONT}_{j}$

$+\gamma_{06}$ NROUT $_{j}+\gamma_{07}$ TOL $_{j}+\gamma_{08}$ FLEX $_{j}+\gamma_{09}$ INTER $_{j}+\gamma_{010}$ INTRA $_{j}$

$+\gamma_{011}\left(\mathrm{TOL}_{j} \times \mathrm{NROUT}_{j}\right)_{j}+\gamma_{012}\left(\mathrm{FLEX}_{j} \times \mathrm{NROUT}_{j}\right)_{j}$

$+\gamma_{013}\left(\text { INTER }_{j} \times \text { NROUT }_{j}\right)_{j}+\gamma_{014}\left(\text { INTRA }_{j} \times \mathrm{NROUT}_{j}\right)_{j}+u_{0 j}$,

(A2b) $\beta_{q i}=\gamma_{q 0}+\gamma_{q i}$ NROUT $_{j}+u_{q j}$ for $q(=4, \ldots, 7)$,

(A2c) $\beta_{q j}=\gamma_{q 0}$ for $q(=1, \ldots, 3)$,

where $i$ stands for individuals; $j$ indicates groups; SERVCLIM involves employee"s SMT service climate appraisal; EDUC, TEN, and AGE, refer to employee"s education, tenure, and age, respectively; SIZE, FRONT, and NROUT are the size of the team, the percentage of front office workers in the team, and type of service, respectively; TOL, FLEX, INTER, and INTRA are tolerance, flexibility, inter-team support, and intrateam support, respectively. 
Substituting Equations A2a-A2c in Equation A1 yields the following multi-level model:

$$
\begin{aligned}
& \text { (A3) } \mathrm{SERVCLIM}_{i j}=\gamma_{00}+\gamma_{10} \mathrm{EDUC}_{i j}+\gamma_{20} \mathrm{TEN}_{i j}+\gamma_{30} \mathrm{AGE}_{i j}+\gamma_{40} \mathrm{TOL}_{i j}+\gamma_{50} \mathrm{FLEX}_{i j} \\
& +\gamma_{6 i} \operatorname{INTER}_{i j}+\gamma_{70} \mathrm{INTRA}_{i j}+\gamma_{80}\left(\mathrm{TOL}_{i j} \times \mathrm{NROUT}_{j}\right)_{i j}+\gamma_{90}\left(\mathrm{FLEX}_{i j} \times \mathrm{NROUT}_{j}\right)_{i j} \\
& +\gamma_{100}\left(\operatorname{NNTER}_{i j} \times \text { NROUT }_{j}\right)_{i j}+\gamma_{10}\left(\operatorname{INTRA}_{i j} \times \mathrm{NROUT}_{j}\right)_{i j}+\gamma_{01} \mathrm{EDUC}_{j}+\gamma_{02} \mathrm{TEN}_{j} \\
& +\gamma_{03} \mathrm{AGE}_{j}+\gamma_{04} \mathrm{SIZE}_{j}+\gamma_{05} \mathrm{FRONT}_{j}+\gamma_{06} \mathrm{NROUT}_{j}+\gamma_{07} \mathrm{TOL}_{j}+\gamma_{08} \mathrm{FLEX}_{j} \\
& +\gamma_{09} \mathrm{INTER}_{j}+\gamma_{010} \mathrm{INTRA}_{j}+\gamma_{011}\left(\mathrm{TOL}_{j} \times \mathrm{NROUT}_{j}\right)_{j}+\gamma_{012}\left(\mathrm{FLEX}_{j} \times \mathrm{NROUT}_{j}\right)_{j} \\
& +\gamma_{013}\left(\operatorname{INTER}_{j} \times \mathrm{NROUT}_{j}\right)_{j}+y_{014}\left(\mathrm{INTRA}_{j} \times \mathrm{NROUT}_{j}\right)_{j}+u_{0 j}+u_{1 j}+u_{2 j} \\
& +u_{3 j}+u_{4 j}+e_{i j}
\end{aligned}
$$

The individual-level error term $e_{i j}$ is normally distributed with a mean of 0 and variance $\sigma^{2}$. The random effects $u_{q j}(q=0,4,5,6,7)$ are multivariate normal distributed over teams with an expected value of 0 , var $\left(u_{q j}\right)=\tau_{q q}$. Finally, $u_{q j}$ is the unique deviation of group $j$ from the overall effect on the intercept $\left(\beta_{0 j}\right)$, while accounting for the group-level predictor variables.

The coefficients $\beta_{0 j}, \beta_{4 j}, \ldots, \beta_{7 j}$ are specified as random coefficients, implying that these coefficients are allowed to vary across groups. The predictor variables $\beta_{1 j}$, $\beta_{2,}$, and $\beta_{3 j}$ are constrained to be invariable across groups (i.e., no random term is included on level 2 for these coefficients). In theory, all $\beta_{q i}$ s could be specified as random effects. However, from a statistical viewpoint such a model is not recommendable, because it impedes model convergence and results into unstable parameter estimates (Bryk and Raudenbush 1992). 


\section{Chapter 4}

\section{Adaptive versus Proactive Behavior in Service Recovery: The Role of Self-Managing Teams}

In this chapter we develop a conceptual model of adaptive versus proactive recovery behavior by self-managing teams (SMTs) in service recovery operations. We take into account characteristics of the organizational context and SMT properties as factors that shape team member perceptions. In order to assess the impact of service recovery performance, we include a number of internal consequences (1.e, in-company performance data) and external service performance outcomes (t.e., recovery satisfaction). Departing from a hierarchical data-strueture (i.e., individuals are nested" within groups), we investigate the antecedents of adaptive and proactive recovery behavior in SMTs, using multi-level modeling. Our findings show positive individuallevel effects of tolerance, organizational support, inter-team support, and intra-team support on both adaptive and proactive recovery behavior. In addition, we find that intra-team support accounts for a significant amount of additional variance in team member perceptions of adaptive and proactive recovery behaviors at the group level of analysis. Conversely, the effects of adaptive and proactive recovery behavior on external performance measures are divergent. It appears that higher levels of adaptive performance positively influence the customer-based parameters (1.e, service recovery satisfaction and loyality intentions), while employee proactive recovery behavior contributes to higher share of customer rates. 


\subsection{Introduction}

In the services marketing literature considerable conceptual and empirical attention has been devoted to the issue of service recovery (Bell and Zemke 1987; Boshoff 1999; Bowen and Johnston 1999). Despite variance in findings, a common theme in this body of research is that the behavior of customer-contact employees is a crucial factor in service recovery. For example, Bitner et al. (1990) argue that mostly it is not the initial inability to deliver the expected service, but service employees' failure to respond adequately to the problem that causes customer dissatisfaction. As customer reactions to service failures frequently involve personal, a-typical, ill-defined and complex problems, the best way to recover from these service mistakes is for service workers to identify and solve the service problem, which implies active decision making and altering the existing service routines to bring them more in line with the customer requests (Hart et al. 1990). It has been suggested that service employees' ability to adapt to the specific situation is a central behavioral ingredient (Boshoff and Leong 1998; Hartline and Ferrell 1996). In addition to displaying adaptive behavior, it has been argued that service workers also need to be proactive in showing anticipative behaviors, such as soliciting suggestions from customers, detecting and correcting causes of service problems and challenging existing routines (e.g., Iacobucci 1998; Van Looy et al. 1998). However, although proactive behavior has been examined in relation to sales force performance, career advancement and role stress (e.g., Aspinwall and Taylor 1997; Crant 1995; Pitt et al. 2002; Seibert et al. 1999), research on proactive behavior in relation to service recovery has remained scarce.

In order to stimulate adaptive and proactive behavior of front-line service workers, several organizational initiatives have been taken recently, one of which is the introduction of self-managing teams (SMTs). A growing number of service firms has relinquished day-to-day managerial responsibilities to work groups to give employees more authority in order to be able to adapt more efficiently to customer expectations. Spreitzer et al. (1999) demonstrate that the implementation of SMTs can be associated with innovative behavior of employees. Furthermore, it has been shown that the use of SMTs in service delivery leads to improved overall financial performance as well as improved customer-perceived service quality (Bak et al. 1995; Emery and Fredenhall 2002). These findings, however, remain yet to be substantiated for the domain of service recovery.

Moreover, as the service recovery effort represents a collective responsibility, perceptions of what shapes adaptive and proactive recovery behavior may not only differ between individual team members, but also between teams. Each work unit may develop a unique set of norms or standards regarding desirable behavior, which may account for between-groups variability (Mathieu and Kohler 1990). Therefore, the effect of behavioral predictors may vary not only at the level of the individuall team member, but also at the group level (Neuman and Wright 1999; Ostroff 1993a). As a result, making the service recovery effort the collective responsibility of SMTs, necessitates the simultaneous conceptualization and operationalization of antecedents of adaptive and proactive recovery behavior at the individual and group level of analysis (Kidwell and Mossholder 1997; Van Yperen and Snijders 2000). Such an approach has been left virtually unexplored in the service recovery literature so far. 
In this chapter we address a number of theoretical and methodological issues that have been not been addressed extensively in the service recovery literature. Specifically, our study has three objectives. First, we introduce the distinction between two types of service recovery behavior by members of boundary-spanning SMTs: adaptive and proactive servicing. Second, we develop and empirically test a framework that contains both antecedents and consequences of aforementioned types of behavior. Third, we investigate whether predictors offer incremental explanation of adaptive and proactive recovery behavior at the group level, in addition to individuallevel effects.

\subsection{Development of a Conceptual Framework}

\subsubsection{Adaptive and Proactive Recovery Behavior}

Problems that occur during service delivery are frequently complicated, ill-defined, and $\mathbb{i d i o s y n c r a t i c}$ in nature where the standard service delivery procedures are not adequately equipped to effectively answer these out-of-range issues (Hart et al. 1990). As a result, effective service recovery performance typically requires concrete extrarole behaviors including adaptive and proactive components (e.g., Hartline and Ferrell 1996; Morrison and Phelps 1999). These behavioral components may be closely related, but are distinctive in nature, as Pulakos et al. (2000) demonstrate. In this chapter, we differentiate between adaptive and proactive behavior as distinct components that are complementary to the establishment of an effective service recovery strategy.

Numerous authors have discussed adaptive performance in a multitude of areas, such as selling (Spiro and Weitz 1990), learning (London and Mone 1999), training (Pulakos et al. 2000) and servicing (Hartline and Ferrell 1996). Adaptive performance typically involves a multiplicity of behaviors related to different work environments. Examples of adaptive performance are creative problem solving, coping with complex and unpredictable work situations, adjustment to technological innovations, and interpersonal adaptability. In service recovery, the interpersonal interaction between service providers and customers is a hallmark feature (Bitner 1990) and it has been implied that the service employee's interpersonal adaptability is of major relevance. It has been agreed upon that front-line employees need to adjust their behavior to properly manage and alleviate customer complaints (Halstead et al. 1993; Spreng et al. 1995). Hartline and Ferrell (1996) define adaptability in a service context as "the ability of contact employees to adjust their behavior to the interpersonal demands of the service encounter" (p. 55). Adaptive recovery behavior involves personalized service recovery, where employees adapt their behavioral approach to optimally respond customers' complaints (c.f., Solomon et al. 1985). Due to the a-typical, complex, and disturbing nature of service recovery problems, employees need to show flexibility in their contact with customers (e.g., Hatano and Inagaki 1986; Holyoak 
1991). In the context of SMTs, this aspect of performance requires the employees to bring complex matters or situations collectively to their desired end or to jointly develop creative solutions in response to novel difficult problems indicated by customers.

In addition to adaptability, the organizational behavior and team literature has investigated proactive personality and behaviors as another job performance success factor (e.g., Aspinwall and Taylor 1997; Bateman and Crant 1993, 1999; Crant 1995, 2000; Hyatt and Ruddy 1997; Kirkman and Rosen 1999; Pitt et al. 2002; Seibert et al. 1999). Furthermore, Kirkman en Rosen (1999) refer to proactivity as an indicator of SMT effectiveness. In recent service marketing research too, there has been growing interest in proactive service approaches by employees (e.g., Peccei and Rosenthal 1997, 2001). Proactive behavior concerns other actions than adaptive behavior, or as Bateman and Crant (1999, p. 63) state: "proaction involves creating change, not merely anticipating it". While adaptive skills include listening to and consider customers' viewpoints and opinions in order to appropriately adjust their service approach, proactivity involves behavioral initiative aimed at improving the current work circumstances in general or creating new ones. It involves challenging the status quo of the operational aspects of the service delivery process rather than passively adapting to the present service conditions (e.g., Iacobucci 1998). Particularly in the case of reoccurring serwice failures, which are caused by inadequacies of the current service delivery system, it is of importance for employees to take behavioral initiative to change existing workplace practice in order to prevent customer complaints in future (Hart et al. 1990). With the introduction of empowerment and the proliferation of SMTs, service workers are assumed to collectively seek for continuous improvement, revise work processes, and search for innovative solutions to work problems (Hyatt and Ruddy 1997; Kirkman and Rosen 1999). Nevertheless, empirical studies that have related proactivity to customer parameters have remained scarce (Kirkman and Rosen 1999), which motivates the need for additional in-depth research on the role of proactive versus more traditional adaptive behavior approaches in service recovery.

\subsubsection{Antecedents of Adaptive and Proactive Recovery Behavior}

Based on a literature review, we discern three types of antecedents that may influence service recovery performance of SMTs (e.g., Emery and Fredenhall 2002; Helfert and Vith 1999; Spreitzer et al. 1999). Three determinants seem of particular interest: (1) higher levels of autonomy (Bowen and Lawler 1992, 1995ab; Hart et al. 1990), (2) facilitative organizational conditions with regard to service recovery (e.g., Bowen and Johnston 1999), and (3) interdependency between and among SMTs in the service recovery effort (e.g., Sergeant and Frenkel 2000).

Tolerance-of self-management. The way in which team employees process job activities involves a crucial determinant of SMT effectiveness. Tolerance-of-selfmanagement (tolerance) concerns the delegation of managerial skills to SMTs by providing them the discretion to make task-related decisions themselves on daily service problems (Kirkman and Rosen 1999; Spreitzer et al. 1999). It has been argued 
by Hocutt and Stone (1998) that inadequate response by customer-contact workers to service failures could be caused by insufficient empowerment to effectively manage non-routine task situations, as are service failures. Furthermore, it appears from many studies that a certain level of autonomy is required to allow for a flexible work approach and behavioral initiatives to make on-the-spot decisions in order to optimally satisfy customers (Hartline and Ferrell 1996; Spreitzer 1995; Van Looy et al. 1998). It has been argued that higher levels of autonomy delegated to the customer-contact employees enhance their ability to adapt to the commonly changing conditions within the service recovery encounter (e.g., lacobucci 1998). Recent research has empirically confirmed the positive influence of empowerment on employees' adaptability towards service customer requests (Chebat and Kollias 2000). In addition to enhanced levels of adaptability, Spreitzer (1995) have argued that empowerment also leads to a proactive orientation towards jobs, management, and organizations, which results in innovative behavior. Furthermore, Van Looy et al. (1998) provide evidence that empowerment of service employees is positively related to various innovative behaviors, including problem recognition, idea generation, getting support for new ideas and commitment to innovations. Kirkman and Rosen (1999) show that team empowerment positively affects team proactivity. Similarly, Wellins et all. (1991) have demonstrated that empowered teams are more likely to engage in initial behaviors to solve existing work problems. Hence, we state that:

$H_{l}$ : There will be a positive effect of tolerance on $\left(H_{l a}\right)$ adaptive recovery behavior and $\left(H_{l a}\right)$ proactive recovery behavior.

Organizational support. Providing authority and freedom to employees is a critical strategy, but it needs to be complemented by supporting organizational arrangements and cooperative service practice among employees that sustain the SMT's capability to resolve customers' grievances. Leading companies, as are Xerox and Caterpillar have introduced electronic sensor systems, which inform service technicians about operational problems in an early stage. Numerous studies have emphasized the importance of facilitative organizational arrangements, such as organizational procedures and policies to support service recovery work (e.g., Armistead and Clark 1994; Bell and Zemke 1987; Bitner et al. 1990; Bowen and Johnston 1999; Hart et al. 1990; Johnston 1995). Two major components of organizational support are: (1) strategic managerial actions aimed at changing service delivery procedures based on customer reactions (e.g., Hartline and Ferrell 1996; Schneider et al. 1998), and (2) the provision of information and feedback about customer complaints and evaluations to front-line employees (Lawler 1986; Ledford 1993; Schneider et al. 1998). Following these notions, we conceptualize organizational support as "facilitative organizational arrangements, initiatives, procedures specifically aimed at supporting the service team members in their ability to deal with service recovery activities".

While many studies have demonstrated positive linkages between supportive organizational arrangements and employee's general service (recovery) behavior (e.g., Boshoff and Allen 2000; Schneider et al. 1998), there exists little empirical evidence on the linkage organizational support and specific behaviors exhibited by front-line employees. Hartline and Ferrell (1996) have demonstrated that a managerial focus on 
behavioral-based employee performance aspects such as efforts to increase flexibility of existing service procedures and the allocation of resources to improve service delivery efforts, eventually have a positive impact on employees' adaptability to meet customer requests. Bansal et al. (2001) contend that the quality of front-line employee decision-making is likely to improve when companies adequately provide them customer complaint information enabling employees to effectively interpret and handle customers" demands. Next to increased adaptive performance, a supportive customeroriented management style also stimulates service improvement employee initiatives and efforts on behalf of the customers (Peccei and Rosenthal 2001). Furthermore, Scott and Bruce (1994) have emphasized that employees are more likely to engage in individual innovation if they receive organizational support for their new ideas and change efforts. Finally, Bansal et al. (2001) argue that information sharing within the organization usually includes suggestions to change existing procedures and might encourage front-line employees to take reasonable action and to exert change efforts. Hence, we hypothesize that:

\section{$\mathrm{H}_{2}$ : There will be a positive effect of organizational support on $\left(\mathrm{H}_{2 \mathrm{a}}\right)$} adaptive recovery behavior and $\left(H_{2 b}\right)$ proactive recovery behavior.

Inter-team support and intra-feam support. It has been recently argued that teamwork or an internal service orientation among employees supporting each other concerns another crucial determinant of service recovery performance (Boshoff and Allen 2000). Inter-team support refers to the internal service and communication between teams and other units within the organization, while intra-team support concerns the mutual willingness of team members to help and to deliver service to each other to reach common group goals (Campion et al. 1993). Supportive (inter)action within and among SMTs are commonly relevant to properly meet customer demands and create a service-minded work environment (Berry et al. 1994; Horwitz and Neville 1996). It has been argued that well-functioning interpersonal processes among employees stimulate an atmosphere of idea generation and creativity (Andrews 1995), which is especially relevant in service recovery. Cooperative support within and between teams is crucial to adaptive behavior. Due to the accumulating use of work or project teams in services, front-line employees need to demonstrate interpersonal flexibility, adjusting their interpersonal style to work effectively with co-workers in a team and to achieve common goals (Brannick and Prince 1997; Klein 1994; Pulakos et al. 2000). When service employees experience interpersonal adaptability from their colleagues, they will be motivated to carry over this adaptive approach in their encounters with customers. In addition to increased levels of adaptability, inter-team and intra-team support are also influential in relation to proactive behaviors. Scott and Bruce (1994) have stated that high frequencies of team-member exchanges accumulate the availability of additional resources such as idea sharing and feedback available to employees. This peer-based learning strengthens employees" intention to engage in innovative behavior. Furthermore, Sergeant and Frenkel (2002) demonstrate that cooperative interaction and information sharing within teams and with other teams in organizations makes employees more confident about there own abilities to satisfy customers. Finally, Morrison and Phelps (1999) have argued that work group norms 
that support and encourage change and initiative motivate employees to take charge, because they perceive doing so as a way to get approval from fellow team members. This leads to the following hypotheses:

$H_{3}$ : There will be a positive effect of inter-team support on $\left(H_{3 a}\right)$ adaptive recovery behavior and $\left(H_{3 b}\right)$ proactive recovery behavior. $H_{4}$ : There will be a positive effect of intra-team support on $\left(H_{4 a}\right)$ adaptive recovery behavior and $\left(H_{4 b}\right)$ proactive recovery behavior.

Drawing from conceptual arguments and empirical evidence, individual-level assessments were used to examine the relationships of the antecedents with adaptive and proactive recovery behavior. Several studies have contended that the individual scores involve the only correct unit of analysis, while others state that work group features can only appropriately be analyzed at the group level (e.g., Lincoln and Zeitz 1980). The next section introduces the levels-of-analysis debate and discusses the incremental value of the group level of analysis in explaining antecedent-outcome linkages.

\subsubsection{Assessment of Predictor-Criterion Relationships Across Levels of Analysis}

Within-group deviations of predictors of adaptive and proactive recovery behavior may reflect actual differences among team members. Members of SMTs usually differ in terms of background (i.e., age, tenure and education) or psychological make up (i.e., personality factors) (Campion et al. 1996). Other studies have argued that systematic individual differences are caused by the idiosyncratic way employees perceive their work environment. Individuals use cognitive schemes to interpret their social environment in terms of previous experiences and personal values (Brown and Leigh 1996; Burke et al. 1992). Some multi-level studies have demonstrated that withingroup deviations of perceptions contain systematic variance (contrary to random error), which may be indicative of differences in cognitive appraisals of the workplace (Ostroff 1993a; Van Yperen and Snijders 2000). Hence, it seems relevant to consider the individual level of analysis when investigating the effects of contextual predictors on adaptive and proactive recovery behavior.

Group-level assessments of the antecedents represent shared team member perceptions of company features (i.e., tolerance, organizational and inter-team support) and work group practice (i.e., intra-team support). It has been argued that interpersonal processes within groups influence group performance. Each team may develop its own norms and standards regarding appropriate behavior (e.g., the level of support to colleagues), which is reflected by between-groups differences (Matthieu and Kohler 1990). These compositional group-level effects stem from explicit and implicit social processes within the team. First, social presentation and cognitive consistency needs (Festinger 1954) drive individual employees to purposely use cognitive and affective strategies to influence the perceptions of other team members (e.g., by exhibiting enthusiasm at helping colleagues) as a way to attain socially appropriate results. Secondly, group processes also operate an implicit manner. Previous research has provided evidence that members in groups without conscious awareness imitate other 
members through vicarious learning, groupthink, etc. (e.g., Bandura 1986; Bartel and Saavedra 2000). Therefore, aggregation of individual-level perceptual measures is necessary to properly consider these group-level phenomena and examine additional cross-level relationships between group-level predictors and individual-level outcomes. Empirical research on withdrawal behavior in auto repair, hospital and banking service teams (Mathieu and Kohler 1990; Blau 1995) has revealed that grouplevel specifications of variables significantly explain extra variance in individual employee outcomes beyond individual-level assessments. These findings confirm the idea that group-level aggregations of contextual properties contain an additional compositional effect, which is not considered by individual-level assessments (Bliese 2000; Ostroff 1993a). Hence, we posit that:

$H_{5}$ : At the group level of analysis there will be positive effects of $\left(H_{50}\right)$ tolerance, $\left(H_{5 s}\right)$ organizational support, $\left(H_{53}\right)$ inter-team support, and ( $\left.H_{s,}\right)$ intra-team support that account for a significant amount of additional variance in individual employee perceptions of adaptive recovery behavior.

$H_{6}:$ At the group level of analysis there will be positive effects of $\left(H_{60}\right)$ tolerance, $\left(H_{6 j}\right)$ organizational support, $\left(H_{6 c}\right)$ inter-team support, and $\left(H_{0 d}\right)$ intra-team support that account for a significant amount of additional variance in individual employee perceptions of proactive recovery behavior.

\subsubsection{Consequences of Adaptive and Proactive Recovery Behavior}

In addition to predictors of service adaptive and proactive recovery behavior by SMTs, it is of interest to examine the consequences. In the evaluation of service firm effectiveness, the distinction between customer-based criteria (e.g., customer satisfaction and customer loyalty) and quantifiable behavioral-based productivity measures (e.g., revenues, sales) (e.g., Anderson et al. 1997; Heskett et al. 1997) is often made. Previous research has related adaptability to various performance measures. Spiro and Weitz (1990) have reported a positive linkage between adaptive selling practice and salesperson performance. Employee adaptability also has been linked to customers' perceptions of the service encounter. Humphrey and Ashforth (1994) have shown that front-line employees are less able to appropriately meet the considerably varying customer requests when they merely carry out scripted rules. Bitner et al. $(1990,1994)$ demonstrate that employees who adapt their approach to meet special customer demands and concerns receive more positive customer evaluations. Alternatively, Kirkman and Rosen (1999) provide empirical evidence that team proactivity is positively related to a number of crucial effectiveness criteria, including, organizational commitment, job satisfaction, customer service, and productivity. Finally, at firm level, Rust et al. (2000) report that proactive changes in service quality and price strategies lead to improvements in market share. In sum, these studies together suggest that adaptive and proactive behaviors are important elements of service company performance. 
Previous research has demonstrated that adaptive as well as proactive behaviors are positively related to customer evaluations of the service encounter (Bitner et al. 1990, 1994; Kirkman and Rosen 1999). Besides these psychological outcomes, it has been contended that the behavioral parameter 'share of customer', or the number of services purchased from a specific front-line employee, forms another criterion of marketing performance (Babin and Attaway 2000). The underlying rationale is that the effect of customer service policies and practices should also become visible in customer behavior, since customer quality evaluations and purchase behavior are significantly related. Therefore, these parameters need to be simultaneously investigated when striving for higher profitability-rates (Soteriou and Zenios 1999). Frequently, service firms also use traditional productivity measures to gauge the performance of service employees, such as volume of services sold (Singh 2000). It has been argued that particularly in highly customized services an underlying tension exists between customer demands (demanding excellent service recovery quality) and productivity goals. Therefore, trade-offs are required between employing customerbased versus productivity-oriented performance parameters (Anderson et al. 1997; Singh 2000). Hence, we expect that a strong focus on adaptive and proactive recovery behavior in SMTs as a strategy to solve service failures may result in lower productivity rates. Therefore, we posit that:

$H_{7}$ : There will be positive effects of $\left(H_{7 a}\right)$ adaptive recovery behovior and $\left(H_{7 b}\right)$ proactive recovery behavior on recovery satisfaction.

$H_{8}$ : There will be positive effects of $\left(H_{8 a}\right)$ adaptive recovery behavior and $\left(H_{8 b}\right)$ proactive recovery behavior on loyalty intentions.

$H_{9}$ : There will be positive effects of $\left(H_{9 a}\right)$ adaptive recovery behavior and $\left(H_{9 b}\right)$ proactive recovery behavior on share of customer.

$H_{10}$ : There will be negative effects of $\left(H_{100}\right)$ adaptive recovery behovior and $\left(H_{10 b}\right)$ proactive recovery behavior on service revenues. 
Aforementioned hypotheses are summarized in the following conceptual model:

Figure 4-1: Relationships in the Conceptual Framework

Antecedents

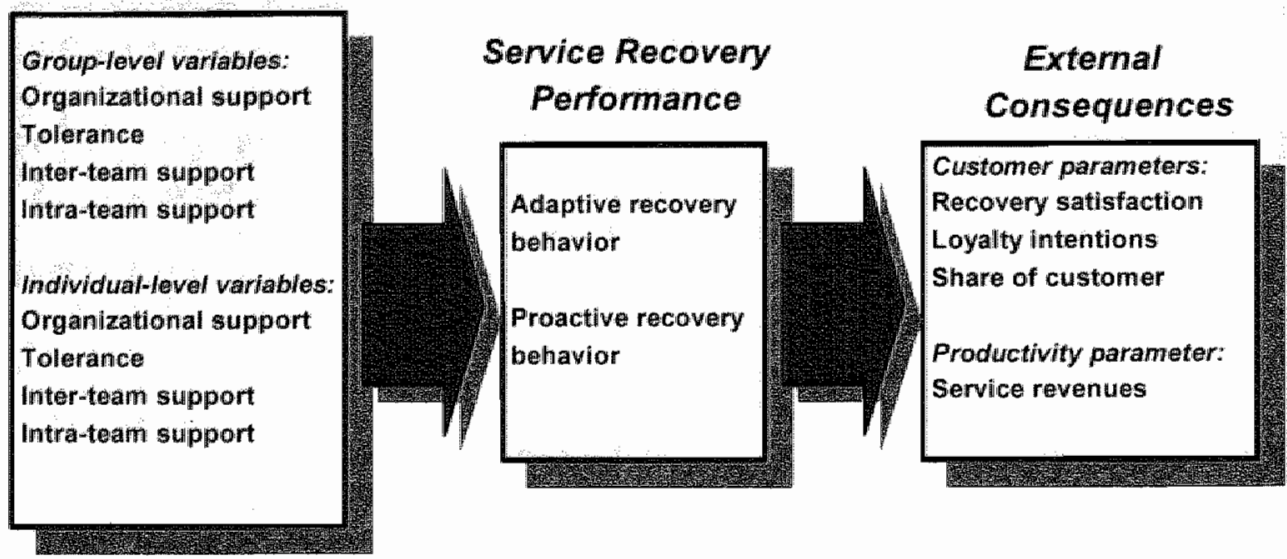

\subsection{Empirical Study}

Since this study is based on the same database, we refer for a more elaborate discussion of the "research setting" to Chapter 3.

\subsubsection{Research Setting}

Employees from SMTs of a large Dutch bank, as well as their customers were surveyed. The bank employs approximately 48,000 people and has 424 branch offices all over the country in order to keep a high local presence. It operates both in business and in consumer markets and strives for service excellence as a critical strategy to marketing success. Within each branch separate SMTs are responsible for the occurring recovery service problems (i.e., 'financial' vs. 'client' advisory teams); problems in relation to non-routine, knowledge-intensive services, such as investment counseling, trust services, business consulting and estate planning and routine or problems with respect to transaction-intensive services, such as checking and savings accounts, currency exchange and credit application accounts.

\subsubsection{Sampling and Surveying ${ }^{\prime}$}

Data was collected through self-report questionnaires from individual employees organized in SMTs and from their customers. Mail questionnaires were sent to employees as well as customers of 61 SMTs. For the employee survey, all members of

\footnotetext{
'In this Chapter we analyzed enployee survey data solely from $\mathrm{ru}$ and customer survey data from $\mathrm{Tz}$. In line with Chapter 3 the lagged relationships between SMT performance (i.e., adaptive and proactive recovery behavior) from $m$ and the consequences (recovery satisfaction, loyalty intentions, share of customer, service revenue) from 12 were analyzed.
} 
the SMT were invited to participate. In total 939 questionnaires were returned $(76.4 \%)$. For the customer survey, a random sample of 150 customers per SMT was drawn. In total, 1884 questionnaires were returned to the researchers by mail $(20.6 \%)$. For the employee survey, 809 questionnaires from 61 teams were used for further analysis. Regarding the customer survey, 1724 questionnaires of customers of the 61 service teams were employed for the analysis. Regarding the employee survey, the following sample profile emerges. Fifty-four percent of the employees are younger than 31 years. With respect to education, a large part of respondents are high school graduates $(45.5 \%)$ and/or has completed tertiary education $(30.8 \%)$. With respect to tenure, most respondents have been with the institution for a relatively long period $(55.9 \%>4$ years). For the customer survey, the following sample profile was acquired. Most respondents were male $(63.8 \%)$ and older than 44 years $(59.2 \%)$. The great majority of the respondents had a long-lasting relationship with the bank $(93.5 \%>5$ years) and about half of them visited the bank at least once a month $(46.5 \%)$.

\subsubsection{Measurement Issues}

All scale items of the employee survey were measured with a 7-point scale, ranging from 'strongly disagree' (1) to 'strongly agree' (7) and were developed mainly on the basis of validated scales. The assessment of adaptive recovery behavior was based on a 16-item adaptive selling scale developed by Spiro and Weitz (1990). To measure adaptive recovery behavior, we modified this scale by dropping redundant items and rewording the remaining items to emphasize team and service recovery aspects. The final 6-item scale assesses team members' ability to adapt to diversified service recovery situations by altering their approach towards customers. Proactive recovery behavior largely consisted of items from an instrument developed by Hyatt and Ruddy (1997). The tolerance-scale was largely derived from an instrument developed by Cook et al. (1981). The operationalization of organizational support was based on the customer feedback scale developed by Schneider et al. (1998). More specifically, we reworded scale items to assess upper-level management's (1) solicitation and use of customer reactions regarding service quality and (2) provision of customer complaint information to the service team. Inter-team and intra-team support were measured using items adapted from scales developed by Campion et al. (1993).

We used two different techniques to examine the factor structure and item loadings. To begin with, we examined coefficient alphas, and the factor structure (through principal component analysis) for all the scale items simultaneously. A sixfactor structure was attained with items loading on the assumed dimensions. Next, we applied confirmatory factor analysis (CFA) employing LISREL (Jöreskog and Sörbom 1993) to determine the major measurement characteristics of the scales. The fit indices of the proposed factor model, construct reliabilities of the scales and confirmatory factor loadings with t-values for each item are represented in Table 4-1. The indices of the proposed factor model yielded a good fit $(\mathrm{GFI}=0.91 \mathrm{AGFI}=0.90 ; \mathrm{RMSEA}=$ $0.047 ; \mathrm{NFI}=0.91 ; \mathrm{CFI}=0.94$ ) revealing unidimensionality of the scales (Steenkamp and Van Trijp 1991). In addition, all measures had Cronbach's alphas of .71 or higher, indicating that the reliability of all constructs was acceptable (Nunnally and Bernstein 1994). 
Next, we investigated the significance and magnitude of the item loadings to test within-method convergent validity. All items loaded significantly on their respective construct (minimum t-value $=13.50$ ) and had a standardized loading of at least 0.47 . Furthermore, a procedure was followed to evaluate discriminant validity by testing whether pairs of constructs were correlated less than 1. Chi-square difference tests with $1 \mathrm{df}$ were used to test for unity between pairs of constructs. All tests were significant at the 05 significance level (c.f., Anderson and Gerbing 1988).

Table 4-1: Measures and Validation

\begin{tabular}{|c|c|c|}
\hline Measwies & $\begin{array}{l}\text { factor } \\
\text { loading }\end{array}$ & value \\
\hline \multicolumn{3}{|l|}{ Employee data } \\
\hline \multirow{2}{*}{\multicolumn{3}{|c|}{$\begin{array}{l}\text { Fit indices: }(\mathrm{GFI}=.91 ; \mathrm{AGFI}=0.90 \mathrm{RMSEA}=.047 ; \mathrm{NFI}=.9 \mathrm{CH} ; \mathrm{CFI}=.94) \\
\text { Tolerance-of-self-management }(\mathrm{n}=6 ; \alpha=.89)\end{array}$}} \\
\hline & & \\
\hline 1. In our team we are permitted to use our own judgment in solving problems. & 72 & 25.69 \\
\hline 2.In our team we are encouraged to take initiative. & .65 & 22.33 \\
\hline 3.Our leam is allowed a high degree of initiative. & .81 & 30.65 \\
\hline 4.In our team we are allowed complete freedom in our work. & .85 & 32.61 \\
\hline 5 In our team we are allowed to do our work the way we think best. & .75 & 27.21 \\
\hline 6 As a team we are able to handle all tasks assigned to us ourselves. & .72 & 25.70 \\
\hline \multicolumn{3}{|l|}{ Organixational support $(n=5 ; \alpha=.85)$} \\
\hline $\begin{array}{l}\text { I. In our bank external customer complaints are used to evaluate the quality of the } \\
\text { delivered services. }\end{array}$ & .72 & 25.59 \\
\hline $\begin{array}{l}\text { 2. Our bank informs our team about customer evaluations of service recovery } \\
\text { delivered by our team. }\end{array}$ & .75 & 26.71 \\
\hline $\begin{array}{l}\text { 3.Our bank regularly asks our team to report possible customer complaints about } \\
\text { the service delivered by our team. }\end{array}$ & .72 & 25.25 \\
\hline $\begin{array}{l}\text { 4. Following customer reactions, our bank continuously adjusts the service delivery } \\
\text { process. }\end{array}$ & .79 & 28.67 \\
\hline 5.Management of our bank seriously considers customer reactions. & .64 & 21.61 \\
\hline \multicolumn{3}{|l|}{ Inter-team support $(n=7 ; \alpha=84)$ (one-reversed item) } \\
\hline 1.Other teams act in a responsive manner when we forward customer co & .58 & 19.30 \\
\hline 2.The knowledge of the other teams assists us in serving customers. & .58 & 19.33 \\
\hline 3.The quality of service dellivered by other teams to our team is good. & .75 & 27.21 \\
\hline $\begin{array}{l}\text { 4. Because of insufficient feedback from other teams our service to customers is } \\
\text { substandard (reversed item) }\end{array}$ & .53 & 17.46 \\
\hline 5.Other teams provide good feedback on how to serwe customers. & .53 & 17.44 \\
\hline 6.The cooperation between teams is good. & .84 & 32.02 \\
\hline 7.The employees of the other teams are help ful i & .75 & 26.90 \\
\hline
\end{tabular}

Note: all $t$-values are significant at $p<.05$. 


\section{Table 4-1: Measures and Validation (Continued)}

Measures

factor

t-

Employee data (continued)

loading value

Intra-team support $(n=4 ; a=.71)$

I.In our team we help each other in serving the customer.

.66

2.The mutual support of team members is highly valued.

.8427 .53

3.Each team member is personally responsible for the assistance of other members in serving the customer.

4. In our team members need not formally be monitored with regard to the assistance of colleagues.

Adaptive recovery behavior $(n=6 ; \alpha=.87)$

1. When we feel that one service recovery effort is not working, we can easily change to another.

2.In our tean we feel that each unhappy customer requires a unique approach.

3.Our team is very sensitive to the needs of our customers.

4.In our team our service style may vary from recovery situation to recovery situation.

5.In our team we try to understand how one customer differs from another in service recovery expectations.

6.In our team it is easy to modify our service approach if the situation calls for it.

\section{Proactive recovery behavior $(\mathrm{n}=6 ; \alpha=.89)$}

1.In our team we actively seek out areas for continuous improvement of our service recovery.

2.In our team we continuously revise service recovery processes.

3.In our team we seek alternative solutions to service recovery problems.

4.In our team we seek innovative solutions to service recovery problems.

5.In our team we address service recovery issues before they become major problems.

6.In our team we are constantly on the lookout for improving our service recovery effort.

\section{Customer data}

Recovery Satisfaction $(\mathrm{n}=1)$

1. How satisfied are you with the way your complaints are processed by the employees?

\section{Loyalty intemtions $(n=3 ; \alpha=.85)$}

1.I consider the XXX bank to be my first choice for all financial services that 1 need.

2.If I want to open a savings account or to get a loan in the future, I probably do it at the XXX bank.

3.About 5 years II expect that II still consider the XXX bank to be my most important bank.

\section{Share of Customer}

Averaged customer usage rates (\%) of the different services offered:

\begin{tabular}{l|l}
\multicolumn{1}{c|}{ Non-routine services } & \multicolumn{1}{c}{ Routine services } \\
\hline Mortgages, Loans $(53.6 \%)$ & Checking account $(95.2 \%)$ \\
Investment funds $(52.7 \%)$ & Savings account $(79.1 \%)$ \\
Stocks $(43.9 \%)$ & Electronic banking/Telebanking $(30.3 \%)$ \\
Insurances $(46.5 \%)$ & Currency exchange $(20.1 \%)$ \\
& Credit application accounts $(44.9 \%)$ \\
& Travel services $(18.7 \%)$ \\
\hline
\end{tabular}


Subsequently, the demographic variables education, organizational tenure, age, and the group design variables "team size", "percentage of front office workers', 'nonroutine services' served as control variables when testing the hypotheses. More specifically, 'percentage of front office workers' concerns the employees of the tean who predominantly perform customer-contact tasks, while "non-routine services" involves a dummy indicating the type of service setting the team operates in (routine services (e.g., managing checking or savings accounts) were coded as 0 and nonroutine services (e.g., investment counseling or personal estate planning) were coded as 1).

By means of a customer survey we assessed recovery satisfaction, loyalty intentions, and share of customer. Service recovery satisfaction was assessed by a 5 . point single-item scale ranging from 'strongly dissatisfied' (1) to 'strongly satisfied' (5). We employed a single-item scale, as it has been argued that the use of multipleitem satisfaction scales may be disadvantageous to respondent behavior and decrease respondent reliability in service research (Drolet and Morrison 2001). The measurement of loyalty intentions was based on items derived from the behavioral intentions battery of Zeithaml et al. (1996) and involved a 5-point scale, ranging from 'strongly disagree' (1) to 'strongly agree' (5). Principal component analysis showed construct validity (one factor was extracted with factor loadings for all items $\geq 0.87$ ). In addition, Cronbach's alpha was .85 , providing clear evidence of construct reliability. Secondly, customers were asked to indicate the different services they actually purchase in order to assess 'share of customer' (this parameter reflects the average number of different services purchased per customer). An overview of the bank services offered in non-routine and routine settings is presented in Table 4-1. Finally, the parameter 'service revenues' was taken from the bank's internal database and reflects the work group's annual service revenues.

The assessment of the linkage between adaptive and proactive recovery behavior and their consequences involves aggregating team member perceptions as well as customer perceptions to the group level. This preference for the group as unit of analysis is based on previous studies (Allen and Grisaffe 2001; Meyer and Allen 1997). It has been argued that aggregate-level assessments of customer evaluations are needed, as customers observe the integral outcome of interpersonal working relationships among multiple employees (Allen and Grisaffe 2001). Furthermore, the outgroup-homogeneity theory has postulated that people consider other groups as more uniform than their own group (Quattrone and Jones 1980). This suggest that individual employees may have relatively differentiated opinions regarding their own team's performance, since they have a detailed picture of the work practice within their team, while external customers are likely to consider the quality of service offered by one or multiple team members as a characteristic that inherently applies to the whole homogeneous 'out-group' of employees. Furthermore, it is not possible to realize linkages between employee and customer parameters and productivity criteria at the 


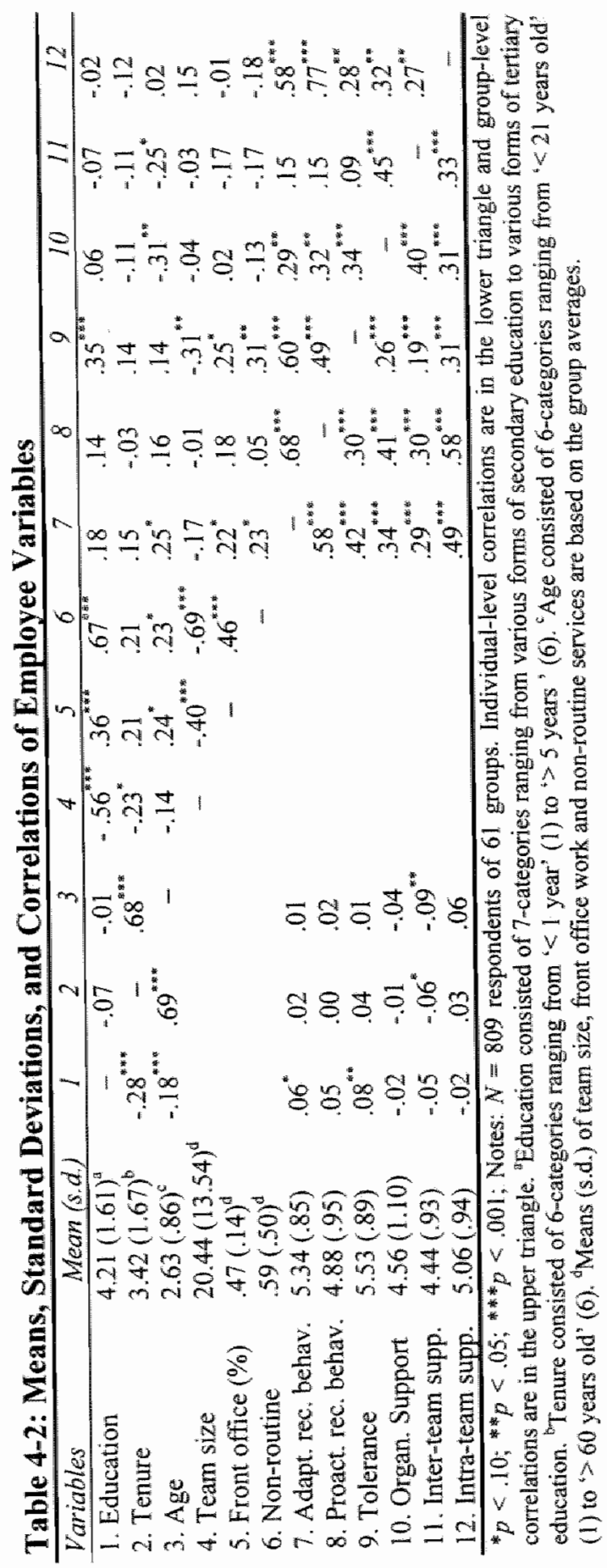




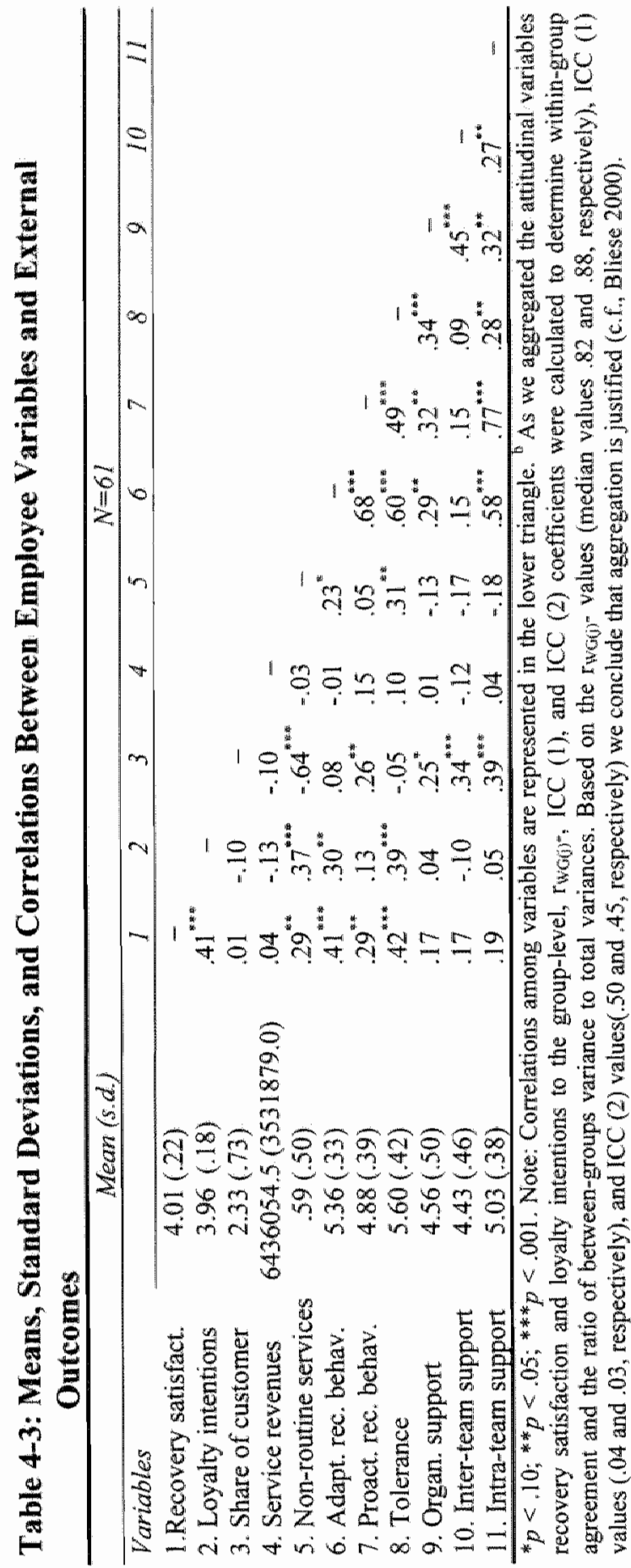


individual level of analysis (Bryk and Raudenbush 1992). Therefore, individual employee scores on the one hand, and individual customer scores on the other hand, were aggregated to the group level of analysis and the linkage between our focal construct and its consequences was tested using the team as unit of analysis. As such, we did not account for individual differences within groups and analyzed the linkage between adaptive and proactive recovery behavior and its consequences at the group level.

Means, standard deviations, and individual-level and group-level correlations between the employee variables are represented in Table 4-2. It appears that scores on organizational support and inter-team support are considerably lower compared to the other work environment variables.

It has been argued that corrections for individual-level measurement error should be made first, before comparing individual and aggregate-level correlations (Ostroff 1993a). Therefore, we calculated individual-level correlations between the antecedents and recovery outcomes after increasing the reliability (= Cronbach's alpha) to .85 for those constructs that had lower reliabilities. Overall, the results indicate some increase of the individual-level correlations, but do not imply substantial changes in the magnitude differences between individual-level and group-level correlations (Nunnally and Bernstein 1994). Additionally, in Table 4-3, group-level means, standard deviations and correlations of the employee variables and external outcome variables are represented.

\subsubsection{Data Analysis}

In order to compare between-groups and within-group coefficients, the four antecedent variables were split into the group mean and the within-group deviation score (individual score minus the group mean) ${ }^{2}$. The coefficient of the group mean concerns the between-groups coefficient, whereas the coefficient of the within-group deviation scores stands for the within-group coefficient (Bryk and Raudenbush 1992; Snijders and Bosker 1999).

In Table 4-4, the average $r_{W G(i)}$-coeflicients and average ICC (intra-class correlation) coefficients are reported to examine adaptive recovery behavior, proactive recovery behavior, tolerance, organizational support, inter-team support, and intrateam support on within-group agreement and on the ratio of between-groups variance to total variance. The $r_{W G(j)}$-coefficients (ranging from .83 to .96) are high for all variables and show consistency in ratings among employees within groups (James et al. 1993). Next, the ICC (1) coefficients (ranging from .07 to .18) indicate that for all variables, a moderate to considerable part concerns between-groups variance. To accurately determine the effect of interdependence, it is of importance to consider the group size. Therefore, we calculated ICC (2) coefficients that are also a function of group size. All ICC (2) values are $\geq .50$, providing evidence for reliable group means,

\footnotetext{
Within-group deviation is similar to group-mean centering. In all analyses, individual-level variables were group-mean centered and group-level variables were grand-mean centered to (1) distinguish between withingroup and between-groups variance, (2) to reduce multicollinearity and (3) to facilitate model estimation (cf. Bryk and Rauderbush 1992).
} 
which permits the detection of aggregate-level relationships even in the case of quite small ICC (1) values (Bliese 2000).

Table 4-4: Justification for Aggregation Measures

\begin{tabular}{|c|c|c|c|}
\hline 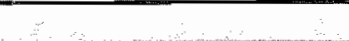 & $r_{W G \text { Gll }}$-coefficient & ICC (1) coefficient ${ }^{\text {al }}$ & ICC (2) coefficient ${ }^{2}$ \\
\hline \multicolumn{4}{|l|}{ Variable } \\
\hline Adaptive recow behavior & .92 & .08 & .54 \\
\hline Proactive recov, behavior & .94 & .09 & .57 \\
\hline Tolerance & .96 & .16 & .72 \\
\hline Organizational support & .84 & .15 & .70 \\
\hline Inter-team suppoit & .91 & .18 & .74 \\
\hline Intra-team support & .83 & .07 & .50 \\
\hline
\end{tabular}

"ICC (1) coefficients and $1 \mathrm{CC}$ (2) coefficients are corrected for measurement error, which is defined as [1 - a] (cf. Van Yperer and Snijders 2000).

Additionally, the hypotheses $\mathrm{H}_{1-6}$ were tested through a multivariate hierarchical linear model regression model using MLwiN software (Rasbash et al. 2000). Three hierarchical levels are specified. Level 1 refers to the dependent variables indexed by $h$ $=1, \ldots, m$, level 2 reflects the individual employees $i=1, \ldots, n_{j}$, and level 3 involves the teams $j=1, \ldots, N$. As such, each assessment of a given outcome variable on a certain team is indicated by a specific line in the data matrix, containing the values $i, j, h, Y_{h i j}$, $x_{1 / j}$, and all other predictors. To formulate the multivariate regression model as a hierarchical linear model, dummy variables $d_{1}$ to $d_{m}$ are used to indicate the outcome variables (i.e., adaptive recovery behavior, proactive recovery behavior). The dummy $d_{t}$ is 1 or 0 , depending on whether the data line refers to outcome variable $Y_{h}$ or to another outcome variable. This principle is expressed by the following equation:

$$
d_{s h j j}= \begin{cases}1 & h=s, \\ 0 & h \neq s .\end{cases}
$$

By means of these dummies, the regression equations for the $m$ outcome variables can be integrated into one three-level hierarchical model by the next expression:

$$
Y_{h i j}=\sum_{s=1}^{m i n} \gamma_{0 s} d_{s s h i j}+\sum_{k=1}^{m} \sum_{s=1}^{m p} \gamma_{k i s} d_{s i h j} x_{k i j}+\sum_{s=1}^{m} u_{s i j} d_{s h i j}+\sum_{s=1}^{m} e_{s i j j} d_{s h i j} .
$$

All variables (including the constant) are multiplied by the dummy variables. With respect to the dummy variables, in the sums over $s=1, \ldots, m$, only the term $s=h$ renders a contribution, while all other terms are removed. For concreteness, we also represent the following regression equation, which is a simplified reformulation of equation 2 :

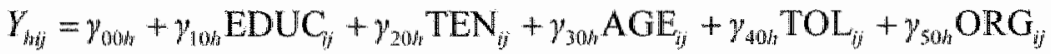

$$
\begin{aligned}
& +\gamma_{60 h} \mathrm{INTER}_{i j}+\gamma_{70 h} \mathrm{INTRA}_{i j}+\gamma_{01 k} \mathrm{EDUC}_{j}+\gamma_{02 h} \mathrm{TEN}_{j}+\gamma_{03 h} \mathrm{AGE}_{j}+\gamma_{04 h t} \mathrm{SIZE}_{j} \\
& +\gamma_{05 h} \mathrm{FRONT}_{j}+\gamma_{06, h} \mathrm{NROUT}_{j}+\gamma_{07 h} \mathrm{TOL}_{j}+\gamma_{08 h} \mathrm{ORG}_{j}+\gamma_{09 h} \mathrm{INTER}_{j}+\gamma_{010 h} \mathrm{INTRA}_{j} \\
& +u_{0 h j}+u_{1 k j}+u_{2 h j}+u_{3, j}+u_{4 h j}+e_{h i j i} \text {, }
\end{aligned}
$$


where $Y_{h i j}$ is the measurement on the $h^{2}$ th variable for individual $i$ of group $f$; EDUC, TEN, and AGE, refer to the employee"s education, tenure, and age, respectively; SIZE, FRONT, and NROUT are the size of the team, the percentage of front office workers in the team, and the type of service setting the team operates in, respectively; TOL, ORG, INTER, and INTRA are tolerance, organizational support, inter-team support, and intra-team support, respectively.

First the individual-level and group-level relationships between the outcome variables were specified (step 1). Secondly, the control variables were included in the model (step 2). Thirdly, the within-group deviation scores of the four antecedent variables were added to the model (step 3). Finally, the group means of these antecedent variables were incorporated (step 4). Multi-level models concern contextual models that may be sensitive to multi-collinearity. Therefore, ordinary regression analyses were performed to investigate multi-collinearity by means of the Variance Inflation Factor (VIF). The VIFs of the control variables and the predictor variables are lower than 3.7 and 1.8 , respectively indicating the absence of severe multi-collinearity (Kleinbaum et al. 1988). Table 4-5 provides the results of the multi-level analyses.

Specifying bivariate relations between adaptive and proactive recovery behavior leads to a significant increase in model fit (step 1), indicating significant linkages between both outcomes. In relation to the control variables, our findings showed a positive effect of type of service setting on adaptive recovery behavior. Furthermore, there occurs a significant positive group-level effect of age, which appears significantly stronger in magnitude relative to the individual-level effect of age. Finally, significant positive effects of the variables team size and percentage of front office workers on proactive recovery behavior were found.

In testing hypotheses, our findings revealed significant positive individual-level effects of tolerance on adaptive and proactive recovery behavior, which means that $H_{1 \mathrm{a}}$ and $\mathrm{H}_{1 b}$ are supported. Organizational support appears to be significantly positively related to both adaptive and proactive recovery behavior at the individual level. Thus, $\mathrm{H}_{2 \mathrm{at}}$ and $\mathrm{H}_{2 \mathrm{~b}}$ are supported. Positive effects of within-group deviation coefficients of inter-team support on both adaptive and proactive recovery behavior were found, which yields support for $\mathrm{H}_{3 \mathrm{a}}$ and $\mathrm{H}_{3 \mathrm{~b}}$. Subsequently, the significant positive effects of intra-team support on both types of recovery behavior indicate support for $\mathrm{H}_{4 i}$ and $\mathrm{H}_{4 \mathrm{~h}}$. With regard to the cross-level hypotheses, we find that for intra-team support only the magnitudes of the between-groups coefficients are significantly greater compared to within-group ones. This means that $\mathrm{H}_{5 \mathrm{a},} \mathrm{H}_{5 \mathrm{~b}}, \mathrm{H}_{5 \mathrm{c}}, \mathrm{H}_{6 \mathrm{as}} \mathrm{H}_{6 \mathrm{~b}}$ and $\mathrm{H}_{6 \mathrm{c}}$ are rejected and that $\mathrm{H}_{5 \mathrm{~d}}$ and $\mathrm{H}_{6 \mathrm{~d}}$ are supported. Finally, the percentage of explained group-level variance is higher compared to individual-level variance for adaptive as well as proactive recovery behavior. This signifies that the antecedents explain between-groups differences better than within-group differences of both dependent variables. 


\section{Table 4-5: Multi-level Analysis of Antecedent-Service Recovery Performance Relationships}

\begin{tabular}{|c|c|c|c|c|}
\hline \multirow{3}{*}{ Dependent variables } & \multicolumn{4}{|c|}{ Antecedent-model } \\
\hline & \multicolumn{2}{|c|}{ Adaptive recovery behavior $(h=1)$} & \multicolumn{2}{|c|}{ Proactive recovery behavior $(h=2)$} \\
\hline & $\begin{array}{l}\text { Coefficient } \\
(\text { SE })^{h}\end{array}$ & $\begin{array}{l}\Delta \text { Magnitude } \\
\text { coef }\end{array}$ & $\begin{array}{l}\text { Coefficient } \\
(\mathrm{SE})^{\mathrm{b}}\end{array}$ & $\begin{array}{l}\Delta \text { Magnitude } \\
\text { coef: }\end{array}$ \\
\hline Intercept & $.730(.945)$ & & $-1.384(.946)$ & \\
\hline Increase model fit' (step 1) & $x^{2}(2)=332.03$ & & & \\
\hline \multicolumn{5}{|c|}{ Control variables: level $2^{4}$} \\
\hline Education & $.025(.024)$ & & $.036(.026)$ & \\
\hline Tenure & $.016(.030)$ & & $.007(.032)$ & \\
\hline Age & $-.036(.057)$ & & $-.018(.060)$ & \\
\hline \multicolumn{5}{|c|}{ Control variables: level $3^{b}$} \\
\hline Education & $-.039(.085)$ & $-.075(.088)$ & $.039(.085)$ & $.013(.090)$ \\
\hline Tenure & $-.035(.108)$ & $-.054(.113)$ & $-.155(.108)$ & $-.160(.114)$ \\
\hline Age & $.293(.210)$ & $.325(.218)$ & $.372(.209)^{*}$ & $.401(.219)^{*}$ \\
\hline Team size & $.001(.004)$ & & $.007(.004)^{*}$ & \\
\hline Front office $(\%)$ & $-.296(.276)$ & & $.521(.270)^{*}$ & \\
\hline Non-routine services & $.257(.141) *$ & & $.172(.141)$ & \\
\hline Increase model fit (step 2) & $x^{2}(18)=18.56$ & & & \\
\hline \multicolumn{5}{|l|}{ Antecedents: level $2^{\text {oi }}$} \\
\hline Tolerance & $.223(.042)^{2}$ & & $.072(.034)^{*}$ & \\
\hline Organ. support & $.124(.026)^{* *}$ & & $.220(.03 .4)^{* * *}$ & \\
\hline Inter-team support & $.095(.033)^{* *}$ & & $.075(.037)^{*}$ & \\
\hline Intra-team support & $.282(.030)^{* *}$ & & $.436(.032)^{* *}$ & \\
\hline Increase model fit (step 3) & $x^{3}(16)=499.95^{*}$ & & & \\
\hline \multicolumn{5}{|l|}{ Antecedents: level $3^{\text {at }}$} \\
\hline Tolerance & $.296(.082)^{*}$ & $.064(.088)$ & $.201(.081)^{* * *}$ & $.119(.089)$ \\
\hline Organ. support & $.085(.069)$ & $-.048(.073)$ & $.084(.068)$ & $-.140(.074)^{*}$ \\
\hline Inter-team support & $-.027(.072)$ & $-.125(.079)$ & $-.036(.072)$ & $-.109(.080)$ \\
\hline Intra-team support & $.474(.089)^{*}$ & $.195(.094)^{*}$ & $.715(.089)^{* * *}$ & $.283(.095)^{*}$ \\
\hline Increase model fit (step 4) & & & & \\
\hline \multirow{3}{*}{\multicolumn{2}{|c|}{$\begin{array}{l}\text { Residual Between-Groups Covariance Matrix } \\
\text { 1. Adaptive recov, behavior }\end{array}$}} & 1. & 2. & \\
\hline & & $.012(.014)$ & & \\
\hline & & $=001(.014)$ & $.004(.013)$ & \\
\hline \multicolumn{2}{|c|}{ Residual Within-Group Covariance Matrix ${ }^{3}$} & 1. & 2. & \\
\hline 1. Adaptive recov, behavior & & $.887(.047)$ & & \\
\hline 2. Proactive recov behavior & & $.344(.037)$ & $.993(.053)$ & ; \\
\hline Explained L-2 variance $(\%)$ & 36.8 & & 44.2 & \\
\hline Explained L-3 variance $(\%)$ & 60.4 & & 718 & \\
\hline
\end{tabular}

${ }_{p<}<.05 ; * 0<.01$. Note: significance of coefficients is based on one-tailed tests. "Unstandardized regression. coefficients. "Standard errors between parentheses. 'Increase in model fit when specifying individual-level and group-level relationships between the dependent variables. ${ }^{2} \operatorname{var}\left(u_{h j}\right)=\tau_{h h_{n}}$, and cov $\left(u_{h j \times}, u_{h y}\right)=\tau_{h h_{j}}$.

var $\left(e_{h y}\right)=\sigma_{h,}$, and $\operatorname{cov}\left(e_{h i j}, e_{h ; j}\right)=e_{h h}$

Next, we test the hypotheses $\mathrm{H}_{7-10}$ by estimating a multivariate two-level regression model. Level I refers to the dependent variables indicated as $h=1, \ldots, m$ and level 2 reflects the teams $j=1, \ldots, N$. Hence, each measurement of a dependent variable on some group is represented by a separate line in the data matrix, including the values, $j$, $h, Y_{h j}, x_{1 j}$, and those of the other explanatory variables. To formulate the multivariate regression model as a hierarchical linear model, dummy variables $d_{1}$ to $d_{m}$ are specified to indicate the dependent variables (i.e., recovery satisfaction, loyalty 
intentions, share of customer, service revemues). Dummy variable $d_{h}$ is 1 or 0 , depending on whether the data line refers to the dependent variable $Y_{*}$ or another dependent variable. By means of these dummies, the regression models for the $m$ dependent variables can be integrated into one two-level hierarchical model by the following equation:

$$
Y_{h j}=\sum_{s=1}^{m} y_{0 s} d_{s y j}+\sum_{k=1}^{p} \sum_{s=1}^{n z} y_{k s} d_{s h j} x_{k j}+\sum_{s=1}^{m} e_{s i j} d_{s h j i} .
$$

All variables (also the constant) are multiplied by the dummy variables. Note that the definition of the dummy variables implies that in the sums over $s=1, \ldots, m$ only the term for $s=h$ gives a contribution, while all other terms are removed. The next model equation involves a simplified version of equation 4 :

$$
Y_{h j}=\gamma_{0 h}+\gamma_{\| h} \mathrm{NROUT}_{j}+\gamma_{2 h} \mathrm{ADAP}_{j}+\gamma_{3 h} \mathrm{PRO}_{j}+e_{h j}
$$

where $Y_{h j}$ is the measurement on the $h$ 'th variable for group $j$; NROUT refers to the type of service setting the team works in; ADAP and PRO indicate the team's level of adaptive and proactive recovery behavior, respectively.

We used the following analysis strategy to test the hypotheses $\mathrm{H}_{7-10}$. First, the "non-routine' dummy was included (step 1). Secondly, the adaptive and proactive recovery behavior variables were added to the model (step 2). To account for multicollinearity we inspected the VIFs of the predictor variables, which all show VIF values below 2.1 indicating that there is no serious multi-collinearity. Our results are presented in Table 4-6 and show significant positive effects of adaptive recovery behavior on recovery satisfaction and loyalty intentions supporting $\mathrm{H}_{7 \mathrm{a}}$ and $\mathrm{H}_{7 \mathrm{~b}}$ respectively. In contrast, proactive recovery behavior is not significantly related to recovery satisfaction and loyalty intentions, which implies that $H_{8,}$ and $H_{8 b}$ are rejected. Next, there exist no significant linkages between adaptive recovery behavior and share of customer or service revenues. Thus, $H_{9 \mathrm{a}}$ and $\mathrm{H}_{9 \mathrm{~b}}$ have to be rejected. Additionally, proactive recovery behavior appears to have a positive effect on share of customer, while it is not significantly related to the service revenues, indicating support for $\mathrm{H}_{10 a}$, whereas $\mathrm{H}_{10 b}$ is rejected. Finally, there occur significant positive effects of non-routine services on recovery satisfaction and loyalty intentions, while the dummy is negatively related to share of customer. 


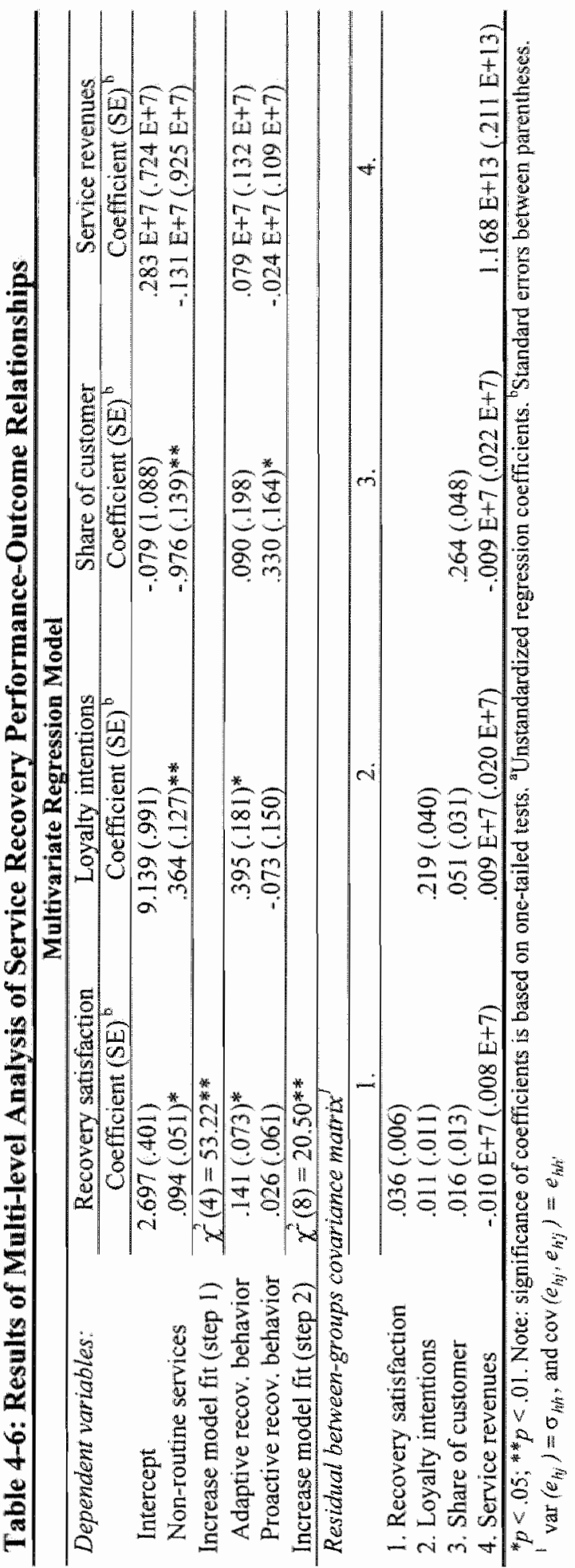




\subsection{Discussion}

The aim of this study was to extend our understanding of service recovery behavior by members of SMTs and to empirically assess the impact of antecedents and consequences of this behavior. Overall, the predictor-criterion relationships show remarkable consistency across the two types of service recovery behavior. Specifically, our results show positive individual-level effects of tolerance, organizational support, inter-team support, and intra-team support on both adaptive and proactive recovery behavior. At the group level, we find that intra-team support adds incremental value in explaining both types of behavior, which suggests that a distinction of between-groups factors and within-group deviation scores contributes to a more comprehensive understanding of the relationships between service recovery behaviors and its antecedents.

Specifically, we find that tolerance has a positive effect on both adaptive and proactive recovery behavior and that this effect essentially operates at the individual level. Employees who perceive a higher degree of autonomy in their work group experience more room for adaptability toward customer requests and task-related initiatives. Consequently, efforts to increase autonomy perceptions may best be directed at the individual employees. In addition, our results indicate a positive effect of organizational support on the two types of service recovery behavior. Since this effect is not significantly different at the group level of analysis, the implication is that organizational information and feedback with regard to customer complaints can be directed more efficiently at the individual level, taking into account, for instance, a team member's individual skill requirements. Similarly, inter-team support contributes positively to both adaptive and proactive recovery behavior. Again, the positive effect of inter-team support on both outcomes was exclusively based on the social comparison process within the team. Employees who, in comparison to their colleagues within the SMT, show a more enthusiastic view on the internal services from other teams are more likely to have positive perceptions of the adaptive and proactive behavioral recovery aspects of their SMT. These findings provide support for the contention that a supporting organizational context strengthens team members' extra-role efforts (Bansal et al. 2001; Peccei and Rosenthal 2001). Interestingly, positive relationships of intra-team support with both adaptive and proactive recovery behavior were encountered. These relationships do vary across levels; the group-level effects of intra team support are significantly greater relative to individual-level effects. These findings indicate that an employee' $s$ appraisal of the team's adaptive and proactive recovery behavior is partly based on his/her subjective perception and partly determined by the shared perceptions of his/her team colleagues. In line with earlier studies, team member informational exchanges prove to be the major driver of innovative service recovery behaviors (Morrison and Phelps 1999).

Only one of the included control variables, the dummy variable "non-routine services' is significantly positively related to adaptive recovery behavior. Non-routine services are associated with intensive, personalized employee-customer encounters, urgently requiring listening skills and empathy toward customers' viewpoints and opinions as prerequisites for employees to properly alter their service approach. A number of control variables are related to proactive recovery behavior. An explanation 
for the positive effect of group size may be that smaller groups are generally more subject to higher levels of group cohesion and more inclined to ignore and neglect existing problems running the risk of "group-think" (Moorhead et al. 1998). The positive group-mean effect of age on proactive recovery behavior suggests that over time employees become more experienced in identifying customer problems and possess better social skills in actively dealing with them. Finally, the positive effect of front office percentage on proactive recovery behavior indicates that groups with a higher number of front-line employees have higher rates for proactive recovery behavior. This may be attributed to the fact that front-office employees, as opposed to back-office employees, are directly faced with suggestions from customers to change or improve current service practice.

We also investigated the effects of adaptive and proactive recovery behavior on several service performance parameters. Generally, our findings show that an adaptive recovery approach has an effect on customer perceptions. Specifically, it appears that a higher degree of adaptive behavior leads to improvements in recovery satisfaction and loyalty intentions. Apparently, the adaptive, personalized and creative way in which front-line employees manage service problems is highly valued by customers and strengthens their repurchase intentions.

Instead of customer perceptions, the impact of proactive recovery behavior becomes apparent in relation to actual customer behavior, as it leads to higher share of customer rates. Higher levels of proactive servicing enhance the average number of different services sold per customer. In highly proactive teams employees initiate more efforts to employ extra resources to deliver additional services. In contrast, proactive recovery behavior is not related to service revenues. This may be attributed to the differential nature of these measures. The share of customer criterion typically concerns a customer behavorial measure, which rationale concerns maximization of the relationship with each individual customer. Conversely, traditional productivity measures do not take such a customer relationship perspective, focusing primarily on input-output convergence. These diverging results confirm that there exists a paradox between customer-based and productivity based performance measures in services. Anderson et al. (1997) contend that trade-offs between different performance parameters are more probable in services and emphasize the necessity to set off customer parameters against productivity parameters in order to create an optimal balance.

\subsection{Limitations and Theoretical Implications}

Our findings have a number of implications for theory development and future research. To begin with, our findings indicate that, while adaptive and proactive recovery behaviors share the same fundamentals, their effects on external marketing outcomes clearly diverge. The differential influences of adaptive and proactive recovery behavior suggest the relevance to discern distinctive components of service recovery performance when investigating internal and external marketing performance linkages in future marketing research. To allow for generalizations of the differential consequences of adaptive versus proactive recovery behaviors, additional comparative 
research on these extra-role servicing behaviors is required in other services sectors (e.g., tourist industry, restaurant industry, automobile industry).

In testing the relationships between antecedents and adaptive and proactive recovery behaviors, different levels of analysis were considered. Employee scores were aggregated at the group level to compare consistency of relationships across levels. An essential limitation, however, concerns common method variance, which may have biased the relationships that were estimated between both outcome variables and its antecedents. For future research, we recommend the use of various independent data sources.

Additionally, our results reveal that most antecedent-performance relationships are consistent across levels of analysis. However, there are significant magnitude differences between group-level and individual-level effects in relation to intra-team support. Additional research is required to address the rationale behind these levels-ofanalysis differences. Although recent multi-level theory and research has been increasingly applied and a number of studies empirically address levels-of-analysis comparisons, theory-grounded hypotheses still need further development (De Jonge et al. 1999; Ostroff et al. 2002; Ostroff and Harrison 1999; Van Yperen and Snijders 2000).

\subsection{Managerial Implications}

Our findings also have a number of managerial implications. First, the differential impact of adaptive and proactive recovery behaviors on external performance parameters suggests that managers need to consider adaptability and proactivity as complementary, but distinctive components of service recovery performance. Accordingly, in developing selection criteria and training programs, recovery should be incorporated and a clear distinction should be made between adaptive recovery behaviors, such as listening skills and problem analysis protocols, and proactive behaviors, such as taking initiative to change failure-prone service routines. One effective way to train employees in both types of behaviors is to develop training scenarios that expose employees to simulated real-life situations that require adaptive or proactive performance. The instruments used in our research provide a framework for diagnosing and defining what types of behavior are required in the field of service recovery.

Second, management should demonstrate its involvement with desirable employee attitudes and behavior in relation to service recovery and clearly delineate the amount of delegated managerial responsibilities. When implemented in an appropriate manner, self-management may serve to decrease the experience of "organizational helplessness" and role stress. Management must communicate the message that SMTs may be confronted with difficult service recovery problems for which they may not be directly responsible, but still may be held accountable by the customer. This requires operational improvements as well as perception management. By showing empathy and support, by improving information and feedback procedures about customer complaints and evaluations, management may increase employees' self-confidence and sense of control and to stimulate SMTs to deal adaptively and 
proactively with service recovery. For example, the implementation of shared databases to achieve an updated registration of essential customer and product information, service failure incidents, and employees' recovery actions may be an effective strategy to sustain employees' recovery efforts. Internal service policies aimed at a service-oriented attitude are also crucial to improve cooperation among employees within and between tearns. The relevance of such a pro-social attitude could be emphasized in monthly organizational meetings, recognition programs and success cases, as well as selection procedures, for instance, by employing tests for applicants" service-oriented value orientation and interpersonal skills.

Third, management action may be taken to encourage helping behavior within the team. Given the group-level impact of intra-team support, team-level interventions may be effective in creating a shared sense of support within the team and to acquire overall knowledge bout problems that occur throughout the entire service delivery system. Such interventions include group trainings intended to improve interpersonal process among team members such as communication, coordination, cooperation, as well as to learn how to properly diagnose occurring service recovery problems and to develop recovery skills. Furthermore, the introduction of shared databases may also improve the internal communication process, whereas discussion meetings on new policies and procedures may contribute to a shared understanding of the team's internal affairs. Furthermore, the implementation of team-based rewards systems could also be considered as a means to encourage supportive behaviors among team members within the SMT.

Finally, the diverging impact of adaptive and proactive recovery behaviors on external performance parameters confirm that excellence in service recovery requires different recovery skills that complement each other. Furthermore, the absence of any relationship of adaptive and proactive service recovery skills with service revenues suggests that exclusively aiming at customer service-oriented recovery skills might lead to a one-sided attention of customer-based parameters, which goes at the expense of the SMT's productivity. This implies that companies need to balance between customer-based and productivity goals in developing their service recovery strategy. Besides extra-role recovery efforts intended to resolve diversified customer requests adequately, it is also relevant to keep an eye on low-cost and efficiency-based recovery procedures. To save time and labor costs it may be worthwhile to employ standard recovery modes in relation to customer complaints that are comparatively routine and uncomplicated in nature. Since IT-based service delivery combines a customized service approach with the advantages of standardization, the implementation of ITbased recovery procedures should be considered as a valuable alternative. All in all, managers should recognize that effective service recovery requires differential behavioral skills and that it is important to take into account the impact of interpersonal processes. 


\section{Chapter 5}

\section{Antecedents and Consequences of the}

\section{Adoption-Level of Information \\ Technology in Self-Managing}

\section{Service Teams}

Drawing from the literature in organizational behavior, services marketing, and information systems, this article examines antecedents and consequences of the adoption-level of standardized information technology (TT) versus customized IT in self-managing service teams (SMTs) in a financial services institution. Linkages between specified antecedents and the adoption-levels of standardized and customized IT were investigated using data collected from bank employees and in-company databases. The hierarchically nested data-structure (i.e, employees nested within groups) allows a multi-level analysis of the linkage between antecedents and IT adoption. First, we find positive individual-level effects of tolerance-of-selfmanagement, ease-of-use and innovativeness on the adoption-level of standardized IT and positive individual-level effects of tolerance-of-self-management and perceived usefulness on the adoption-level of customized IT. Next, our findings demonstrate that group-level usefulness explains a significant amount of additional variance in the adoption-level of standardized IT, while a significant incremental group-level effect of risk aversion was found on the adoption-level of customized IT. These differential findings for IT types suggest that discriminating between different types of IT creates a better understanding of IT adoption in SMTs. Finally, a similar investigation of the II adoption-service performance relationships shows that the adoption-level of customized IT rather than of standardized IT has a crucial impact on service performance both in terms of efficiency and effectiveness. 


\subsection{Introduction}

The adoption of information technology (IT) across many service industries is rapidly changing the nature of the service delivery process, necessitating employees and encouraging customers to interact with technology, either as a substitute or complement to face-to-face interactions (Parasuraman 2000). It has been argued that the use of IT enthances the performance of service employees, both in terms of efficiency and effectiveness, by enabling customization and flexibility in their encounters with customers (Bitner et al. 2000). Thus far, the focus in the emerging body of (self-) service technology research has been on the technology-customer linkage (Dabholkar and Bagozzi 2002; Meuter et al. 2000), while the technologyemployee interface has primarily aimed at internal operations, as opposed to front-line support technologies in boundary-spanning processes (Parasuraman and Grewal 2000). Despite the wide-scale implementation of IT in services, there has been little researchbased guidance regarding critical success factors in adoption and customer-contact employee usage, as well as the impact on service performance parameters. From the information systems literature (e.g., Davis et al. 1989; DeLone and McLean 1992), and from research on the customer-technology interface, there is accumulating empirical evidence that both personal (e.g., innovativeness) and IT (e.g., perceived ease-of-use) characteristics may explain individual adoption variance.

However, it has also been argued that adoption of IT by boundary spanners may also depend on the way in which the organization is structured (Ives and Olson 1984; Leonard-Barton and Deschamps 1988; Lucas 1978). While IT has been viewed as an enabler for contact employees to customize their service delivery, it has also been argued that this is highly contingent on "the use of flexible processes and organizational structures" (Hart 1996, p. 13). Rathnam et al. (1995) argue that, while IT implementation has significantly decreased time, space and information distances by facilitating the coordination of the total service delivery process, contact employees also require the authority and autonomy to deal effectively with sophisticated technological tools in their encounters with customers (Parasuraman 2000). If, for instance, IT leads to more efficient service recovery actions of contact personnel by equipping them with sufficient information, the use of technology will be contingent on the empowerment to act in accordance with this information (Bitner et al. 2000). An increasing number of service firms (e.g., Eastman Chemical Company, Xerox, and Sun Microsystems), therefore, have complemented the IT infusion of service delivery with the introduction of self-managing teams (SMTs). Delegating the collective responsibility for service delivery to SMTs may be an important condition for enhancing the degree of adoption of IT by employees, in addition to personal and IT characteristics. The general objective of this chapter is to empirically assess this assumption.

Our chapter has a multi-disciplinary focus, as it integrates the literature on services management, IT adoption, and organizational behavior and is structured as follows. First, we discuss the role of IT adoption in SMTs with regard to service performance and develop a conceptual model that identifies individual-level and aggregate-level antecedents and consequences of the adoption-level IT. Next, we empirically examine whether IT adoption-level is an important differentiating factor 
between SMTs with respect to key performance indicators in a financial services setting. Furthermore, we test multi-level regression models to determine which antecedents affect IT adoption by SMTs. We conclude the chapter by discussing our findings as well as their theoretical and managerial implications.

\subsection{Adoption-Level of IT in Services}

The concept of IT adoption or acceptance has long been regarded as a dichotomous variable in studies on the adoption of innovations (Westphal et al. 1997). In an attempt to capture more accurately the considerable variation in IT adoption by employees more differentiated criteria of user adoption, such as, "frequency of times the technology system is used', or 'the number of different technology system applications used' have been developed to measure the individual's level of adoption rather than individual's choice to adopt IT or not (Davis 1989; Schillewaert et al. 2000). Instead of considering these indicators simultaneously, various studies base their conceptualization of adoption on single indicators (Schillewaert et al. 2000), and/or do not distinguish between different types of use. Discriminating different types of use is, however, crucial to measure adequately the current IT adoption practice characteristic of boundary-spanning service teams. This IT adoption process is complex, because it involves both front- and back-office activities. More specilically, boundary-spanning service technologies are intended (1) to enhance the efficiency and effectiveness of employee-customer encounters, but also (2) to facilitate the coordination among employees within and between teams. Second, while in hierarchically structured organizations innovations are usually implemented by top-management (LeonardBarton and Deschamps 1988) or by IT-specialists (Janz et al. 1997), nowadays this innovation authority has been delegated to a relatively large degree to SMTs in many service organizations (Morrison et al. 2000). Consequently, these firms are facing a dispersed IT practice in which standardized (i.e., company-wide) as well as customized IT (i.e., team-specific) applications have been implemented.

Several studies in the services marketing literature have addressed customization versus standardization of services with respect to major service characteristics such as diversity of customer demand, degree of customer participation, and intensity of employee-customer contact (e.g., Larsson and Bowen 1989; Verma 2000). The customization of service technology is inherently implied in the definition of service customization. For the aim of this study, it is important to make a distinction between standardized and customized applications of service supporting technology. On the one hand, the use of centralized company-wide standard IT applications facilitates economies of scale and the coordination of the total service delivery process leading to significant decreases in time, space, and information distances (Rathnam et al. 1995; DeSanctis and Jackson 1994). On the other hand, customer service requirements, standards, and procedures vary substantially across services types and customers. This means that service providers must also adopt additional servicesupporting technology to optimally fit individual customer requirements (Mulligan 1999). SMTs may use their authority and budgets to adopt additional technological tools to improve their performance in their encounters with customers (Janz et al. 
1997). The very characteristics of services urge contact employees to use complementary technology to deliver service that better meet the needs and demands of their customers. The adoption of customized technologies may play a crucial role in the ability of companies to adjust adequately their services to customer's diversified requests and is, therefore, considered as a crucial competitive edge (Karimi et al. 2001). Hence, there seems to be a rationale for making a distinction between the adoption of standardized versus customized IT in relation to SMTs in service organizations.

\subsection{Adoption-Level of IT and Service Performance}

Technology support in service delivery is not an end but a means to enhance service performance by boundary spanning teams. In the marketing literature, service performance has recently been posited as a phenomenon consisting of two related but distinct aspects. On the one hand, it pertains to process-oriented, subjective measures that are often based on customer satisfaction and customer perceptions of quality. On the other hand, service performance involves objectively verifiable and quantifiable service outcomes, which often concern service productivity measures such as 'volume of services delivered'. Quinn (1996) argues that flexibility in the delivery of services is one "of the most important quality gains technology produces" (p. 74). Large amounts of information that could not be remembered, saved, or organized previously are now easily accessible for employees via high end IT (e.g., Customer Relationship Management (CRM) software). Through the use of IT firms are able to effectively provide mass-production services in a personalized way to meet diversified customer expectations. Harvey and Filiatrault (1991) demonstrate that IT adoption in the banking industry may speed up client queries and implement client requests and ultimately results in more favorable service quality evaluations. The use of centralized company-wide standard IT applications facilitates economies of scale and the coordination among employees within and across teams throughout the organization and enhance consistence in responding customer requests (DeSanctis and Jackson 1994; Mulligan 1999), while complementary customized IT applications enables team members to provide quicker, more detailed answers to customers" questions, resulting in better meeting customer expectations and higher productivity rates. Hence, we state that:

$H_{1}:$ SMTs with relatively higher adoption-levels of $\left(H_{10}\right)$ standardized IT and $\left(H_{l b}\right)$ customized IT perform significantly better in terms of customer satisfaction scores than SMTs with lower adoption-levels. $\mathrm{H}_{2}$ : SMTs with relatively higher adoption-levels of $\left(\mathrm{H}_{2 a}\right)$ standardized IT and $\left(H_{2 b}\right)$ customized IT perform significantly better in terms of productivity parameters than SMTS with lower adoption-levels.

It has been argued by Mulligan (1999) that combining different service tasks with differential IT competence increases company performance. He contends that the exclusive application of IT to highly standardized tasks makes all knowledge 
requirements redundant, while applying IT to tasks with limited standardization emphasizes the importance of content-based knowledge. As such a mid-continuum perspective has been advanced, which aims at know-how to accomplish automated routine tasks as well as IT aimed at content-based knowledge about specific service procedures to create competitive advantage (Davenport 1997). Furthermore, DeSanctis and Jackson (1994) emphasize the importance of a hybrid IT management approach, where some IT resources (e.g., telecommunications, shared customer databases, largescale computer operations) are managed company-wide, while other IT resources are managed locally (e.g., office computing and special applications development). Such hybrid forms of organizing IT seems to be a reasonable strategy for balancing between the advantages of standardized IT and customized IT. Hence, we hypothesize:

\begin{abstract}
$H_{3}: S M T s$ with relatively higher adoption-levels of both standardized and customized IT will perform significantly better in terms of customer satisfaction scores than SMTS that are characterized by relatively lower adoption-levels of one or both types of technology.

$H_{4}$ : SMTs with relatively higher adoption-levels of both standardized and customized IT will perform significantly better in terms of productivity parameters than SMTs that are characterized by relatively lower adoption-levels of one or both types of technology.
\end{abstract}

\title{
5.4 Antecedents of the Adoption-Level of IT in Self-Managing Service Teams
}

As IT adoption is expected to be a key driver of service performance, it seems relevant to investigate its determinants. Following previous work on technology use, three focal categories of antecedents can be distinguished. First of all, studies on technology adoption have identified characteristics of the organizational context as a major determinant (DeCanio et al. 2000; Ives and Olson 1984; Leonard-Barton and Deschamps 1988; Schillewaert et al. 2000). This has led DeCanio et al. (2000, p. 1297) to conclude that: "organizational structure is indeed a crucial element in the diffusion of technological innovations". A second group of antecedents pertains to characteristics of the technology itself (as perceived by its users). For example, perceived ease-of-use and usefulness have been identified as critical factors of IT adoption in previous research (e.g., Davis 1989; Venkatesh and Davis 2000). Finally, recent research has identified adopter characteristics as a third crucial category of determinants of IT adoption (e.g., Dabholkar and Bagozzi 2002; Parasuraman 2000). In the remainder of this section we specify the relationship of predictor variables pertaining to these three categories in relation to IT adoption by SMTs as a criterion variable. 


\subsubsection{Organizational Characreristics}

Tolerance-of-self-management. Tolerance refers to a general organizational orientation or climate in which employees have the discretion to make day-to-day decisions about job-related activities (cf., Bowen and Lawler 1995). In a work group context, tolerance refers to the fact whether team group members are empowered to make task and investment-related decisions and accept the responsibility for the outcomes of these decisions (Campion et al. 1993). In general, delegating authority to teams of employees allows for greater flexibility and adaptability in performing various service activities through better problem solving, closer employee cooperation, and more efficient knowledge exchange. More specifically, tolerance leads to more investments and a rapid diffusion of technological innovations among employees within teams (DeCanio et al. 2000). Furthermore, as a climate of empowerment provides employees better access to information sources about recent technological developments and innovative service practices, it leaves employees more room to get acquainted and to experiment with new IT systems, and ultimately to determine which tools they prefer (Janz 1999). It is likely therefore, that the more autonomy is granted to SMTs, the more they will make use of their ability to invest in IT to support the service delivery process. Higher levels of autonomy are likely to yield more room for decision-making in relation to both types of technology. Accordingly, we hypothesize that:

\section{$H_{5}$ : There will be a positive effect of tolerance on individual team member"s adoption-level of $\left(H_{5 a}\right)$ standardized IT and $\left(H_{5 b}\right)$ customized $I T$.}

Inter-team network. A climate of self-management may facilitate flexibility and rapid response to the diversified and changing customer requests by service teams, but it may also act as a hindrance to integration of the team activities and objectives with those of the organization. Too much autonomy may lead to SMTs that develop norms and adopt innovations that are not aligned with innovation objectives set by the organization. Therefore, a number of companies are experimenting with hybrid selfmanagement structures in which SMTs operate within a formalized network or an alliance of interdependent teams, much like partnerships in external markets, such as the airline industry (DeSanctis and Jackson 1994). In this way, teams are granted selfmanagement with respect to some elements of service operations, while they have to adhere to the rules and procedures of a network structure with respect to, for instance, the synchronization of quality goals, database procedures, and human resources policies. Recent studies have argued that such an inter-team network structure contributes to team performance (Frambach et al. 1998). Institutionalizing the interdependency between organizational units provides structure to the SMT activities, as it explicates and "internalizes" the content of organizational goals and objectives, while still allowing operational autonomy by SMTs. Networks of SMTs may facilitate the coordination between teams in the case of standard organization-wide innovation projects (Michaels et al. 1996). As such, inter-team networks facilitate a sophisticated understanding of how to use standard applications and may act as an information 
platform with respect to adaptive IT systems that are intended to alleviate specific service operations. Therefore, we hypothesize:
$H_{6:}$ There will be a positive effect of the participation of SMTS in inter- team networks on individual team member's adoption-level of $\left(H_{6,6}\right)$ standardized IT and $\left(H_{60}\right)$ customized IT.

\subsubsection{Technology Characteristics}

Usefulness. Several studies have demonstrated the positive impact of perceived usefulness on the adoption of IT (e.g., Davis 1989; Teo and King 1996; Venkatesh and Davis 2000). It refers to "the degree to which a person believes that using a particular system would enhance his or her performance" (Davis 1989, p. 320). Usefulness typically denotes an extrinsic motivation factor, i.e., the activity is perceived to be an instrument to a desirable end. Employees who perceive technology systems as useful vehicles to achieve desired outcomes are more motivated to use technological innovations. Hence, we hypothesize:

\section{$H_{7}$ : There will be a positive effect of usefulness on individual team} member's adoption-level of $\left(H_{\gamma_{0}}\right)$ standardized $I T$ and $\left(H_{7 b}\right)$ customized $I T$.

Ease-of-use. Ease-of-use refers to "the degree to which a person believes that using a particular system is free of effort" (Davis 1989, p. 320). Where usefulness pertains to extrinsic motivation, ease-of-use involves an intrinsic motivational variable. More specifically, ease-of-use refers to the degree to which people like to perform an IT task for the sake of the activity (Atkinson and Kydd 1997). By investigating customer attitudes towards service innovations, many recent studies have demonstrated that the adoption of IT increases when people expect the use of a system to be user-friendly (Davis et al. 1989; Teo and King 1996; Venkatesh and Davis 2000). When a system is easy to use, it requires less effort on the part of the users, thereby increasing the chance of adoption and usage (Teo and King 1996). Consequently, we expect that ease-of-use will have a strong impact on SMT members' intention to use technologies for the purpose of delivering customer service. Therefore, it is hypothesized that:

$H_{\xi}$ : There will be a positive effect of ease-of-use on individual team member's adoption-level of $\left(H_{s a}\right)$ standardized IT and $\left(H_{s h}\right)$ customized IT.

\subsubsection{User Characteristics}

Innovativeness. In the marketing literature innovativeness has been identified as an important driver of adoption (e.g., Rogers 1995). The term innovativeness refers to the degree to which employees are willing to use new concepts, ideas, products, or services and their awareness of the potential of innovations. Contrary to motivational variables like usefulness and ease-of-use, innovativeness typically reflects a 
personality characteristic, which is relatively stable and enduring across differemt types of contexts. As such, it has been conceptualized as a "persisting personal predisposition to innovate" (Schillewaert et al. 2000, p. 8). Frequently, a distinction has been made between general and domain-specific innovativeness, where it has been argued that domain-specific innovativeness is a more powerful predictor of a specific innovation (Schillewaert et al. 2000). Following this line of reasoning, we define the construct as the "SMT member's personal willingness to adopt service IT". Employees who show a highly innovative attitude towards information technology are assumed to exhibit more positive beliefs towards using service-supporting technology (Parasuraman 2000). These employees, in turn, have more technology-related experiences, and are more competent in handling them. Thus, innovative employees will make more comprehensive use of standard applications and are more likely to engage in additional adaptive IT applications to facilitate services activities. Therefore, we hypothesize that:

$H_{9}$ : There will be a positive effect of innovativeness on individual SMT member's adoption-level of $\left(H_{g_{i}}\right)$ standardized IT and $\left(H_{9 h}\right)$ customized IT.

Risk aversion. Risk aversion refers to the undesirable consequences people expect when they use technological innovations. Like innovativeness, risk aversion concerns a user characteristic, which is critical in IT adoption (Pennings and Smidts 2000). The infusion of IT requires extensive adaptation on the part of employees in terms of attending computer training and adjusting to the changing nature of the service activities. As a consequence, many employees feel uncertain about the implementation of complex technologies in the service delivery process (Bitner et al. 2000). In other words, IT adoption requires a climate of risk-taking and experimentation (Kock and McQueen 1998), which implies that perceptions of risk are relevant. Findings of previous studies have alreadly extensively demonstrated that risk-taking behaviors of managers (Nakata and Sivakumar 1996) and risk perceptions of customers towards new types of services and products (e.g., Dabholkar and Bagozzi 2002) have a crucia! impact on IT adoption. In the context of SMTs, risk attitudes of employees seem particularly relevant. By delegating authority to employees, they have more freedom and are assumed to decide themselves on how to deal proficiently with customer demands. As a consequence, employees also bear more responsibility and have to take more risks with regard to innovative decisions in complex service situations. These employees, in turn, have more technology-related experiences, and are more competent in handling them. Thus, employees with high levels of risk aversion are less likely to comprehensively use standard IT systems and additional adaptive IT applications to facilitate their services activities. Therefore, we hypothesize that:

$H_{10:}$ There will be a negative effect of risk aversion on individual team member's adopion-level of ( $\left.H_{100}\right)$ standardized IT and $\left(H_{10 b}\right)$ customized IT. 
Aforementioned hypotheses are summarized in Figure 5-1.

Figure 5-1: Relationships in the Conceptual Framework

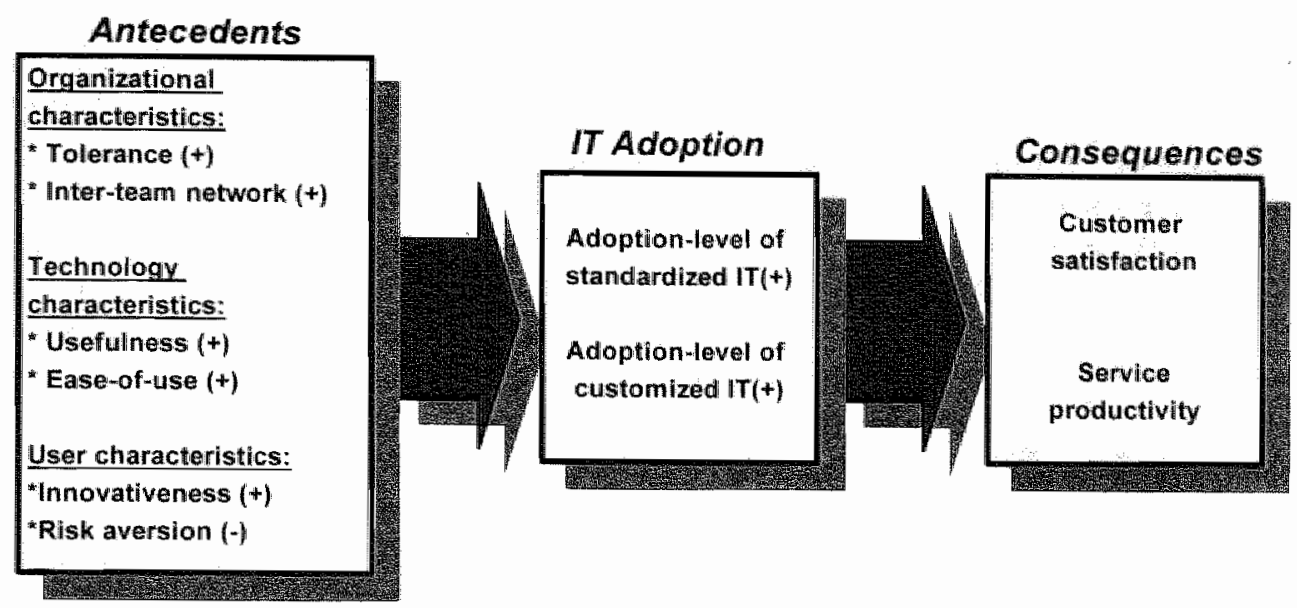

\subsection{Refinement of the Conceptual Framework}

The choice of the antecedents specified in our conceptual framework is largely founded on previous conceptual and empirical work that proposed the use of individual-level measures when predicting organizational phenomena (e.g., Lincoln and Zeitz 1980). Other researchers state, however, that organizational characteristics can be best analyzed at the group level and emphasize the relevance to consider individuall characteristics also at higher levels of analysis (Bliese 2000). The grouplevel assessments of the antecedents reflect shared team member perceptions of organizational characteristics (i.e., tolerance), technology characteristics (i.e., usefulness and ease-of-use) and user characteristics (i.e., innovativeness and risk aversion). Social dynamics in work groups may have an important influence on individual team member's perception of surrounding organizational characteristics (e.g., the level of tolerance within the team) as well as on his/her personal attitudes (e.g., the risk aversion to the use of IT). Each team has its own culture and norms with respect to appropriate performance attitudes and behavior (e.g., shared norms about the desired adoption-level of standardized IT), which is reflected by between-groups differences (Matthieu and Kohler 1990). These synergetic group-level effects originate from interpersonal processes among team members. Interpersonal processes may be implicit or explicit in nature. In social psychology literature it has been long contended that human beings in a social context (e.g., a team) strive for higher-order needs, as are social presentation needs and needs for cognitive consistency (Festinger 1954; Maslow 1970). These needs drive individual employees to use their cognition and affect to intentionally influence other team members' perceptions and attitudes within the team (e.g., by exhibiting risk aversion towards IT in presence of other colleagues) in order to reach socially acceptable outcomes. Furthermore, interpersonal processes may also 
affect team members in an implicit way. It has been argued that employees withouit conscious awareness tend to conform to other colleagues' attitudes and behaviors within the group. This happens through social mechanisms, as are groupthink, vicarious learning, and emotional contagion (e.g., Bandura 1986; Bartel and Saavedra 2000). Findings from previous studies have demonstrated that group-level assessments of variables significantly explain extra variation in individual employee outcomes that is not covered by the individual-level assessments of these variables (Mathieu and Kohler 1990; Blau 1995). These empirical results support the rationale that group-level aggregations of team member perceptions include an extra compositional effect, for which individual team member scores do not account (Bliese 2000; Ostroff 1993a). To determine the occurrence of compositional effects the aggregation of individual-level perceptual measures is needed to test additional cross-level relationships between group-level specifications of the antecedents and individual-level outcomes. Therefore, we posit the following hypotheses:

$H_{11}$ : At the group-level of analysis there will be positive effects of $\left(\mathrm{H}_{\text {lI }}\right)$ tolerance, $\left(H_{1 / b}\right)$ usefulness, $\left(H_{1 / \mathrm{d}}\right)$ ease-of-use, and $\left(H_{1 / \mathrm{d}}\right)$ innovativeness, and a negative effect of $\left(H_{H}\right)$ risk aversion that account for a significant amount of additional variance in individual team member's adoption-level of standardized IT.

$H_{12}$ : At the group-level of analysis there will be positive effects of $\left(H_{12 a}\right)$ tolerance, $\left(H_{12 b}\right)$ usefulness, $\left(H_{12 C}\right)$ ease-of-use, and $\left(H_{120}\right)$ innovativeness, and a negative effect of $\left(H_{12}\right)$ risk aversion that account for a significant amount of additional variance in individual team member's adoption-level of customized IT.

\subsection{An Empirical Study}

\subsubsection{Research Setting}

Employees of SMTs of a large European bank, headquartered in Belgium, were surveyed. The bank employs approximately 25,000 employees. It operates both in business and consumer markets and has a widespread branch network, serving many local communities. Traditionally, the branch offices constitute small-scale and often in-home offices staffed by a relatively small number of employees. Within each branch, SMTs of employees are responsible for offering a wide range of financial services, such as investment services, private banking, housing and mortgage services, savings accounts, life insurances, etc. More specifically, the key activities of the SMTs vary from basic transactions aimed at provision of services in a quick and consistent way to more complex work with the emphasis to meet customer's unique specifications. Approximately half of the SMTs operate within an inter-team network. The infusion of information technology in service operations by the SMTs is 
considered to be an important organizational change process. Therefore, the practical rationale for conducting a survey among employees was to examine the impact of IT adoption-rates on SMT service performance. In the next section we provide further details on the survey.

\subsubsection{Sampling and Surveying}

Data was collected by means of self-report questionnaires from individual employees organized in SMTs that have an average size of 5.7. Each SMT constitutes a separate branch. In total, 968 mail questionnaires were sent to employees of 170 SMTs. All employee members of the SMT were invited to participate. We ended up with an effective response rate of $44.8 \%$ ( $=434$ respondents). The following sample profile emerges. To begin with, from the data it appears that $71.0 \%$ of the employees is younger than 40 years. With respect to bank and computer training, the majority of the respondents have attended less than 10 weeks bank training (87.3\%) and less than 10 days computer training courses $(88.9 \%)$. Finally, at least 2 respondents were effectively surveyed per team.

\subsubsection{Measurement Issues}

All scale items of the employee survey were measured with a 7 -point scale, ranging from 'strongly disagree" (1) to "strongly agree' (7), largely on the basis of validated scales. The operationalization of tolerance was largely based upon an instrument from Cook et al. (1981). The usefulness and ease-of-use scales were measured using a scale designed by Davis (1989). Innovativeness and risk aversion were measured using items from a scale developed by Grewal et al. (2000).

We employed two techniques to test the factor structure and item loadings of the scale constructs. We initially examined coefficient alphas and the factor structure (through principal component analysis) for all the scale items simultaneously. A fivefactor structure was achieved with items loading on the assumed dimensions. In addition, we performed a confirmatory factor analysis (CFA) and used LISREL to assess the critical measurement properties of the scales. The fit indices of the proposed factor model, construct reliabilities of the scales, and confirmatory factor loadings with $t$-values for each item are represented in Table 5-1. The indices of the proposed factor model provided a good fit $(\mathrm{GFI}=0.92 ; \mathrm{AGFI}=0.90 ; \mathrm{RMSEA}=0.042 ; \mathrm{NFI}=0.91$; $\mathrm{NNFI}=.95 ; \mathrm{CFI}=0.96$ ), showing unidimensionality of the scales (Steenkamp and Van Trijp 1991). Construct reliabilities of the scales were tested by means of Cronbach's alpha. Coefficients of all measures were $\geq 80$, which implies that reliability is deemed acceptable (Nunnally and Bernstein 1994).

Additionally, within-method convergent validity was examined by investigating the significance and magnitude of the item loadings. All items loaded significantly on their respective construct (minimum t-value $=12.01$ ) and had a standardized loading of at least 0.60 . Next, discriminant validity was examined by testing whether pairs of constructs were correlated less than 1 (Anderson and Gerbing 1988). Chi-square difference tests with 1 d.f. were used to test for unity between pairs of constructs. All tests were significant at the .05 significance level. 
Table 5-1: Results of Confirmatory Factor Analysis

\begin{tabular}{|c|c|c|}
\hline Measures & $\begin{array}{l}\text { factor } \\
\text { loadings }\end{array}$ & value \\
\hline \multicolumn{3}{|c|}{ Fit indices: $\mathrm{GFI}=0.92 ; \mathrm{AGFI}=0.90 ; \mathrm{RMSEA}=0.042 ; \mathrm{NFI}=0.91 ; \mathrm{NNFI}=.95 ; \mathrm{CFI}=0.96)$} \\
\hline \multicolumn{3}{|l|}{$\begin{array}{l}\text { Tollerance-of-self-management }(n=5 ; a=.81) \\
\text { In our team we are... }\end{array}$} \\
\hline 1. encouraged to take initiative. & .60 & 1221 \\
\hline 2allowed complete freedom in our work. & .76 & 16.14 \\
\hline 3. permitted to use our own judgment in solving problems. & .70 & 14.50 \\
\hline 4.allowed to do our work the way we think best. & .60 & 12.01 \\
\hline 5.trusted to exercise good judgement. & .62 & 12.42 \\
\hline \multicolumn{3}{|l|}{ Usefulness $(\mathrm{n}=6 ; a=.91)$} \\
\hline 1. Using IT enables me to accomplish tasks more quickly. & .77 & 17.89 \\
\hline 2.Using IT improves ny job performance. & .77 & 18.64 \\
\hline 3. Using IT increases my productivity. & .81 & 19.83 \\
\hline 4.Using IT enhances my effectiveness on the job. & .91 & 23.57 \\
\hline 5. Using IT makes it easier to do my job. & .75 & 18.03 \\
\hline 6. verall, I find IT useful in my job. & .69 & 16.13 \\
\hline \multicolumn{3}{|l|}{ Ease-of-use $(n=6 ; \alpha=.90)$} \\
\hline 1.IT provides me a helpful guidance in performing tasks. & .70 & 16.06 \\
\hline 2.I find it easy to get IT to do what I want it to do. & .72 & 16.84 \\
\hline 3. My interaction with IT is easy for me to understand. & .88 & 22.61 \\
\hline 4.IT is flexible to interact with. & .78 & 18.85 \\
\hline 5.It is easy for me to remember how to perform tasks using IT. & .76 & 18.16 \\
\hline 6.Overall, Ifind IT easy to use. & .85 & 21.54 \\
\hline \multicolumn{3}{|l|}{ Innovativeness $(\mathrm{n}=5 ; a=.83$ ) } \\
\hline \multicolumn{3}{|l|}{ 1.In general, your are among the first in your circle of friends to acquire new IT } \\
\hline \multicolumn{3}{|l|}{ 2. You can usually figure out new high-tech products and services without help } \\
\hline from others. & .65 & 14.30 \\
\hline 3.You keep up with the latest technological developments in your areas of interest. & .81 & 18.10 \\
\hline 4. You enjoy the challenge of figuring out high-tech gadgets. & .75 & 17.17 \\
\hline \multicolumn{2}{|l|}{$\begin{array}{l}\text { 5. You find you have fewer problems than other people in making technology work } \\
\text { for you. }\end{array}$} & 15.17 \\
\hline \multicolumn{3}{|l|}{ Risk aversion $(\mathrm{n}=4 ; \alpha=.80)$} \\
\hline 1. You do not consider it safe giving out a credit card number over a computer. & 64 & 13.38 \\
\hline 2.You do not consider it safe to do any kind of financial business online. & .72 & $\mathbb{1 5 . 3 8}$ \\
\hline $\begin{array}{l}\text { 3. You worry that information you send over the Internet will be seen by other } \\
\text { people. }\end{array}$ & $.80^{\circ}$ & 17.51 \\
\hline $\begin{array}{l}\text { 4. You do not feel confident doing business with a place that can only be reached } \\
\text { online. }\end{array}$ & .66 & 13.93 \\
\hline
\end{tabular}

Note: all t-values are significant at $p<.05$.

In addition, the adoption-level of IT was operationalized as an employee's usage-rate of standardized and customized IT applications on a 6-point scale, ranging from 'never' (0) to "more times a day' (5). More specifically, standardized IT concerns the three different modules of the standard IT configuration (i.e., the task manager, promotions/selections, and order book modules). To properly assess the adoption-level of customized IT we inventoried the different additional software packages available within the bank (i.e., exchange rates analysis software, euro emulation software, and insurance DSS). In addition, a comprehensive list of 20 software applications was drafted and individual team members were asked to indicate: (1) which three IT 
applications they used most frequently and, consequently, (2) their usage-rates for these applications. The group-level variable inter-team network concerns a dummy indicating whether a team participated in a network of multiple teams. Finally, the demographic variables computer training, bank training and age served as control variables when testing the hypotheses.

Furthermore, Table 5-2 indicates means, standard deviations and individuallevel as well as group-level correlations between antecedents and the adoption-level of standardized and customized IT. It has been argued that corrections for individuallevel measurement error should be made first, before comparing individual and aggregate-level correlations (Ostroff 1993a). Therefore, we calculated individual-level correlations between the antecedents and IT adoption variables after increasing the reliability (= Cronbach's alpha) to .85 for those antecedent constructs that had lower reliabilities, using the following equation:

(1) $r_{x y}=r_{x y} \frac{\sqrt{r_{x x}^{\prime}}}{\sqrt{r_{x x}}}$,

where $r_{x y}^{\prime}=$ estimated correlation between variables $x$ and $y$ if their reliabilities are changed, $r_{x x}^{\prime}=$ changed reliability for $x$, $r_{x x}=$ obtained reliability for $x$.

Overall, the results indicate some increase of the individual-level correlations, but do not imply major changes in the magnitude differences between individual-level and group-level correlations (Nunnally and Bernstein 1994).

Regarding the team outcome measures, team customer satisfaction ratings measured on a 7-point scale, ranging from 'strongly dissatisfied' (1) to 'strongly satisfied' (7) were collected from the bank's internal database. Similarly, we obtained a number of productivity metrics on five major service categories (i.e., savings accounts, investment funds, pension funds, euro obligations, long term savings, and life insurances). Aforementioned service parameters indicate the average amount of services sold per team per year and reflect service productivity. Table 5-3 represents the overall means, standard deviations, and the correlations between the adoption-level of standardized and customized IT, and the outcome variables. 


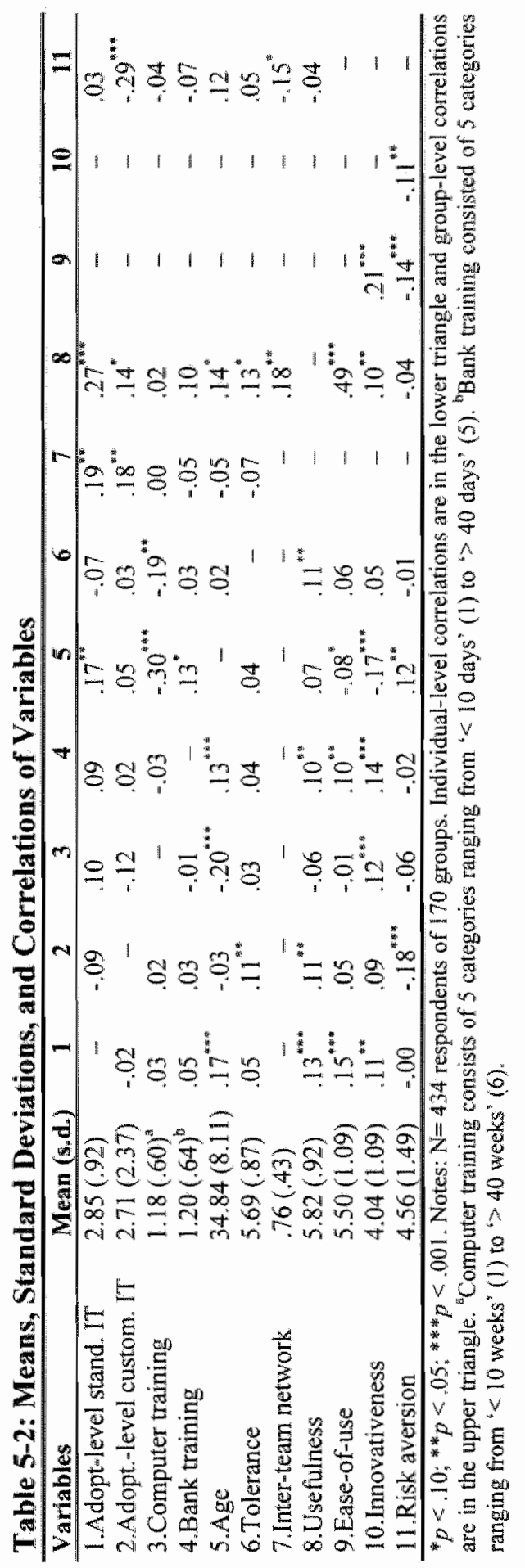




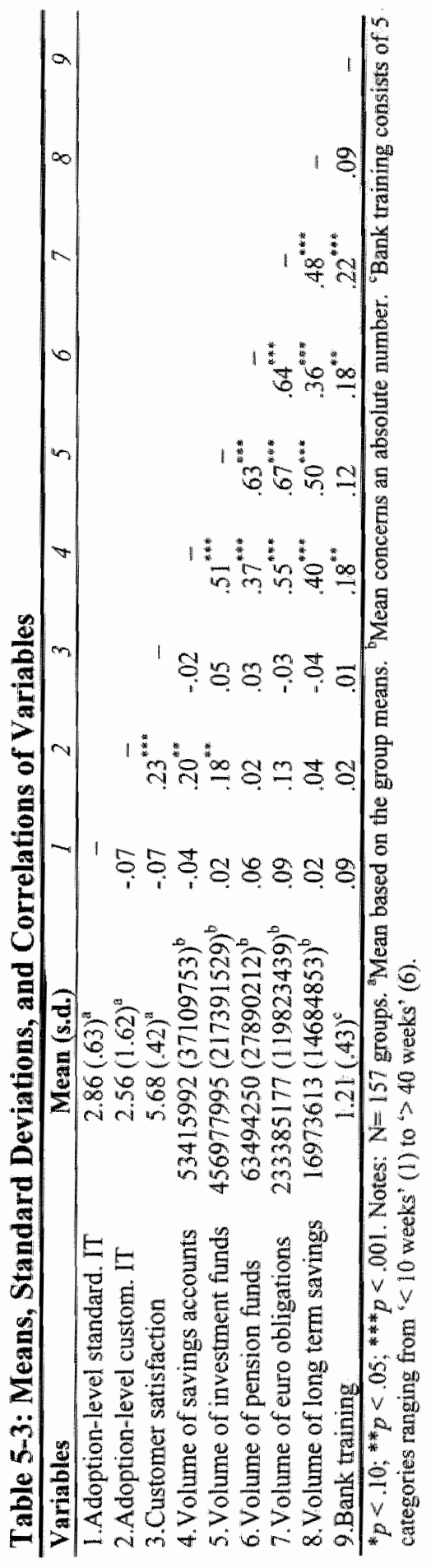




\subsubsection{Data Analysis}

To determine the occurrence of contextual influences in the antecedents of tolerance, usefulness, ease-of-use, innovativeness, and risk aversion we examine within-group agreement and the ratio of within-group variance for these antecedents. Therefore, empirical justification of aggregation was required, which was tested by means of the $r_{w G(j)}$ coefficient, which is an indicator of within-group agreement (James et al. 1993) and the ICC (1) coefficient, which involves the ratio of within-group and betweengroups variance. The $r_{w a(j)}$ coefficients of the antecedents (median values range from .81 and .96 ) indicate high consistency in ratings among employees within groups on these variables. In addition, we calculated the $\mathrm{ICC}^{\prime}$ for each antecedent. Tolerance $(\mathrm{ICC}=.17)$, usefulness $(\mathrm{ICC}=.09)$, and risk aversion $(\mathrm{ICC}=.15)$ show relatively high ICC values indicating that a substantial part of these antecedents concerns betweengroups variance. Conversely, the ICCs of ease-of-use and innovativeness turn out to be zero indicating that these antecedents operate exclusively at the individual level. Hence, based on the values of the $r_{W G(j)}$ coefficients and ICC coefficients it can be concluded that for tolerance, usefulness, and risk aversion data aggregation in order to examine their cross-level effects on IT adoption is justified. In contrast, from the zero ICC values it appears that aggregate-level specifications of ease-of-use and innovativeness do not yield extra significant information, which implies that we have to reject $H_{11 c}, H_{1 / d}, H_{12 c}$, and $H_{12 d}$ a priori. As such we did not specify cross-level relationships for ease-of-use and innovativeness.

To test $\mathrm{H}_{4}, \mathrm{H}_{2}, \mathrm{H}_{3}$ and $\mathrm{H}_{4}$ we analyzed the relationships between IT adoptionlevel and service outcome parameters at the group level. As it was not practically possible neither conceptually plausible to match employee perceptions with the selected productivity and customer criteria at the individual level, individual employee's I'T adoption rates were aggregated to the group level of analysis to establish a match between the focal constructs and their consequences using the team as a unit of analysis. Moreover, it can be argued that it is more congruent to link the shared performance behaviors of team members to outcomes that are measured at the 'macro level' (cf., Campion et al 1996). As such, the hypothesized IT-adoption service performance relationships were tested at the group level. A completely crossed twoby-two (higher-level/lower-level IT adoption by standardized/customized IT) quasiexperimental design was employed. In total, 157 teams were used for this analysis. Through median splitting the group mean adoption-rates of standardized IT and customized IT, the teams in our study were divided into four conditions: (1) lowerlevel adoption of standardized IT / lower-level adoption of customized IT $(n=47),(2)$ higher-level adoption of standardized IT / lower-level adoption of customized IT ( $n=$ 43) (3), lower-level adoption of standardized IT / higher-level adoption of customized IT $(\mathrm{n}=32)$, and (4) higher-level adoption of standardized IT / higher-level adoption of customized IT $(n=35)$. Table 5-4 includes the means and standard deviations of the dependent variables for each separate condition.

Next, we conducted MANCOVA to test the main and interactive effects of the adoption-level of standardized IT and the adoption-level of customized IT on the specified dependent variables (i.e., customer satisfaction and productivity measures),

'ICCs were corrected for measurement error (cf., Van Yperen and Snijders 2000). 
where bank training served as covariate to adjust for differences between the conditions. In addition, assumptions of MANCOVA were tested. First, histograms were inspected to check for violations of multivariate normality. The results showed only slight departures from normality. Secondly, the number of observations (i.e., teams) was about equal across the conditions, which implies that robustness of MANOVA could be assumed. Furthermore, homogeneity of regression slopes was checked to control for covariate by condition interactions. No significant interactions were found, which meant that the inclusion of the covariate bank training was allowed.

\section{Table 5-4: Means of Outcome Variables by Adoption-Level and Type of IT}

\begin{tabular}{|c|c|c|c|c|}
\hline \multirow[t]{2}{*}{ Variable } & \multicolumn{4}{|c|}{ Adoption-level of standardized IT Adoption-Level of customized IT } \\
\hline & Mean (s.d.) $)^{b}$ & $\begin{array}{c}\text { Adjusted } \\
\text { mean }^{\text {ab }}\end{array}$ & Mean (s.d.) & $\begin{array}{l}\text { Adjusted } \\
\text { mean }^{\text {ab }}\end{array}$ \\
\hline \multicolumn{5}{|l|}{ Customer satisfaction } \\
\hline Lower-level condition & $5.70(.44)$ & 5.71 & $5.63(.46)$ & 5.62 \\
\hline Higher-level condition & $5.67(.40)$ & 5.68 & $5.76(34)$ & 5.77 \\
\hline \multicolumn{5}{|l|}{ Volume of savings accounts } \\
\hline Lower-level condition & $56704849(38548473)$ & 59096397 & $46483933(29659939)$ & 46073646 \\
\hline Higher-level condition & $50084969(35530503)$ & 50278337 & $62727713(43763179)$ & 63301087 \\
\hline \multicolumn{5}{|c|}{ Volume of investment funds } \\
\hline Lower-level condition & $4.65 \mathrm{E}+08(219474894)$ & 4.77E +08 & $4.13 E+08(179764433)$ & 4. $11 \mathrm{E}+08$ \\
\hline Higher-level condition & $4.49 \mathrm{E}+08(216354595)$ & $4.52 \mathrm{E}+08$ & $5.16 \mathrm{E}+08(248907630)$ & $5.18 \mathrm{E}+08$ \\
\hline \multicolumn{5}{|l|}{ Volume of pension funds } \\
\hline Lower-level condition & $62221723(26531922)$ & 62114467 & $61282099(23453849)$ & 60917130 \\
\hline Higher-level condition & $64783091(29317281)$ & 65196361 & $66465796(32881177)$ & 66393698 \\
\hline \multicolumn{5}{|l|}{ Volume of euro obligations } \\
\hline Lower-level condition & $2.25 \mathrm{E}+08(104084798)$ & $2.28 \mathrm{E}+08$ & $2.12 \mathrm{E}+08(99420137)$ & $2.10 \mathrm{E}+08$ \\
\hline Higher-level condition & $2.42 E+08(134043677)$ & $2.45 \mathrm{E}+08$ & $2.62 \mathrm{E}+08(138359419)$ & $2.62 \mathrm{E}+08$ \\
\hline \multicolumn{5}{|c|}{ Volume of long term savings } \\
\hline Lower-level condition & $16140512(13305293)$ & 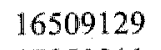 & $15816292(13329208)$ & 15801280 \\
\hline Higher-\|evel condition & $17817395(16003992)$ & 17850811 & $18528224(16304722)$ & 18558659 \\
\hline
\end{tabular}

Mleans are adjusted by the bank training covariate. Means concenn absolute numbers.

The MANCOVA results produced significant F-values for the main effect of the adoption-level of customized IT $\left(\mathrm{F}_{6,147}=3.308[p=.004]\right)$ and the two-way interaction effect of the adoption-level of standardized IT $\times$ customized IT $\left(\mathrm{F}_{6,147}=\right.$ $3.043[p=.008])$, whereas no effect of the adoption-level of standardized IT $\left(\mathrm{F}_{6,147}=\right.$ $1.642[p=.614]$ ) was found. These results are presented in Table 5-5. Consequently, ANCOVA's were conducted to investigate main and interaction effects for each dependent variable separately. Regarding the adoption-level of standardized IT, on none of the specified dependent variables significant differences between higher-level adoption groups and lower-level groups were found, which implies that $\mathrm{H}_{1 \mathrm{a}}$ and $\mathrm{H}_{2 \mathrm{a}}$ can be rejected. With respect to the adoption-level of customized IT, however, groups with higher-level adoption-rates of customized IT appear to have significant higher customer satisfaction scores than the lower-level groups $\left(F_{1,152}=4.395[p=.038]\right)$. Hence, $\mathrm{H}_{1 \mathrm{~b}}$ is supported. In addition, we also tested whether groups with a higher adoption-level of customized IT are more productive. 
Table 5-5: MANCOVA and ANCOVA Results

\begin{tabular}{|c|c|c|c|}
\hline MANCOVA & $\overline{F_{6,14}}$ & $P$ & Power \\
\hline \multicolumn{4}{|l|}{ Factor } \\
\hline Adoption-level of standardized IT & 1.642 & .139 & .614 \\
\hline Adoption - evel of customized IT & $3.308 * *$ & .004 & .927 \\
\hline \multicolumn{4}{|l|}{ Adoption-level of standardized JT } \\
\hline$x$ & & & \\
\hline Adoption-llevel of customized IT & $3.043 * *$ & .008 & .901 \\
\hline
\end{tabular}

\begin{tabular}{|c|c|c|c|c|}
\hline ANCOVA & & $F_{1,4: 2_{2}}^{\text {ia }}$ & $\boldsymbol{P}$ & Power \\
\hline Factor & Dependent variable & & & \\
\hline \multirow{6}{*}{ Adoption-level of standardized \T } & Customer satisfaction & .236 & .628 & .077 \\
\hline & Volume of savings accounts & 2.326 & .129 & .329 \\
\hline & Volume of investment funds & .559 & .456 & .115 \\
\hline & Volume of pension funds & 495 & .483 & .108 \\
\hline & Volume of euro obligations & .849 & .358 & .150 \\
\hline & Volume of long term savings & .316 & .575 & .086 \\
\hline \multirow[t]{6}{*}{ Adoption-level of customized IT } & Customer satisfaction & $4.395 *$ & .038 & .549 \\
\hline & Volume of savings accounts & $8.910^{* *}$ & .003 & .843 \\
\hline & Volume of investment funds & $9.653^{*} *$ & .002 & .870 \\
\hline & Volume of pension funds & 1.568 & .212 & .238 \\
\hline & Volume of euro obligations & $7.958 *$ & .005 & .800 \\
\hline & Volume of long term savings & 1.340 & .249 & .210 \\
\hline \multicolumn{5}{|l|}{ Adoption-level of standardized IT } \\
\hline$x$ & & & & \\
\hline \multirow{6}{*}{ Adoption-level of customized IT } & Customer satisfaction & .147 & .702 & .067 \\
\hline & Volume of savings accounts & .085 & .771 & .060 \\
\hline & Volume of investment funds & .003 & .958 & .050 \\
\hline & Volume of pension funds & $6.552^{\text {tis }}$ & .011 & .720 \\
\hline & Volume of euro obligations & $6.229 *$ & .014 & .699 \\
\hline & Volume of long term savings & .000 & .998 & .050 \\
\hline
\end{tabular}

${ }^{*} p<.05 ;{ }^{* *} p<.01$. Results are controlled for the bank training covariate. "F-approximation.

The higher-level and lower adoption-level groups do not significantly differ in their service performance on pension funds and long-term savings, which implies that we need to reject $\mathrm{H}_{2 b}$ for those criteria. Conversely, higher adoption-level groups appear to have significantly higher volumes of savings accounts $\left(\mathrm{F}_{1,152}=8.910[p=.003]\right)$, investment funds $\left(\mathrm{F}_{1,152}=9.653[p=.002]\right)$, and euro obligations $\left(\mathrm{F}_{1,152}=7.958[p=\right.$ .005]) than lower-level groups. Therefore, $\mathrm{H}_{2 b}$ is supported for those service categories.

In addition, no significant two-way interaction effect of the adoption-level of standardized IT $\times$ the adoption-level of customized IT was found in relation to customer satisfaction, which implies that $\mathrm{H}_{3}$ is rejected. Next, there exist positive twoway interaction effects of the adoption-level of standardized IT $\times$ the adoption-level customized IT with regard to pension funds $\left(\mathrm{F}_{6,152}=6.552[p=.014]\right)$ and euro obligations $\left(\mathrm{F}_{6,152}=6.229[p=.011]\right)$, indicating that those teams with higher adoption-rates for both standardized and customized IT score significantly better than teams with lower adoption-scores for one or both of these IT types, implying support for $\mathrm{H}_{4}$ with respect to these performance criteria. 
Next, we tested the hypothesized antecedent-IT adoption-level relationships. Our conceptual framework of the antecedents of IT adoption includes variables at two levels of aggregation: the individual and the team level. Such data are designated as multi-level data. The levels are hierarchical, as employees are nested within groups. Conventional statistical techniques (e.g., ordinary regression analysis) ignore this hierarchy and may, therefore, yield incorrect estimates (Bryk and Raudenbush 1992). Conversely, hierarchical linear models also called multi-level models are an effective approach to deal with hierarchical data structures. To perform multi-level analysis we used MLwiN (Rasbash et al. 2000) a software program, which computes regression estimates by means of an iterative approach known as the EM algorithm (Dempster et al. 1977).

Additionally, hypotheses $\mathrm{H}_{5-12}$ were tested through a multivariate hierarchical linear model regression model using MLwiN software (Rasbash et al. 2000). Three hierarchical levels are specified, where level 1 refers to the dependent variables indicated by $h=1, \ldots, m$, level 2 concerns the individual employees $i=1, \ldots, n_{j},\left(n_{j}=\right.$ 434 employees $)$ and level 3 involves the teams $j=1, \ldots, N(N=170$ teams). Hence, each measurement of a dependent variable on some group is represented by a separate line in the data matrix, containing the values $i, j, h, Y_{i i j}, x_{1 i j}$, and those of other explanatory variables. To represent the multivariate regression model as a hierarchical linear model, the dummy variables $d_{1}$ to $d_{m}$ are used to indicate the dependent variables (i.e., adoption-level of standardized IT, adoption-level customized IT). Dummy variable $d_{h}$ is 1 or 0 , depending on whether the data line indicates dependent variable $Y_{h}$ or the other dependent variable. This procedure is indicated as:

$$
d_{s h i p}= \begin{cases}1 & h=s \\ 0 & h \neq s\end{cases}
$$

With these dummies, the regression equations for the $m$ dependent variables can be integrated into one three-level hierarchical model by the expression:

$$
Y_{h i j}=\sum_{s=1}^{m n} \gamma_{0 s} d_{s h i j}+\sum_{k=1}^{p} \sum_{s=1}^{m} \gamma_{k s s} d_{s h i j} x_{k i j}+\sum_{s=1}^{m m} u_{s i} d_{s h i j}+\sum_{s=1}^{m} e_{s i j} d_{s h i j}
$$

All variables of the model (also the constant term) are multiplied by the dummy variables. In relation to the dummy variables, it should also be noticed that in the sums over $s=1, \ldots, m$, only the term for $s=h$ accounts for a contribution, whereas all other terms are excluded. Next regression equation, concerns a simplified representation of equation 3 :

$$
\begin{aligned}
& \text { (4) } Y_{h i j}=\gamma_{00 h}+\gamma_{10 h} \mathrm{COMP}_{i j}+\gamma_{20 h} \mathrm{BANK}_{i j}+\gamma_{30 h} \mathrm{AGE}_{i j}+\gamma_{40 h} \mathrm{TOL}_{i j}+\gamma_{50 h} \mathrm{USE}_{i j}+ \\
& \gamma_{60, h} \mathrm{EASE}_{i j}+\gamma_{70 h l} \mathrm{INNO}_{i j}+\gamma_{80 h} \mathrm{RISK}_{i j}+\gamma_{01 h} \mathrm{COMP}_{j}+\gamma_{02 h} \mathrm{BANK}_{j}+\gamma_{03 h} \mathrm{AGE}_{j} \\
& +\gamma_{04 h} \mathrm{TOL}_{j}+\gamma_{05 h} \mathrm{INTER}_{j}+\gamma_{06 h} \mathrm{USE}_{j}+\gamma_{07 h} \mathrm{RISK}_{j} \\
& +u_{0 h j}+u_{4 h j}+u_{5 h j}+u_{6 h j}+u_{9 h j}+u_{8 h j}+e_{h i j} \text {, }
\end{aligned}
$$


where $Y_{h i j}$ is the assessment on the $h^{\text {'th }}$ variable for individual $i$ of group $j$; COMP, BANK, and AGE, refer to employee's amount of computer training and bank training, and age, respectively; TOL, USE, EASE, INNO, RISK, and INTER are tolerance, usefulness, ease-of-use, innovativeness, risk aversion, and team's participation into the inter-team network, respectively.

Table 5-6: Results of Multi-Level Analyses

\begin{tabular}{|c|c|c|c|c|}
\hline \multirow{3}{*}{ Dependent wartables } & \multicolumn{4}{|c|}{ Model A } \\
\hline & \multicolumn{2}{|c|}{$\begin{array}{l}\text { Adoption-level of } \\
\text { standardized IT }(h=1)\end{array}$} & \multicolumn{2}{|c|}{$\begin{array}{l}\text { Adoption-level of } \\
\text { customized IT }(h=2)\end{array}$} \\
\hline & $\underset{b}{\text { Coefficient }(\mathrm{SE})}$ & $\begin{array}{c}\Delta \text { Magnitude } \\
\text { coef }\end{array}$ & $\underset{\text { Coeflicient }}{(\mathrm{SE})}$ & $\begin{array}{l}\Delta \text { Magnitude } \\
\text { coef: }\end{array}$ \\
\hline Intercept & $-.203(.720)$ & & $3.004(1.953)$ & \\
\hline Increase model fit (step 1) & $x^{2}(2)=.26$ & & & \\
\hline \multicolumn{5}{|l|}{ Conrol vartables: level $2^{\text {ti }}$} \\
\hline Computer training & $-.070(.089)$ & & $.209(.221)$ & \\
\hline Bank training & $-.069(.086)$ & & $.140(.216)$ & \\
\hline Age & $.022(.007)^{* * *}$ & & $-.022(.017)$ & \\
\hline \multicolumn{5}{|c|}{ Control variablex: level $3^{b}$} \\
\hline Computer training & $.244(.124)^{*}$ & $.310(.152)^{*}$ &. $.458(.340)$ & $-.659(.405)$ \\
\hline Bank training & $.085(.108)$ & $.149(.139)$ & $-.057(.292)$ & $-.146(.367)$ \\
\hline Age & $.024(.009)^{* *}$ & $.003(.011)$ & $.014(.025)$ & $.037(.029)$ \\
\hline Increase model fit (step 2) & $x^{2}(12)=22.68 *$ & & & \\
\hline \multicolumn{5}{|l|}{ Antecedens: level $2^{\prime \prime}$} \\
\hline Tolerance & $.146(.066)^{*}$ & & $.448(.164)^{* *}$ & \\
\hline Usefulness & $.074(.045)$ & & $.195(.112)^{*}$ & \\
\hline Ease-of-use & $.110(.045)^{2 * 2 *}$ & & $-.165(.116)$ & \\
\hline Innovativeness & $.092(.036)^{* * * 2 *}$ & & $.102(.093)$ & \\
\hline Risk aversion & $-.003(.026)$ & & $-.032(.071)$ & \\
\hline Increase model fit (step 3) & $\chi^{2}(20)=41.74 * *$ & & & \\
\hline \multicolumn{5}{|l|}{ Antecedents: level $3^{\circ}$} \\
\hline Inter-team network & $.226(.106)^{*}$ & & $.539(.290)^{*}$ & \\
\hline Tolerance & $-.071(.073)$ & $-.225(.097)^{*}$ & $.047(.201)$ & $-.381(.257)$ \\
\hline Usefulness & $.113(.051)^{*}$ & $.172(.065)^{* *}$ & $.198(.138)$ & $.023(.170)$ \\
\hline Risk aversion & $.023(.030)$ & $.027(040)$ & $-.313(.082)^{* * 2}$ & $-.265(.105)^{* *}$ \\
\hline \multicolumn{5}{|c|}{ Increase model fit (step 4$) \quad x^{2}(8)=34.86^{*}$} \\
\hline \multirow{2}{*}{\multicolumn{2}{|c|}{$\begin{array}{l}\text { Residual Between-Groups Covariance Matrix }{ }^{2} \\
\text { 1. Adoption-tevel standard. IT }\end{array}$}} & 1. & 2. & \\
\hline & & $.031(.039)$ & & \\
\hline \multicolumn{2}{|c|}{ 2. Adoption-level customiz IT } & $-.076(.075)$ & $.550(.288)$ & \\
\hline \multirow{3}{*}{\multicolumn{2}{|c|}{$\begin{array}{l}\text { Residual Within-Group Covariance Matrix } \\
\text { 1. Adoption-level standard. IT } \\
\text { 2. Adoption-level customiz. IT }\end{array}$}} & 1. & 2. & \\
\hline & & $.712(.060)$ & & \\
\hline & & $-.029(.108)$ & $4.527(.387)$ & \\
\hline Explained level 2 variance & $12.4 \%$ & & $9.7 \%$ & \\
\hline Explained level 3 variance & $19.4 \%$ & & $12.3 \%$ & \\
\hline
\end{tabular}

$p<.05 ; p<.01$. Note: significance of coefficients is based on one-tailed tests. "Unstandardized regression coefficients. ${ }^{6}$ Standard errors between parentheses. Increase in model fit when specifying individual-level and

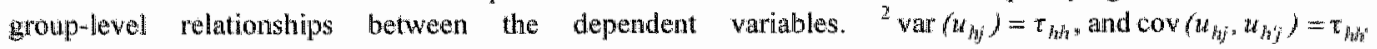
${ }^{3} \operatorname{var}\left(e_{h i j)}\right)=\sigma_{h, t}$ and cov $\left(e_{h i j}, e_{h i j, j}\right)=e_{h, h^{\prime}}$ 
The following analysis strategy was used. First of all, an intercept-only nodel was estimated. This is a model without predictors at any level and represents the (unexplained) variation of the outcome variables (i.e, adoption-level of standardized IT and adoption-level of customized IT) at individual and team level. In addition, individual-level and group-level relationships between the outcome variables were specified (step 1). Next, the control variables (i.e., computer training, bank training, age) were included at these both levels of the model $(\text { step } 2)^{2}$. Secondly, the specified individual-level antecedents were added to the model (step 3$)^{3}$. Thirdly, the grouplevel antecedents were incorporated into the model (step 4).

Multi-level models are considered as contextual models that may be subject to multi-collinearity. Therefore, ordinary regression analyses were conducted to investigate multi-collinearity of the model by means of the Variance Inflation Factor (VIF). The VIF's of the specified independent variables were not higher than 1.62 indicating that no multi-collinearity problems were to be expected.

The results of the multi-level analysis are presented in Table 5-6. To begin with, the intercept-only model shows that team member's adoption-level of customized IT $(\mathrm{ICC}=.10)$ and standardized IT $(\mathrm{ICC}=.13)$ encompasses a considerable part of between-groups variance. In addition, including control variables, individual-level antecedents and group-level antecedents (step 2 thru step 4) all lead to significant improvements of the model fit ${ }^{4}$. Regarding the hypothesized relationships, there exist strong positive effects of the individual-level tolerance on employee's adoption-levels of standardized IT and customized IT, which implies that $\mathrm{H}_{5 \mathrm{a}}$ and $\mathrm{H}_{56}$ are supported. Next, participation of the SMT in an inter-team network positively affects team member's adoption-level of standardized IT and customized IT, which means support for $\mathrm{H}_{6 \mathrm{a}}$ and $\mathrm{H}_{6 \mathrm{~b}}$. Furthermore, it appears that individual-level perceived usefulness is not significantly related to team member's adoption-level of standardized IT, while it shows a significant positive relationships the adoption-level of customized IT. These findings imply that $\mathrm{H}_{7 \mathrm{a}}$ is rejected, whereas $\mathrm{H}_{7 \mathrm{~b}}$ is supported. In addition, individuallevel ease-of-use has a positive impact on employee's adoption-level of standardized IT, while no significant relationship emerges with respect to team member's adoptionlevel of customized IT. These findings indicate support for $\mathrm{H}_{8 \mathrm{a}}$, while $\mathrm{H}_{8 \mathrm{~b}}$ is rejected. In addition, there exists a significant positive individual-level effect of innovation on employee's adoption-level of standardized IT, while there exist no significant linkage with regard to the adoption-level of customized IT. This implies that $H_{9 \mathrm{a}}$ is supported, whereas $\mathrm{H}_{96}$ has to be rejected. Subsequently, individual-level risk aversion is not

\footnotetext{
${ }^{2}$ The control variables computer training, bank training, and age as well as the antecedents tolerance, usefulness, and risk aversion were specified both at the individual level (i.e., level 2) and the group level (i.e., level 3 ) of analysis. The level 2 variables were group-mean centered (i.e., individual score minus the group mean, which yield within-group deviation score) to distinguish the individual-level effect from the group-level effect (cf. Bryk and Raudenbush 1992).

${ }^{3}$ Coefficients of the intercept and the individual-level antecedents were specified as random coefficients (i.e, the coefficients were allowed to vary across teams). Therefore, random parameters were specified at group level. In theory, all effects of the coefficients could be specified as random effects. Methodologically, this is, however, not plausible, since it has a negative impact on the model estimation procedure and the stability of the parameter estimates (Bryk and Raudenbush 1992).

* The predictive power of the different models can be compared by a likelihood ratio vest (Bryk and Raudenbush 1992). Deviance is computed for each model and the difference between the deviance statistics ( $\Delta$ Deviance) has a $\chi^{2}$-distribution under $H_{0}$ that the extended model does not predict significantly better than the reduced model Critical values of the $\chi^{2}$-statistic mean that the reduced model is too simple a description of the data.
} 
related to the adoption-levels of standardized IT and customized IT indicating that there exists no support for $\mathrm{H}_{10 \mathrm{a}}$ and $\mathrm{H}_{10 \mathrm{~b}}$.

With respect to the cross-level hypotheses, we find that the (absolute) magnitudes of the between-groups coefficients are significantly greater compared to the within-group ones only for the effect of usefulness on employee's adoption-level of standardized IT and for the effect of risk aversion on employee's adoption-level of customized IT. This means that $\mathrm{H}_{11 \mathrm{a}}, \mathrm{H}_{1 \text { les }}, \mathrm{H}_{12 \mathrm{a}}$, and $\mathrm{H}_{12 \mathrm{~b}}$ are rejected and that $\mathrm{H}_{11 \mathrm{~b}}$ and $\mathrm{H}_{12 \mathrm{e}}$ are supported. Finally, the percentage of explained group-level variance is higher compared to individual-level variance for both the adoption-level of standardized and customized IT. This signifies that the antecedents explain between-groups differences better than within-group differences of both dependent variables.

\subsection{Discussion}

The objective of this chapter was to investigate antecedents and consequences of standardized as well as customized IT adoption in self-managing service groups, taking into account individual-level, group-level, and cross-level relationships. First, the linkage between IT adoption and service performance has been examined. A key finding is the fact that teams with higher levels of customized IT adoption display higher satisfaction ratings. This seems to be indicative of the fact that a higher adoption-level of customized service technology may be relevant to generate higher customer satisfaction scores. This confirms the findings of previous studies that report that technology may enhance the service delivery process (e.g., Bitner et al. 2000). In addition to higher customer ratings, it appears that customized IT adoption positively affects a number of productivity parameters (i.e., savings accounts, investment funds, and euro obligations). Apparently, the relatively frequent use of customized IT by the SMT has an impact on both its effectiveness and efficiency. Interestingly, the adoption-level of standardized or company-wide IT does not seem to have an impact on customer satisfaction and the various productivity parameters. It may be that the adoption of common technology systems involves a fundamental precondition enabling SMTs to provide customer service at a core level, while it is not directly responsible for excellence in service performance of the SMT. This notion is supported by the existence of interaction effects between customized and standardized IT adoption and two productivity parameters (i.e., pension funds, euro obligations), which implies that for these specific services both types of technology complement each other to achieve a higher level of productivity.

Regarding the hypothesized antecedent-IT adoption relationships, our findings reveal a relationship between individual-level tolerance and the adoption-levels of the different IT types, whereas no group-level effects of tolerance were found. These findings suggest that the tolerance-IT adoption linkage is primarily based on the social comparison process within the team. Employees who, in comparison to their colleagues within the team, are more positive about the freedom given to their team to perform the service task, have higher adoption-levels of standardized and customized IT relative to their colleagues. These findings suggest that in comparison to a higherlevel self-management environment, the employee's own subjective feeling of freedom 
(that does not necessarily reflect an object reallity of self-management) seems to thave an even higher contribution to his/her adoption-level of technology.

Furthermore, we found inter-team network partichpation to have a positive impact on team member's adoption-level of standardized IT as well as customized IT. These findings illustrate that, in addition to a certain degree of autonony for the team's members, teams as a whole have a need for a platform to agree on rules and regulations and to get feedback on how to deal with front office service tasks and imnovative back office improvements. Consensus among teams on how to work together within a network and how to solve work problems promotes a mutual involvement with regard to adopting service technologies and enhances performance, as suggested by Ephross and Vassil (1988). In order to both enjoy the tolerance of freedom and the frame of reference consisting of organizational rules and regulations as well as of team-based norms, it seems important that there is adequate inter-team communication, since self-managing work groups are actively responsible for obtaining and sharing information with other departments in the organization in order to establish a good climate for service IT adoption.

In addition, we found no significant individual-level effect of usefulness on employee's adoption-level of standardized $I T$, whereas there exists a positive effect at the group level. In contrast to these findings, no significant group-level effect of usefulness was found on team member's level of adoption of customized 1T, while there emerges a significant positive effect at the individual level. These findings suggest that whether team member's adoption-level of IT is a function of his/her own subjective perception of usefulness or a function of shared team member perceptions of usefulness depends on the specific type of IT (standardized versus customized). Apparently, the decision to use standard, company-wide systems is largely predetermined by the team as a whole, which makes unique opinions of individual employees about the necessity to use this type of IT less relevant or even redundant. In comparison to standardized IT, individual employees have more freedom to decide themselves whether to adopt invaluable, but often expensive additional IT systems as instruments to support and to facilitate service activities.

Next, there exists a positive effect of the individual-level predictor ease-of-use on team member's adoption of standardized IT, whereas there appears no effect on customized IT. Since the usefulness of standardized IT applications concerns a matter of shared team member perceptions, individual employees will pay more critical attention to the user friendliness of these already implemented technologies. In service situations that are a-typical in nature, which cannot be managed by the existing standard IT applications individual employees are forced to search for alternative IT systems solve their problems. Consequently, the usefulness-issue dominates the customized IT adoption process, as employees are mainly focused on extrinsic motivational aspects in terms of "what should be done" to obtain higher rewards.

A similar discrepancy in findings occurs between the different types of IT accurs with respect to innowativeness and risk aversion. The individual-level predictor innovativeness has a positive relationship with the adoption-level of standardized IT, while it is not related to the adoption-level of customized IT. The other specified user characteristic risk aversion has a negative group-level effect on employee's adoptionlevel of customized IT, while there exists no individual-level effect. With respect to 
standardized IT, there appear no effects of risk aversion. Again, these differential findings between standardized and customized IT indicate that particular user characteristics to employee's adoption-level of IT are related to particular types of IT. The positive effect of innovativeness on standardized IT adoption is in line with other studies reporting that people with more innovative attitudes have higher degrees of IT adloption (e.g.; Schillewaert et al. 2000). Although the introduction of standard company-wide systems is largely predetermined by the top-management, the team member's personal attitude towards these imposed IT innovations remains a crucial predictor of the actual usage-rates. Surprisingly, innovativeness is not related to the adoption of customized IT. An explanation may be that shared risk perceptions are more relevant to customized IT adoption and may even overrule individual employees' personal attitudes of innovativeness in terms of importance. Employees primarily have to decide themselves whether to acquire or use those additional IT systems that are not well established in organizational IT practice. This heightened responsibility and authority together with the lack of knowledge inherent to these forms of IT enlarge the risks team members collectively run and experience when adopting customized IT.

\subsection{Theoretical Implications}

Limitations of our research may serve as anchor points for the theoretical implications of our study. To begin with, our results are based on service employees organized in teams of one financial services company. Therefore, future research should examine the generalizability of our findings across different types of service organizations and types of service settings.

Secondly, different levels of analysis were considered in testing the hypothesized antecedent-IT adoption relationships. Although multi-level analysis accounts for clustering of the data, an important drawback, however, remains common method variance, which may have inflated the hypothesized relationships between the diverse scale constructs. For future research, we recommend the employment of multiple independent data sources.

Thirdly, all relationships that were estimated in our study were cross-sectional in nature, which impedes making assumptions of causality. Longitudinal (e.g., panel) research is required to perform cross-lagged analyses in order to demonstrate causality of the hypothesized relationships and to explore the occurrence of reciprocal effects (cf. Schneider et al. 1998).

Fourthly, in this study we used a multi-level approach to investigate the IT adoption process. Our results show that the simultaneous comparison of individuallevel and group-level effects of antecedents on IT adoption provides additional insight into the processes that lead to higher adoption rates. Future studies on IT practice in work groups need to employ such a multi-level perspective to determine the impact of team member's subjective perception and personal attitudes as well as the impact of interpersonal processes (e.g., Leonard-Barton and Deschamps 1988). Specifically, additional conceptual work is needed to properly address the underlying theoretical 
mechanisms that cause these magnitude differences between individual-level and group-level relationships. Particularly additional theoretical work is required on impact of interpersonal processes among team members on individual employee's IT-related behaviors.

Finally, from our study it has become clear that predictor-performance relationships appear to differ with regard to different types of technologies. Future research may extend the present study and compare other types of technologies to determine whether the differences that were found are related to distinct underlying structural patterns of the innovations.

\subsection{Managerial Implications}

Several managerial implications with regard to the functioning of contact employees in SMTs follow from our study. First, it has been demonstrated that the adoption-level of customized IT rather than of standardized IT has an impact on service performance in terms of efficiency and effectiveness. From a managerial standpoint it seems worthwhile to increase the adoption-level of IT applications that are suited to support specific service operations of service employees in SMTs. The differential effects of antecedents on employee's adoption-levels of standardized and customized IT suggest that managers need to discriminate between types of technology and fine-tune their IT adoption strategy to the specific type of IT concerned.

Especially with respect to customized IT, the findings of our study suggest a number of points to focus on. In this study it is found that shared employees perceptions of risk were strongly linked to the adoption rate of customized IT. As such it seems especially relevant to pay attention to the influence of similar short introductions of newly designed IT applications. Designers should strive for simplified techmologies aimed at the IT-competence of employees. This can be achieved by organizing communal meetings where designers talk with the team as a whole. Also, managers should give team members room to experiment to become familiar with the nature of new techniques by scheduling in IT trial-and-error hours and to exchange their IT experiences to develop a positive communal sense of new IT applications. In addition, individual employee's unique perceptions of the IT's usefulness were significantly linked his/her own adoption rate of customized IT, which implies that designers have an important job to personally persuade employee of the necessity to acquire IT by showing the clear-cut advantages of new systems over the existing ones.

In addition, individual-level tolerance appears to be relevant to customized IT adoption and suggests the relevance to pay attention to the personal perceptions of freedom of the potential individual users. Therefore, in encouraging self-management managers need to intrinsically motivate people by shifting their attention to natural (intrinsic) rewards that are built into the task rather than to externally administer rewards in order to get people more involved with their job. The current knowledge requiring IT-supported service activities involves ample intrinsically motivating aspects. IT-supported service activities often concern meaningful, complete entities, typically having an identifiable beginning (e.g., starting and shutting-off a financial 
consulting program) (Janz et al. 1997). Managers should, therefore, leave more decision room for self-managing team workers to decide what specific activities the different employees within the SMT want to do. Finally, IT use in itself may act as a way to further mobilize this intrinsic motivation and to reinforce self-management. 


\section{Chapter 6}

\section{Conclusion}




\subsection{Synopsis}

The research perspective taken in this dissertation is motivated by the importance of SMTs as an effective strategy to manage service operations in companies. Based on the broad consensus about the issue that the delegation of managerial responsibilities to work teams of employees is critical to company effectiveness in terms of quality of work (life), customer satisfaction, and productivity, we investigated SMTs that offered varied types of services (i.e., core service and after-sales) across different industries (i.e., business-to-business and business to consumer) to acquire a comprehensive and multi-faceted understanding of SMT effectiveness in services operations. The focus in this dissertation was on service climate as a holistic aspect of work group practice in SMTs. Frequently, service activities and problems are idiosyncratic, ill-defined, and complex in nature, which implies that extra-role behaviors are critical components of effective SMT service performance. Therefore, we have investigated adaptive and proactive behavior as well as the level of IT adoption, which are concrete service performance behaviors and as such involve relevant components of service climate in SMTs. Next, with the rapid technological advancements, service operations in SMTs that are increasingly sustained by information technology to increase efficiency and effectiveness. The implication is that the use of IT systems has become inherently part of the SMT's technical task responsibilities and influences the way team members interact with each other.

In Chapter 1, we stated that the overall aim of the dissertation was: to determine the impact of SMTS on marketing effectiveness in service companies. In addition, we developed specific objectives for each separate chapter. In Chapter 2, the focus has been on the antecedents and consequences of SMT service climate in SMTs that offer after-sales services in an industrial marketing context. In Chapter 3 we examined a conceptual framework of SMT service climate in relation to SMTs that delivered core services in a business-to-consumer context. Here, we took a social-systems perspective and compared standardized services to customized services. In Chapter 4, we investigated and compared the role of adaptive and proactive service recovery behavior in SMTs functioning in a business-to-consumer marketing context. Finally, in Chapter 5 we studied adoption of standardized and customized IT by SMT team members that dealt with core services in a business-consumer setting. In sum, we have considered various antecedents in relation to different indicators of SMT service performance that range from the relatively generic construct of SMT service climate to more specific behavioral indicators of SMT service performance.

In this final chapter, we will provide a general overview of the findings that have been discussed in the separate chapters. First in section 6.2 , we report the main conclusions of the chapters with respect to the objectives that were stated in the introduction. Secondly, based on our findings we present in 6.3 an integral perspective. We attempt to develop an integral vision on improving marketing effectiveness using a SMT approach, which goes beyond the conclusions that were drawn on the basis of the individual chapters. We conclude this chapter and this dissertation by offering a number of recommendations for future research. 


\subsection{Main Conclusion of the Chapters}

\subsubsection{Chapter 2}

The objectives we formulated to acquire a general understanding of service climate practice in SMTs providing after-sales service in a business-to-business context were: 1) develop a comprehensive conceptual framework grounded in several research fields that identifies antecedents and consequences of SMT service climate, and 2) to empirically determine the antecedents and consequences of SMT service climate. Our results reveal that organizational and group factors and, to a lesser extent; employeespecific factors have a significant influence on SMT service climate. These findings clearly indicate that SMT service climate is a composite of individual-level and higherlevel factors. Furthermore, we demonstrate that higher levels of employee perceived SMT service climate positively affect customer perceived service quality and firsttime-fixed rates.

\subsubsection{Chapter 3}

In Chapter 3, we elaborated on the construct of SMT service climate by taking a social systems perspective and investigated its impact in teams that provided core services to end-consumers. This chapter contained the following objectives: 1) develop a conceptual framework of antecedents and consequences of SMT service climate taking a social systems perspective, 2) to determine whether the antecedents and consequences of SMT service climate are contingent on the type of service offered, 3) to explore the effects of group-level and individual-level antecedents on SMT service climate perceptions.

The findings show positive individual-level effects of tolerance-of-selfmanagement, flexibility and inter-team as well as intra-team support. Furthermore, at the group level intra-team support explains a significant amount of extra variance in SMT service climate perceptions and a positive interaction effect of non-routine services and flexibility is found. Moreover, it appears that between-groups variability in SMT service climate is significantly related to external outcomes, as are customer perceived service quality, share of customer, and service productivity. Finally, our findings reveal that SMT service climate-perceived service quality relationship is contingent on the type of service.

\subsubsection{Chapter 4}

In Chapter 4 we have studied and compared the role of adaptive and proactive recovery behavior in SMT that offered after-sales service to end-consumers. The objectives of Chapter 4 were: 1) develop a conceptual framework of antecedents and consequences of adaptive and proactive recovery behavior, 2) to determine the differences in antecedents and consequences between adaptive and proactive recovery behavior, and 3) to explore the antecedent effects on adaptive and proactive recovery behovior at the group level and the individual level of analysis. 
Our results show positive individual-level effects of tolerance-of-selfmanagement, organizational support, inter-team support, and intra-team support on both adaptive and proactive recovery behavior. In addition, there exists an incremental group-level effect of intra-team support on both types of recovery behavior. These findings suggest that adaptive and proactive recovery behavior share the same fundamentals and are dependent on contextual influences. In contrast to their common base, the impact of adaptive and proactive recovery behavior on external marketing criteria clearly diverges. It appears that higher levels of adaptive behavior positively affect customer parameters, as are recovery satisfaction and loyalty intentions, while proactive recovery behavior leads to higher share of customer rates.

\subsubsection{Chapter 5}

In chapter 5, we studied the adoption of IT by employees from SMTs that offered core services to end-consumers. Specifically, the objectives of this chapter were: 1) to develop a theoretical framework, based on several literature streams, that identifies antecedents and consequences of the adoption-level of standardized and customized IT by SMTs, 2) to empirically examine whether the level of IT adoption is a critically differentiating factor of SMT service performance, and 3) to determine the differences berween the adoption of standardized IT and customized IT types.

To begin with, our results report significant positive individual-level effects of tolerance-of-self-management, ease-of-use and innovativeness on the adoption-level of standardized IT and significant positive individual-level effects of tolerance-of-selfmanagement and perceived usefulness on the adoption-level of customized IT. In addition, there appear to be significant group-level effects of inter-team network and usefulness on the adoption-level of standardized IT and significant group-level effects of inter-team network and risk aversion on the adoption-level of customized IT. Finally, it is found that higher-level adoptions of customized IT - as opposed to higher adoption-levels of standardized IT - are significantly related to higher customer satisfaction scores and productivity rates.

\subsection{An Integrated Perspective}

By means of mediator models we investigated the antecedents and consequences of SMT service performance from different point-of-views. These different perspectives share a number of common features. In this section, we discuss these issues and the consequences this might have on the design, management, and research of SMTs in service companies.

\subsubsection{Social and Technical Task Determinants of Self-Managing Team Performance}

In the introduction we discussed the social technical systems theory as one of the fundamentals of the SMT approach. The findings of this dissertation confirm the importance of both social issues and technical task issues as determinants of SMT service effectiveness. 
To begin with, in all chapters tolerance-of-self-management is found to be a crucial determinant of SMT service performance. In the various service settings that have been investigated higher levels of self-management appear to be a necessary prerequisite for work teams to deliver excellent customer services. Generally, our findings show that particularly team members' cognitions and individual interpretation of the self-management process is related to SMT service performance (e.g., Spreitzer 1995), while shared perceptions of self-management do not significantly explain additional variance beyond individual employees" subjective perceptions. This signifies that the service performance in self-managing service teams particularly involves a matter of individual management skills. Therefore, the implementation of self-management can be best directed at individual team members and ainted at individual member skills such as managing customer expectations, goal setting, planning, and evaluating individual performance to improve self-directed customer service.

Consequently, it is found that formalization and inter-team network have a positive impact on SMT service performance. This implies that the self-management process in work groups needs to be guided by written rules and formalized procedures imposed by management as well as by formalized social structures. Work teams that have too much managerial freedom may develop service performance goals that do not correspond to the general objectives set by the organization. The availability of a few general procedural guidelines and feedback from the organization, combined with the presence of integrative networks, is indispensable to appropriately coordinate the selfmanagement process in highly empowered service teams and to align team goals with general organizational goals to achieve higher performance rates (e.g., Polley and Van Dyme 1994).

The findings in this dissertation also emphasize the importance of supporting group processes within and between teams to the establishment of a SMT service climate as well as to adaptive and proactive recovery behavior. Mutual social support among team members within and between teams forms an invaluable ingredient to establish a high service quality climate. Customer employees who are appropriately treated by their co-workers are inclined to use this attitude in their personal encounters with external customers as well. The importance of pro-social interpersonal relationships among employees to SMT service performance confirms the incremental value of teamwork in service operations. Furthermore, the research suggests that a collective understanding of each other's technical tasks and a shared sense of how the team members should work together in providing high quality customer service is particularly relevant in the commonly more extended and complex non-routine service operations. To effectively coach teams in non-routine services managers should pursue a mutual understanding of each other's tasks and roles within the SMT.

In addition to cooperation among team members, interpersonal interactions between the team and other teams within the organization appear crucial to SMT service performance. SMTs do not operate in isolation, but are strongly dependent on the surrounding organizational context. Service companies involve organizational systems in which work teams act as interdependent units that possess complementary skills and expertise and that are interrelated through the social dynamics of employees working together. Therefore, the quality of interpersonal processes between teams 
within organizations forms a crucial leverage point to SMT service performance. Hence, to effectively manage SMTs in services it appears of importance to take interteam relationships into account and to pay attention to the organizational infrastructure in order to facilitate, coordination, cooperation, and the sharing of information across functional boundaries within the organization.

This dissertation clearly demonstrates that SMT service performance is not exclusively a matter of social issues, but also involves technical task-related performance behaviors and attitudes. Individual team member attitudes towards and perceptions of IT appear to have a crucial impact on the usage-rates of service supporting IT applications. Team member's IT task-related performance behavior is, however, not exclusively a matter of individual factors, but is also influenced by normative social processes within teams. It is found that a shared sense of risk aversion or shared perceptions of usefulness among team members may either inhibit or facilitate IT-usage behavior. This implies that task-related issues in SMTs in services are significantly related and influenced by social processes. When changing existing task responsibilities and conditions of service employees or implementing task-related innovations it is of paramount interest not only to consider individual team member opinions, but also the leading social norms within SMTs.

In general, our findings in relation to the antecedent-service performance relationships demonstrate that the performance of empowered service teams is the result of a combination of inter-personal processes and technical task-related issues. It appears that the effects of antecedents may be moderated by service type and/or are differential across the distinctive service performance behaviors investigated. Therefore, to acquire a sophisticated understanding of empowered work teams in services it is of major relevance to develop a contingency perspective and relate both social and task antecedents to distinctive behaviors of service team performance.

\subsubsection{Individual versus Shared Perceptions}

An important theme throughout this dissertation involves the distinction between individual and shared employee perceptions. By means of hierarchical linear modeling techniques we have determined to what extent SMT service performance is based on individual team member's subjective experience, as well as on shared team member perceptions. We have compared the effects of individual-level and group-level assessments for work contextual characteristics, group properties, and individual characteristics in relation to different service performance indicators.

In sum, the findings in this dissertation clearly indicate that SMT service performance assessments are a composite of individual employee perceptions and shared team member perceptions. The results of this research further suggest that whether individual team member experiences or shared team member experiences of antecedents are relevant depends on the particular type of service performance that has been investigated. For instance, it appears that individual employee perceptions of usefulness have a crucial impact on the adoption-level of customized IT, while shared perceptions of usefulness among team members are significantly related to employees' adoption-level of standardized IT. As such, the conclusion can be drawn that a distinction between individual team member experiences and shared experiences 
yields significant incremental insight into the differential role of individual and shared team member perceptions when investigating antecedent-service performance relationships in SMTs.

\subsubsection{The Influence of Self-Managing Team Service Performance on External Marketing Outcomes}

The results in this dissertation demonstrate that all investigated SMT performance indicators are significantly related to external company outcomes including customer perceptions, actual customer behavior, and quantifiable productivity criteria.

In the first place, the relationship between SMT service performance and customer-based attitudinal and behavioral parameters has been examined. The results show positive (lagged) effects of SMT service climate, as well as adaptive and proactive recovery behavior on customer evaluations about the service quality delivered and on actual customer purchase behavior (i.e., share of customer). Although customer-contact employees and customers evaluate the service delivery process from a different perspective, their appraisals are significantly related. As such, these findings demonstrate the importance of a multi-faceted perspective taking both employee perceptions and customer perceptions into account as a way to determine and validate the marketing impact of service delivery practice in work groups.

The occurrence of delayed effects of SMT service climate suggests the causal nature of the relationship between employee perceptual measures and customer attitudinal and behavioral measures. It is important to realize that internal organizational practice may have a delayed effect on customer parameters. Due to implementation problems the impact of service practice in SMTs can be better determined after a period of time (Cohen and Bailey 1997). Furthermore, it has been demonstrated that customers' assessments of service quality are unlikely to change much over time (Bolton and Drew 1991). Therefore, service managers as well as linkage researchers should consider varying time frames and develop long-term perspectives to appropriately determine the influence of internal service practice on customer outcomes.

In addition, it appears that distinctive service performance behaviors affect differential customer measures. While excellent listening skills and being open-minded to customers lead to more positive customer evaluations, changes in actual customer purchase behavior are more the result of employee behavioral initiative and improvement actions to resolve problems timely and effectively, or to utilize extra resources to deliver additional services. Therefore, it is important to realize that certain service performance aspects are more appropriate to influence customer attitudes, whereas other performance aspects are more relevant to create changes in actual customer purchase behavior. To acquire a comprehensive understanding of the linkage between internal service performance and external customer outcomes, it is of importance to simultaneously consider distinctive aspects of internal performance.

Furthermore, it can be concluded that the linkage between SMT service climate and customer quality evaluations is contingent on service type. It appears that SMT service climate is significantly stronger related to customer perceived service quality in non-routine services when compared to routine services. This implicates that the 
specific type of service offered moderates linkages between internal performance measures and external customer-based parameters. Hence, the intensiveness of personal encounters between customer-contact employees and their customers may significantly vary across types of services. Therefore, it is recommendable to adopt a contingency approach when investigating internal-external performance linkages in different services settings.

In general, the positive impact of service-oriented performance measures (i.e., SMT service climate, adaptive and proactive behavior) on customer parameters clearly diverge with the absence of positive relationships with traditional company-based productivity measures. Too much emphasis on service-quality might result in sub-goal optimization leading to reduced team productivity. It is therefore relevant to pursue an appropriate balance between customer- and productivity issues by taking a dual-goal approach, setting explicit customer-oriented goals and productivity-oriented goals. Particularly with respect to non-routine customer services it remains a challenge to align quality goals with productivity aims. The implication is that priority setting should be the leading rationale when formulating goals for SMTs in services.

Additionally, it is found that the effects of SMT service climate also diverge in relation to the different productivity criteria investigated. For example, it is found that SMT service climate positively affect the service productivity measured as first-timefixed rate, but leads to decreases in productivity indicated as the average number of services sold per team member. This discrepancy in results may be attributed to the differential nature of these productivity criteria. The first-time-fixed rate criterion involves an example of an objective performance measure that typically reflect a dual perspective taking both the customer and management component into account, since the logic behind these measures concerns maximization of the relationship with each individual customer. Actually, this measure refers to timely and the effective problem solving of individual customer requests by employees. The extra time required to solve problems appropriately may go at the expense of servicing other customers within the required time leading to lower service productivity rates per employee. Conversely, conventional (financial) service productivity measures do not take such a customer relationship perspective, focusing primarily on the efficiency of working methods and input-output convergence.

In contrast to the other service performance measures investigated, SMT's adoption-level of customized IT is both related to customer satisfaction and traditional productivity measures. This research suggest that the use of additional IT is the appropriate response to the increase both customer parameter scores and productivity rates. The implementation of additional specialized IT systems better integrates the frequently conflicting efficiency and effectiveness demands in comparison to other service performance indicators such as SMT service climate and adaptive and proactive service behavior that mainly reflect the social dynamics associated with SMT service performance.

In conclusion, the differential findings should stimulate the ongoing debate between academicians about the compatibility of customer-oriented parameters and financial metrics for services companies thereby distinguishing between types of services. Since relatively higher usage-rates of additional customized IT systems are both related to higher customer satisfaction and productivity, the implementation of 
additional IT systems may be an appropriate strategy to reduce the existing gap between customer-oriented and traditional productivity measures. To create a competitive edge service companies should aim at the implementation IT systems that optimally fit with team members' task requirements.

\subsubsection{Virtual Self-Managing Teams: A Future Challenge}

Given the growing implementation of service-supporting IT systems in services, the influence of IT task-related issues increasingly requires attention in futures studies on self-managing teams in services. The findings of Chapter 5 have made obvious the importance of information technology as a facilitator of customer service operations leading both to increased customer satisfaction and higher scores on productivity parameters. From a company perspective the relevance of virtual teams is high. Virtual teams are typically characterized by high mobility, increased speed of work, and highly integrated resources. Virtual work aspects also improve quality of work life of team members. It reduces disruption of work life, as they do not have to travel up-anddown to meet other team colleagues. Additionally, service teams with working relationships across time and geographical place are able to deliver better customer service, since customers can be served timely and quickly everywhere, 24 hours a day.

The rapid technological developments and the trend towards globalization have led to a work environment in which coordination, communication and cooperation process among team members increasingly take place across boundaries of time, geographic regions, and organizations. Due to the infusion of information technology, a considerable part of teamwork has become virtual in many service organizations. Lipnack and Stamps (2000) define virtual teams "a group of people who work interdependently with a shared purpose across space, time, and organization boundaries using technology" (p. 18). It has been argued that work teams in services become more distributed to overcome frictions of distance and time.

Particularly in multinational organizations virtual teamwork has become commonplace. For example, Texas Instruments, a global semiconductor company, decided that its employees at company sites around the world needed an easy way of sharing information, it chose WebEx Meeting Center, a customizable hosted service that enables interactive meeting capabilities. WebEx Meeting allows secure shared viewing and control of presentations, applications and documents. When employees $\log$ in they get immediate access to online WebEx Meetings. As a result, work teams throughout the company are making WebEx Meetings part of the way they work. WebEx Meeting Center is also allowing the company to deliver quicker, more costefficient and higher quality service to its customers. Engineering teams are beginning to use WebEx to work side-by-side (virtually speaking) with customer support teams. The engineers can easily detect failures and in this way assist customer support teams in finding quick solutions to customer service problems.

Virtuality implicates accumulating complexity. Duarte and Snyder (2001) have distinguished two major factors that make virtual team more complex in relation to 'normal' work teams. In the first place, virtual teams overcome constraints related to time, distance (geography), and organization. Secondly, virtual teams typically use technology as a strategy to improve the quality of communication and to facilitate the 
cooperation and coordination among team members. The use of information technology increases complexity, as team members have an increased number of possibilities to interact with each other. While traditional work teams typically interact face-to-face, members of virtual team commonly interact by means of electronic communication and collaboration technology such as audio or video conferences, chat rooms, shared databases, and e-mail messages.

Several critical factors of virtual teams also apply to the performance of work teams in general, like human resource policies, interpersonal processes, and training on the job. A critical success factor that distinguishes virtual teams from traditional selfmanaging teams, involves the comprehensive use of advanced information and communication technology. Although several recent managerial books have been published about virtual teams, academic studies on empowered service teams that make extensive use of information systems with the purpose to communicate, coordinate, cooperate among team members and customers have remained scarce. Future conceptual and empirical work is needed for an in-depth investigation of the phenomenon of virtual service teams in customer services and their impact on marketing performance.

\subsection{A Perspective on Future Research}

Directions for additional research were provided at the end of each chapter. In this final section we would like to indicate some general directions for future research on SMTs in services.

To begin with, in this dissertation we have primarily focused on qualityoriented indicators of SMT performance, like SMT service climate, adaptive and proactive recovery behavior. In general, these service quality-oriented indicators demonstrate positive effects on customer-based parameters and/or customer behavorial measures, while they appear not related or negatively related to traditional companybased productivity parameters. These diverging results indicate that the demands from customers are not in line with company productivity and imply the importance to make reasonable trade-offs between quality and productivity team goals. Therefore, future research on SMT in services needs to simultaneously consider team member perceptions, and norms in relation to service quality as well as productivity goals and procedures. In addition to SMT service climate, future SMT studies may therefore adjust the conceptual framework and incorporate SMT service productivity as another crucial mediator of internal-performance and external marketing outcomes.

In addition, the findings of this dissertation indicate the incremental value of longitudinal designs in comparison to cross-sectional research when investigating SMT in services. Especially when investigating internal-external performance linkages it is relevant to build in time lags. Frequently, customer quality evaluations do not vary strongly over time. Therefore longitudinal assessments are required to appropriately measure the true impact of service changes in terms of observable customer behavior (e.g., actual services purchased). So far, however, lengths of lags are chosen arbitrarily (e.g., Spreitzer 1995) and there exists unclarity about what may be the appropriate lag- 
length. Future SMT service research should consider varying lag-lengths to determine, which lag best explains performance of SMTs in services.

Furthermore, an unresolved issue concerns the fact that the service performance measures investigated in this dissertation SMT service climate, adaptive and proactive recovery behavior have differential effects on the different specified productivity criteria. For example, it is found that higher levels of SMT service climate are related to increased first-time-fixed rates, but also lead to lower quantities of services sold per team member. Future SMT service research is needed to find out by what factors these differences are caused. A reasonable explanation may be that these discrepancies can be attributed to the differential nature of the productivity instruments. For instance, traditional financial productivity measures exclusively emphasize input-output efficiency to increase company profitability, while measures such as response time or the percentage of service breakdowns handled properly involve quantifiable measures that also take the quality of work into account. Therefore, future academic work is needed on the distinctive rationales behind the different productivity indicators.

In this dissertation we focused on the phenomenon of self-managing teams. To assess the amount to of managerial autonomy given to work teams we applied a onedimensional construct tolerance-of-self-management. Instead of using the term selfmanaging teams, some recent studies have proposed the term empowered teams and recommended the application of a similar, but more comprehensive multi-dimensional construct of team empowerment thereby distinguishing four aspects of empowerment, namely (1) potency, (2) meaningfulness, (3) autonomy, and (4) impact (e.g., Kirkman and Rosen 1999; Spreitzer 1995). Therefore, we recommend future research on SMTs in service to adopt the empowerment approach to better work out the phenomenon of team empowerment and to address these distinctive aspects of empowerment.

Next, the findings in Chapter 3 suggest that the nature and consequences of SMT service climate may be contingent on the type of service offered to the customer. Future studies are required to investigate the role of SMT service performance indicators across differential types of services (e.g., banking, hospitals, after-sales, consultancy) to determine to what extent the antecedents and consequences of SMT service performance measures such as SMT service climate, adaptive and proactive recovery behavior or adoption-levels IT on external performance outcomes (i.e., customer-based measures, productivity criteria) are moderated by service type.

In this dissertation we compared individual-level and group-level specifications of organizational characteristics, group properties, and attitudinal variables on SMT service performance assessments or IT-related performance behaviors. Our findings frequently demonstrate that group-level effects of antecedent variables explain a significant amount of additional variance in the different SMT service performance assessments and behaviors. These findings should encourage future theory and research to take a multi-level perspective and to address the theoretical mechanisms that cause these levels-of-analysis differences. Several empirical studies have addressed predictor-criterion relationships across levels of analysis (De Jonge et al. 1999; Ostroff et al. 2002; Ostroff and Harrison 1999; Van Yperen and Snijders 2000). However, conceptual work in relation to within-group variations in assessments of contextual and work group characteristics as well as group-level assessments of 
individual characteristics has remained scarce. Therefore, additional theory development is required to distinguish between individual factors and the influences of interpersonal processes.

Finally, we also recommend future multi-level studies on teams to account for distortions in employee perceptions and experiences of their work environment. Ratings of group properties or organizational characteristics may be influenced by mechanisms such as "purpose of ratings", "performance norms" and "social dynamics" (e.g., Ostroff 1993b). For reasons of social desirability employees tend to evaluate their own team more positively when compared to other (competing) units within the company. 


\section{References}

Albanese, R. and D.D. Van Fleet (1985). Rational Behavior in Groups: The Free-Riding Tendency, Academy of Monagement Review, 10, 244-255.

Albrecht, K. and R. Zemke (2001). Service America in the New Econowy. McGraw-Hill, New York.

Allen, N.J. and D.B. Grisaffe (2001). Employee Commitment to the Organization and Customer Reactions Mapping the Linkages. Human Resource Management Review, $\mathbb{1}$, 209-236.

Alper, S., D. Tjosvold and K.S. Law (1998). Interdependence and Controversy in Group Decision Making: Antecedents to Effective Self-Managing Teams. Organizational Behavior and Human Decision Processes, 74, 33-52.

Anderson, E.W., C. Fornell and R.T. Rust (1997). Customer Satisfaction, Productivity, and Profitability: Differences between Goods and Services. Marketing Science, 16 (2), 129 . 145.

Anderson, J.C. and D.W. Gerbing (1988). Structural Equation Modeling in Practice: A Review and Recommended Two-Step Approach. Psychological Bulletin, 103 (1), 411 423.

Andrews, K.Z. (1995). Cross-Functional Teams. Harvard Business Review, 73 (6), 12-13.

Andrews, T.L. and S.G. Rogelberg (2001). A New Look at Service Climate: Its Relationship with Owner Service Values in Small Businesses. Journal of Business and Psychology, 16 (1), 119-131.

Anthony, W.P. (1978). Participative Management. Reading, MA: Addison-Wesley.

Argote, L. (1989). Agreement about Norms and Work. Unit Effectiveness: Evidence from the

Field. Basic and Applied Social Psychology, 10, 131-140.

Argyris, C. (1957). Personality and Organization. New York: Harper \& Row.

Argyris, C. (1964). Integrating the Individual and the Organization. New York: John Wiley \& Sons.

Armistead, C.G. and G. Clark (1994). Service Quality and Service Recovery: The Role of Capacity Management. In: Control Motivation and Social Cognition, Weary, G., F., Gleicher and K.L., Marsh (Eds.), 33-73, Springer-Verlag, New York, NY.

Aspinwall, L.G. and S.E. Taylor (1997). A Stitch in Time: Self-Regulation and Proactive Coping. Psychological Bulletin, 121 (3), 417-436.

Atkinson, M.A. and C. Kydd (1997). Individual Characteristics Associated with World Wide Web Use: An Empirical Study of Playfulness and Motivation. The Database for Advances in Information Systems, 28, 53-62.

Babin, B.J. and J.A. Attaway (2000). Atmospheric Affect as a Tool for Creating Value and Gaining Share of Customer. Joumal of Business Research, 49 (2), $91-99$.

Babin, B.J. and J.S. Boles (1996). The Effects of Perceived Co-Worker Involvennent and Supervisor Support on Service Provider Role Stress, Performance and Job Satisfaction. Jowrnal of Retailing, 72 (1), 57-75.

Bak, C.A., L.H. Vogt, W.R. George and I.R. Greentree (1995). Management by Team: An Innovative Tool for Running a Service Organization Through Internal Marketing. Logistics Information Management, 8 (4), 12-18.

Bandurit, A. (1986). Social Foundations of Thought and Action: A Social Cognitive Theory. Englewood Cliffs, NJ: Prentice Hall.

Bandura, A. (1997). Self-Efficacy: The Exercise of Control. New York: W.H. Freeman and Company. 
Banker, R.D., J.M. Field, and K.K. Sinha (1997). Work Team Implementation and

Trajectories of Manufacturing Quality: A Longitudinal Field Study. Working Paper.

Bansal, H.S., M.B. Mendelson and B. Sharma (2001). The Impact of Internal Marketing Activities on External Marketing Outcomes. Journal of Quality Management, 6, $61-76$.

Barker, J.R. (1993). Tightening the Iron Case: Concertive Control in Self-Management

Teams. Administrative Science Quarterly, 38, 408-437.

Barnard, C.I. (1938). The Functions of the Executive. Cambridge, MA: Harvard University Press.

Baron, R.M. and D.A. Kenny (1986). The Moderator-Mediator Variable Distinction in Social Psychological Research: Conceptual, Strategic, and Statistical Considerations, Journal of Personality and Social Psychology, 51 (6), 1173-1182.

Barry B. and G.L. Stewart (1997). Composition, Process and Performance in Self-Managed Groups: "The Role of Personality. Joumal of Apptied Psychology, 82 (1), 62-79.

Bartel, C.A. and R. Saavedra (2000). The Collective Construction of Work Group Moods. Administrative Science Quarterly, 45, 197-231.

Bartol, K.M. and L.L. Hagmann (1992). Team-Based Pay Plans: A Key to Effective Teamwork. Compensation and Benefits Review, 24, 24-29.

Bateman, T.S. and M.J. Crant (1993). The Proactive Component of Organizational Behavior. Journal of Organizational Behavior, 14, 103-118.

Bateman, T.S. and M.J. Crant (1999). Proactive Behavior: Meaning, Impact, and Recommendations. Business Horizons, 42 (3), 63-70.

Batt, R. (1999). Work Organization, Technology and Performance in Customer Service and Sales. Industrial and Labor Relations Review, 52, 539-563.

Bell, S.J. and B. Menguc (2002). Raising the Bar of Service Quality: The Role of the Salesperson-Organisation Relationship and Organisational Citizenship Behaviours. Working Paper in Marketing, 2 Department of Marketing, University of Melbourne.

Bell, C.R. and R.E. Zemke (1987). Service Breakdown: The Road to Recovery. Management Review, 32-35.

Bernhardt, K.L., N. Donthu and P.A. Kennett (2000). A Longitudinal Analysis of Satisfaction and Profitability. Journal of Business Research, 47, 161-171.

Berrien, F.K. (1968). General and Social Systems. New Brunswick: Rutgers University Press. Berry, L.L., A. Parasuraman and V. Zeithaml (1994). Improving Service Quality in America: Lessons Learned. Academy of Management Executive, 8, 32-45.

Berry, L.L., V.A. Zeithaml and A. Parasuraman (1990). Five Imperatives for Improving Service Quality. Slocm Management Review, 31 (4), 29-38.

Bettencourt L.A. and S.W. Brown (1997). Contact Employees: Relationships Among Workplace Fairness, Job Satisfaction and Prosocial Service Behaviors. Journal of Rerailing, 73 (1), 39-61.

Bitner, M.J. (1990). Evaluating Service Encounters: The Effects of Physical Surroundings and Employee Responses. Journal of Marketing, 54, 69-82.

Bitner, M.J., B.H. Booms and L.A. Mohr (1994). Critical Service Encounters: The Employee's Viewpoint. Journal of Marketing, 58, 95-106.

Bitner, M.J., B.H. Booms and M. Stanfield Tetreault (1990). The Service Encounter: Diagnosing Favorable and Unfavorable Incidents. Jowrnal of Marketing, 54, 69-82.

Bitner, M.J., S.W. Brown and M.L. Meuter (2000). Technology Infusion in Service Encounters. Joumal of the Academy of Marketing Science, 28, 138-149.

Blau, G. (1995). Influence of Group Lateness on Individual Lateness: A Cross-Level Examination. Academy of Management Journal, 38 (5), 1483-1496. 
Blauner, R. (1964). Alienation and Freedom. Chicago: University of Chicago Press.

Bhese, P.D. (2000). Within-Group Agreement, Non-Independence, and Reliability: Implications for Data Aggregation and Analysis. In: Multilevel Theory, Research, and Methods in Organizations, Klein, K.J. and S.W.J. Kozlowski (Eds.), 349-381, San Francisco, CA: Jossey-Bass.

Boles, J.C. and B.J. Babin (1996). On the Front Lines: Stress, Conflict, and the Customer Service Provider. Joumal of Business Research, 37, 41-50.

Bolon, D.S. (1999). Level of Analysis Considerations in Organizational Citizenship Behavior Research: An Empirical Investigation of Individual and Work Group Effects Among Hospital Employees. Health Management Research, 12, 92-108.

Bolton, R.N. and J.H. Drew (1991). A Longitudinal Analysis of the Impact of Service Changes on Customer Attitudes. Journal of Marketing, 55, 1-9.

Boshoff, C. (1999). RECOVSAT: An Instrument to Measure Satisfaction with TransactionSpecific Service Recovery. Joumal of Service Research, 1 (3), 236-249.

Boshoff C. and J. Allen (2000). The Influence of Selected Antecedents on Frontline Staff's Perceptions of Service Recovery Performance, International Journal of Serwice Jwdustry Management, 11 (1), 63-90.

Boshoff, $C$. and $J$. Leong (1998). Empowerment, Attribution and Apologising as Dimensions of Service Recovery: An Experimental Study. Internarional Joumal of Service Industry Management, 9 (1), 24-47.

Bowen, D.E. (1990). Interdisciplinary Study of Service: Some Progress, Some Prospects. Joumal of Business Research, 20, 71-79.

Bowen, D.E. and R. Johnston (1999). Internal Service Recovery: Developing a New Construct. International Joumal of Service Industry Management, 10 (2), 118-131.

Bowen, D.E. and E.E. Lawler III (1992). The Empowerment of Service Workers: What, Why, How, and When. Sloan Managenent Review, 33 (Spring), $31-39$.

Bowen, D.E. and E.E. Lawler III (1995a). Empowering Service Employees. Sloan Management Review, 36 (Summer), 73-84.

Bowen, D.E. and E.E. Lawler III (1995b). Organizing for Service: Empowerment or Production Line? In: Understanding Services Management, Glynn, W.J., and J.G. Barnes (Eds.), 269-294, Chichester: John Wiley \& Sons.

Brannick, M.T. and C. Prince (1997). An Overview of Team Performance Measurement. In: Team Performance Measurement and Assessment, Brannick, M.T., E. Salas and C. Prince (Eds.), 3-16, Lawrence Erlbaum Associates, Mahwah, NJ.

Brown S.P. and T.W. Leigh (1996). A New Look at Psychological Climate and its Relationship to Job Inwolvement, Climate, and Performance. Jownat of Applied Psychology, 81(4), 358-368.

Bryk. A.S. and S.W. Raudenbush (1992). Hierapchical Linear Models: Applications and Data Analysis Methods. Newbury Park, CA: Sage Publications.

Burke, M.I., C.C. Borucki and A.E. Hurley (1992). Reconceptualizing Psychologicall Climate un a Retail Service Environment: A Multiple-Stakeholder Perspective. Jownal of Applied Psychology, 77 (5), 717-729.

Bursic, K.M. (1992). Strategies and Benefits of the Successful Use of Teams in Manufacturing Organizations, IEEE Transactions on Engineering Management, 39, 277289.

Cameron, K.S. (1986). Effectiveness as Paradox: Consensus and Conflict in Conceptions of Organizational Effectiveness. Management Science, 32, 539-553. 
Campion, M.A., G.J. Medsker and A.C. Higgs (1993). Relations Between Work Group Characteristics and Effectiveness: Implications for Designing Effective Work Teams. Personnel Psychology, 46, 823-850.

Campion, M.A., E.M. Papper and G.I. Medsker (1996). Relations Between Work Team Characteristics and Effectiveness: A Replication and Extension. Personnel Psychology. $49,429-452$.

Chaston, 1. (1998). Self-Managed Teams: Assessing the Benefits for Small Service-Sector Firms. British Journal of Management, 9, 1-12.

Chebat, J.C. and P. Kollias (2000). The Impact of Empowerment on Customer Contact Employees' Roles in Service Organizations. Journal of Service Research, 3 (1), 21 7-229

Chiles, A.M. and T.E. Zorn (1995). Empowerment in Organizations: Employees' Perceptions of the Influences of Empowerment. Journal of Applied Communication Research, 23, 125.

Churchill, G.A., Jr., N.M. Ford and O.C. Walker Jr. (1974). Measuring Job Satisfaction of Industrial Salesmen. Journal of Marketing Research, 11, 254-360.

Cohen, S.G. (1994). Designing Effective Self-Managing Work Teams. In: Advances in Interdisciplinary Studies of Work Teams, Beyerlein, M.M. and D.A. Johnson (Eds.), 1, $67-$ 102, JAI Press, Greenwich, CT.

Cohen, S.G. and D.E. Bailey (1997). What Makes Teams Work: Group Effectiveness Research from the Shop Floor to the Executive Suite. Journal of Management, 23, 239290.

Cohen, S.G. and G.E. Ledford Jr. (1994). The Effectiveness of Self-Managing Teams: A Quasi-Experiment. Human Relations, 47, 13-43.

Cook, J.D., S.J. Hepworth, T.D. Wall and P.B. Warr (1981). The Experience of Work: A Compendium and Review of 249 Measures and their Use. Academic Press Inc.(Londen) Lid.

Cordery, J.L., W.S. Mueller and L.M. Smith (1991). Attitudinal and Behavioral Effects of Autonomous Group Working: A Longitudinal Field Study. Academy of Management Journal, 34, 464-476.

Crant, J.M. (1995). The Proactive Personality Scale and Objective Job Performance Among Real Estate Agents. Journal of Applied Psychology, 80, 532-537.

Crant, J.M. (2000). Proactive Behavior in Organizations. Journal of Management, 26 (3), 435462.

Dabholkar, P.A. and R.P. Bagozzil (2002). An Attitudinall Model of Technology-Based SelfService: Moderating Effects of Consumer Traits and Situational Factors. Joural of Academy of Marketing Science, 30 (3), 184-201.

Davenport, T.H. (1997). Knowledge and Knowledge Managemem. Paper presented to the Boston University School Press, Boston, MA.

David, F.R., J.A. Pearce II and W.A. Randolph (1989). Linking Technology and Structure to Enhance Group Performance. Joumal of Applied Psychology, 74, 2, 233-242.

Davis, L.E. (1971). The Coming Crisis in Production Management Technology and Organization. Intermational Joumal of Production Research, 9, 65-82.

Davis, L.E. (1977). Evolving Alternative Organization Designs: Their Sociotechnical Bases. Human Relations, 30, 261-273.

Davis, T.R.V. (1999). Different Service Firms, Different Core Competencies. Business Horizons, 42 (5), 23-34. 
Davis, F.D., R.P. Bagozzi and P.R. Warshaw (1989). User Acceptance of Infomation Technology: A Comparison of Two Theoretical Models. Managenent Science, 35, 982 1003.

DeCanio S.J., C. Dibble and K. Amir-Atefi (2000). The Importance of Organizational Structure for the Adoption of Innovations. Management Science, 46, 1285-1299.

De Jonge, J., G.J.P. Van Breukelen, J.A. Landeweerd and F.J.N. Nijhuis (1999). Comparing Group and Individual Level Assessments of Job Characteristics in Testing the Job Demand-Control Model: A Multi-Level Approach. Human Relations, 52 ; $95-122$.

DeLone, W. and E. McLean (1992). Information System Success: The Quest for the Dependent Variable. Information Systems Reseanch, 3, 60-95.

Dempster, A.P., N.M. Laird and D.B. Rubin (1977). Maximum Likelihood from lncomplete Data via the EM Algorithm. Jownal of Royal Statistical Association, 76, 341-353.

DeSanctis, G. and B.M. Jackson (1994). Coordination of Information Technology Management: Team Based Structures and Computer-Based Communication Systems. Jounal of Management Information Systems; 10, 85-110.

Drolet, A.L. and D.G. Morrison (2001). Do we Really Need Multiple-Item Measures in Service Research? Jownal of Service Research, 3 (3), 196-204.

Duarte, D.L. and N. Tennant Snyder (2001). Mastering Virtual Teams: Strategies, Tools, and Techniques that Succeed ( $2^{\text {nd }}$ Ed) Jossey-Bass, San Francisco.

Dumaine, B. (1994). The Trouble with Teams. Fortune, September, 86-92.

Ellemers, N., D. De Gilder and H. Van den Heuvel (1998). Career-Oriented versus TeamOriented Commitment and Behavior at Work. Journal of Applied Psychology, 83, 717 730 .

Emery, C.R. and L.D. Fredenhall (2002). The Effect of Teams on Firm Profitability and Customer Satisfaction. Joumal of Serwice Research, 4 (3), 217-229.

Ephross, P.H. and T.V. Vassil (1988). Teams that Work: Structure \& Process. New York: Columbia University Press.

Fayol, H. (1949). General and Industrial Management. London: Pitman.

Feldman, D.C. (1984). The Development and Enforcement of Group Norms. Academy of Management Review, 9 (1), 47-53.

Ferrell, O.C. and S.J. Skinner (1988). Ethical Behavior and Bureaucratic Structure in Marketing Research Organizations. Joumal of Marketing Research, 25, 103-109.

Festinger, L. (1954). A Theory of Social Comparison Processes. Human Relations, 7, 117140.

Furebaugh G. (1979). Assessing Group Effects: A Conparison of Two Methods. Sociological Methods and Research, 7, 384-395.

Ford, J.D. and J.W. Slocum (1977). Size, Technology, Environment, and the Structure of Organizations. Academy of Management Review, $2,561-573$.

Frambach, R.T., H.G. Barkema, B. Nooteboom and M. Wedel (1998). Adoption of a Service Innovation in the Business Market: An Empirical Test of Supply-Side Variables. Jonmal of Business Research, 41, 161-174.

George, J.M. (1990). International Marketing and Organizational Behavior: A Partnership in Developing Customer-Conscious Employees at Every Level. Journal of Business Research, 20, 63-70.

Gerth, H.H. and C.W. Mills (1958). From Max Weber: Essays in Sociology. New York: Oxford University Press. 
Gilks, W., S. Richardson and D.J. Spiegelhalter (1996). Markow Choin Monre Corlo in Practice. London, Chapman atid Hall.

Gilson, L.L., C.E. Shalley and T.C. Blum (2001). Team and Organizational Attitudes as a Lens and Mirror Impacting Customer Satisfaction: An Empirical Test in Self-Managed Teams. Jownal of Quality Management, 6, 235-256.

Gladstein; D.L. (1984). Groups in Context: A Model of Task Group Effectiveness. Administrative Science Quarterly, 29 (4), 499-517.

Goldstein, H. (1995). Multlevel Statistical Models (2td Ed.). London: Griffin.

Goldstein, H., J. Rasbash, I. Plewis, D. Draper, W. Browne, M. Yang, G. Woodhouse and M. Healy (1998). A User's Guide to MLwiN. Multilevel Models Project Institute of Education: University of London.

Goodman, P.S. (1979). Assessing Organizational Change: The Rushton Quality of Work Experiment. New York: Wiley-Interscience.

Goodman, P.S., R. Devadas and T.L. Griffith Hughson (1988). Groups and Productivity: Analyzing the Effectiveness of Self-managing Teams. In: Productivity in Organizations, Campbell, J.P., R.J. Campbell and Associates (Eds.), 295-327, San Francisco: JosseyBass.

Grewal, R., R. Mehta and F.R. Kardes (2000). The Role of the Social-Identity Function of Attitudes in Consumer Innovativeness and Opinion Leadership. Journal of Economic Psychology, 21, 233-252.

Griffin, R.K., D. Baldwin and R.T. Sumichrast (1994). Self-Management Information System for the Service Industry: A Conceptual Model. Jounnal of Management Information Systems, 10, 111-133.

Grönroos, C. (1990). Relationship Approach to Marketing in Service Contexts: The Marketing and Organizational Behavioral Interface. Joumol of Business Research, 20, 312.

Hackman, J.R. (1976). Group Influences on Individuals in Organizations. In: Homdbook of Industrial and Organizational Psychology, Dunnette, M. (Ed.), 1455-1525, Chicago: Rand MeNally.

Hackman, J.R. (1987). The Design of Work Teams. In: Handbook of Organizational Behavior, Lorsch, J.W. (Ed.), 315-342, Prentice-Hall, Inc., Englewood Cliffs.

Hackman, J.R. (1990). Groups That Work (and Those That Don'). Jossey-Bass, San lancisco.

Hackman, J.R. and G.R. Oldhan (1976). Motivation through the Design of Work: A Test of a Theory. Organizational Behavior and Human Performance, 16, 250-279.

Hackman, J.R. and G.R. Oldham (1980). Work Redesign. Reading, MA: Addisson-Wesiey. Hackman, J.R and R.E. Walton (1986) Leading Teams in Organizations. In: Designing Effective Work Teams, Goodman, P.S. (Ed.), 72-1 19, San Francisco: Jossey-Bass.

Halstead, D., C. Droge and M. B. Cooper (1993). Product Warranties and Post-Purchase Service: A Model of Consumer Satisfaction with Complaint Resolution. Jownal of Service Marketing, 7 (1), 33-40.

Harkins, S.G. (1987). Social Loafing and Social Facilitation. Jownal of Experimental Social Psychology, 23, 1-18.

Hart, C.W.L. (1996). Made to Order. Mowketing Management, 5, 10-22.

Hart C.W.L., I.L. Heskett and W.E. Sasser (1990). The Profitable Art of Service Recovery. Haward Business Review, 148-156. 
Hartline, M.D. and O.C. Ferrell (1996). The Management of Customer-Contact Service Employees. Journal of Marketing, 60, 52-70.

Farvey, C.W. and P. Filiatrault (1991). Service Delivery Processes: New Technology and Design. International Jounal of Bank Makketing, 9, 25-31.

Hatano, G. and K. Inagaki (1986). Two Sources of Expertise. In: Child Develophent and Education in Japan, Stevenson, H., H. Azuma and K. Hakuta (Eds.), 262-272, New York: W. H. Freeman.

Hays, J.M and A.V. Hill (2001). A Preliminary Investigation of the Relationships between Employee Motivation/Vision, Service Learning, and Perceived Service Quality. Journal of Operations Management, 19,335-349.

Helfert, G., K. Vith (1999). Relationship Marketing Teams: Improwing the Utilization of Customer Relationships Potentials through a High Team Design Quality. Industrial Marketing Management, 28, 553-564.

Heskett, J.L., W.E. Sasser and L.A. Schlesinger (1997). The Senvice Profit Cham. New York, Free Press.

Hill, S. (1991). Why Quality Circles Failled But Total Quality Might Succeed. British Joumal of Industrial Relations, 29, 541-568.

Hocutt, M.A. and T.H. Stone (1998). The Impact of Employee Empowerment on the Quality of a Service Recovery Effort. Joumal of Quality Management, 3 (1), 117-132.

Hofmann, D.A. (1997). An Overview of the Logic and Rationale of Hierarchical Linear Models. Jownal of Management, 23, 723-744.

Holt, D.H. (1990). Management: Principles and Practices. Englewood Cliffs, NJ: Prentice Hall.

Holyoak, K.J. (1991). Symbolic Connectionism: Toward Third-Generation Theories of Expertise. In: Toward a General Theory of Expertise, Eriesson, K.A. and J. Smith (Eds.), 301-335, Cambridge, England: Cambridge University Press.

Horwitz, F. and M.A. Neville (1996). Organization Design for Service Excellence: A Review of the Literature. Human Resource Management, 35, 471-492.

Humphrey, R.H. and B.E. Ashforth (1994). Cognitive Scripts and Prototypes in Service Encounters. In: Advances in Service Marketing and Management, Swartz, T.A., D.E. Bowen and S.W. Brown (Eds.), 3, 175-99, Greenwich, CT: JAI Press.

Hyatt, D.E. and T.M. Ruddy (1997). An Examination of the Relationship between Work Group Characteristics and Performance: Once More into the Breech. Personnel Psychology, 50, 553-585.

Iacobucci, D. (1998). Services: What Do we Know and Where Shall we Go? A View from Marketing. In: Advances in Service Markering and Management, Swartz, T.A., D.E. Bowen and S.W. Brown (Eds.), 7, 1-96, Greenwich, CT: JAI Press.

Ives, B. and M. Olson (1984). User Involvement and MIS Success: A Review of Research. Management Science, 30, 586-603.

James, L.R. (1982). Aggregation Bias in Estimates of Perceptual Agreement. Joumal of Applied Psychology, 67, 219-229.

James, L.R. R.G. Demaree and $G$. Wolf (1993). $r_{w g}$. An Assessment of Within-Group Interrater Agreement. Jownal of Applied Psychology, 78, 306-309.

Janz, B.D. (1999). Self-Directed Teams in IS: Correlates for Improved Systems Development Work Outcomes. Information \& Management, 35, 171-192.

Janz, B.D., J.C. Wetherbe, G.B. Davis and R.A. Noe (1997). Reengineering the Systems Development Process: The Link between Autonomous Teams and Business Process Outcomes. Journal of Management Information Systems, 14, 41-68. 
Johnson, J.W. (1996). Linking Employee Perceptions of Service Climate to Customer Satisfaction. Personnel Psychology, 49, 831-851.

Johnston, R. (1995). Service Failure and Recovery: Impact, Attributes, and Process. Advances in Service Marketing and Management: Research and Practice, 4, 211-228.

Jöreskog, K.G. and D. Sorrbom (1993). LISREL 8: A Guide to the Program and Applications. Chicago: SPSS.

Kalbaugh, E.G. (1998). Self-directed Teams: Organizing the Modern Agency. Rough Notes; Indianapolis.

Karimi, J., T.M. Somers and Y.P. Gupta (2001). Impact of Information Technology Management Practices on Customer Service. Journal of Management Information Systems, $17,125-158$.

Katz, R. and D. Kahn (1978). The Social Psychology of Organizations (2 ${ }^{\text {nd }}$ Ed.). New York: John Wiley.

Katzenbach, J.R. and D.K. Smith (1993). The Wisdom of Teams. Boston: Harvard Business School Press.

Kellogg, D.L: and Chase R.B. (1995). Constructing an Empirically Derived Measure for Customer Contact. Management Science, 41 (11), 1734-1749.

Kellogg; D.L. and W. Nie (1995). A Framework for Strategic Service Management. Journal of Operations Management, 13 (4), 323-337.

Kelly, J.E. (1978). A Reappraisal of Socio-Technical Systems Theory. Human Relations, 31, 1069-1099.

Kidwell, R.E., Jr. and K.W. Mossholder (1997). Cohesiveness and Organizational Citizenship Behavior: A Multilevel Analysis Using Work Teams and Individuals. Journal of Management, 23, 775-793.

Kirkman, B.L. and B. Rosen (1999). Beyond Self-Management: Antecedents and Consequences of Team Empowerment. Academy of Management Jourral, 42, 58-74.

Klein, J.A. (1994). Maintaining Expertise in Multi-Skilled Teams. In: Advances in Interdisciplinary Studies of Work Teams, Beyerlein, M.M. and D.A. Johnson (Eds.), 1, 145-165, JAI Press, Greenwich, CT.

Klein K.J., A.B. Conn, D.B. Smith and J.S. Sorra (2001). Is Everyone in Agreement? An Exploration of Within-Group Agreement in Employee Perceptions of the Work Environment. Journal of Applied Psychology, 86 (1), 3-16.

Kleinbaum, D.G., L.L. Kupper and K.E. Muller (1988). Applied Regression Analysis and Other Multivariable Methods (2nd Ed). Boston: PWS-KENT Publishing Company.

Kock, N. and R. J. McQueen (1998). Groupware Support as a Moderator of Interdepartmental Knowledge Communication in Process Improvement Groups: An Action Research Study. Information Systems Journal, 8, 183-198.

Kouzes, J.M. and B.Z. Posner (1987). The Leadership Challenge. New York: Jossey-Bass.

Kozlowski, S.W.J. and K.J. Klein (2000). A Multilevel Approach to Theory and Research in Organizations: Contextual, Temporal, and Emergent Processes. In: Multilevel Theory. Research, and Methods in Organizations, Klein, K.J. and S.W.J. Kozlowski (Eds.), 3-90, San Francisco: Jossey-Bass.

Larson, C.E. and F.M.J. LaFasto (1989). Teamwork. London: Sage.

Larsson, R. and D.E. Bowen (1989). Organization and Customer: Managing Design and Coordination of Services. Academy of Management Review, 14 (2), 213-233.

Lawler, E.E., III (1986). High-Involvement Management: Participative Strategies for Improving Orgamisational Performance. San Fransisco: Jossey-Bass. 
Lawler, E.E. II, S.A. Mohman and G.E. Ledford Jr. (1995). Creatimg Migh Performance Organizations: Practices and Results of Employee Involwement and Total Quality Management in Fortune 1000 Companies. San Francisco: Jossey-Bass

Ledford, G.E. (1993). Employee Involvement: Lessons and Predictions. In: Organizing for the Furure, Galbraith, J.R. and E.E. Lawler, 43-64, San Francisco, CA: Jossey-Bass.

Leonard-Barton, D. and I. Deschamps (1988). Managerial Influence in the Implementation of New Technology. Management Science, 31, 1252-1265.

Levitt, T. (1972). Product-Line Approach to Service. Harvard Business Review, SeptemberOctober, $41-52$.

Lincoin J.R. and G. Zeitz (1980). Organizational Properties from Aggregate Data: Separating Individual and Structural Effects. American Sociological Review, 45, 391-408.

Lindsley, D.H. D.J. Brass and J.B. Thomas (1995). Efficacy-Performance Spirals: A Multilevel Perspective. Academy of Management Review, 20, 645-678.

Lipnack, J. and J. Stamps (2000). Virtwal Teams: People Working Across Bowndaries with Technology (2 ${ }^{\text {nd }}$ Ed). Jolm Wiley \& Sons, Inc. New York.

Locke, E.A. and G.P. Latham (1984). Goal Setring: A Morivational Technique that Works. New Jersey: Englewood Cliffs Inc.

Locke, E.A., K.N. Shaw, L.M. Saari, and G.P. Latham (1981). Goal Setting and Task Performance: 1969-1680. Psychological Bulletin, 90, 125-152.

London, M. and E.M. Mone (1999). Continuous Learning. In: The Changing Nature of Performance: Implications for Staffing, Motivation, and Development, IIgen, D.R. and E.D. Pulakos (Eds.), 119-153, San Francisco: Jossey-Bass.

Loveman, G.W. (1998). Employee Satisfaction, Customer Loyalty, and Financial Performance: An Empirical Examination of the Service Profit Chain in Retail Banking. Journal of Service Research, 1, 18-31.

Lowry, C.B. (2000). The Vision of a Team-Based Learning Organization. Working Paper, University of Maryland Libraries.

Lucas, H. (1978). Empirical Evidence for a Descriptive Model of Implementation. MIS Quarterly, 2, 27-41.

Lusch R.F. and B.J. Jaworski (1991). Management Control, Role Stress, and Retail Store Management Performance. Joumal of Retailing, 67 (4), 397-419.

Magjuka, R.F. (1991/1992). Survey: Self-Managed Teams Achieve Continuous Improvement Best. National Productivity Review, $51-57$.

Manz, C.C. and H.P. Sims, Jr. (1987). Leading Workers to Lead Themselves: The External Leadership of Self-Managing Work Teams. Administnative Science Quarterly, 32, 106128.

Manz, C.C. and H.P. Sims, Jr. (1989). Superleadership. New York: Prentice Hall.

Manz, C.C. and H.P. Sims, Jr. (1995). Challenges to Implementing Self-Managing Teams. Journal for Quality \& Participation, 18 (2), 24-32.

Marks, M.A., S.C. Burke, M.J. Sabella and S.J. Zaccaro (2002). The Impact of Cross-Training on Team Effectiveness. Journal of Applied Psychology, 87 (1), 3-13.

Marks, M.A., S.J. Zaccaro and J.E. Mathieu (2001). A Conceptual Framework and Taxonomy of Team Processes. Academy of Management Review, 26, 356-376.

Martinko, M.J. and W.L. Gardner (1982). Learned Helplessness: An Alternative Explanation for Performance Deficits. Academy of Management Review, 7 (2), 195-204.

Mathieu, J.E. and D.V. Day (1997). Assessing Processes Within and Between Organizatonal Teams: A Nuclear Power Plant Example. In: Team Performance Measturement and Assessment, Brannick, M.T., E. Salas and C. Prince (Eds.), 173-196, Lawrence Erlbaum Associates, Mahwah, NJ. 
Mathieu, J.E., T.S. Heffner, G.F. Goodwin, E. Salas and J.A. Cannon-Bowers (2000). The Influence of Shared Mental Models on Team Process and Effectiveness. Journal of Applied Psychology, 85, 273-283.

Mathieu, J.E. and \$. Kohler (1990). A Cross-Level Examination of Group Absence Influence on Individual Absence. Journal of Applied Psychology, 75, 217-220.

Maslow, A.H. (1970). Motivation and Personality (2 ${ }^{\text {nid }}$ Ed.). New York: Harper and Row.

McGregor, D. (1960). The Human Side of Enterprise. New York: McGraw Hill.

Meuter, M.L., A.L. Ostrom, R.I. Roundtree and M.J. Bitner (2000). Self-Service Technologies: Understanding Customer Satisfaction With Technology-Based Service Encounters. Journal of Marketing, 64, 50-64.

Meyer, J.P. and N.J. Allen (1997). Commitment to the Workplace: Theory, Research, and Application. Thousand Oaks, CA: Sage.

Meyer, M.W. and V. Gupta (1995). The Performance Paradox. Research in Organizational Behavior, 16, 309-369.

Michaels, R.E., W.L. Cron, A.J. Dubinsky and E.A. Joachimsthaler (1988). Influence of Formalization on the Organizational Commitment and Work Alienation of Salespeople and Industrial Buyers. Journal of Marketing Research, 25, 376-383.

Michaels, R.E., A.J. Dubinsky, M. Kotabe and C.U. Lim (1996). The Effects of Organizational Formalization on Organizational Commitment and Work Alienation in US, Japanese and Korean Industrial Salesforces. European Journal of Marketing, 30, 8-24.

Miles, R.E. (1965). Human Relations or Human Resources. Harvard Business Review, 43 (4), 148-151.

Miller, J.G. (1978). Living Systems. New York: McGraw-Hill.

Moorhead, G., C.P. Neck and M.S. West (1998). The Tendency toward Defective Decision Making within Self-Managing Teams: The Relevance of Groupthink for the $21^{\text {st }}$ Century. Organizational Behavior and Human Decision Processes, 73 (2/3), 327-351.

Morris, J.H., R.M. Steers (1980). Structural Influences on Organizational Commitment. Journal of Vocational Behavior, 17, 50-57.

Morrison, E.W. and C.C. Phelps (1999). Taking Charge at Work: Extra-Role Efforts to Initiate Workplace Change. Academy of Management Journal, 42 (4), 403-419.

Morrison, P.D., J.H. Roberts and E. Von Hippel (2000). Determinants of User Innovation and Innovation Sharing in a Local Market. Management Science, 46, 1513-1527.

Mowday, R.T. and R.I. Sutton (1993). Organizational Behavior: Linking Individuals and Groups to Organizational Contexts. In: Annual Review of Psychology, Porter, L.W. and M.R. Rosenzweig (Eds.), 195-229, Palo Alto, CA: Annual Reviews.

Mulligan, P. (1999). Differentiating Service Tasks for IT Application: An Exploratory Analysis in Financial Services. International Joumal of Service Industry Management, 10 (2), 1904210 .

Murphy, P.R. and S.E. Jackson (1999). Managing Work Role Performance: Challenges for Twenty-First Century Organizations and Their Employees. In: The Changing Nature of Performance: Implications for Staffing, Motivation, and Development, Ilgen, D.R. and E.D. Pulakos (Eds.), 325-365, San Francisco: Jossey-Bass.

Nadler, D.A. and M.L. Tushman (1988). Strategic Linking: Designing Formal Coordination Mechanisms. In: Reading in the Management of Innovations, Tushman, M.L. and W.L. Moore (Eds.), 469-486, Cambridge: MA Ballinger Publishing Company. 
Nakata, C. and K. Sivakumar (1996). National Culture and New Product Development: An Integrative Review. Jownd of Morkering, $60,61-72$.

Neck, C.P., G.L. Stewart and C.C. Manz (1996). Self-Leaders within Self-Leading Teans: Toward an Optimal Equilibrium. In: Advances in Interdisciplinary Studies of Work Teams, Beyerlein, M.M., D.A. Johnson and S.T. Beyerlein (Eds.), 3, 43-65.

Neuman, G.A. and J. Wright (1999). Team Effectiveness: Beyond Skills and Cognitive Ability. Jownal of Applied Psychology, 84 (3), 376-389.

Nicholson, N. and G. Johns (1985). The Absence Culture and Psychological Contract - Who's in Control of Absence? Academy of Management Review, 10 (3), 397-408.

Nunnally, J.C. and I.H. Bernstein (1994). Psychometric Theory (3 Ed. New York.

Nygren, R. and E.L. Levine (1996). Leadership of Work Teams: Factors Influencing Team Outcomes. In: Advances in Interdisciplinary Studies of Work Teams, Beyerlein, M.M., D.A. Johnson and S.T. Beyerlein (Eds.), 3, 67-104.

Ostroff, C. (1993a). Comparing Correlations Based on Individual-Level and Aggregated Data. Joumal of Applied Psychology, 78 (4), 569-582.

Ostroff, C. (1993b). Rater Perceptions, Satisfaction and Performance Ratings. Jowrnal of Occupational and Organizational Psychology, 66, 345-356.

Ostroff, C. (2002). Substantive and Operational Issues of Response Bias Across Levels of Analysis: An Example of Climate-Satisfaction Relationships. Journal of Applied Psychology, 87 (2), 355-268.

Ostroff, C. and D.A. Harrison (1999). Meta-Level of Analysis; and Best Estimates of Population Correlations: Cautions for Interpreting Meta-Analytic Results in Organizational Behavior. Journal of Applied Psychology, 84 (2), 260-270.

Ostroff, C., A.J. Kinicki and M.A. Clark (2002). Substantive and Operational Issues of Response Bias Across Levels of Analysis: An Example of Climate-Satisfaction Relationships. Journal of Applied Psychology, 87 (2), 355-368.

Parasuraman, A. and D. Grewal (2000). The Impact of Technology on the Quality-ValueLoyalty Chain: A Research Agenda. Joumal of Academy of Marketing Science, 28, 168 174.

Parasuraman, A., V.A. Zeithaml and L.L. Berry (1988). SERVQUAL: A Multiple-Item Scale for Measuring Consumer Perceptions of Service Quality. Jounal of Retailing. 64, 12-40.

Parker, L.D. (1984). Control in Organizational Life: The Contribution of Mary Parker Follett. Academy of Managenent Rewiew, 9 (4), 736-745.

Pasmore, W.A. (1988). Designing Effective Organizations: The Sociotechnical Systems Perspective. New York: John Wiley.

Pasmore, W.A., C. Francis, J. Haldeman and A. Shani (1982). A Sociotechnical Systems: A North American Reflection on Empirical Studies of the Seventies. Human Relations, 35 (12), 1179-1204.

Pearce, J.A. and E.C. Ravlin (1987). The Design and Activation of Self-Regulating Work Groups. Human Relations, 40, 751-782.

Peccei, R. and P. Rosenthal (1997). The Antecedents of Employee Commitment to Customer Service: Evidence from a UK Service Context. The International Joumal of Humam Resource Management, 8, 66-86.

Peccei, R. and P. Rosenthal (2001). Delivering Customer-Oriented Behaviour through Empowerment: An Empirical Test of HRM Assumptions. Journal of Management Studies, $38(6), 831-857$. 
Pennings, J.M.E. and A. Smidts (2000). Assessing the Construct Validity of Risk Attitude. Management Science, 46, 1337-1348.

Perrow, C. (1986). Complex Organizations ( $3^{\text {rd }}$ Ed.). New York: Random House.

Pitt L.F., M.T. Ewing and P.R. Berthon (2002). Proactive Behavior and Industrial Salesforce Performance. Industrial Marketing Management, 31, 639-644.

Plunkett, L.C. and R. Fournier (1991). Participative Management: Implementing Empowerment. New York: John Wiley.

Polley, D, and L. Van Dyne (1994). The Limits and Liabilities of Self-Managing Work Tearns. In Advances in Interdisciplinary Studies of Work Teams, Beyerlein, M.M. and D.A. Johnson (Eds.), 1, 1-38, JAI Press, Greenwich, CT.

Pulakos, E.D., S. Arad, M.A. Donovan and K.E. Plamondon (2000). Adaptability in the Workplace: Development of a Taxonomy of Adaptive Performance. Journal of Applied Psychology, 85 (4), 612-624.

Quattrone G.A. and E.E. Jones (1980). The Perception of Variability within In-Groups and Out-Groups: Implications for the Law of Small Numbers. Journal of Personality and Social Psychology, 38 (1), 141-152.

Quinn, J.B. (1996). The Productivity Paradox Is False: Information Technology Improves Service Performance. In: Advances in Service Marketing and Management, Swartz, T.A., D.E. Bowen and S.W. Brown (Eds.), 5, 71-84, JAI Press Inc., Greenwich, Connecticut.

Rasbash, J., W. Browne, H. Goldstein, M. Yang, I. Plewis, M. Healy, G. Woodhouse, D. Draper, I. Langford and T. Lewis (2000). A User's Guide to MiwiN. Multilevell Models Project Institute of Education, University of London.

Rathnam, S., V. Mahajan and A.B. Whinston (1995). Facilitating Coordination in Customer Support Teams: A Framework and its Implications for the Design of Information Technology. Management Science, 41, 1900-1921.

Raudenbush, S.W. (1993). Hierarchical Linear Models and Experimental Design. In: Applied Analysis of Variance in Behowioral Science, Edwards, L.K. (Ed.), 459-496, New York: Marcel Dekker.

Rizzo, J.R., R.J. House and S.I. Lirtzman (1970). Role Conflict and Ambiguity in Complex Organizations. Administrative Science Quarterly, 15, 150-163.

Rogers, E. (1995). Diffusion of Innovations. New York: The Free Press.

Rust, R.T., P.J. Danaher and S. Varki (2000). Using Service Quality Data for Competitive Marketing Decisions. International Jownal of Service Industry Management, 11 (5), 438469.

Schillewaert, N., M.J. Altearne, R.T. Frambach and R.K. Moenaert (2000). The Acceptance of Technology in the Sales Force. E-Business Center Working Paper, The Vlerick Leuven Ghent Management School, Belgium.

Schmit, M.J. and S.P. Allscheid (1995). Employee Attitudes and Customer Satisfaction: Making Theoretical and Empirical Connections. Personnel Psychology, 49, 853-882.

Schneider, B. (1990). The Climate for Service: An Application of the Climate Construct. In: Organizational Climate and Culture, Schneider, B. (Ed.), 383-412, San Francisco: JosseyBass.

Schneider, B., S. Ashworth, A. Higgs and L. Carr (1996). Design, Validity, and Use of Strategically Focused Employee Attitude Surveys. Personnel Psychology, 49, 695-705.

Sclmeider, B. and D.E. Bowen (1985). Employee and Customer Perceptions of Service in Banks: Replication and Extension. Journal of Applied Psychology, 70, 423-433. 
Schneider, B. and D.E. Bowen (1993). The Service Organization: Human Resources Management is Crucial. Organizational Dymamics, $21,39-52$.

Schneider, B. and D.E. Bowen (1995). Wimning the Service Gome. Boston: Harvard Business School Press.

Sichmeider, B., S.K. Gunnarson and K. Niles-Jolly (1994). Creating the Climate and Culture of Success. Organizational Dynamics, 23 (1), 17-29.

Schneider, B., A.N. Salvaggio and M. Subirats (2002). Climate Strength: A New Direction for Climate Research. Joumal of Applied Psychology, 87 (2), 220-229.

Schneider, B., J.K. Wheeler and J.F. Cox (1992). A Passion for Service: Using Content Analysis to Explicate Service Climate Themes. Journal of Applied Psychology, 77 (5), 705-716.

Schneider, B., S.S. White and M.C. Paul (1998). Linking Service Climate and Customer Perceptions to Service Quality: Test of a Causal Model. Jownal of Applied Psychology, $83,150-163$.

Scott, S.G. and R.A. Bruce (1994). Determinants of Innovative Behavior: A Path Model of Individual Innovation in the Workplace. Academy of Management Joumal, 37, 580-607.

Scott, T.W. and P. Tiessen (1999). Performance Management and Managerial Teams. Accounting, Organizations, and Society, 24, 263-285.

Seibert, S.E., J.M. Crant and M.L. Kraimer (1999). Proactive Personality and Career Success. Joumal of Applied Psychology, 84 (3), 416-427.

Sergeant, A. and S. Frenkel (2000). When Do Customer Contact Employees Satisfy Customers? Journal of Service Research, 3 (1), 18-34.

Shalley, C.E., L.L. Gilson and T.C. Blum (2000). Matching Creativity Requirements and the Work Environment: Effects on Satisfaction and Intentions to Leave. Acadeny of Management Journal, 43, 215-223.

Shaw, M.E. (1981). Group Dynamics: The Psychology of Small Group Behavior. New York: McGraw-Hill.

Shonk, J.H. (1992). Team-Based Organizations: Developing a Successful Team Envimannent. Homewood, IL: Business One, Irwin.

Siegel, S. and N.J. Castellan, Jr. (1988). Nonparametrics for the Behavioral Sctences $\left(2^{\text {nd }}\right.$ Ed.). McGraw-Hill Book Co., Singapore.

Silverman, D. (1970). The Theory of Organizations. London: Heinemann.

Singh, J. (1993). Boundary Role Ambiguity: Facets, Determinants, and Impacts. Journal of Marketing, 57, 11-31.

Singh, J. (2000). Performance Productivity and Quality of Frontline Employees in Service Organizations. Journal of Marketing, 64, 15-34.

Snijders, T.A.B. and R.J. Bosker (1999). Multilevel Analysis: An Introdwction to Basic and Advanced Multilevel Modeling. Sage Publications: London, New Delhi: Thousand Oaks.

Solomon, M.R., C. Surprenant, J.A. Czepiel and E.G. Gutman (1985). A Role Theory Perspective on Dyadic Interactions: The Service Encounter. Joumal of Morketing. 49 (Winter), 99-111.

Soteriou, A. and S.A. Zenios (1999). Operations, Quality, and Profitability in the Provision of Banking Services. Management Science, 45 (9), 1221-1238.

Spiro, R.L. and B.A. Weitz (1990). Adaptive Selling: Conceptualization, Measurement, and Nomological Validity. Journal of Marketing Reserrch, 27, 61-69.

Spreitzer, G.M. (1995). Psychological Empowerment in the Workplace: Dimensions, Measurement, and Validation. Academy of Management Journal, 38 (5), 1442-1465. 
Spreitzer, G.M., S.G. Cohen and G.E. Ledford, Jr. (1999). Developing Self-Managing Work Teams in Service Organizations. Group \& Organization Management, 24 (3), 340-366.

Steenkamp, J.-B.E.M. and H.C.M. Van Trijp (1991). The Use of LISREL in Validating Marketing Constructs. International Journal of Research in Marketing, 8, 283-299.

Steenkamp, J.-B.E.M., F. Ter Hofstede and M. Wedel (1999). A Cross-National Investigation into the Individual and National Cultural Antecedents of Consumer Innovativeness. Journal of Marketing, 63 (April), 55-69.

Stewart G.L. and M.R. Barrick (2000). Team Structure and Performance: Assessing the Mediating Role of Intrateam Process and the Moderating Role of Task Type. Academy of Management Journal, 43 (2), 135-148.

Sundstrom, E., K.P. de Meuse and D. Futrell (1990). Work Teams: Applications and Effectiveness. American Psychologist, 45, 120-133.

Susman, G.I. (1979). Autonomy at Work: A Sociorechnical Analysis of Participative Management. New York: Praeger.

Taylor, F.W. (1911). The Principles of Scientific Management. New York: Harper.

Teare, R, L. Munro-Faure, M. Munro-Faure, E. Scheuing and J.T. Bowen (1999). Modeling Team Structures: A Grounded Approach. International Journal of Service Research, 10 (4), 380-392.

Teo, T.S.H. and W.R. King (1996). Key Dimensions of Facilitators and Inhibitors for the Strategic Use of Information Technology. Journal of Management Information Systems, $12,35-53$.

Tesluk, P.E., D.J. Brass and J.E. Mathieu (1996). An Examination of Empowerment Processes at Individual and Group Levels. Paper presented at the 11 th annual conference of the Society for Industrial and Organizational Psychology, San Diego.

Tesluk, P.E., J.E. Mathieu, S.J. Zaccaro and M. Marks (1997). Task and Aggregation Issues in the Analysis and Assessment of Team Performance. In: Team Performance Measurement and Assessment, Brannick, M.T., E. Salas and C. Prince (Eds.), 197-224, Lawrence Erlbaum Associates, Mahwah, NJ.

Thomas, K.W. and B.A. Velthouse (1990). Cognitive Elements of Empowerment: An "Interpretive" Model of Intrinsic Task Motivation. Academy of Management Review, 15, 666-681.

Trist, E.L., G.L. Susman and G.R. Brown (1977). An Experiment in Autonomous Working in an American Underground Mine. Human Relations, 30, $201-236$.

Tubbs, S.T. (1994). The Historical Roots of Self-Managing Work Teams in the Twentieth Century: An Annotated Biography. In: Advancess in Interdisciplinary Studies of Work Teams, Beyerlein, M.M. and D.A. Johnson (Eds.), 1, 39-66, JAI Press, Greenwich, CT.

Uhi-Bien, M. and O.B. Graen (1998). Individual Self-management: Analysis of Professionais' Self-Managing Activities in Functional and Cross-Functional Work Teams. Academy of Management Joumal, 41, 340-350.

Van den Heuvel, H., N. Ellemers and B. Seghers (1995). The importance of Career-Oriented and Team-Oriented Commitment among Male and Female Employees: A Study among PhD Students. Social Psychology and its Applications, 9, 1.68-186. 
Van Looy, B., S. Desmet, K. Krols and R. Van Dierdonck (1998). Psycllological Empowerment in a Service Environment: Some Empirical Findings. In: Advances in Service Marketing and Management, Swartz, T.A., D.E. Bowen and S.W. Brown (Eds.), 7, 293-311, Greenwich, CT: JAI Press.

Van der Vegt, G.S., B.J.M. Emans and E. Van de Vliert (2001). Patterns of Interdependence in Work Teams: A Two-Level Investigation of the Relations with Job and Team Satisfaction. Personnel Psychology, 54 (1), 51-69.

Van Yperen, N.W., T.A.B. Snijders (2000). A Multi-Level Analysis of the Demands-Control Model: Is Stress at Work Determined by Factors at the Group Level or the Individual Level? Journal of Occupational Health Psychology, 5 (1), 182-190.

Venkatesh, V. and F.D. Davis (2000). A Theoretical Extension of the Technological Acceptance Model: Four Longitudinal Field Studies. Management Science, 46, 186-204.

Verma, R. (2000). An Empirical Analysis of Management Challenges in Service Factories: Service Shops, Mass Services and Professional Services. International Jounnal of Service Industry Management, 11 (1), 8-25.

Wageman, R. (1997). Critical Success Factors for Creating Superb Self-Managing Teams. Organizational Dynamics, 26, 49-61.

Wall, T.D., N.J. Kemp, P.R. Jackson and C.W. Clegg (1986). Outcomes of Autonomous Workgroups: A Long-Term Field Experiment. Academy of Management Jownal, 29, 280304.

Weick, K.E., and K.H. Roberts (1993). Collective Mind in Organizations: Heedful Interrelating on Flight Decks, Administrative Science Quarterly, 38, 357-381.

Wellins, R.S., W.C. Byham and J.M. Wilson (1991). Empowered Teams: Creating SelfDirected Work Groups that Improve Quality, Productivity, and Participation. San Francisco, CA: Jossey-Bass.

Westphal, J.D., R. Gulati and S.M. Shortell (1997). Customization of Conformity? An Institutional and Network Perspective on the Content and Consequences of TQM Adoption. Administrative Science Quarterly, 42, 366-394.

Wetzels, M., K. De Ruyter and M. Van Birgelen (1998). Marketing Service Relationships: The Role of Commitment. Jowrnal of Business and Industrial Marketing, 13 (4/5), 406423.

Yagil, D. and I. Gal (2002). The Role of Organizational Service Climate in Generating Controll and Empowerment among Workers and Customers. Jounal of Retailing and Consumers Services, 9, 215-226.

Yeatts, D.E. and C.C. Hyten (1998). High-pexforming Self-managed Teams: A Comparison of Theory to Practice. Thousand Oaks, CA: Sage.

Zethaml, V.A. and A. Parasuraman (1.996). The Behavioral Consequences of Service Quality. Joumal of Marketing, $60,31-46$.

Zey-Fertell, M. (1979). Dimensions and Organizations: Environment, Context, Structure, Process, and Performance. Santa Monica, CA: Goodyear.

Zohar, D. (2000). A Group-Level Model of Safety Climate: Testing the Effect of Group Climate on Microaccidents in Manufacturing Jobs. Joumal of Applied Psychology, 85 (4). $587-596$. 


\section{Nederlandse Samenvatting}

\section{Inleiding}

Uit de service marketing literatuur blijkt in toenemende mate dat innovatieve managementbenaderingen, zoals het geven van meer vrijheid en bevoegdheden aan medewerkers en het werken in teamverband tot hogere medewerkertevredenheid, en klanttevredenheid leiden. Veel bedrijven melden daarnaast aanzienlijke productiviteitsstijgingen als gevolg van de invoering van zelfsturende teams. Ook in de huidige wetenschappelijke literatuur is een groot aantal boeken en artikelen gewijd aan teams van medewerkers die zelf hun dagelijkse werkzaamheden reguleren.

Het cruciale kenmerk dat zelfsturende teams onderscheidt van teams in het algemeen is het gegeven dat zelfsturende teams bestaan uit medewerkers die gezamenlijk verantwoordelijk zijn voor het reguleren en uitvoeren van complete taken met betrekking tot een te leveren product of dienst. Vanwege de hoge mate van vrijheid, hebben zelfsturende teams meer controle over de groepsnormen, het gedrag van individuele teamleden en de effectiviteit van het team. Typische verantwoordelijkheden die aan de teamleden gedelegeerd worden, betreffen thet managen van dagelijkse activiteiten, het op peil houden van de productiviteit en het reguleren van de kwaliteit van afgeleverde producten en diensten. De taken binnen teams worden vaak gerouleerd over de teamleden om de medewerkers veelzijdig te maken, wat leidt tot rolflexibiliteit en job enrichment. Een zelfsturend team kan worden gedefinieerd als: "een groep medewerkers die wederzijds afhankelijk van elkaar zijn, over complementaire vaardigheden beschikken en gezamenlijk de bevoegdheid en verantwoordelijkheid dragen voor het managen en uitvoeren van relatief volledige taken om daarmee duidelijk gespecificeerde teamdoelen te realiseren."

Het principe van zelfsturing is voornamelijk gebaseerd op de sociaaltechnische systeemtheorie. Een basisassumptie van deze theorie is dat de gezamenlijke optimalisering van sociale systemen en taakgerichte systemen binnen de organisatie een belangrijke voorwaarde vormt voor het functioneren van zelfsturende teams. Ondanks het stijgend aantal wetenschappelijke studies over teamwork en zelfsturing in de dienstverlening, is er weinig bekend over de aard van het diensiverleningsproces binnen zelfsturende teams en de effecten hiervan. Sinds het gebruik van zelfsturende teams steeds meer gemeengoed geworden is, is het van belang om te onderzoeken welke sociale en taakgerichte aspecten de kwaliteit van dienstverlening beïnvloeden.

In de marketing literatuur is het algemeen aanvaard dat de aanwezigheid van een service klimaat binnen dienstverlenende organisaties een cruciale determinant vormt voor externe marketing effectiviteitseriteria. De aandacht in wetenschappelijk onderzoek voor het fenomeen "service klimaat" onderstreept dit. Ondanks de centrale rol van een service klimaat bimnen bedrijven, is er weinig bekend over invloed van groepsprocessen en organisatorische factoren die het service klimat binnen zelfsturende teams bepalen. Daarnaast is het vanwege de operationele aard van het werk klimaat binnen teams ook van belang om meer aandacht te besteden aan de 
gedragsaspecten en attitudes die bepalend zijn voor het bewerkstelligen van een dergelijk service klimaat.

Een ander aandachtspunt betreft de externe marketing uitkomsten van service klimaat binnen zelfsturende teams. In tegenstelling tot productiebedrijven, waar het productieproces onzichtbaar is voor de klant, zijn service organisaties betrekkelijk "open" organisaties waarin klanten een prominente rol spelen. Immers, klanten zijn gewoonlijk in staat om het dienstverleningsproces waar te nemen en nemen er vaak zelfs deel aan. Om de effectiviteit van zelfsturende teams in het dienstverleningsproces goed te kunnen evalueren is het dus van belang om interne effectiviteitsmaatstaven (b.v., medewerkertevredenheid, en betrokkenheid bij de organisatie) en traditionele productiviteitsmaatstaven te complementeren met klantevaluaties over de kwaliteit van het dienstverleningsproces alsmede indicatoren van klantgedrag. Het onderzoek naar zelfsturende teams vereist dus een interdisciplinaire aanpak. Tot dusver hebben verschillende onderzoeken gericht op de link tussen interne en externe effectiviteitsmaatstaven het effect van klantgerichte aspecten binnen de organisatie op klantgebaseerde parameters en productiviteit voornamelijk onderzocht en aangetoond op het niveau van de organisatie, terwijl weinig bekend is over onderzoek op teamniveau.

Service klimaat belichaamt het sociaal dynamische aspect van team effectiviteit. De sociaaltechnische systeemtheorie benadrukt daarnaast het belang van taakgerichte aspecten, zoals werkprocespatronen en IT systemen als belangrijke determinanten van team effectiviteit. Door de opkomst van IT systemen bedoeld om het dienstverleningsproces te ondersteunen, hebben veel recente studies het belang van het gebruik van IT bij het verlenen van diensten klanten onderkend. Weinig onderzoek heeft zich echter gericht op het gebruik van IT door teammedewerkers die in direct contact met de klant staan.

De centrale doelstelling van deze dissertatie is: bepalen wat de inwloed van zelfsturende teams is op de marketing effectiviteit van dienstverlenende bedrijven. Hiertoe formuleren we de volgende onderzoeksvragen:

1) Wat is het effect van service klimaat in zelfsturende teams die diensten verlenen aan zakelijke klanten (hoofdstuk 2)

2) Is het effect van service klimaat in zelfsturende teams afhankelijk van het type dienst dat wordt verleend? (hoofdstuk 3)

3) Wat is het effect van adaptief en proactief probleem oplossingsgedrag in zelfsturende teams? (hoofdstuk 4)

4) Wat is effect van het gebruik van informatietechnologie in zelfsturende teams? (hoofdstuk 5)

\section{Service Klimaat in Zelfsturende Teams: Een Studie in de Zakelijke Markt}

In hoofdstuk 2 onderzoeken we het functioneren van zelfsturende teams van service monteurs die onderhoudsdiensten verlenen aan zakelijke klanten. In de eerste plaats ontwikkelen we een gedetailleerd conceptueel raamwerk van antecedenten en uitkomsten van service klimaat in zelfsturende teams. Ten tweede bepalen we middels statische analyses de antecedenten en uitkomsten van service klimaat in teams. 
Het onderzoek vond plaats binnen de after-sales service afdeling van een bedrijf dat kantoorapparatuur produceert. Daarbij werden de percepties van teamleden die onderhoudsreparaties verrichtten aan kantoorapparaten bij zakelijke klanten gremeten. Uit de resultaten blijkt dat organisatorische factoren, groepsfactoren en, in mindere mate, medewerker-specifieke factoren het service klimat binnen zelfsturende teams bepalen. Kortom, service klimaat in teams blijkt het resuitaat van individuele en geaggregeerde factoren. Verder, tonen we aan dat bij teams met een sterker service klimaat de kwaliteit van de service positiever door klanten wordt beoordeeld en dat deze teams er beter in slagen de onderhoudsbeurten in één keer af te ronden.

\section{Service Klimaat in Zelfsturende Teams: Een Contingentiebenadering}

In hoofdstuk 3 onderzoeken we verder de rol van service klimaat binnen zelfsturende teams die diensten verlenen aan particuliere klanten. In vergelijking met het vorige hoofdstuk maken we in dit hoofdstuk expliciet gebruik van een sociaal systeemperspectief. We richten ons hierbij op de verschillende ondersteunende sociale processen binnen en tussen teams in de organisatie en benadrukken het belang van deze interpersoonlijke processen voor de effectiviteit van zelfsturende teams. Ten eerste ontwikkelen we een conceptueel raamwerk van antecedenten en uitkomsten van team service klimaat vanuit een sociaal systeemperspectief. Ten tweede bepalen we in hoeverre de antecedenten en uitkomsten van team service klimaat afhankelijk zijn van het type service setting (maatwerk diensten versus gestandaardiseerde diensten). Ten derde analyseren we de effecten van de antecedenten op service klimaat op individueel en groepsniveau.

Dit onderzoek werd uitgevoerd bij een Nederlandse bank. Hierbij werden de meningen van zowel team medewerkers als hun klanten gemeten. Uit de resultaten blijken positieve individuele effecten van zelfsturing tolerantie, flexibiliteit, interteam en intrateam support op team service klimaat. Verder blijkt op groepsniveau dat het effect van intrateam support extra variantie in team service klimaat verklaart en is er sprake van een positief interactie effect tussen maatwerk services en flexibiliteit. Daarnaast, blijkt dat de verschillen in team service klimaat tussen teams gerelateerd zijn aan externe uitkomsten, zoals waargenomen service kwaliteit, koopgedrag, en productiviteit. Ten slotte laten de uitkomsten van het onderzoek zien dat de relatie tussen team service klimaat en waargenomen service kwaliteit sterker is in maatwerk services dan in relatief gestandaardiseerde services.

\section{Het Effect van Adaptief en Proactief Probleem Oplossingsgedrag: De Rol van Zelfsturende Teams}

In hoofdstuk 2 en 3 hebben we rol van team service klimaat in zelfsturende teams bestudeerd. Het service klimaat in zelfsturende teams is een integraal concept dat zich vooral kenmerkt door expliciete gedragingen die duidelijk van elkaar onderscheiden zijn. In dit hoofdstuk maken we een onderscheid tussen adaptief gedrag en proactief gedrag bij het oplossen van service problemen door zelfsturende teams. We maken daarbij weer gebruik van het sociaal systeemperspectief. De eerste doelstelling betreft het ontwikkelen van een conceptueel raamwerk van antecedenten en uitkomsten van 
adaptief en proactief probleem oplossingsgedrag. Als tweede doelstelling geldt het bepalen van de verschillen in antecedenten en uitkomsten tussen adaptief en proactief gedrag. Ten derde analyseren we de antecedenten van adaptief en proactief gedrag op individueel en groepsniveau

Het onderzoek werd wederom uitgevoerd bij een Nederlandse bank waarbij de meningen van team medewerkers en hun klanten over met name klachten en service problemen werden bevraagd. De uitkomsten van het onderzoek tonen positieve individuele effecten van zelfsturing tolerantie, organisatie support, interteam support en intrateam support op zowel adaptief als proactief werkgedrag. Daarnaast blijkt een positief groepseffect van intrateam support op beide typen probleem oplossingsgedrag. Deze resultaten geven aan dat adaptief en proactief probleem oplossingsgedrag in zelfsturende teams op dezelfde basis zijn gestoeld en afhankelijk zijn van een service gerichte cultuur binnen de teams. Met betrekking tot uitkomsten van adaptief en proactief probleem oplossingsgedrag, blijken echter duidelijke verschillen. De resultaten geven aan dat een hogere mate van adaptief gedrag leidt tot hogere klanttevredenheid met de klachtafhandeling, en sterkere klantloyaliteit, terwijl proactief gedrag juist leidt tot beter koopgedrag.

\section{Het Effect van het Gebruik van Informatie Technologie in Zelfsturende Teams}

In voorgaande hoofdstukken lag de nadruk op de rol van sociale processen binnen en tussen zelfsturende teams. In hoofdstuk 5 richten we ons vooral op taakgerichte aspecten en onderzoeken we de invloed van het gebruik van IT bij het verlenen van diensten. Als eerste ontwikkelen we een conceptueel raamwerk van antecedenten en uitkomsten van het gebruik van standaard en op-maat-gemaakte typen IT door zelfsturende teams. Vervolgens hebben we dit conceptueel raamwerk empirisch getest. Ten derde zijn we nagegaan wat de verschillen zijn tussen het gebruik van standaard en op-maat-gemaakte typen IT.

Dit onderzoek werd verricht bij een Belgische bank waarbij de meningen en het gedrag van bankmedewerkers met betrekking tot IT werd gemeten. De uitkomsten van het onderzoek tonen positieve individuele effecten van zelfsturing tolerantie, gebruiksgenak, en innovatieve attitude op het gebruik van standaard IT and positieve individuele effecten van zelfsturing tolerantie en waargenomen nut op op-maatgemaakte IT. Daarnaast blijken er groepseffecten van interteam netwerk en waargenomen nut op het gebruik van standaard IT en groepseffecten van interteam netwerk en risicomijdende attitude op het gebruik van klantgerichte IT. Tenslotte, tonen de resultaten dat zelfsturende teams die meer gebruik maken van klantgerichte IT hogere klanttevredenheidsscores en productiviteitscijfers hebben.

\section{Conclusie}

De uitkomsten van ons promotieonderzoek geven aan dat het service klimaat en klantgericht gedrag in zelfsturende teams sterk wordt beïnvloed door sociale processen, zoals de mate van autonomie en de onderlinge bereidheid bij team medewerkers om elkaar te helpen bij het leveren van diensten aan klanten. Ook in het 
geval van taakgericht werkgedrag, zoals het gebruik van IT door individuele medewerkers spelen niet alleen individuele percepties, maar ook groepsprocessen een belangrijke rol.

Wat het effect van klantgericht team functioneren op externe marketing uitkomsten betreft, blijkt dat zelfsturende teams met een kwalitatief betere dienstverlening positiever worden beoordeeld door hun klanten en dat er bij deze teams ook sprake is van een hoger gemiddelde dienstafname per klant. De resultaten uit dit proefschrift zijn echter niet eenduidig over de relatie tussen klantgericht functioneren van het team en de uiteindelijke productiviteit. Een betere dienstverlening door teams resulteert veelal niet in een hogere productiviteit. Soms is er zelfs sprake van een negatief effect. Uit dit onderzoek blijkt verder dat het effect van zelfsturende teams op externe uitkomsten sterker wordt naarmate er enige tijd is verstreken.

Bij het onderzoeken van zelfsturende teams in services blijkt dat het gebruik van zelfsturende teams effectiever is in maatwerk services dan in meer gestandaardiseerde services. Het is dus van het belang rekening te houden met het type service omgeving bij het onderzoeken van zelfsturende teams in services.

Een andere opvallende uitkomst is het gegeven dat de meningen van individuele team medewerkers over het functioneren van hun team zijn gebaseerd op zowel hun eigen subjectieve perceptie als op de gemeenschappelijke perceptie van teamleden binnen het team. Werkgerelateerde percepties van individuele medewerkers staan niet op zichzelf, maar worden via wederzijdse beïnvloeding mede gevormd door de overige teamleden.

De verwachting is dat in de komende jaren het gebruik van zelfsturing en teamwork in dienstverlenende organisaties nog verder zal toenemen. Vanwege de continue ontwikkeling van nieuwe technologieën is het aannemelijk dat het gebruik. van IT systemen een essentiële rol gaat spelen bij het functioneren van zelfsturende teams in services. 


\section{Curriculum Vitae}

Ad de Jong was born on November 18, 1974 in Streefkerk, the Netherlands. After completion of the secondary school at "Scholengemeenschap Guido de Brès" in Rotterdam, be studied at the Faculty of Social Sciences at the University of Leiden, the Netherlands. He specialized in psychometrics and organizational psychology and obtained his Master's Degree in 1998. In May 1998, he started to work as a research fellow at the Department of Marketing and Marketing Research, Facully of Economics and Business Administration, Maastricht University, the Netherlands. Since September 1998 he has been working as a $\mathrm{PhD}$-student on his dissertation. His main research interests are: consumer behavior, management of service operations, services marketing, the service profit chain, linkage research, multi-level theory and research, and multichannel research. The journals in which he has published include the International Journal of Research in Marketing, the International Journal of Service Industry Management, and the Journal of Retailing. In addition, an article in the Journal of Service Research is due to appear shortly. Finally, he has also contributed various papers to conference proceedings and the yearbook of the Dutch Marketing Research Association. 